\title{
Estimation of striped bass (Morone saxatilis) diets using fatty acid signature analysis
}

\author{
Edward J. McGinley \\ West Virginia University
}

Follow this and additional works at: https://researchrepository.wvu.edu/etd

\section{Recommended Citation}

McGinley, Edward J., "Estimation of striped bass (Morone saxatilis) diets using fatty acid signature analysis" (2012). Graduate Theses, Dissertations, and Problem Reports. 3560.

https://researchrepository.wvu.edu/etd/3560

This Dissertation is protected by copyright and/or related rights. It has been brought to you by the The Research Repository @ WVU with permission from the rights-holder(s). You are free to use this Dissertation in any way that is permitted by the copyright and related rights legislation that applies to your use. For other uses you must obtain permission from the rights-holder(s) directly, unless additional rights are indicated by a Creative Commons license in the record and/ or on the work itself. This Dissertation has been accepted for inclusion in WVU Graduate Theses, Dissertations, and Problem Reports collection by an authorized administrator of The Research Repository @ WVU.

For more information, please contact researchrepository@mail.wvu.edu. 


\section{Estimation of striped bass (Morone saxatilis) diets using fatty acid signature analysis}

\section{Edward J. McGinley}

Dissertation submitted to the Davis College of Agriculture, Natural Resources, and Design

at West Virginia University in partial fulfillment of the requirements

for the degree of

Doctor of Philosophy

in

Forest Resource Science

Approved by

Kyle J. Hartman, Ph.D., Chair

Ashok Deshpande, Ph.D.

John Jacobs, Ph.D.

Patricia Mazik, Ph.D.

Stuart A. Welsh, Ph.D.

Division of Forestry and Natural Resources

Mogantown, West Virginia

2012

Keywords: Chesapeake Bay, Atlantic menhaden, blue crab, spot, bay anchovy, Accelerated Solvent Extractor, gas chromatography - mass spectrometry, Quantitative fatty acid signature analysis (QFASA) 


\title{
Abstract \\ Estimation of striped bass (Morone saxatilis) diets using fatty acid signature analysis
}

\author{
Edward J. McGinley
}

Accurate estimates of diets are essential for the management of fisheries, especially when this information is used to construct food webs for a system. Traditionally, these studies have relied on examining the stomachs contents through direct observation of sacrificed fish, or using instruments to "flush" the items from the stomach. These methods only provide information on the recent feeding history. Fatty acid analysis is a biochemical technique that offers promise for examining diets in fish over a longer time scale than just the last few prey species consumed. The goal of this dissertation was to examine the feasibility and efficacy of using fatty acid signature analysis to record striped bass (Morone saxatilis) diets.

I examined how collection location (Upper or Lower Chesapeake bay), species, and season affected the fatty acid signature (a compilation of all fatty acids present) and lipid content of four common striped bass prey items: Atlantic menhaden (Brevoortia tyrannus), bay anchovy (Anchoa mitchilli), spot (Leiostomus xanthurus), and blue crab (Callinectes sapidus). Demersal species (spot and blue crab) were separated from pelagic species (menhaden and bay anchovy) based upon their fatty acid signature. Spot and blue crab were also grouped by season, with summer blue crab and spot distinct from fall blue crab and spot. Blue crab and spot within a season had very similar fatty acid signatures. Anchovy and menhaden did not show the same type of seasonal grouping as the demersal species. Anchovy and menhaden had the highest lipid content followed by spot, and blue crab had the lowest lipid content. Collection location did not appear to play a role in structuring the fatty acid signature. These results necessitate the collection of prey species at the same time as collection of predators for fatty acid signature analysis.

Fatty acids are deposited in tissues based upon the needs of that particular tissue. I assessed the diet history of striped bass based on two different tissues, adipose and liver tissue. Striped bass were held in flow through tanks at the NOAA Fisheries James J. Howard Laboratory in Sandy Hook, New Jersey, with water being pumped directly from the Sandy Hook Bay. Fish were fed a diet of spot for six weeks, at which point the spot diet was switched to a diet consisting of menhaden. Lipid levels in both tissues increased after the diet was switched to menhaden, a prey that had approximately twice the amount of lipid. The entire fatty acid signature did not change to mimic the prey as reported in a study in which the authors demonstrated that the fatty acid signature of cod (Gadus morhua) significantly changed to a squid signature in approximately three weeks. However, in the present study, certain marker fatty acids specific to the prey were able to distinguish the diet switch from spot to menhaden. The change in marker fatty acids and lipid levels was evident after a period of 31 days. Both liver tissue and adipose tissue demonstrated the change in diet, but adipose tissue may offer a more surgically feasible and non-lethal sample in striped bass.

The effect of striped bass size on fatty acid incorporation was analyzed for three different size classes; small $(150-200 \mathrm{~mm})$, medium $(300-380 \mathrm{~mm})$ and large (fish greater than 460 $\mathrm{mm})$. Fish were housed in flow through tanks at the NOAA Laboratory in Oxford, Maryland, with water being pumped directly from the Tred Avon River. Striped bass were fed a diet of spot for four weeks, at which time the diet was switched to menhaden for four weeks. Lipid levels for 
these fish indicated that there was little to no deposition of lipids throughout the experimental feeding of menhaden. Fatty acid signatures also indicated that the entire fatty acid signatures, nor marker fatty acids, were able to determine the diet switch. Based upon these findings and negligible growth, the most likely cause was a lack of consumption by striped bass. Due to high turbidity, feeding was difficult to observe.

One of the most promising aspects of fatty acids analysis is the ability to estimate the proportional contribution of different prey items to the diet using prey fatty acids and their respective lipid levels. The statistical program, quantitative fatty acid signature analysis (QFASA), can perform this type of analysis, and also takes into account the effect of predator metabolism of each fatty acid by using calibration coefficients. I tested this model using striped bass fed diets containing mixtures of spot and menhaden and a control diet of just menhaden. In this experiment, the striped bass were fed spot for six weeks before the menhaden feeding experiment began to allow sufficient time for the fatty acids to become homogenized within the striped bass tissues. The model correctly quantified the contribution of spot after six weeks, but it was unable to correctly assess the inputs from the mixed diets or menhaden diet alone. Recent studies have shown that fatty acids may take $12-14$ weeks to stabilize in fish, which is twice as long as this experiment ran. Most of the work performed with QFASA has tested the model for homeotherms, e.g. marine mammals and seabirds. The fact that fish are poikilotherms may necessitate the duration of fatty acid incorporation to be on the scale of several months rather than weeks. Poikilotherms regulate the internal body temperature based upon ambient water temperatures, while homeotherms require a constant energy source to maintain a set body temperature. Fatty acids may be mobilized quicker and have a shorter retention time in homeotherm tissues. However, this situation is improbable for a generalist fish species like striped bass that will consume a variety of prey items and have the potential to be highly mobile.

Lastly, I tested the QFASA model on wild caught striped bass to determine the possibility of using this model on wild fish with prey items caught at the same time. Fish were caught during the fall when they are most likely to be consuming a high proportion of menhaden. Percent biomass of the stomach contents for these fish was compared to previous studies that collected similar sized fish (age-3) during the same season. The stomach contents of fish for this experiment, and fish from previous studies, showed that menhaden made the bulk of the diet (greater than 70\%). The QFASA estimated the contribution of menhaden to be minimal (less than $2 \%$ ). It is possible that striped bass were not feeding on menhaden for a long enough duration for the fatty acid signatures of menhaden to become predominant. 


\section{Dedication}

I would like to dedicate this dissertation to my wife, Emily. She was always willing to help in both the field and laboratory without complaint, and was able to keep her sense of humor throughout the trying process. I would still be working on samples in the lab and writing my dissertation if not for her. I would also like to dedicate this to my loving parents, John and Mary Ellen. They have always supported my endeavors and told me I could grow up to be anything I wanted. With their help, I have achieved my dreams. 


\section{Acknowledgments}

This project was funded by the National Oceanic and Atmospheric Administration Chesapeake Bay Office. I am eternally grateful for their support to work on such an amazing project. My committee members have provided invaluable help throughout my time here at West Virginia University. I thank Ashok Deshpande for his patience and mentoring in the lab as I learned how organic chemistry is important in the biological sciences. I thank John Jacobs for his advice and the opportunity to sample on the Chesapeake. These experiences have help guide me towards further work with estuaries. I thank Pat Mazik for always looking out for my best interests and continually encouraging me to do even better. I thank Stuart Welsh for always providing a fresh viewpoint to look at problems I was encountering.

Due to the large scale of this project and the varied location of labs and sampling locations, there are people along most of the Mid Atlantic who have helped me. Wendy Lowrey at VIMS provided samples from the lower Chesapeake Bay. A.K. Leight, Jimmy Councilman, and Julianna Brush provided much needed assistance and humor when collecting samples from the upper Chesapeake Bay. Many people at the NOAA lab in Sandy Hook provided guidance and sympathetic ear when things were not going well. Thank you John Richardson, Ehren Habeck, Jasmine, Matt Brescia, Beth Phalen, and Bruce Dockum. Ken Stewart and Tiffany Biddle were gracious enough to let me use their lab at the National Research Center for Coal and Energy here at WVU. Thank you to past and present graduate students who have made life a lot easier by helping and being willing to discuss why experiments did not go as planned. Thank you Gabe Strain, Adam Hnatkovich, Jered Studinski, Holly Henderson, Daniel Hanks, Mike Porto, Ryan Utz, Andy Hafs, and Jon Niles for all your hard work and guidance. 
And of course, I have to thank Kyle Hartman for taking the chance on me as a graduate student. You have been an amazing advisor, always willing to go to bat for your students. Your ability to instill knowledge in your students was not lost on me. You were always willing to stop writing an e-mail, put your hands on your head, and listen to any problem that I came to you with. For this, I will always be grateful and try to emulate your passion for the discipline as I move on. 


\section{Table of Contents}

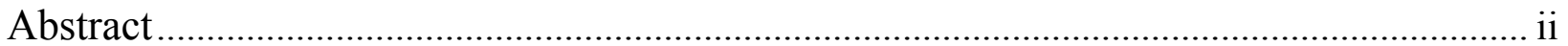

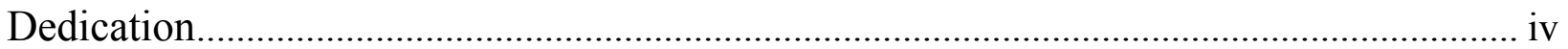

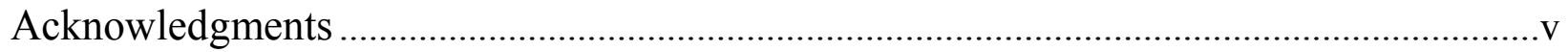

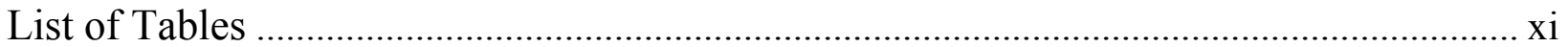

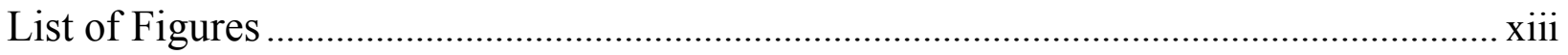

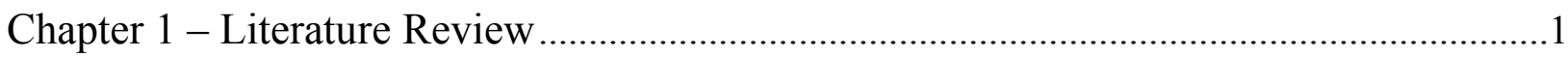

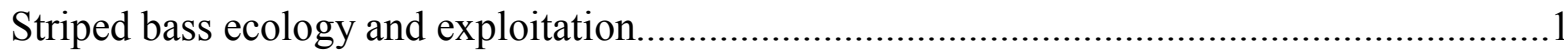

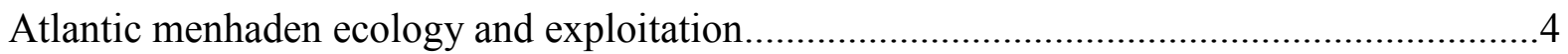

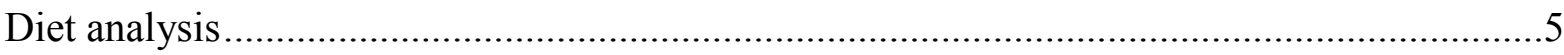

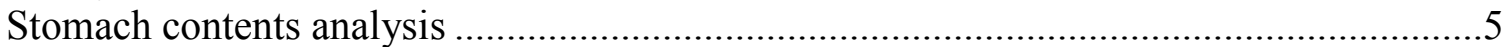

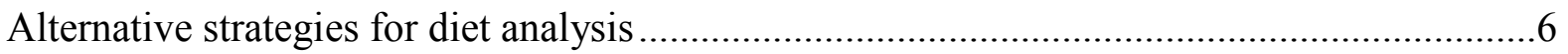

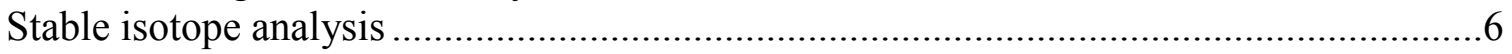

Fatty acid analysis ...............................................................................................

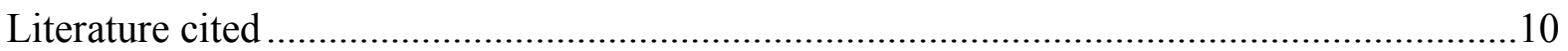

Chapter 2 - Spatial and temporal patterns in fatty acids signatures of striped bass prey

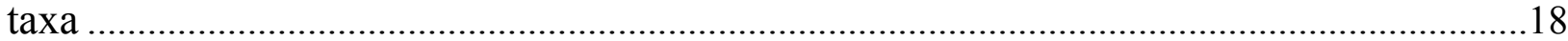

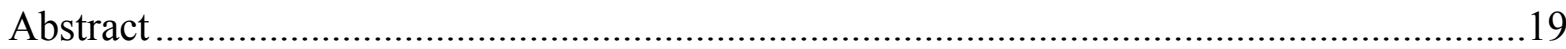

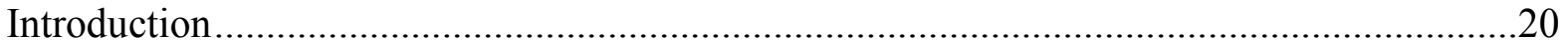

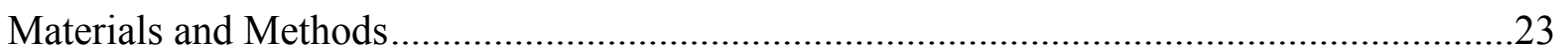

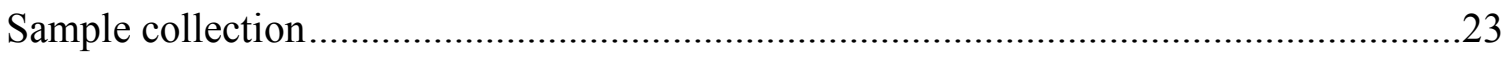

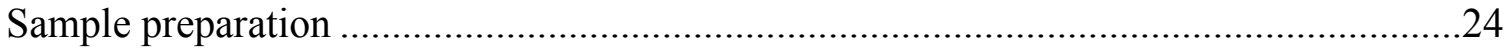

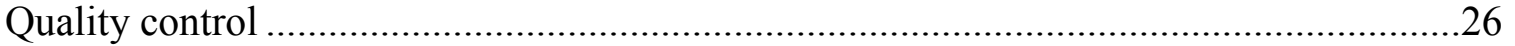

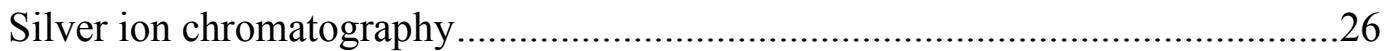

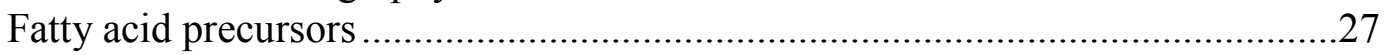

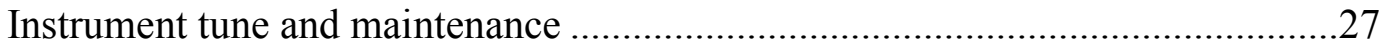

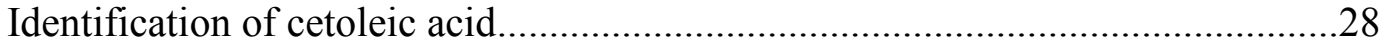

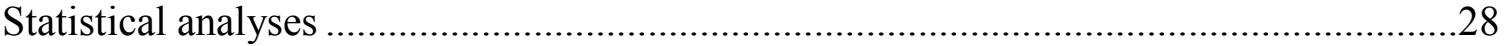

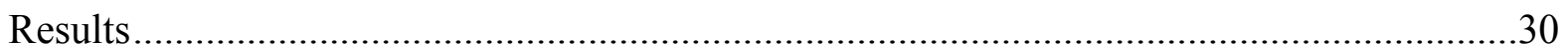

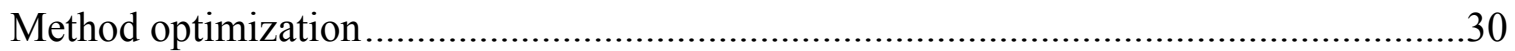




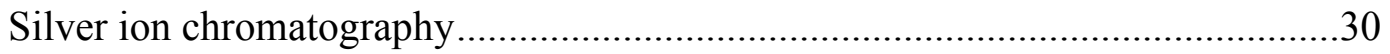

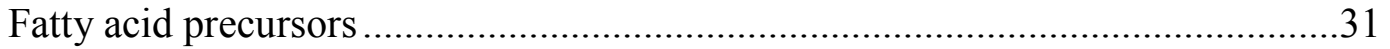

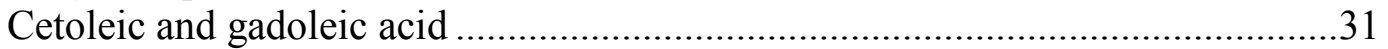

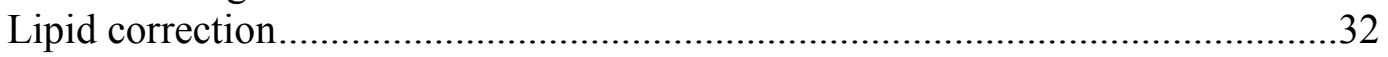

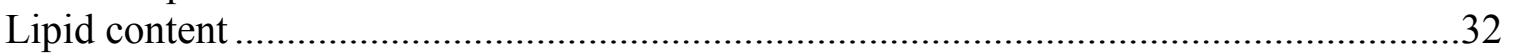

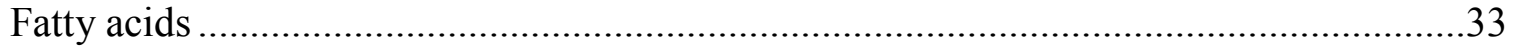

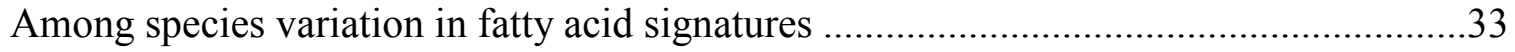

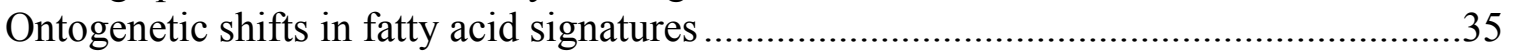

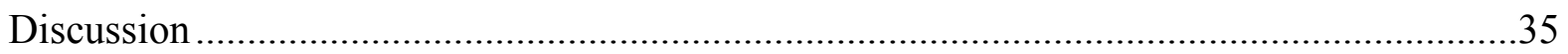

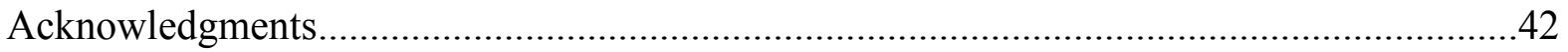

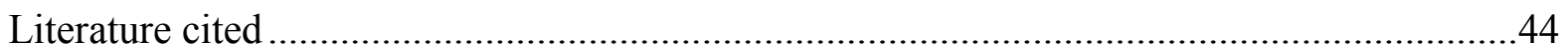

Chapter 3 - A comparison of liver and belly flap for evaluating striped bass diet using

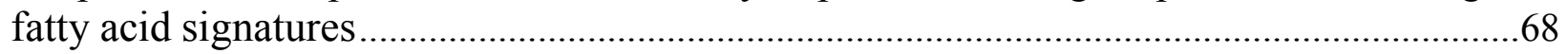

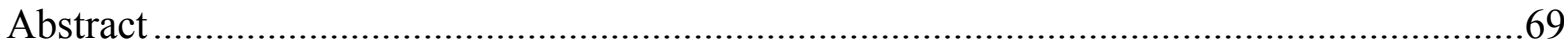

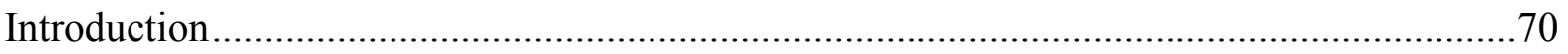

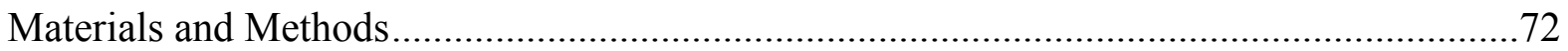

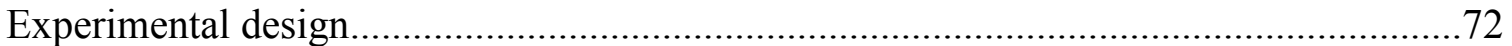

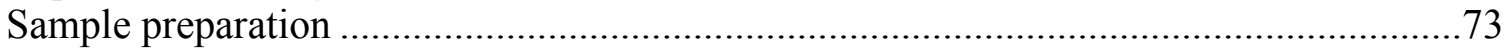

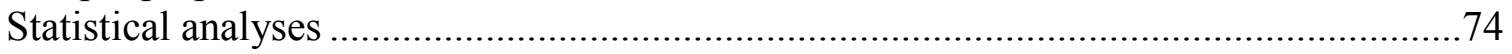

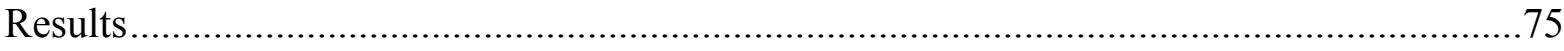

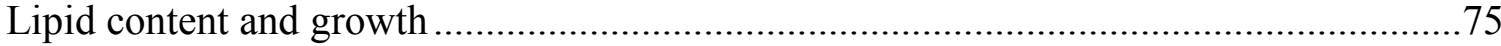

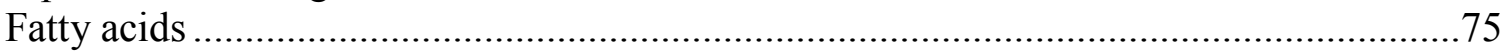

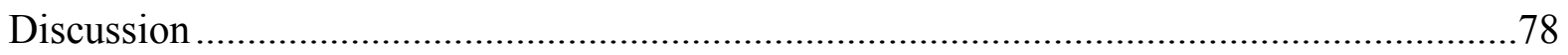

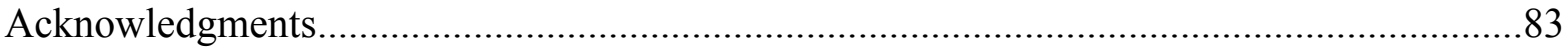

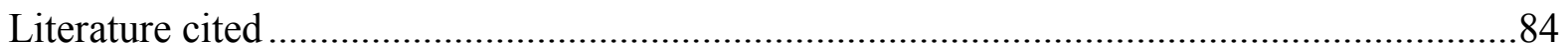

Chapter 4 - The effect of striped bass size on fatty acid signature incorporation ..............98

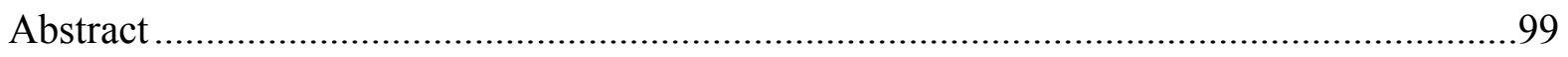

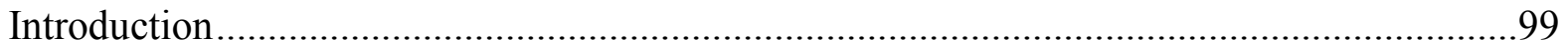

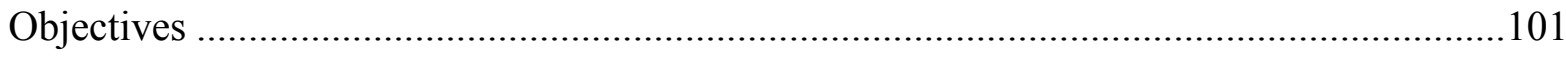

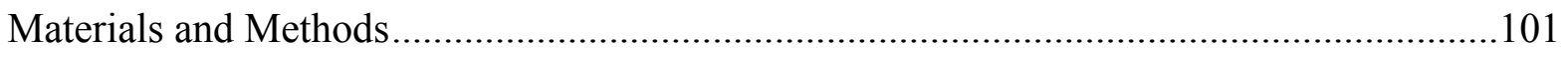




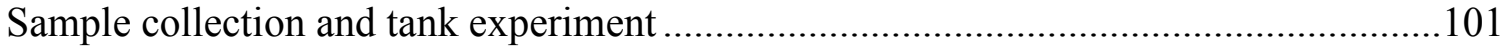

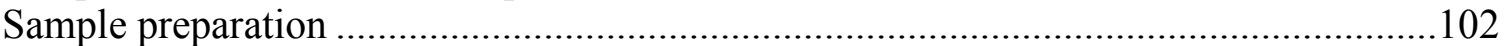

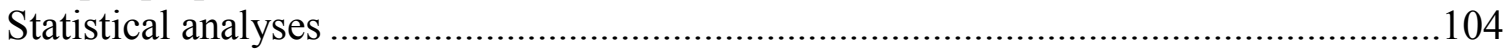

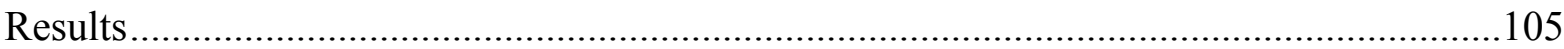

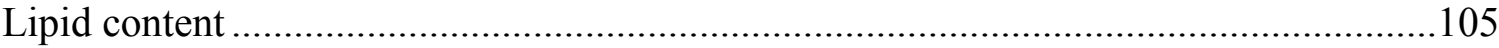

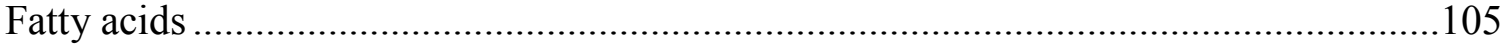

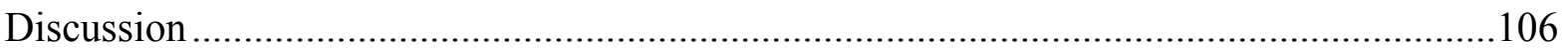

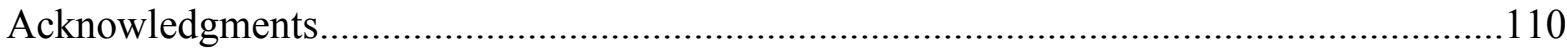

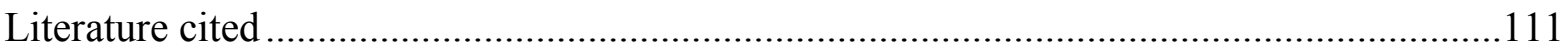

Chapter 5 - Evaluation of quantitative fatty acid signature analysis (QFASA) to estimate

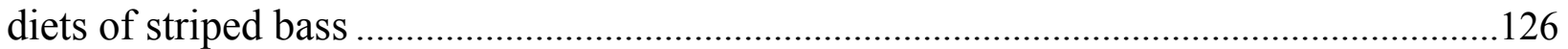

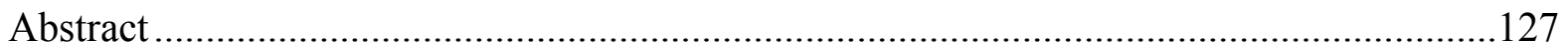

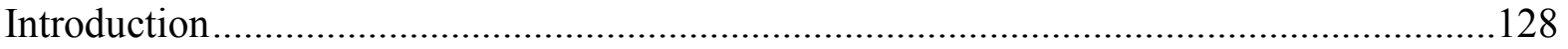

Material and Methods ........................................................................................ 130

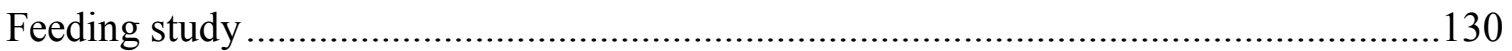

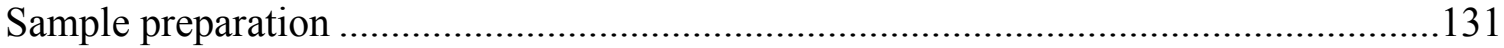

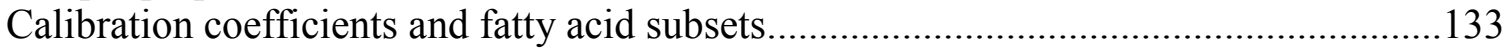

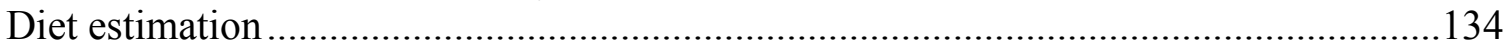

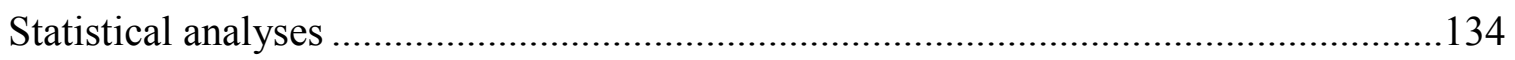

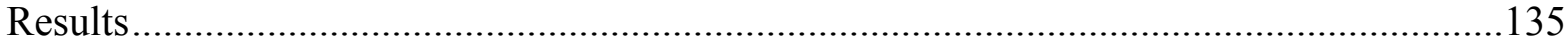

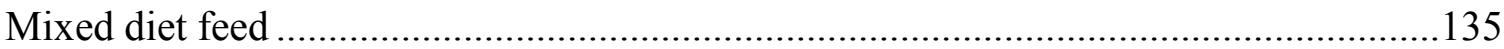

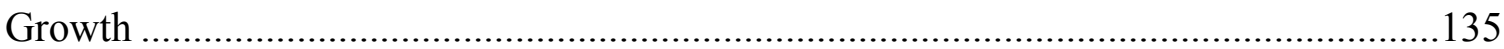

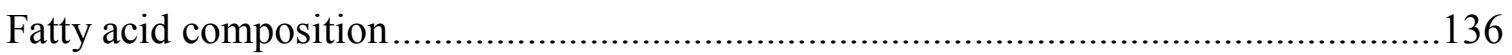

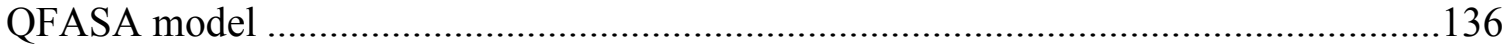

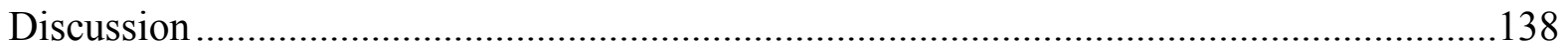

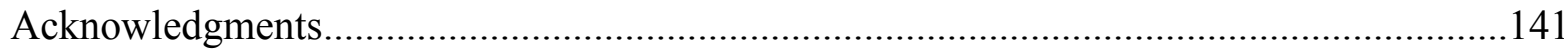

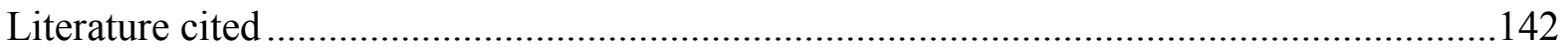

Chapter 6 - Field validation of quantitative fatty acid signature analysis (QFASA) for

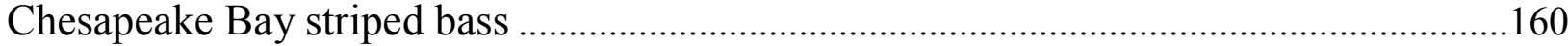

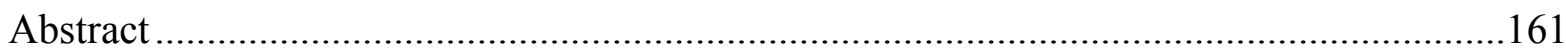

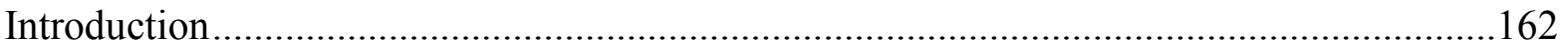




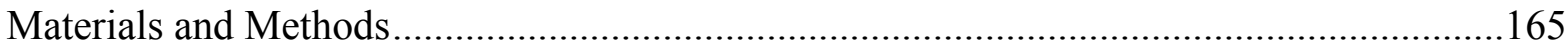

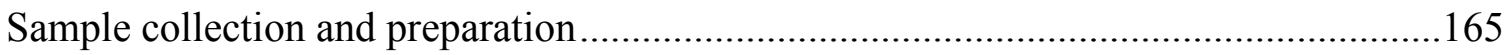

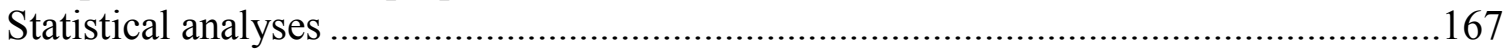

Calibration coefficients and fatty acid subsets............................................................167

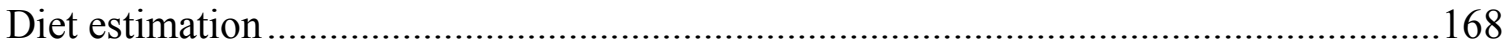

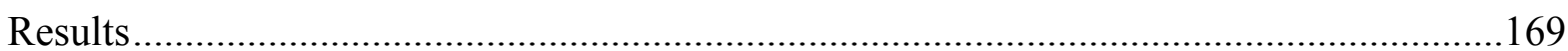

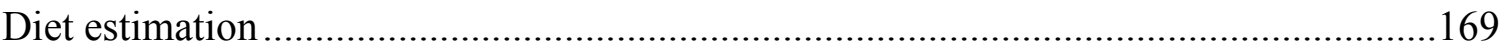

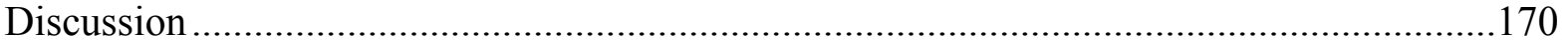

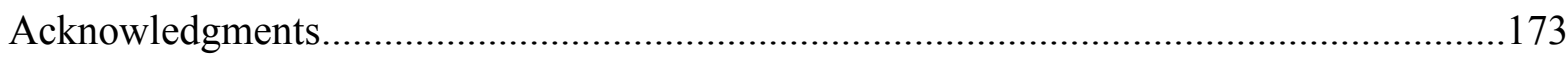

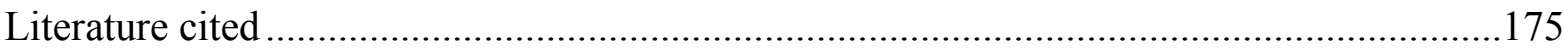

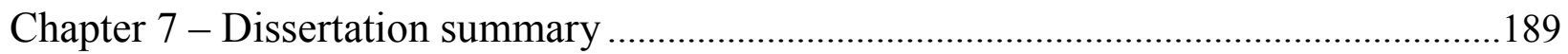

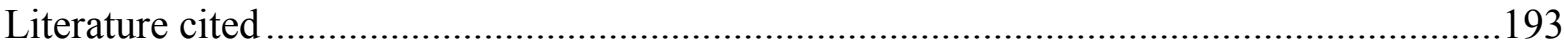

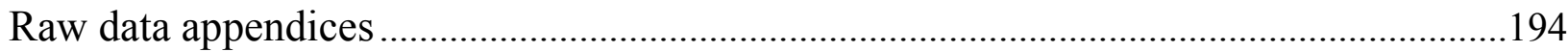

Chapter 2 raw data ..................................................................................................... 194

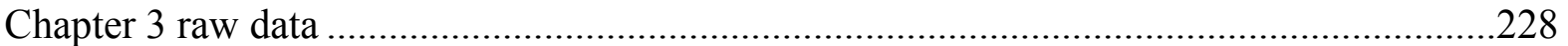

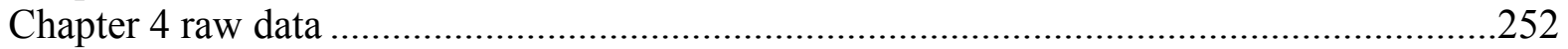

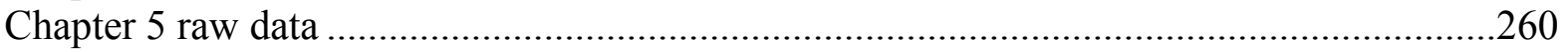

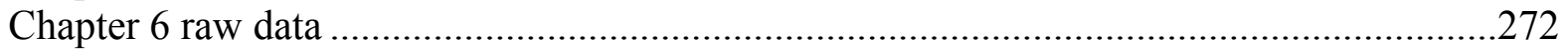

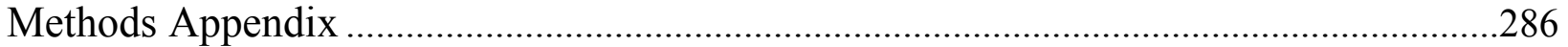

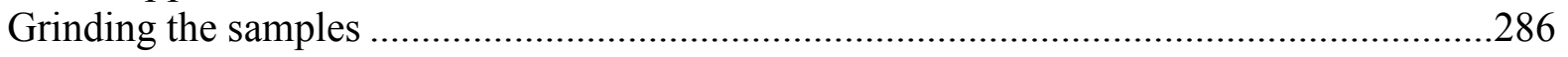

Running the samples on the Accelerated Solvent extractor (ASE) ....................................28

Backwashing samples .................................................................................................228

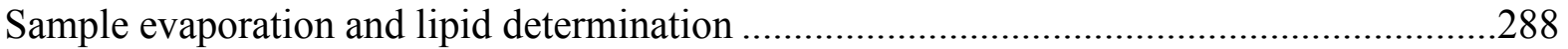

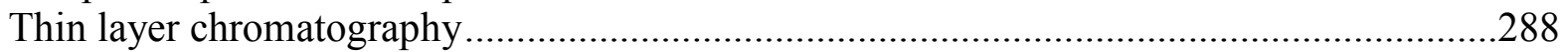

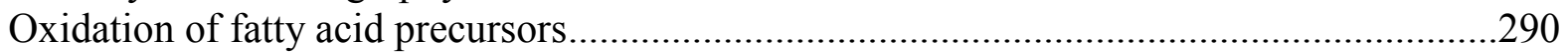

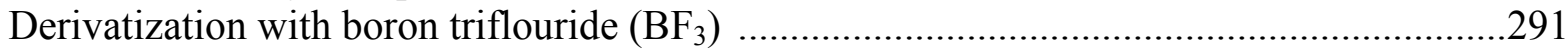

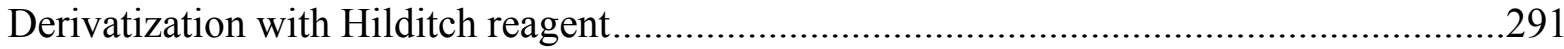

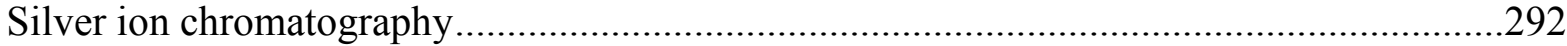

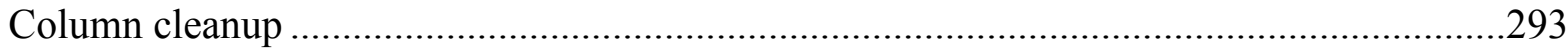

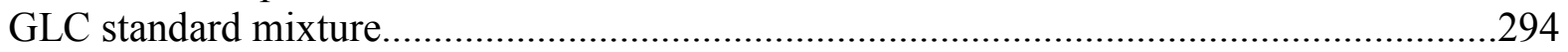

Running samples on the gas chromatograph/mass spectrometer (GC/MS) ..........................294

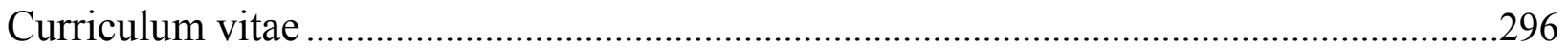




\section{List of Tables}

\section{Chapter 2}

Table 1. The library of prey species analyzed for fatty acid analysis. The values for length, weight, and lipid content represent the mean \pm 1 standard error of the mean. Lipid content is based upon gram of lipid per gram of fish

Table 2. Summary of model selection statistics for lipid percent in samples; K represents the number of parameters in the model; $\triangle \mathrm{AIC}_{\mathrm{c}}$ represents the difference between the $\mathrm{AIC}_{\mathrm{c}}$ value for that model and the set's minimum $\mathrm{AIC}_{\mathrm{c}}$ value; $\mathrm{W}$ represents the Akaike weight of each model.

Table 3. Parameter estimates from the AIC model that included all factors (weight, species, and season) along with the second order interaction term of weight by season. The standard error (SE) of the estimate is given along with the $\mathrm{p}$ value. The weight of the model was $0.71 \ldots \ldots . . .54$

Table 4. Parameter estimates from the AIC model that included all factors (weight, species, and season) along with the second order interaction terms of weight by species, weight by season, and species by season. The standard error (SE) of the estimate is given along with the $\mathrm{p}$ value. The weight of the model was 0.14

Table 5. Parameter estimates from the AIC model that included all factors (weight, species, and season). The standard error (SE) of the estimate is given along with the $\mathrm{p}$ value. The weight of the model was 0.10

Table 6. Results from the classification and regression trees (CART) and discriminant function analysis (DFA) in this experiment. The discriminant function analysis was used on the 5 FA with the highest variation and metrics consisting of saturated, monounsaturated, omega 3 , omega 6, and co-eluted FAs. Sample size in each group is denoted by n, and the number correctly classified is listed under CART and the two DFA categories.

\section{Chapter 3}

Table I. Results from the PERMANOVA performed on the fatty acid data from each sample. The entire fatty acid signature from each group was compare to all other groups. Asterisks represent a significant difference in overall signature

\section{Chapter 4}

Table 1. Summary of model selection statistics for lipid percent in samples; $\mathrm{K}$ represents the number of parameters in the model; $\triangle \mathrm{AIC}_{\mathrm{c}}$ represents the difference between the $\mathrm{AIC}_{\mathrm{c}}$ value for that model and the set's minimum $\mathrm{AIC}_{\mathrm{c}}$ value; $\mathrm{AICc}$ represents the Akaike weight of each model, and $\mathrm{W}$ represents the cumulative weight 
Table 2. Mean fatty acid concentrations expressed as a mass percent of all fatty acids present \pm 1 standard error of the mean; nd = not detected. The fatty acids shown are for the prey item, spot, and the tissues collected from striped bass days 0 through 40 . Unless specified, all unsaturated fatty acids have cis configuration....

\section{Chapter 5}

Table 1. Calibration coefficients calculated for fatty acids in the liver and belly flap samples. Fatty acid datasets represent the variables included in the QFASA models 148

Table 2. Mean fatty acid concentrations expressed as a mass percent of all fatty acids present \pm 1 standard error of the mean; nd = not detected. The fatty acids shown are for the menhaden and spot, the two prey taxa that comprised the mixed diets: $70 \%$ menhaden and 30\% spot (70MH:30SP) and 30\% menhaden and 70\% spot (30MH:70SP)

Table 2. Length, weight, and lipid levels of liver and belly flap samples for each diet fed during the experiment. Values represent the mean and 1 standard error of the mean

\section{Chapter 6}

Table 1. Length, weight, and fat content of striped bass and the four prey species collected in the upper bay during the fall (September - October). Values represent the mean \pm 1 standard error of the mean; $\mathrm{N}$ refers to the samples size of each group.

Table 2. Mean FA concentrations expressed as a mass percent of all FAs present \pm 1 standard error of the mean; nd = not detected. FAs shown are for striped bass and the four prey species analyzed in the QFASA model. All species were collected in the upper bay in fall (September October). FAs listed are in the cis configuration unless otherwise noted. 


\section{List of Figures}

\section{Chapter 2}

Figure 1. Map of collection sites in the Chesapeake Bay. The black line represents a division between bay locations. Above the line, salinities ranged from 2-8 parts per thousand (ppt), and below the line samples salinities ranged from 10-16 ppt. The larger map is a representation of the box in the inset.

Figure 2. Natural log lipid percent (of wet weight) of samples collected in the a) spring, b) summer, and c) fall

Figure 3. Major fatty acids in a) anchovy; and b) menhaden signatures. Solid bars represent samples collected from the upper Bay and patterned bars represent samples collected from the lower Bay

Figure 4. Major fatty acids in a) spot; and b) blue crab signatures. Solid bars represent samples collected from the upper Bay and patterned bars represent samples collected from the lower Bay

Figure 5. Classification and regression tree (CART) output for prey species classification. The frequency refers to which individual was classified at that terminal node. Letters in the legend correspond to letters at the end of each branch of the dendrogram.

Figure 6. Discriminant function analysis of the group means centroids for the 5 fatty acids with the highest variation. The first 2 functions explained $70.5 \%$ of the variation. Arrows on the axes represent increases in that particular fatty acid in the direction noted.

Figure 7. Discriminant function analysis of the group means centroids for the 5 composite sums of fatty acids. The first 2 functions explained $71.5 \%$ of the variation. Arrows on the axes represent increases in that particular fatty acid metric in the direction noted

Figure 8. Abundance of 4 fatty acids that exhibit differences based upon the size of menhaden analyzed $(n=26)$. The adult menhaden length refers to total length, with head and tail included

\section{Chapter 3}

Figure 1. Fat contents of the liver ( $\mathbf{\square})$ and belly flap ( $\bullet$ ) of striped bass analyzed. Spot was fed starting on day 0 until day 40 , and the diet was switched to menhaden on day 40 as indicated by the vertical line 
Figure 2. Average wet weight of striped bass from each sampling day. Spot was fed starting on day 0 until day 40, and the diet was switched to menhaden on day 40 as indicated by the vertical line...

Figure 3. Average mass percent of the major fatty acids detected in menhaden ( $\square$ ) and spot ( $\square$ ) and striped bass tissues: a) liver samples, and b) belly flap samples on days 0 ( $⿴ 囗 0), 12$

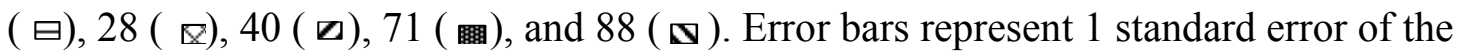
mean

Figure 4. Non-metric multidimensional scaling (NMDS) plot of striped bass tissue samples and the prey items, spot and menhaden. A plot of a) axes 1 and 2 and b) axes 1 and 3 was needed to reduce the stress value (10.42). The alphanumeric code refers to the tissue (Liv $=$ liver and $\mathrm{BF}$ $=$ belly flap) and the day on which the sample was collected (i.e. $0=$ day $0,40=$ day 40, etc.).

The two prey species are spot and menhaden $(\mathrm{MH})$...... .96

Figure 5. Patterns in abundance of select fatty acids. Abundance is based upon mass percent of total fatty acids. The diet was changed from spot to menhaden on day 40. Solid bars represent lipid masses during the time when striped bass were fed spot, while pattern bars represent lipid masses after switching the diet to menhaden. Part a) spot (solid bars) and menhaden (patterned bars) fatty acids, b) liver fatty acids for days $0,12,28,40,71$, and 88 and c) belly flap fatty acids for days $0,12,28,40,71$, and 88 . .97

\section{Chapter 4}

Figure 1. Water temperature for the experimental tanks throughout the experiment. The dashed line represents the day on which the diet was switched from the baseline prey of spot to that of the experimental prey of menhaden

Figure 2. Baseline fatty acid signature of all three size classes of striped bass after four weeks of being fed spot.

Figure 3. Lipid content of the three size classes of striped bass analyzed. Spot was fed as a baseline prey for four weeks prior to the start of the experiment. Starting on day zero, menhaden was used as the experimental prey. Error bars represent 1 standard error of the mean

Figure 4. Wet weight of striped bass from each sampling day. Error bars represent 1 standard error of the mean.

Figure 5. Nonmetric multidimensional scaling of fatty acid signatures for striped bass, the baseline prey, spot, and the experimental prey, menhaden. Size class of fish is denoted as Sm for small, Med for medium, and Lg for large. The sampling days for each size class are denoted as 0 is day 0,13 is day 13 , and 28 is day 28 . MH refers to menhaden fed as the experimental prey. 
Figure 6. Patterns in abundance of select fatty acids for the three sizes of striped bass and the prey species fed during this experiment. Abundance is based upon mass percent of total fatty acids

\section{Chapter 5}

Figure 1. NMDS plot of fatty acids identified in the diets, liver, and belly flap tissue in striped bass during the experiment. Fish were fed a diet of spot for six weeks and sampled on day 0 . Striped bass were fed three diets: menhaden in tank 1 (T1), 70\% menhaden:30\% spot in tank 2 (T2), and 30\% spot:70\% menhaden in tank 3 (T3). These fish were sampled after a period of 6 weeks

Figure 2. Mean values of select fatty acids from striped bass fed a mixed diet of $70 \%$ menhaden $30 \%$ spot for a) liver samples and b) belly flap samples. Error bars represent 1 standard error of the mean

Figure 3. Mean values of select fatty acids from striped bass fed a mixed diet of $30 \%$ menhaden $70 \%$ spot for a) liver samples and b) belly flap samples. Error bars represent 1 standard error of the mean

Figure 4. Proportional contributions of spot and anchovy to the fatty acid signature of striped bass during the baseline feeding of spot as calculated by the QFASA model. Anchovy was used as the feed during the acclimation of striped bass to the tank system. The dietary dataset of fatty acids variables was used to evaluate contributions

Figure 5. Proportional contributions of spot and menhaden to the fatty acid signature of striped bass as calculated by the QFASA model. The full dataset of fatty acids variables was used to evaluate contributions. Day refers to when the striped bass was sacrificed, $\mathrm{MH}$ is the $100 \%$ menhaden diet, $70 \mathrm{MH}: 30 \mathrm{SP}$ is the $70 \%$ menhaden $30 \%$ spot diet, and $30 \mathrm{MH}: 70 \mathrm{SP}$ is the $30 \%$ menhaden $70 \%$ spot diet

Figure 6. Proportional contributions of spot and menhaden to the fatty acid signature of striped bass as calculated by the QFASA model. The dietary dataset of fatty acids variables was used to evaluate contributions. Day refers to when the striped bass was sacrificed, $\mathrm{MH}$ is the $100 \%$ menhaden diet, $70 \mathrm{MH}: 30 \mathrm{SP}$ is the $70 \%$ menhaden $30 \%$ spot diet, and $30 \mathrm{MH}: 70 \mathrm{SP}$ is the $30 \%$ menhaden $70 \%$ spot diet

\section{Chapter 6}

Figure 1. FA proportions for the four prey taxa examined in this study. Values represent the mean of each FA; errors bars represent one standard error of the mean

Figure 2. NMDS of FA signatures from striped bass and the four prey taxa collected in the fall (September - October). Symbols represent the group centroid mean of each taxon, and ellipses are the $95 \%$ confidence intervals around the mean 
Figure 3. Proportional contribution of the four prey taxa to the diets of striped bass. QFASA model results from a 16 FA dataset and a 30 FA dataset are based on the contribution of each prey taxa fatty signature to striped bass FA signatures in the belly flap. Values for stomachs are the percent biomass of each prey taxa in striped bass samples in this experiment. Values from Hartman and Brandt (1995) and Overton et al. (2000) are contribution of each prey taxa based upon percent biomass to the diets of age 3 striped bass in the middle portion of the Chesapeake Bay during the fall (September - October) ..........................................................................188 


\section{Chapter 1 - Literature Review \\ Striped bass ecology and exploitation}

Striped bass (Morone saxitilis) are a large anadromous fish that spawn in the Chesapeake Bay tributaries between April and May and then return to the coastal waters afterwards

(Chapoton and Sykes 1961). The Chesapeake Bay is not the only spawning grounds, but may be responsible for a majority of the coastal stock (Kohlenstein 1981). Eggs hatch in about five to seven days, with larvae consuming their yolk sac for the next several days (Setzler-Hamilton and Hall 1991). Age-3 striped bass and younger may move minimally away from the natal estuaries (Mansueti 1961). Juveniles feed upon a diet of mostly invertebrates, but they also consume larvae of other fish (Boynton et al. 1981). Age-1 striped bass still consume a diet of invertebrates, but start to feed on fish as the year continues, and by age- 2 these fish are primarily piscivores (Hartman and Brandt 1995).

Striped bass males reach sexual maturity at age- 2 while only a few females reach maturity at the same age. Females may not spawn annually until they reach age-7 (Maryland DNR 1987). Once sexual maturity is reached, some striped bass migrate to coastal waters to join the migratory population. Some fish may remain in the Bay until they reach anywhere between three to eight years with older year classes representing a smaller and smaller proportion of the resident population (Rugolo and Jones 1989).

The large numbers and size of striped bass have supported a commercial and recreational fishery since colonial times (CBEF 2006). However, starting in the 1970s, annual recruitment of striped bass began to plummet and the population began a drastic decline (ASMFC 1981). The U.S. Congress passed legislation that declared any state in violation of the plan prepared and adopted by Atlantic States Marine Fisheries Commission (ASMFC) would have a moratorium 
placed on their striped bass fishery (Atlantic Striped Bass Conservation Act 1984). In 1985, Maryland imposed a self moratorium, and Virginia followed suit in 1989. These measures, along with stocking efforts (Secor and Houde 1998) appeared to adequately address the problem as the population began to rebound. The three year average of Maryland's juvenile index from 19871989 exceeded 8.0, a criterion needed to reopen the fishery (Richards and Rago 1999). Amendment 4 to the ASMFC Plan was adopted in 1989, and it allowed states to reopen a tightly controlled fishery on striped bass. Another caveat of the amendment was that states had to monitor their striped bass populations (ASMFC 1989). Several factors, including an improved juvenile index and improved spawning stocks led to a declaration by the ASMFC that striped bass could be considered a recovered species (ASMFC 1995). Continuing research and monitoring of striped bass populations is needed to prevent a similar situation from occurring again.

Diets of striped bass undergo an ontogenetic shift as striped bass grow. Juveniles are opportunistic feeders, and their diets are comprised of insect larvae, polychaetes, larval fish, and amphipods (Setlzer-Hamilton and Hall 1991). The location of juvenile striped bass will influence their diet, with fish in freshwater portions of the Potomac Estuary feeding on oligochaetes and insects and fish in higher salinities were feeding more on amphipods, mysids, and fish larvae (Boynton et al. 1981). Striped bass become more dependent on fish species as a prey source as they grow, and are primarily piscivorous by age-2 (Hartman and Brandt 1995).

The diets of piscivorous striped bass have been well studied (Gardinier and Hoff 1982, Hartman and Brandt 1995, Overton et al. 2000, Rudershausen et al. 2005). These fish prey upon a variety of items such as Atlantic menhaden (Brevoortia tyrannus), bay anchovy (Anchoa mitchilli), spot (Leiostomus xanthurus), other clupeids, and blue crab (a decapod; Callinectes 
sapidus). Atlantic menhaden can make up a large proportion of the diet (Hartman and Brandt 1995, Overton et al. 2000).

The diets of striped bass may have undergone a shift in the Chesapeake Bay unrelated to life stage. The mean daily consumption by striped bass on menhaden in 2000 was consistently less for all age groups than observed in 1993 (Overton et al. 2000). Striped bass mean daily consumption of blue crabs was also higher in 2000 than estimated for striped bass in 1993 (Overton et al. 2000). The decreased presence of menhaden in the diet also coincided with a change in the weight-at-length and weight-at-age measurements for striped bass suggesting that striped bass were not sufficiently substituting other prey items for lost menhaden (Uphoff 2003). Based upon calculations, striped bass demand began to exceed prey supply in the late 1990s (Uphoff 2003) due to a seven fold increase in the population between 1982 and 1994 (NEFSC 1998).

Weakfish (Cynoscion regalis) and bluefish (Pomatomus saltatrix) compete with striped bass for bay anchovy, menhaden, and spot (Merriner 1975, Hartman and Brandt 1995, Parthree et al. 2006). The weakfish population was at a low level in the late 1980s until recruitment increased from a low point in 1989 and the population rebounded to high numbers in the 1990s (NESFC 2000). Bluefish (Pomatomus saltatrix) consume menhaden, spot, and anchovies (Hartman and Brandt 1995, Harding and Mann 2001, Scharf et al. 2004) and are therefore considered a competitor of striped bass. The biomass of this population had a historic high in 1981, and then decreased by roughly $84 \%$ over the next 14 years. Recruitment increased in 1994 and 1996 and in 1999 was the highest since 1989 (Beal et al. 2000). As striped bass were increasing during the mid to late 1990s, two other major competitors also saw their numbers increase which would lead to more pressure on the already fragile prey base. 
Environmental stressors may have led to emaciated striped bass with visible lesions collected between 1997 and 2000 (Uphoff 2003). Overton et al. (2003) found an infection rate of $53 \%$ for striped bass in the Chesapeake Bay. Infected fish were defined as having granulomas originating from Mycobacterium spp. that were associated with organs or external lesions. This study also documented the condition of the fish; striped bass with no granulomas or external lesions had the highest Fulton condition factor (0.99) and fish with both granulomas and external lesions had the lowest condition (0.81). Studies have demonstrated that more than one species of bacteria of the genus Mycobacterium may be responsible for the outbreak seen in striped bass (Heckert et al. 2001, Rhodes et al. 2004). What is not clear is whether striped bass are in poor condition because of the bacterial infection, or if they are in poor condition prior to contracting the infection. It is important to understand the life history of the primary prey of striped, Atlantic menhaden, in order to make appropriate management decisions

\section{Atlantic menhaden ecology and exploitation}

Atlantic menhaden breed throughout inshore waters along the Atlantic and at around one month the young are carried by currents into various estuaries, including the Chesapeake Bay (Massmann et al. 1962). Larvae metamorphose into juveniles and concentrate in large schools throughout the summer. These fish remain in the Chesapeake Bay until fall, at which point they migrate out and overwinter along southern coastal waters (Lippson 1991).

Atlantic menhaden have been an important commercial fishery since the 1950 s, and each year hundreds of thousands metric tons are harvested (NOAA 2009). Menhaden can reach ages of 10-12 (Ahrenholz 1991), however the size structure has become truncated due to overfishing with few fish obtaining ages greater than six (Ahrenholz 1987). Vaughan and Smith (1988) 
reported that the fishery was beginning to rely more heavily on younger fish (pre-spawners age-2 and younger), and the trend has continued to present day. The percentage of age- $3+$ fish present in the catch from 2004-2008 was never more than $27 \%$, and the bulk of the fish were age-2 (NOAA 2009). A cap on the harvest of menhaden was instituted, but the landings from 20062008 have fell below the cap by an average of $30 \%$, which means the cap could be ineffective in preventing overfishing of the stock (CBEF 2009).

\section{Diet analysis}

\section{Stomach content analysis}

Historically the method for determining the diet of fish was to collect samples, sacrifice the fish, and observe what was present in the stomach (i.e. Ewers and Boesel 1935, Moffet and Hunt 1945). A method was also developed by Seaburg (1957) in which the stomach contents were "flushed" out and the fish did not need to be sacrificed. These data were usually analyzed using metrics such as frequency of occurrence, percent composition by number, or percent composition by weight (Bowen 1996). These metrics by themselves often emphasize large and possibly infrequent prey items or small and possibly numerous items (George and Hadley 1979, Hyslop 1980). Combinations of these metrics have been used in order to try and reduce the bias involved (George and Hadley 1979).

There are some inherent biases that are associated with the analysis of stomach contents (Iverson et al. 2004). The identification of prey items in the stomach is easier if the meal has just been eaten, and little digestion has taken place. However, if it has been some time since the meal was eaten, the whole prey item may no longer be intact, forcing the identification of the prey to be made from what materials are left, i.e. chitinous hard parts or scales (Bowen at al. 1993). The 
rate of digestion for tissues is not homogeneous, and this could also bias the conclusion of the predator's diet. The stomach contents of a fish are also assumed to be representative of the forage base in the area. A voracious piscivore, e.g. bluefish, may feed randomly on encountered prey items (Juanes et al. 1993), which may lead to a misrepresentation of what prey base is available to a predator. Opportunistic predators like striped bass may encounter an unusual prey item during feeding, or encounter prey not regularly consumed. Due to these factors, the published diet of any given predator may be incorrect as the information used may not represent the entire picture.

\section{Alternative strategies for diet analyses}

\section{Stable isotope analysis}

Stable isotopes are present in natural materials, can be measured with great precision and isotopic concentrations change in predictable ways as elements cycle through the biosphere. Isotopic values of carbon show modest increases with each trophic level while values of nitrogen increase through each successive trophic level (Peterson and Fry 1987), and can lead to a determination of trophic level (Hecky and Hesslein 1995, Vander Zanden et al. 1997).

The use of stable isotope analysis to determine origins of materials in the environment requires that the samples are isotopically different. The fractionation of isotopes refers to the pathway that the "heavy" and "light" isotopes take in various reactions. These pathways need to be known for stable isotope analysis to be applied in a system (Lajtha and Michener 1994). There may be too many sources of isotopes, i.e. prey species, to resolve the diet of a predator. This occurs when prey isotopic signatures are not significantly different from one another. One solution is to group prey species (Phillips et al. 2005) such as fish or krill diets of penguins 
(Tierney et al. 2008) or littoral, pelagic, or profundal energy sources in a lake (Lepak et al. 2006). Another possible solution is to obtain a range of feasible contributions from each source, and then combine related sources a posteriori (Phillips et al. 2005). The combination of sources in stable isotope analysis leads to decreased taxonomic resolution, but offers a longer time frame in which to infer diets (Tierney et al. 2008).

\section{Fatty acid analysis}

Fatty acids are a class of lipids that are comprised of a carboxylic acid group and a relatively long chain of carbon and hydrogen atoms. These compounds can be saturated (no double bonds) or contain one to six double bonds between the carbons atoms and they can perform a variety of functions (Gurr and Hardwood 1991). Eicosanoids are molecules that are synthesized from 20 carbon length (C20) polyunsaturated fatty acids and are involved in blood clotting, immune responses, renal function, and neural function (Tocher 2003). Sargent et al. (1999) found that certain fatty acids obtained exclusively from the diet in salmon were responsible for the parr-smolt transformation.

Fatty acids are deposited largely unmodified from prey to predator (Iverson 1997a). For example, adult menhaden persist on a diet of larger phytoplankton (Friedland et al. 1989) which is deficient in the fatty acids C20 and C22:1, and consequently the signature of the menhaden are lacking in these two compounds (Arts et al. 2001). An organism that does not require a large supply of energy immediately can store fatty acids in molecules known as triacylglycerols. Triacylglycerols are a major class of neutral lipid in which the fatty acid is esterified to the alcohol group of the glycerol (Tocher 2003). Unused protein and carbohydrates can be converted to fats, but the process is not reversible (Gurr and Hardwood 1991). The triacylglycerols are 
stored in a variety of locations including the mesenteric adipose tissue and the adipose tissue between myosepta (Henderson and Tocher 1987).

"Essential fatty acids" cannot be biosynthesized and must be obtained from the diet (Tocher 2003). They range between 12-24 carbons in length (usually even in number) and may undergo moderate changes, such as chain lengthening and desaturation (Tocher 2003) or remain completely unchanged (Budge et al. 2006). Some fatty acids are biosynthesized by the organism and also contribute to the fatty acid reservoir. The combination of these three components leads to a "fatty acid signature" (Iverson 1993) or fingerprint that is unique to that species. For example, juvenile cobia (Rachycentron canadum) started to exhibit a significant change in their fatty acids after 3 days of diet change, and greater than $90 \%$ of the PUFAs were conserved after an average of 12 days (Turner and Rooker 2005).

The fatty acids can be tracked as they move their way through the food web (Iverson 1997a), and diet can be estimated from the fatty acids present and their proportions with respect to other fatty acids (Iverson 2004). Fatty acids may be present in the prey in a form that is not readily available to the predator. Wax esters are a neutral lipid in which the fatty acid is esterified to a fatty alcohol group (Gurr and Hardwood 1991). The predator removes the fatty alcohol, oxidizes it to a fatty acid, and its fate will be the same as other fatty acids ingested, i.e. incorporation into triacylglycerols and phosphoglycerides (Sargent et al. 1979, Tocher 2003).

Studies have also shown that a broader temporal scale can be inferred from analyzing the fatty acids of an organism. Often, it is possible to determine diet items eaten over the past several weeks, versus the last meal (Iverson 1997b). Digestion rates and the presence of gastric enzyme resistant body parts are no longer an issue because researchers are investigating trace marker 
products of food resources, and not the food resource itself to determine diet. This could lead to elimination of biases present when trying to determine diet from examination of the stomach.

Exact abundances of prey items cannot be inferred, but it is possible to estimate the proportions of various prey species in the diet. Very mobile species such as striped bass would make an ideal candidate for this technique as they feed both in coastal waters and in the Chesapeake Bay as adults. Fatty acid signature analysis may also be able to delineate between resident striped bass, or blackbacks, and those migrating upstream to spawn, or greenbacks (Gallagher et al. 1998). They key for this technique is establishing a library of prey fatty acid signatures that can be compared to striped bass tissues. Despite variation within species, relatively few fatty acids may be needed to distinguish between the prey types (Recks and Seaborn 2008). Because preferred prey of striped bass in the Chesapeake Bay has been well documented; the next step becomes determining how these molecules are incorporated by striped bass. Fatty acid analysis may overcome the deficiencies of stomach content analysis (removal of unidentifiable items from analyses and short term time frame) and stable isotope analysis (low taxonomic resolution) to provide detailed information for a longer time frame than the last meal. 


\section{Literature cited}

Ahrenholz, D.W. 1991. Population biology and life history of the North American menhadens, Brevoortia spp. Marine Fisheries Review 53:3-19.

Ahrenholz, D.W., W.R. Nelson, and S.P. Epperly. 1987. Population and fishery characteristics of Atlantic menhaden, Brevoortia tyrannus. Fishery Bulletin 85:569-600.

Arts, M.T., R.G. Ackman, and B.J. Holub. 2001. "Essential fatty acids" in aquatic ecosystems: a crucial link between diet and human health and evolution. Canadian Journal of Fisheries and Aquatic Sciences 58:122-137.

ASMFC (Atlantic States Marine Fisheries Commission). 1981. Interstate fisheries management plan for the striped bass. Fisheries Management Report No. 1, Washington, D.C.

ASMFC (Atlantic States Marine Fisheries Commission). 1989. Supplement to the striped bass FMP-Amendment \#4. ASMFC, Fisheries Management Report 15, Washington, D.C.

ASMFC (Atlantic States Marine Fisheries Commission). 1995. Amendment \#5 to the interstate fishery management plan for Atlantic striped bass. ASMFC. Fisheries Management Report 24, Washington, D.C.

Atlantic Striped Bass Conservation Act of 1984. 16 U.S.C. $§ ~ 5151-5158$.

Beal, R. 2000. Review of the Atlantic States Marine Fisheries Commission fishery management plan for bluefish (Pomatomus saltatrix). Atlantic States Marine Fisheries Commission.

Bowen, S.H. 1996. Quantitative description of the diet. In: Fisheries Techniques (eds. Murphy, B.R. and Willis, D.W.), pp. 513-532. American Fisheries Society, Bethesda, MD.

Bowen, W.D., J.W. Lawson, and B. Beck. 1993. Seasonal and geographic variation in the species composition and size of prey consumed by grey seals (Halichoerus grypus) on the Scotian shelf. Canadian Journal of Fisheries and Aquatic Sciences 50:1768-1778. 
Boynton, W.R., H.H. Zion, T.T. Polgar, 1981. Importance of juvenile striped bass diets in the Potomac estuary. Transactions of the American Fishery Society 110:56-63.

Budge, S.M., S.J. Iverson, H.N. Koopman. 2006. Studying trophic ecology in marine ecosystems using fatty acids: a primer on analysis and interpretation. Marine Mammal Science 22:759-801.

CBEF (Chesapeake Bay Ecological Foundation). 2009. Ecological depletion of Atlantic menhaden effects on Atlantic coast striped bass: First year-round diet study of large Chesapeake Bay striped bass.

Chapoton, R.B. and J. E. Sykes. 1961. Atlantic coast migration of large striped bass as evidenced by fisheries and tagging. Transactions of the American Fisheries Society 90:13-20.

Ewers, L.A. and M.W. Boesel. 1935. The food of some buckeye lake fishes. Transactions of the American Fisheries Society 65:57-70.

Friedland, K.D., D.W. Ahrenholz, and J.F. Guthrie. 1989. Influence of plankton on distribution patterns of filter-feeder Brevoortia tyrannus (Pisces: Clupeidae). Marine Ecology Progress Series 54:1-11.

Gallagher, M.L., L. Paramore, D. Alves, and R.A. Rulifson. 1998. Comparison of phospholipid and fatty acid composition of wild and cultured striped bass eggs. Journal of Fish Biology 52:1218-1228.

Gardinier, M.N. and T.B. Hoff. 1982. Diet of striped bass in the Hudson River estuary. New York Fish and Game Journal 29:152-165.

George, E.L. and W.F. Hadley. 1979. Food habitat partitioning between rock bass (Ambloplites rupestris) and smallmouth bass (Micropterus dolomieui) young of the year. Transactions of the American Fisheries Society 108:253-261. 
Gurr, M.I. and J.L. Hardwood. 1991. Lipid biochemistry: an introduction. $4^{\text {th }}$ ed. Chapman and Hall. London, England.

Harding, J.M. and R. Mann. 2001. Diet and habitat use by bluefish, Pomatomus saltatrix, in a Chesapeake Bay estuary. Environmental Biology of Fishes 60:401-409.

Hartman, K.J. and S.B. Brandt. 1995. Trophic resource partitioning, diets, and growth of sympatric estuarine predators. Transactions of the American Fishery Society 124:520537.

Heckert, R.A., S. Elankumaran, A. Milani, and A. Baya. 2001. Detection of a new Mycobacterium species in wild striped bass in the Chesapeake Bay. Journal of Clinical Microbiology 39:71-715.

Hecky, R.E. and R.H. Hesslein. 1995. Contributions of benthic algae to lake webs as revealed by stable isotope analysis. Journal of the North American Benthological Society 14:631-653.

Henderson, R.J. and D.R. Tocher. The lipid composition and biochemistry of freshwater fish. Progress in Lipid research 26:281-347.

Hyslop, E.J. 1980. Stomach contents analysis - a review of methods and their application. Journal of fish Biology 17:411-429.

Iverson, S.J. 1993. Milk secretion in marine mammals in relation to foraging: can milk fatty acids predict diet? Symposium of the Zoological Society of London 66:263-291.

Iverson, S.J. C. Field, W.D. Bowen, and W. Blanchard. 2004. Quantitative fatty acid signature analysis: a new method of estimating predator diets. Ecological Monographs 74:211-235.

Iverson, S.J., K.J. Frost, and L.F. Lowry. 1997a. Fatty acid signatures reveal fine scale structure of foraging distribution of harbor seals and their prey in Prince William Sound, Alaska. Marine Ecology Progress Series 151:255-271. 
Iveson, S.J., J.P.Y. Arnold, and I.L. Boyd. 1997b. Milk fatty acid signatures indicate both major and minor shifts in the diet of lactating Antarctic fur seals. Canadian Journal of Zoology 75:1881-97.

Juanes, F., R.E. Marks, K.A. McKown, and D.O. Conover. 1993. Predation by age-o bluefish on age-0 anadromous fishes in Hudson River estuary. Transactions of the American Fisheries Society 122:348-356.

Kohlenstein, L.C. 1981. On the proportion of the Chesapeake Bay stock of striped bass that migrates into the coastal fishery. Transactions of the American Fishery Society 110:168179.

Lajtha, K. and R.H. Michener. 1994. Stable isotopes in ecology and environmental science. Blackwell Scientific Publications. London, England.

Lepak, J.M., C.E. Kraft, and B.C. Weidel. 2006. Rapid food web recovery in response to removal of an introduced apex predator. Canadian Journal of Fisheries and Aquatic Sciences 63:569-575.

Lippson, R.L. 1991. Atlantic menhaden (Brevoortia tyrannus). in Habitat requirements for Chesapeake Bay living resources. Funderbunk, S.L., S.J. Jordan, J.A. Mihursky, D. Riley, eds. Chesapeake Research Consortium, Inc. Solomons, MD.

Mansueti, R.J. 1961. Age, growth, and movements of the striped bass, Roccus saxitilis, taken in size selective fishing gear in Maryland. Chesapeake Science 2:9-36.

Maryland DNR (Department of Natural Resources). 1987. Third annual status report on striped bass 1987. Tidewater Administration, Fisheries Division, Annapolis, MD.

Massmann, W.H., J.J. Norcross, and E.B. Joseph. 1962. Atlantic menhaden larvae in Virginia coastal waters. Chesapeake Science 3:42-45. 
Merriner, J.V. 1975. Food habits of the weakfish, Cynoscion regalis, in North Carolina waters. Chesapeake Science 16:74-76.

Moffet, J.W. and B. P. Hunt. 1945. Winter feeding of bluegills, Lepomis macrochirus Rafinesque, and yellow perch, Perca flavescens (Mitchill) in Cedar Lake, Washtenaw County, Michigan. Transactions of the American Fisheries Society 73:231-242.

NEFSC (Northeast Fisheries Science Center). 1998. Report of the $26^{\text {th }}$ regional stock assessment workshop $\left(26^{\text {th }} \mathrm{SAW}\right)$ : Stock assessment review committee (SARC) consensus summary of assessments. NEFSC Reference Document 98-03, Woods Hole, MA, USA, pp. 142160.

NEFSC (Northeast Fisheries Science Center). 2000. A report of the $30^{\text {th }}$ Northeast regional stock assessment workshop $\left(30^{\text {th }} \mathrm{SAW}\right)$ : Public review workshop. Woods Hole, MA, USA, 58 pgs.

NOAA (National Oceanic and Atmospheric Administration). 2009. Forecast for the 2009 Gulf and Atlantic menhaden purse-seine fisheries and review of the 2008 fishing season. Sustainable Fisheries Branch, NMFS Beaufort, NC.

Overton, A.S., E.B. May, J. Griffin, F.J. Margraf. 2000. A bioenergetics approach for determining the effect of increased striped bass population on its prey and health in the Chesapeake Bay. Report to: Maryland Department of Natural Resources. Maryland Cooperative Fish and Wildlife Research Unit, University of Maryland Eastern Shore, Princess Anne, MD.

Parthree, D.J., C.F. Bonzek, R.J. Latour. Final report: Chesapeake Bay trophic interactions laboratory series. Virginia Institute of Marine Science, Gloucester Point, VA. 
Peterson, B.J. and B. Fry. 1987. Stable isotopes in ecosystem studies. Annual Review of Ecology and Systematics 18:293-320.

Phillips, D.L., S.D. Newsome, J.W. Gregg. 2005. Combining sources in stable isotope mixing models: alternative methods. Oecologia 144:520-527.

Recks, M.J. and G.T. Seaborn. 2008. Variation in fatty acid composition among nine forage species from a southeastern US estuarine and nearshore coastal ecosystem. Fish Physiology and Biochemistry 34:275-287.

Rhodes, M.W., H. Kator, I. Kaattari, D. Gauthier, W. Vogelbein, C.A. Ottinger. 2004. Isolation and characterization of mycobacteria from striped bass Morone saxatilis from the Chesapeake Bay. Diseases of Aquatic Organisms 61:41-51.

Richards, R.A. and P.J. Rago. 1999. A case history of effective fishery management: Chesapeake Bay striped bass. Transactions of the American Fisheries Society 19:356-375.

Rudershausen, P.J., J.E. Tuomikoski, and J.A. Buckel. 2005. Prey selectivity and diet of striped bass in western Albemarle Sound, North Carolina. Transactions of the American Society $134: 1059-1074$.

Rugolo, L.J. and P.W. Jones. 1989. A recruitment based interseason control model for Chesapeake Bay striped bass. Maryland Department of Natural Resources, Annapolis, MD.

Sargent, J., G. Bell, L. McEvoy, D. Tocher, A. Estevez. 1999. Recent developments in the essential fatty acid nutrition of fish. Aquaculture 177:191-199.

Sargent, J.R., R. McIntosh, A. Bauermeister, and J.H.S. Blaxter. 1979. Assimilation of the wax esters of marine zooplankton by herring (Clupea harengus) and rainbow trout (Salmo gairdnerii). Marine Biology 51:203-207. 
Scharf, F.S., J.P. Manderson, M.C. Fabrizio, J.P. Pessutti, J.E. Rosendale, R.J. Chant, A.J. Bejda. 2004. Seasonal and inter-annual patterns of distribution and diet of bluefish within a middle Atlantic bight estuary in relation to abiotic and biotic factors. Estuaries 27:426436.

Seaburg, K.G. 1957. A stomach sampler for live fish. The Progressive Fish-Culturist 19:137-139.

Secor, D.H. and E.D. Houde. 1998. Use of larval stocking in restoration of Chesapeake Bay striped bass. ICES Journal of Marine Science 55:228-239.

Setzler-Hamilton, E.M. and L. Hall Jr. 1991. In Habitat requirements for Chesapeake Bay living resources. Eds. Funderburk, S.L., S.J. Jordan, J.A. Mihursky, D. Riley. Chesapeake Research Consortium. Solomons, MD.

Tierney, M., P.D. Nichols, K.E. Wheatley, M.A. Hindell. 2008. Blood fatty acids indicate interand intra-annual variation in the diet of Adelie penguins: comparison with stomach content and stable isotope analysis. Journal of Experimental Marine Biology and Ecology $367: 65-74$.

Tocher, D.R. 2003. Metabolism and functions of lipids and fatty acids in teleost fish. Reviews in Fisheries Science 11:107-184.

Turner, J.P. and J.R. Rooker. 2005. Effect of dietary fatty acids on the body tissues of larval and juvenile cobia and their prey. Journal of experimental Marine Biology and Ecology 322:13-27.

Uphoff Jr., J.H. 2003. Predator-prey analysis of striped bass and Atlantic menhaden in upper Chesapeake Bay. Fisheries Management and Ecology 10:313-322. 
Vander Zanden, M.J., G. Cabana, J.B. Rasmussen. 1997. Comparing trophic position of freshwater fish calculated using stable nitrogen isotope ratios $\left(\delta^{15} \mathrm{~N}\right)$ and literature dietary data. Canadian Journal of Fisheries and Aquatic Sciences 54:1142-1158.

Vaughan, D.S. and J.W. Smith. 1988. Stock assessment of the Atlantic menhaden, Brevoortia tyrannus, fishery. NOAA Technical Report NMFS 63. 26p. 
Chapter 2 - Spatial and temporal patterns in fatty acids signatures of striped bass prey taxa ${ }^{1}$

${ }^{1}$ This chapter is written in the style of the journal Transactions of the American Fisheries Society 


\begin{abstract}
The Chesapeake Bay striped bass Morone saxatilis population was declared recovered from overfishing in the late 1990's. However, the new burgeoning population has exerted a large predation pressure on other species that also support important commercial fisheries. In the context of Ecosystem Based Fisheries Management, accurate estimates of diet are needed to determine: 1) estimates of relative prey consumption and 2) the occurrence of dietary shifts. Fatty acid analysis is an alternative to traditional diet estimators which could possibly remove inherent biases related to stomach analyses and more accurately estimate feeding history. In this study, we created a library of fatty acids and lipid values for common striped bass prey items to determine the effects of season, location, and life stage. We targeted four commonly consumed striped bass prey in the Chesapeake Bay: Atlantic menhaden Brevoortia tyrannus, bay anchovy Anchoa mitchilli, spot Leiostomus xanthurus, and blue crab Callinectes sapidus. The prey samples were collected in spring, summer, and fall in multiple locations throughout the Bay in order to capture the seasonal and spatial variation in fatty acid signatures contained within each prey group. Results indicate that pelagic feeders, e.g. menhaden and anchovy, differ in their fatty acid signature compared to demersal feeders, e.g. spot and blue crab, when separated by classification and regression trees (CART) and discriminant function analysis (DFA). Spot and blue crab generally have lower lipid content, making them possibly less nutritious alternatives for striped bass. Menhaden and anchovy have similar signatures, and these signatures change very little with respect to season and location while blue crab and spot exhibit a strong seasonal signature. Blue crab and spot have similar signatures within a season. Menhaden exhibit differences in abundances of certain fatty acids when juveniles are compared to adults. Our
\end{abstract}


results suggest fatty acid signatures of prey taxa vary by season and location, and these parameters need to be incorporated into food web modeling.

\section{Introduction}

Striped bass Morone saxatilis are an abundant piscivore that have supported a commercial and recreational fishery since colonial times (Chesapeake Bay Fisheries Ecosystem Advisory Panel 2006). The fishing pressure along the entirety of its range eventually manifested itself in a population decline observed in the 1970s and 1980s (Boreman and Austin 1985). Through legislation and stocking efforts (Secor and Houde 1998), the population began to rebound. Striped bass numbers peaked in 2004 with an estimated abundance of 70.8 million fish up from a low in 1982 of 8.8 million fish.

A recovered striped bass population could lead to increased prey demand (Hartman 2003). Altering one aspect of the food web will have ramifications on all other species that are connected. Atlantic menhaden Brevoortia tyrannus not only constitute a large proportion of striped bass diets, they also contribute to a reduction fishery along the Atlantic coast. These fish can make up $>50 \%$ of the diets of age- $1+$ striped bass, depending on the month (Hartman and Brandt 1995). The Atlantic menhaden fishery has started to rely more heavily on younger fish, including pre-spawners (age-2 and below, Vaughn and Smith 1988). Removal of key striped bass prey items by humans has led to a shortage for striped bass (Uphoff 2003). Griffin and Margraf (2003) found that large striped bass in the 1990s relied more on bay anchovy and age-0 clupeids compared to the 1950s, when Atlantic menhaden was the primary prey for large striped bass. This lack of menhaden may have led to a higher mean daily consumption of blue crabs in Chesapeake Bay striped bass from 1993 to 2000 (Overton et al. 2000). This pattern also occurred 
in the Hudson River, where it was estimated that striped bass consumption exceeded alosid supply (Hartman 2003). An increase in consumption beyond what the preferred prey can support would necessitate striped bass consuming other species. A diet shift may be indicative of an insufficient prey base to support the striped bass population.

Interactions among species are complex, and are not fully accounted for in single-species approaches to management. The concept of ecosystem based fisheries management has become increasingly important. This framework tries to incorporate species interactions like food web dynamics into the system's model rather than trying to manage each species separately (Brodziak and Link 2002). Links among species and energy flow are examples of reference points that have been postulated as aspects that offer possibilities for modeling (Link 2005). In order to measure these reference points, accurate estimates of feeding history are needed.

Traditional analysis of diet via stomach content analysis is relatively easy and inexpensive (Hyslop 1980). Stomach flushing (Seaburg 1957) involves injecting water into the stomach of the fish to retrieve diet items. While this method does provide information about the diet, gastric evacuation rates of the prey are not accounted for, and may bias the results (Hyslop 1980, Iverson et al. 2004). Identification of prey items in the stomach is easier if the meal has just been eaten, and little digestion has taken place. Once the digestive processes have been initiated, correct identification of prey becomes more difficult. Prey items will remain in the gut for a shorter duration at elevated temperatures (Elliot 1972, He and Wurtsbaugh 1993) and prey species with chitinous material that resists digestion will be more readily enumerated (Gannon 1976). Larger prey size, especially whole fish, will affect the rate of digestion due to the small surface area to volume ratio (He and Wurtsbaugh 1993). Therefore, stomach content analysis 
becomes a snapshot of instantaneous foraging unless corrections for evacuation rates are included.

An alternative to analyzing stomach contents is fatty acid analysis. Fatty acids are deposited in predator tissues with little modification (Iverson 1997a). An organism that does not require a large supply of energy immediately can store fatty acids in molecules known as acylglycerols (Gurr and Hardwood 1991). The fatty acids can be tracked as they are cycled through the food web (Iverson 1997a, Beck et al. 2005, Turner and Rooker 2005, Beck et al. 2007), and diet composition can be estimated from the fatty acids present and their proportions with respect to other fatty acids (Iverson et al. 2004).

Studies have also shown that a broader temporal scale can be inferred from analyzing the fatty acids of an organism. Often, it is possible to determine diet items eaten over the past several weeks, versus the last meal (Iverson 1997b). Digestion rates and the presence of gastric enzyme resistant body parts are no longer an issue because researchers are investigating end products of food resources, and not the food resource itself to determine diet. This could lead to elimination of biases when trying to determine diet from examination of the stomach.

Fatty acid analysis does have problems that need to be addressed for the technique to be a valuable resource. For one, exact abundances of prey items cannot be inferred, but it is possible to estimate the proportions of various prey species in the diet using fatty acid specific statistical techniques (quantitative fatty acid signature analysis; Iverson et al. 2004). Another downside of fatty acid analysis is that no fatty acid is completely unique to a species (Dalsgaard et al. 2003) and several fatty acids may be needed to distinguish between species (Recks and Seaborn 2008). Therefore, it is difficult to assign fatty acid trophic markers (FATMs) for food webs. A way to alleviate this problem is to design laboratory experiments that examine the process of lipid 
integration by a predator for a specific group of prey, e.g. striped bass in the Chesapeake Bay (see Kirsch et al. 1998).

To address the issue of clarifying the diet of striped bass in the Chesapeake Bay, FATMs must be established specifically for this system. In order to complete this task, the fatty acid signature of prey striped bass encounter must be analyzed for their fatty acid signatures throughout the bay, and throughout multiple seasons to determine how fatty acids and lipid levels change in time and space.

The specific goals of this project were to determine 1) if fatty acid signatures and lipid levels of common striped bass prey were different from one another within a season and region; and 2) if there was intra-species variation in prey taxa fatty acid signature and lipid levels based upon season or region.

\section{Materials and Methods}

\section{Sample collection}

In order to assess spatial and temporal variation, Atlantic menhaden and bay anchovy Anchoa mitchilli were collected during spring (2008), summer (2008), and fall (2009) in regions in the Chesapeake Bay with differing salinities (2-8 parts per thousand [ppt] in the upper bay, and 10-16 ppt in the lower bay, Fig. 1). Spot Leiostomus xanthurus and blue crab Callinectes sapidus were collected during summer and fall (2008) in the upper bay (Table 1). Sufficient numbers of spot and blue crab were not collected from the lower bay in any season or from the upper bay in spring to perform fatty acid analysis. Samples from the upper Chesapeake were collected by trawl net and beach seines in collaboration with the National Oceanic and Atmospheric Administration (NOAA) lab in Oxford, Maryland. Adult menhaden were obtained 
from a pound net fisherman in Cambridge, Maryland. The large size of adult menhaden necessitated removal of heads and caudal fins to homogenize the tissue. Therefore, the values obtained for this sample group reflect analysis on the body minus the head and caudal fin. All other individuals analyzed were whole prey species. Species in the lower Chesapeake were collected by the Virginia Institute of Marine Science (VIMS) with bottom trawls (Tuckey and Fabrizio 2011). Once collected, species collected from a location were separately vacuum sealed and frozen at $-20^{\circ} \mathrm{C}$.

\section{Sample preparation}

Prey samples were thawed at the time of analysis, weighed to the nearest 0.1 gram, and total length was measured to the nearest millimeter. Each sample consisted of a homogenate of three to five grams of fish or blue crab and, in the case of small individuals several organisms were combined until the weight range was reached. A sample group refers to a collection of individual samples of a single taxon, collected from a single location in one season.

Small organisms were ground whole with a chemical drying agent, diatomaceous earth (Dionex, Sunnyvale, CA). Larger prey items were homogenized, and a three to five gram sample was ground with the drying agent. Lipid was extracted with methylene chloride/methanol (3:1; v:v) under nitrogen using an Accelerated Solvent Extractor (ASE 300, Dionex, Sunnyvale, CA) according to Folch et al. (1957). Samples were extracted at $100^{\circ} \mathrm{C}$ and $1500 \mathrm{psi}$ (USEPA 2007). Three samples of tissue were extracted at both $100^{\circ}$ and $120^{\circ} \mathrm{C}$ to compare the yield in total lipid extracted (Schafer 1998) and create a correction factor.

Back extraction with $0.88 \%$ potassium chloride solution in deionized water was performed to remove non-lipid materials from extracts according to Folch et al. (1957). The extraction process can be repeated for a sample to maximize the yield, and a comparison between 
one and two extractions was performed for two sample groups (spring anchovy and menhaden from the upper bay). The lipid levels obtained in the second extraction were used to create a corrected lipid content for all other samples which were extracted only once. This step also allowed verification that the correct fatty acid signature can be obtained without extracting all lipids. Total lipid extracted was determined gravimetrically for each sample and reported as a percent of wet weight.

Extracted lipid species containing fatty acids as various derivatives were transesterified using a solution of sulfuric acid and methanol. In this process, aclyglycerols are broken apart to their constituents: glycerol and fatty acids methyl esters (FAMEs). Free fatty acids present in the lipid mixture are also converted to FAMEs (Christie 2003). Sample extracts were cleaned with silica gel and anhydrous sodium sulfate to remove polar components and water, which may degrade the performance of the gas chromatograph column. The silica column was conditioned with hexane and the sample was added along with hexane and diethyl ether, 95:5, v/v (Christie 2003). The mixture was concentrated to $5 \mathrm{ml}$ and diluted to a final total lipid concentration of $100 \mu \mathrm{g} / \mathrm{ml}$. Finished samples were run on a gas chromatograph (Agilent 6890N Network GC System, Santa Clara, CA) / mass spectrometer (GC/MS, Agilent, 5973 Network Mass selective detector, Santa Clara, CA) in select ion monitoring mode.

The GC/MS was used to identify and quantify fatty acids methyl esters in each sample. Fatty acid methyl esters were injected into a fused silica capillary column, DB-23 60m length X 0.250mm OD X 0.25 $\mu \mathrm{m}$ film thickness (Agilent, Santa Clara, CA) using an autosampler (Agilent 7683 Series Auto Sampler) with hydrogen as a carrier gas. The temperature program was as follows: hold at an initial temperature of $50^{\circ} \mathrm{C}$ for $2 \mathrm{~min}$, hold for $1 \mathrm{~min}$ at $150^{\circ} \mathrm{C}$ after ramping at $20^{\circ} \mathrm{C} \cdot \mathrm{min}^{-1}$, ramp to $215^{\circ} \mathrm{C}$ at $1.25^{\circ} \mathrm{C} \cdot \mathrm{min}^{-1}$. The fatty acid retention times were compared to 
known standards from Nu-Chek Prep (GLC MIX 85, 411, 642, 632, Elysian, MN). These four standard mixtures were combined along with stearidonic acid methyl ester (C18:4n3, Cayman Chemical, Ann Arbor, MI) to make a total FAME standard solution of $12.25 \mu \mathrm{g} / \mathrm{ml}$. Matreya 25 FAME mixture (Pleasant Gap, PA) was used to obtain retention times for C20:1n7. Restek cis/trans FAME mixture (Bellefonte, PA) was used to obtain retention times for C18:1n9 trans and C18:2n6 trans. These standards and an internal standard of C13:0 FAME $(100 \mu \mathrm{g} / \mathrm{ml})$ were added to quantify the amount of each fatty acid methyl ester present. The GC/MS tracks the select ion signature of each compound and was used to verify the identity of each peak. There were peaks which consisted of more than one fatty acid and it was impossible to determine which fatty acid was creating the peaks. Therefore, the term fatty acid "complex" was assigned to this peak. The complex refers to which fatty acid(s) could be responsible for the peak, e.g. $\mathrm{C} 22: 5 \mathrm{n} 3$ and $\mathrm{C} 22: 6 \mathrm{n} 3$.

\section{Quality control}

\section{Silver ion chromatography}

An aliquot of solution from several sample groups was analyzed using silver ion chromatography and compared to the Resek cis/trans FAME standard (FAMES: C18:1n9 trans, $\mathrm{C} 18: 2$ n6 cis, $\mathrm{C} 18: 1 \mathrm{n} 9$ cis, $\mathrm{C} 18: 1 \mathrm{n} 12$ cis, $\mathrm{C} 18: 1 \mathrm{n} 12$ trans, $\mathrm{C} 18: 0, \mathrm{C} 18: 1 \mathrm{n} 7$ trans, $\mathrm{C} 18: 1 \mathrm{n} 7$ cis) to verify the elution order of cis and trans monomers (Christie 1989). The step was performed on

fatty acid methyl esters. The aliquot was washed with seven different solutions; three containing hexane and acetone $(96: 4,90: 10$, and $25: 75$ by volume), and four solutions containing acetone and acetonitrile (95:5, 93:7, 88:12, and $85: 15$ by volume). These solutions allow different monomers to be eluted separately, and the samples are run on the GC/MS. 


\section{Fatty acid precursors}

We used thin layer chromatography (TLC) to determine if fatty acid precursors (plasmalogens and wax esters) were present in the prey species (Harding et al. 1975). Silica coated glass plates (Whatman, Piscataway, NJ) were soaked in toluene and allowed to dry overnight. An aliquot of $200 \mu \mathrm{l}$ was pipetted onto the plates. Toluene was absorbed onto the plates until the top of the sample aliquot was reached. Plates were developed in toluene and allowed to dry. Bands were sprayed with 2-7-dichloroflourescin dye to identify bands of lipid classes. Each band was scraped separately, dissolved in methylene chloride, and shaken for one hour. Samples were moved to a clean test tube, oxidized using Jones's reagent, transesterified, and run on the GC/MS (Touchstone 1995).

Samples were oxidized using Jones's reagent, a solution of chromium trioxide in dilute sulfuric acid and acetone (Budge and Iverson 2003). The resulting solution was transesterified as described above, and run on the GC/MS along with the portion that did not undergo oxidation. A standard of the compound C16:0 dimethyl acetal (DMA) was obtained and run as the only fatty acid precursor standard on the GC/MS. The ion signature of C16:0 DMA was used as the basis to indentify other dimethyl acetals.

\section{Instrument tune and maintenance}

The Autotune function was performed on the GC/MS prior to every batch run (20-26 samples). This function measures the relative abundance of three mass ions, 69.00, 219.00, and 502.00. Once the relative abundance of mass ion 219.00 dropped below 90.00 , the mass spectrometer source was cleaned. Also prior to each batch run, the injector septum was changed. The column, injector inlet, and seal were changed as needed during the course of this experiment. After each column change, the column was allowed to condition before any samples 
were run. Standards were run through the instrument several times to ensure the correct retention times were being recorded.

\section{Identification of cetoleic acid}

Analyses and identification of cetoleic acid methyl ester and gadoleic acid methyl ester in herring liver were performed by Ashok Deshpande and Bruce Dockum of NOAA Fisheries, Sandy Hook Laboratory in collaboration with Sue Budge of Dalhousie University. Herring are known to contain the compound $\mathrm{C} 22: \ln 11$ (cetoleic acid), therefore, a sample of herring liver was obtained from a NOAA-NEFSC Groundfish Survey during the course of this experiment and analyzed. Cetoleic acid is an important fatty acid in marine systems (Cooper et al. 2006), and therefore this sample was obtained to determine if this fatty acid was prevalent in the Chesapeake Bay food web.

\section{Statistical analyses}

We used an a priori model building strategy (generalized linear model in program $\mathrm{R}[\mathrm{R}$ Development Core Team 2010]) to determine the effects of season, species, and weight of the sample on the lipid content (as percent of wet weight) of each sample. Bay location was not included in the model because spot and blue crab were only collected in the upper bay. Weight was deemed the most important variable as lipid levels will vary with the size of the prey species. Species was also determined to be an important variable as different organisms will have varying levels of lipid. These two variables were included in most of the models. Season was also included because species will have different lipid levels throughout the year. Due to the sample size of prey species and the necessity to include second- and third-order interactions, not all combinations of models were included in the analysis. Models included: 1) a global of all three predictor variables and all second-order and third-order interaction terms, 2) predictor 
variables and a single second-order interaction term, 3) a single predictor variable, and 4) a null model that included no predictor variables (Table 2). The Akaike information criterion for small sample size $\left(\mathrm{AIC}_{\mathrm{C}}\right.$; Burnham and Anderson 2002) was used to select the best model. A plot of residuals demonstrated that the data violated the assumption of normality. Both the continuous variables weight and lipid content were natural log transformed which corrected the violation of normality. All model building and selection was performed in R (R Development Core Team 2010).

Differences in fatty acid signature were analyzed with different multivariate techniques or methods to determine which provided the best separation among groups. The first multivariate technique used was classification and regression trees (CART). CART partitions the data recursively into groups that are increasingly homogenous. The end result is a dichotomous key that allows the researcher to follow the variables responsible for the group structure (McCune and Grace 2002). The stopping point is determined by either reaching a minimum deviance of a final node or the minimum number of observations has been met (Iverson et al. 2002). Due to size restrictions, the dataset could not be separated into a learning and predictive subset. Instead, the data was separated into 10 equal parts within R (R Development Core Team 2010), and the model was built with $90 \%$ of the data, and the remaining $10 \%$ became the test set. This cross validation technique was run 50 times in $\mathrm{R}$ to produce the error and misclassification rate. Only, fatty acids that had a mean value of $0.4 \%$ or higher of the total fatty acids identified were used in order to remove any observations that may be erroneous. Sample groups that grouped close together at the bottom of the dendrogram were assumed to have similar fatty acid signatures.

The second technique, discriminant function analysis (DFA), maximizes among group variation compared to within group variation (McCune and Grace 2002). Wilk's lambda $(\lambda)$ was 
used to indicate the power of the analysis, with smaller values indicating greater success. The analysis provided a classification matrix, and the predicted group membership provided a basis for the misclassification rate of the technique. The variables used in DFA must be 1 less than the number of organisms in a sample group, therefore, DFA was performed using the 5 fatty acids that exhibited the highest amount of variation, and was also performed using 5 composite metrics: sum of saturated fatty acids, sum of monounsaturated fatty acids, sum of omega 6 fatty acids, sum of omega 3 fatty acids, and the sum of all co-eluted compounds. The mean of the ordination scores was calculated for each sample group, and was plotted for each DFA. This technique was then compared to CART to determine which method provided the better classification scheme for the sample groups in this study.

The difference in mass percent of fatty acids was compared among adult menhaden and two groups of juveniles. Patterns in fatty acid abundance based upon fish total length were examined using regression. All statistical tests were performed using the $\mathrm{R}$ statistical package ( $\mathrm{R}$ Development Core Team 2010). The ANOVA performed on fatty acid abundances between menhaden juveniles and adults had a Bonferonni correction applied to the alpha level for the four group comparisons $(\alpha=0.0125)$.

\section{Results}

\section{Method optimization}

\section{Silver ion chromatography}

The first fraction consisted of saturated fatty acids (C18:0) and trans monoenes

$(\mathrm{C} 18: 1 \mathrm{n} 12 \mathrm{t}, \mathrm{C} 18: \ln 9 \mathrm{t}$, and $\mathrm{C} 18: 1 \mathrm{n} 7 \mathrm{t})$; the second fraction consisted of cis monoenes $(\mathrm{C} 18: 1 \mathrm{n}$ 
12c, $\mathrm{C} 18: 1 \mathrm{n} 9 \mathrm{c}$, and $\mathrm{C} 18: 1 \mathrm{n} 7 \mathrm{c})$; and the third fraction consisted of cis-cis dienes $(\mathrm{C} 18: 2 \mathrm{n} 6 \mathrm{c})$. The retention times for cis and trans monomers were obtained and used for peak identification.

\section{Fatty acid precursors}

Jones's oxidation indicated the fatty acid precursor C16:0 DMA was contributing 0.01 $1.26 \%$ of the total fatty acid signature and was included in all analyses for fatty acids. Values for C17:0 DMA and C18:0 DMA were never higher than 0.05\% and were not included. The attempt to use TLC was unsuccessful in this experiment. Chromatograms of the transesterified bands revealed no peaks.

\section{Cetoleic and gadoleic acid}

Identification of cetoleic acid FAME (C22:1n11) was achieved using herring liver samples. The retention time was compared to prey species run in this experiment. Cetoleic acid was identified in three sample groups: bay anchovy from the lower Chesapeake in spring (average $0.37 \%$ total mass) and fall (average $0.25 \%$ total mass), and from menhaden collected from the Choptank River in summer (average $1.73 \%$ total mass). Cetoleic acid was also identified in individuals from other samples groups, but the average for the group was less than $0.05 \%$ total mass. Because identification of cetoleic acid was based the retention time from one herring liver, and was not run with each sample group, this compound was not included in the analysis.

Gadoleic acid (C20:1n11) is very similar in structure to $\mathrm{C} 20: 1 \mathrm{n} 12$, a compound included in our Nu-Chek standard solution. Peaks were identified as $\mathrm{C} 20: 1 \mathrm{n} 12$, which may be of minimal importance for marine organisms. However, no commercial standard is available for gadoleic acid and the peak is labeled as both compounds (C20:1n11/12, Budge, personal communication). 


\section{Lipid correction}

Corrections were applied to the total lipid data to approximate the lipid values as closely as possible. The second extraction of a sample at $100^{\circ} \mathrm{C}$ revealed a recovery of approximately $14.7 \%$ of the total lipid recovered in the first extraction ( $\mathrm{g}$ lipid per $\mathrm{g}$ fish; $\mathrm{n}=16$ ). All samples extracted were corrected based upon this amount. Samples run on the ASE at temperatures of $100^{\circ} \mathrm{C}$ and $120^{\circ} \mathrm{C}$ yielded an average of $16.74 \%$ more lipid when extracted at $120^{\circ} \mathrm{C}(\mathrm{g}$ lipid $/ \mathrm{g}$ of fish; $n=3$ ). All prey samples were corrected to this amount because samples were run at $100^{\circ} \mathrm{C}$.

\section{Lipid content}

The average lipid content ranged from $1.18 \%-15.10 \%$ for all sample groups tested

(Table 1). Blue crab had the lowest average lipid content of any species $(1.18-1.49 \%)$, followed by spot $(4.49-6.05 \%)$, Atlantic menhaden $(4.95-12.46 \%)$, and bay anchovy $(5.89-15.10 \%)$. The best model to predict wet weight lipid content included the predictor variables of species, season, and sample weight, along with the interaction term between species and sample weight. This model had a $\Delta \mathrm{AIC}_{\mathrm{c}}$ value of 0.71 and had 11 parameters (Table 2). Two other models had low $\triangle \mathrm{AIC}_{\mathrm{c}}$ values of 3.19 and 3.86. While these models had low Akaike weights $(0.14$ and 0.10$)$ they still were able to explain some of the variation. Based upon parsimony and the graphical output, which indicated that some interaction was occurring in the model (Fig. 2), the model described above was chosen as the most appropriate. Parameter estimates for the three models with the highest weight are provided in Tables $3-5$.

All three predictor variables were important for determining the lipid content. Anchovy and blue crab both decreased in lipid percent as the weight of the sample increased, regardless of the season. Menhaden decreased in lipid percent as weight increased in the spring, showed no 
relationship in summer, and increased in lipid percent as sample weight increased in the fall. Spot showed no relationship in summer, and decreased in lipid as weight increased in the fall.

\section{Fatty acids}

A total of 36 fatty acids and fatty acid complexes (peaks consisting of 2 indistinguishable fatty acids) were identified and quantified from the sample groups. The most abundant fatty

acids present across all species were (in elution order on a DB-23 column): C14:0, C15:0, C16:0, $\mathrm{C} 16: 1 n 7, \mathrm{C} 17: 0, \mathrm{C} 18: 0, \mathrm{C} 18: 1 \mathrm{n} 9, \mathrm{C} 18: 1 \mathrm{n} 7, \mathrm{C} 18: 2 \mathrm{n} 6, \mathrm{C} 20: 4 \mathrm{n} 6, \mathrm{C} 20: 5 \mathrm{n} 3$, the complex $\mathrm{C} 22: 5 \mathrm{n} 3+$ C22:6n3, and C24:1n9 (Figs. 3 and 4). The sums of their concentrations ranged from $80-93 \%$ of total fatty acids present. Some fatty acids had higher relative concentrations in certain prey species. Stearidonic acid (C18:4n3) was higher in menhaden and bay anchovy than demersal species. Spot and blue crab had higher abundances of C20:1n11/12, C20:1n9, and C20:1n7 compared to anchovy and menhaden.

\section{Among species variation in fatty acid signatures}

CART analysis was able to correctly classify $92.8 \%$ of the individual samples (refers to a sample of a single prey taxa or a composite of prey taxa to reach the weight range of three to five grams) in 17 sample groups $(n=142$ of 153 , Table 6$)$. A sample group refers to a collection of individual samples of a single taxon, collected from a single location in one season. Both sample groups of blue crab had no misclassifications $(0 \%)$. The fall group of spot had no misclassifications while the summer group had only one misclassification (5.9\%). Six anchovy sample groups had a maximum misclassification of one within a sample group, and overall three misclassifications were made (5.5\%). Menhaden were more difficult to classify. A total of seven menhaden specimens were misclassified (11.7\%). Two menhaden sample groups had two individual samples misclassified, and one group had three. 
Blue crab and spot were separated from anchovy and menhaden in terms of fatty acid signature (Fig. 5). There was a seasonal aspect to the grouping, with blue crab and spot from the same season grouped together. All samples of blue crab and spot were collected from the upper Bay so the influence of Bay location could not be evaluated. A lower abundance of C20:4n6 was indicative of fall blue crab and spot (Fig. 5: $\mathrm{O}$ and Q) while summer blue crab and spot (Fig. 5: N and P) had a higher abundance of $\mathrm{C} 20: 1 \mathrm{n} 7$. Anchovy and menhaden sample groups were separated from blue crab and spot, but overlapped with each other on the CART dendrogram. Anchovy displayed some signs of being grouped by season and location, e.g. samples collected in the summer and fall of the lower bay (Fig. 5: E and C) and samples collected in spring from the upper and lower bay (Fig. 5: A and B) were similar in fatty acid signature. Menhaden adults collected in the summer and menhaden juveniles collected in the fall from the upper bay were also similar in fatty acid signature (Fig. 5: L and M). The patterns structuring menhaden signatures seem limited to this coupling. Overall, there appears to be some separation of menhaden and anchovy signal, but there is also overlap in their fatty acid signatures.

The DFA using the five fatty acids with highest variation and five fatty acid metrics had lower classification rates when compared to CART (79.7 and 73.9\% respectively, Table 3). Both methods were able to correctly classify spot, but had much higher misclassification rates for anchovy, menhaden, and blue crab.

Even with the higher misclassification rates, there was still separation among blue crab/spot and anchovy/menhaden (Figs. 6 and 7). The DFA using five fatty acids had better separation, and demonstrated that spot and blue crab are higher in C18: $\ln 9$ when compared to menhaden and anchovy, and have a higher abundance of C14:0 and C16:1n7 than anchovy (Fig. 6). There was some overlap of menhaden and anchovy, but separation between the two species 
was evident. Anchovy have a higher proportion of $\mathrm{C} 16: 0$ and the complex of $\mathrm{C} 22: 5 \mathrm{n} 3+$ $\mathrm{C} 22: 6 \mathrm{n} 3$, while menhaden have a higher proportion of $\mathrm{C} 14: 0$ and $\mathrm{C} 16: 1 \mathrm{n} 7$.

The DFA that used fatty acid metrics did not exhibit the same separation seen with CART or DFA for the five fatty acids (Fig. 7). Blue crab and spot were separated from anchovy and menhaden by having higher abundances of monounsaturated fatty acids, omega- 6 , and omega-3 fatty acids. Menhaden and anchovy overlapped and no discernible patterns were evident.

\section{Ontogenetic shifts in fatty acid signatures}

Several of the 36 fatty acids analyzed exhibited differences when compared to the size of the menhaden (Fig. 8). There were significant differences in the mass percent of certain fatty acids between adult and juvenile menhaden from the upper bay in summer. Adult menhaden had significantly higher levels of C18:1n7 (ANOVA, $\left.\mathrm{F}_{2,23}=17.95, \mathrm{p}<0.001\right)$ and $\mathrm{C} 20: 5 \mathrm{n} 3\left(\mathrm{~F}_{2,23}=\right.$ 56.01, $\mathrm{p}<0.001)$. Juvenile menhaden had significantly higher levels of $\mathrm{C} 16: 0\left(\mathrm{~F}_{2,23}=18.01, \mathrm{p}<\right.$ $0.001)$ and $\mathrm{C} 18: \ln 9\left(\mathrm{~F}_{2,23}=36.47, \mathrm{p}<0.001\right)$. The two sample groups of juvenile menhaden were not significantly different from one another for any of the four fatty acids listed above.

\section{Discussion}

Fatty acid analysis holds promise for accurately determining forage history in striped bass. The classification rate ranged between 73.9 and 92.8 depending on the technique. Both CART and DFA of 5 fatty acids and 5 fatty acid metrics were able to show patterns among the species groups. Further, we showed that there are discrete differences among the total lipid content of prey species encountered by striped bass which vary by season and ontogeny. This work is extremely important in the context of Ecosystem Based Fisheries Management and 
modeling efforts. This study offers a library of fatty acids that can be used as trophic markers for striped bass forage species in multiple seasons and locations, along with the spatial and temporal variation in lipid of prey that are often neglected when modeling consumption.

The main factors influencing total lipid content of prey items appear to be species, season, and weight of the sample. Blue crab had the lowest lipid content of the four species in all seasons tested. The values seen in this experiment are consistent with other values found in the literature for corresponding seasons (Farragut 1965, Gokodlu and Yerlikaya 2003). Spot had higher lipid content than blue crab. The values we observed for spot in the Chesapeake Bay were lower than those reported in the literature for summer and similar to values reported for fall. Lipid content in our study was $4.04 \%$ for summer samples and $5.86 \%$ for fall samples while Waters (1982) reported levels of 8.69\% for summer and 5.45\% for fall. Our study used small age- 0 spot ranging in size from $4-14 \mathrm{~g}$, versus a range of $113-340 \mathrm{~g}$ for Waters (1982) with a similar extraction technique of organic solvents. Values reported by Waters (1982) reflect lipid content of fillets versus whole organisms as used in this experiment. Whole body lipids tend to be higher than fillets (Lanari et al. 1999, Chaiyapechara et al. 2003), therefore, the difference seen is not attributable to sampling technique, but rather may reflect a natural ontogenetic change in the lipid storage capabilities of spot.

The lipid levels of menhaden in our experiment ranged from $4.95-12.59 \%$ (mean $=$ 10.41\%). These fish represented a broad spectrum of sizes from $1.57-140.80 \mathrm{~g}$ fish, although size did not appear to affect the percent lipid seen in this species. Dubrow et al. (1976) found that menhaden lipid levels ranged from $2.46-20.75 \%($ mean $=12.08 \%)$ depending on season. Menhaden sampled in our experiment represented a broad size range, $78.7-455.4 \mathrm{~g}$. There was a 
seasonal component, with lowest levels present in spring, and increasing through the summer and fall.

Seasonal change in lipid is expected in temperate fish that experience cold water temperatures throughout the winter. Fish can exit winter months in poor condition due to relying on lipid reserves for energy. Once these reserves have been exhausted, mortality is likely to occur (Biro et al. 2004). Similar results have been found in other species, e.g. Atlantic menhaden (Dubrow et al. 1976), gilthead sea bream Sparus aurata (Grigorakis et al. 2002), and alewife Alosa pseudoharengus (Flath and Diana 1985), although there appears to be substantial variation. Therefore it is imperative for an individual to deposit lipid reserves during the warmer months in order to make it through winter.

As the weight of the sample increases, the lipid content decreases for some species tested. This value is the relative proportion of wet weight that is comprised of lipid. As a fish gets larger, the absolute amount of lipid it contains will be larger when compared to small fish, but the proportion appears to decrease in anchovy and blue crab for each season and for menhaden and spot in certain seasons. The trend of lipid increase or decrease is species dependent (Thompson et al. 1991, Anthony et al. 2000). Blue crab, menhaden, and anchovy were sampled across a large size range, however, the number of samples was relatively small, and therefore more samples are needed to verify this pattern. As for spot, only juvenile fish were sampled but the trend of decreasing lipid appears to be present. The size of spot collected in our experiment represents the size of fish that will be consumed by juvenile striped bass. A larger prey item would still be preferable for striped bass because of the larger absolute value of lipid available for the predator. 
Although the four prey species share common fatty acids, differences among the prey species were observed. The fatty acids that were different separated demersal feeding species, e.g. spot (Homer and Mihursky 1991) and blue crab (van Heukelem 1991), from planktivores, e.g. menhaden (Ahrenholz 1991) and bay anchovy (Hartman et al. 2004). Demersal fish have higher proportions of $\mathrm{C} 20$ monounsaturated isomers, which were much less prevalent in the planktivores. This lack of 20:1 isomers can be attributed to the dearth of these fatty acids in the phytoplankton consumed by menhaden (Arts et al. 2001). Other possible sources include benthic copepods (Arts et al. 2001) and polychaete worms associated with muddy substrate (Luis and Passos 1995). The Chesapeake Bay mesozooplankton community is dominated by copepods, specifically two calenoid copepods (Brownlee and Jacobs 1987), yet the C20:1 isomers are still at lower levels than for demersal species. The stomach contents were not removed from the prey samples which could affect their fatty acid signature. However these prey items are eaten whole by striped bass. Including the stomach contents of prey provides a more realistic representation of fatty acid signatures that will be encountered by striped bass. Therefore, it seems that these isomers form a larger part of the demersal rather than the pelagic food web.

The multivariate tools helped to provide insight into the structure behind fatty acid signatures. Among the three techniques evaluated, CART provided the best separation and lowest misclassification rate for the sample groups. The first and second nodes in CART were the demersal species, and as stated before, a C20 isomer was important in the branching pattern of these sample groups. The other fatty acid responsible for separating demersal and pelagic species was arachidonic acid (C20:4n6) which separates summer and fall demersal species. Linoleic acid (C18:2n6) is synthesized by phototrophic organisms (Desvilettes et al. 1997), and in turn is converted to arachidonic acid by higher organisms (Sargent et al. 1999). Phytoplankton 
can settle out of the water column, and there is an opportunity for demersal organisms to consume fatty acids that would normally be present within the pelagic food web. Budge and Parrish (1998) found that very little of the organic material settling out was buried within the sediments. This suggests that demersal organisms have a high degree of efficiency in utilizing organic material before it can be incorporated into the sediments and is removed from the benthic food web. Further work needs to be done to compare the ability of demersal and pelagic species to desaturate and elongate fatty acids like linoleic acid (C18:2n6).

The demersal species consisted of blue crab and spot, and were grouped by season and not by species. Because both species may be viewed as opportunistic demersal feeders, it is not surprising to see such a high degree of overlap in their fatty acid signatures. The fact that the species are split according to season may indicate a seasonal shift in prey availability for the two species. There are some fatty acids that are higher in blue crab and spot in one season versus the other (C20:0, and C22:0), which may suggest that the fatty acid signature of demersal prey shifts from summer to fall. Hines et al. (1990) found that spot and blue crab had similar diets within a season, and that both species experienced a diet shift from spring to fall. Our results indicate that these two species have similar diets, and do experience a seasonal shift even though all four sample groups were collected from different systems in the upper Chesapeake Bay.

Among the planktivore sample groups (menhaden and anchovy), there was less distinction provided by season or location within the bay. While the CART dendrogram does separate menhaden and anchovy (Fig. 5), there is an anchovy grouping, a group of overlap, and a group of menhaden. The menhaden are not grouped in couplets as are the other species, suggesting that the fatty acid signature of each sample groups is unique. There is not enough overlap among menhaden sample groups to place them on the same couplet. 
The difference seen in menhaden and anchovy signatures from benthic feeders is most likely the result of the plankton signatures themselves. Menhaden feed on zooplankton as larvae, and start to develop the ability to utilize phytoplankton as juveniles (June and Carlson 1971). Menhaden switch to a diet comprised mainly of phytoplankton as late stage juveniles and adults, but retain the ability to feed upon zooplankton (Lippson 1991). Anchovy feed on a diet of zooplankton throughout their lives (Johnson et al. 1990, Hartman et al. 2004).

Phytoplankton can have different fatty acid signatures (Napolitano et al. 1997). As zooplankton graze on the phytoplankton, another level of complexity is added because zooplankton will incorporate phytoplankton signatures and some modification may take place (Sargent and Falk-Petersen 1981). The fact that menhaden signatures are a mix of zooplankton and phytoplankton may explain why there is some similarity to anchovy and not a distinct signature for menhaden.

Adult menhaden were assumed to have a different fatty acid signature compared to smaller conspecifics, due to differences in feeding. This should be manifested in a separation of adult and juvenile menhaden in the CART output. According to the CART analysis, it is possible to distinguish adult versus juvenile menhaden. Of the 36 fatty acids and complexes identified, several fatty acids were significantly different in abundance between adult and juvenile menhaden. A small number of fatty acids appear capable of separating sample groups. Napolitano et al. (1997) demonstrated that only a change in the abundance of three to four fatty acids marked the difference among three different species of phytoplankton seen in Argentina. In both our study and that of Napolitano et al. (1997), the spectrum of fatty acids was similar in groups studied. It was the difference in abundance of fatty acids rather than a difference in fatty acids present that separated groups. 
A more limited technique, DFA, was compared to CART to determine if a small number of fatty acids, or fatty acid metrics could provide the same information. This technique can only use $\mathrm{n}-1$ variables for the model. The misclassification rates were much higher for DFA (20.3 and 26.1) compared to CART; however, the graphical output is still able to show separation among the groups. The DFA based upon the five fatty acids with highest variation separated the demersal species from the planktivorous species by oleic acid (C18:1n9) rather than arachidonic acid or a C20:1 isomer as in CART analysis. Anchovy and menhaden are categorized by having less oleic acid. Menhaden, however, have a higher abundance of myristic acid (C14:0) and palmitoleic acid (C16:1n7), while anchovy are more rich in palmitic acid (C16:0) and a combination of DPA (C22:5n3) and DHA (C22:6n3). These fatty acids were chosen because they exhibited the highest variation among all fatty acids. The higher values of C14:0 and C16:0 in menhaden versus demersal species corresponds to the literature (Gruger et al. 1964, Lytle and Lytle 1994), which suggests these fatty acids may indicate a planktivore. This technique is less effective in modeling the fatty acid signatures of striped bass prey items, because the misclassification rate is higher, and information is being left out because small sample groups necessitate fewer variables in the model.

Omega-3 fatty acids are found in high levels in marine environments because phytoplankton are able to synthesize certain fatty acids (e.g. DHA), which are then transferred up the food web through zooplankton and fish. Certain demersal polychaetes can also be high in omega-3 fatty acids, along with palmitic and oleic acids (Garcia-Alonso et al. 2008). It should be noted that co-eluted fatty acids for this DFA refer to eicosapentaenoic acid (EPA) and docohexsaenoic acid (DHA), two fatty acids which do make up a large proportion of the omega3 category. Even though spot and blue crab are categorized by omega 3 fatty acids, menhaden 
and anchovy still have omega-3 fatty acids at relatively high levels (7.09-27.44\%) because of EPA and DHA. The groupings seen for this technique still separate demersal and pelagic species, but there seems to be more overlap between the anchovy and menhaden. It would be advisable to avoid DFA because information is left out in making the metrics.

Fatty acid analysis is a valuable technique in distinguishing among species (Gallagher et al. 1991, Lytle and Lytle 1994, Budge et al. 2002) or among seasons (Bandarra et al. 2001, Zlatanos and Laskaridis 2007). In the present study, the four species were correctly classified $92.8 \%$ of the time despite variation within a sample group. The second goal of this study was to determine if season or location influenced the fatty acid signature. The demersal species, spot and blue crab, were collected from the upper bay and demonstrated a clear seasonal pattern in fatty acid signature. Planktivorous fish, menhaden and anchovy, did not exhibit the same such pattern differences. Season and location appear to have less of an influence on these two species. It is also apparent that the fatty acid signature of Atlantic menhaden changes as these fish grow. Overall, there are differences in lipid values and fatty acid abundances among seasons and locations. These differences need to be taken into account when constructing food web models. The information obtained in this study offers a suite of fatty acids and lipid values that will provide fatty acid trophic markers for modeling forage history of top predators located in the Chesapeake Bay.

\section{Acknowledgments}

The authors would like to thank J. Councilman, A. Leight, J. Brush, and W. Lowery for assistance in collecting samples. We are also indebted to B. Dockum and L. Gonsalves for advice and assistance in the chemical analysis of samples. E. Chambers provided invaluable help in the 
laboratory preparing and analyzing samples. We are grateful for the comments provided by anonymous reviewers. This research was made possible by funding from NOAA Chesapeake Bay Office Grant No. NA07NMF4570330 and all research was conducted under Animal Care and Use Protocol number 09-0102. 


\section{Literature cited}

Ahrenholz, D. W. 1991. Population biology and life history of the North American menhadens, Brevoortia spp. Marine Fisheries Review 53:3-19.

Anthony, J.A., D.D. Roby, and K.R. Turco. 2000. Lipid content and energy density of forage fishes from the northern Gulf of Alaska. Journal of Experimental Marine Biology and Ecology 248:53-78.

Arts, M. T., R.G. Ackman, and B.J. Holub. 2001. "Essential fatty acids" in aquatic ecosystems: a crucial link between diet and human health and evolution. Canadian Journal of Fisheries and Aquatic Sciences 58:122-137.

Bandarra, N., I. Batista, M.L. Nunes, and J.M. Empis. 2001. Seasonal variation in the chemical composition of horse-mackerel (Trachurus trachurus). European Food Resources and Technology 212:535-539.

Beck, C. A., L.D. Rea, S.J. Iverson, J.M. Kennish, K.W. Pitcher, and B.S. Fadely. 2007. Blubber fatty acid profiles reveal regional, age-class and sex difference the diet of young Stellar sea lions in Alaska. Marine Ecology Progress Series 338:269-280.

Beck, C. A., S.J. Iverson, and W.D. Bowen. 2005. Blubber fatty acids of gray seals reveal sex differences in the diet of a size-dimorphic marine carnivore. Canadian Journal of Zoology $83: 377-388$.

Biro, P.A., A.E. Morton, J.R. Post, and E.A. Parkinson. 2004. Over-winter lipid depletion and mortality of age-0 rainbow trout (Oncorhynchus mykiss). Canadian Journal of Fisheries and Aquatic Sciences 61:1513-1519.

Boreman, J. and H.M. Austin. 1985. Production and harvest of anadromous striped bass stocks along the Atlantic coast. Transactions of the American Fisheries Society 114:3-7 
Brodziak, J. and J. Link. 2002. Ecosystem-based fishery management: what is it and how can we do it? Bulletin of Marine Science 70:589-611.

Brownlee, D.C. and F. Jacobs. 1987. Mesozooplankton and microzooplankton in the Chesapeake Bay. In: Majumdar, Pages 217-269 in S.K., L.W. Hall, H.W. Austin, editors. Contaminant problems and Management of living Chesapeake Bay resources, vol. 527. The Pennsylvania Academy of Science, Philadelphia, PA.

Budge, S. M., S.J. Iverson, W.D. Bowen, and R.G. Ackman. 2002. Among- and within-species variability in fatty acid signatures of marine fish and invertebrates on the Scotian shelf, Georges Bank, and southern Gulf of St. Lawrence. Canadian Journal of Fisheries and Aquatic Sciences 59:886-898.

Budge, S. M., and C.C. Parrish. 1998. Lipid biogeochemistry of plankton, settling matter and sediments in Trinity Bay, Newfoundland. II. Fatty acids. Organic Geochemistry 29:15471559.

Burnham, K.P., and D.R. Anderson. 2002. Model selection and multi-model inference. $2^{\text {nd }}$ ed. Springer, Berlin, Germany

Chaiyapechara, S., M.T. Casten, R.W. Hardy, F.M. Dong. 2003. Fish performance, fillet characteristics, and health assessment index of rainbow trout (Oncorhynchus mykiss) fed diets containing adequate and high concentrations of lipid and vitamin E. Aquaculture 219:715-738.

Chesapeake Bay Fisheries Ecosystem Advisory Panel (National Oceanic and Atmospheric Administration Chesapeake Bay Office). 2006. Fisheries ecosystem planning for Chesapeake Bay. American Fisheries Society, Trends in Fisheries Science and Management 3, Bethesda, Maryland. 
Christie, W.M. 2003. Lipid Analysis. PJ Barnes and Associates. Bridgewater, England.

Dalsgaard, J. M. S. J., G. Kattner, D. Muller-Navarra, and W. Hagen. 2003. Fatty acid trophic markers in the pelagic marine environment. Advances in Marine Biology 46:225-340.

Desvilettes, C.H., G. Bourdier. C.H. Ambland, and B. Barth. 1997. Use of fatty acids for the assessment of zooplankton grazing on bacteria, protozoans, and microalgae. Freshwater Biology 38:629-637.

Dubrow, D., M. Hale, and A. Bimbo. 1976. Seasonal variations in chemical composition and protein quality of menhaden. Marine Fisheries Review 38:12-16.

Elliot, J.M. 1972. Rates of gastric evacuation in brown trout, Salmo trutta L. Freshwater Biology $2: 1-18$

Farragut, R. 1965. Proximate composition of Chesapeake Bay blue crab (Callinectes sapidus). Journal of Food Science 30:538-544.

Flath, L.E. and J.S. Diana. 1985. Seasonal energy dynamics of the alewife in southeastern Lake Michigan. Transactions of the American Fisheries Society 114:328-337.

Folch, J., M. Lees, and G.H.S. Stanley. 1957. A simple method for the isolation and purification of total lipids from animal tissues. Journal of Biological Chemistry 226:497-509.

Gallagher, M. L., M.L. Harrell, and R.A. Rulifson. 1991. Variation in lipid and fatty acid contents of Atlantic croakers, striped mullet, and summer flounder. Transactions of the American Fisheries Society 120:614-619.

Gannon, J.E. 1976. The effects of differential digestion rates of zooplankton by alewife, Alosa pseudoharengus, on determinations of selective feeding. Transactions of the American Fisheries Society 105:89-95. 
Garcia-Alonso, J., C.T. Muller, and J.D. Hardege. 2008. Influence of food regimes and seasonality on fatty acid composition in the ragworm. Aquatic Biology 4:7-13.

Gokodlu, N. and P. Yerlikaya. 2003. Determination of proximate composition and mineral contents of blue crab (Callinectes sapidus) and swim crab (Portunus pelagicus) caught of the Gulf of Antalya. Food Chemistry 80:495-498.

Griffin, J. C. and F. J. Margraf. 2003. The diet of Chesapeake Bay striped bass in the late 1950s. Fisheries Management and Ecology. 10:323-328.

Grigorakis, K., M.N. Alexis, K.D.A. Taylor, and M. Hole. 2002. Comparison of wild and cultured gilthead sea bream (Sparus aurata); composition, appearance and seasonal variation. International Journal of Food Science and Technology 37:477-484.

Gruger, E.H., R.W. Nelson, and M.E. Stansby. 1964. Fatty acid composition from 21 species of marine fish, freshwater fish, and shellfish. Journal of the American Oil Chemists Society 41:662-667.

Gurr, M.I. and J.L. Hardwood. 1991. Lipid biochemistry: an introduction. $4^{\text {th }}$ ed. Chapman and Hall. London, England.

Hartman, K.J. and S.B. Brandt. 1995. Trophic resource partitioning, diets, and growth of sympatric estuarine predators. Transactions of the American Fishery Society 124:520537.

Hartman, K. J. 2003. Population-level consumption by Atlantic coastal striped bass and the influence of population recovery upon prey communities. Fisheries Management \& Ecology 10:281-288.

Hartman, K. J., J. Howell, and J.A. Sweka. 2004. Diet and daily ration of bay anchovy in the Hudson River, New York. Transactions of the American Fisheries Society 133:762-771. 
He, E. and W.A. Wurtsbaugh. 1993. An empirical model of gastric evacuation rates for fish and an analysis of digestion in piscivorous brown trout. Transactions of the American Fisheries Society 122:717-730.

Hines, A., A.M. Haddon, and L.A. Wiechert. 1990. Guild structure and foraging impact of blue crabs and epibenthic fish in a subestuary of Chesapeake Bay. Marine Ecology Progress Series 67:105-126.

Homer, M. L. and J. A. Mihursky. 1991. Spot (Leiostomus xanthurus). Pages 11-17 in S. L. Funderburk, S.J. Jordan, J.A. Mihursky, and D. Riley, editors. Habitat requirements for Chesapeake Bay living resources. Chesapeake Research Consortium, Inc., Solomons, MD.

Hyslop, E.J. 1980. Stomach contents analysis - a review of methods and their application. Journal of Fish Biology 17:411-429.

Iverson, S.J., K.J. Frost, and L.F. Lowry. 1997a. Fatty acid signatures reveal fine scale structure of foraging distribution of harbor seals and their prey in Prince William Sound, Alaska. Marine Ecology Progress Series 151:255-271.

Iveson, S.J., J.P.Y. Arnold, and I.L. Boyd. 1997b. Milk fatty acid signatures indicate both major and minor shifts in the diet of lactating Antarctic fur seals. Canadian Journal of Zoology 75:1881-97.

Iverson, S. J., K.J. Frost, and S.L.C. Lang. 2002. Lipid content and fatty acid composition of forage fish and invertebrates in Prince William Sound, Alaska: factors contributing to among and within species variability. Marine Ecology Progress Series 241:161-181.

Iverson, S.J. C. Field, W.D. Bowen, and W. Blanchard. 2004. Quantitative fatty acid signature analysis: a new method of estimating predator diets. Ecological Monographs 74:211-235. 
Johnson, W.S., D.M. Allen, M.V. Ogburn, and S.E. Stancyk. 1990. Short-term responses of adult bay anchovies Anchoa mitchilli to estuarine zooplankton availability. Marine Ecology Progress Series 64:55-68.

June, F.C. and F.T. Carlson. 1971. Food of young Atlantic menhaden, Brevoortia tyrannus, in relation to metamorphosis. Fishery Bulletin 68:493-512.

Kirsch, P. E., S.J. Iverson, W.D. Bowen, S.R. Kerr, and R.G. Ackman. 1998. Dietary effects on the fatty acid signature of whole Atlantic cod (Gadus morhua). Canadian Journal of Fisheries and Aquatic Sciences 55:1378-1386.

Lanari, D., B.M. Poli, R. Ballestrazzi, P. Lupi, E. D’Agaro, and M. Mecatti. 1999. The effects of dietary fat and NFE levels on growing European sea bass (Dicentrachus labrax L.). Growth rate, body and fillet composition, carcass traits and nutrient retention efficiency. Aquaculture 179-351-364.

Link, J.S. 2005. Translating ecosystem indicators into decision criteria. ICES Journal of Marine Science 62:569- 576

Lippson, R. L. 1991. Atlantic menhaden (Brevoortia tyrannus). Pages 7.1-7.6 in S. L. Funderburk, S.J. Jordan, J.A. Mihursky, and D. Riley, editors. Habitat requirements for Chesapeake Bay living resources. Chesapeake Research Consortium, Solomons, MD.

Luis, O.J. and A.M. Passos 1995. Seasonal changes in lipid content and composition of the polychaete Nereis (Hediste) diversicolor. Comparative Biochemistry and Physiology Part B: Biochemistry and Molecular Biology 111: 579-586.

Lytle, J. S., and T. F. Lytle. 1994. Fatty acid pattern differences among individuals of two estuarine fishes (Leiostomus xanthurus and Mugil cephalus). Gulf Research Reports 9:49-56. 
McCune, B. and J.B. Grace. 2002. Analysis of ecological communities. MjM Software, Gleneden Beach, OR.

Napolitano, G.E., R.J. Pollero, A.M. Gayoso, B.A. MacDonald, and R.J. Thompson. 1997. Fatty acids as trophic markers of phytoplankton blooms in the Bahia Blanca estuary (Buenos Aires, Argentina) and in Trinity Bay (Newfoundland, Canada). Biochemical Systematics and Ecology 25:739-755.

Overton, A. S., E.B. May, J. Griffin, and F.J. Margraf. 2000. A bioenergetics approach for determining the effect of increased striped bass population on its prey and health in the Chesapeake Bay. Maryland Department of Natural Resources, Annapolis.

R Development Core Team (2008). R: A language and environment for statistical computing. $\mathrm{R}$ Foundation for Statistical Computing, Vienna, Austria. ISBN 3-900051-07-0, URL http://www.R-project.org.

Recks, M.J. and G.T. Seaborn. 2008. Variation in fatty acid composition among nine forage species from a southeastern US estuarine and nearshore coastal ecosystem. Fish Physiology and Biochemistry 34:275-287.

Sargent, J, G. Bell, L. McEvoy, D. Tocher, and A. Estevez 1999. Recent developments in the essential fatty acid nutrition of fish. Aquaculture 177:191-199.

Sargent, J.R. and S. Falk-Petersen. 1981. Ecological investigations on the zooplankton community in Balsfjorden, northern Norway: lipids and fatty acids in Meganyctiphanes norvegica, Thysanoessa raschi, and T. inermis during mid-winter. Marine Biology 62:131-137.

Schafer, K. 1998. Accelerated solvent extraction of lipids for determining the fatty acid composition of biological material. Analytica Chimica Acta 358:69-77. 
Seaburg, K. G. 1957. A stomach sampler for live fish. The Progressive Fish Culturist:137-139.

Secor, D.H. and E.D. Houde. 1998. Use of larval stocking in restoration of Chesapeake Bay striped bass. ICES Journal of Marine Science 55:228-239.

Thompson, J.M, E.P. Bergensen, C.A. Carlson, and L.R. Kaeding. 1991. Role of size, condition, and lipid content in the overwinter survival of age- 0 Colorado squawfish. Transactions of the American Fisheries Society 120:346-353.

Turner, J. P., and J. R. Rooker. 2005. Effect of dietary fatty acids on the body tissues of larval and juvenile cobia and their prey. Journal of Experimental Marine Biology and Ecology $322: 13-27$.

Uphoff Jr., J.H. 2003. Predator-prey analysis of striped bass and Atlantic menhaden in upper Chesapeake Bay. Fisheries Management and Ecology 10:313-322.

USEPA (United States Environmental Protection Agency). 2007. Pressurized fluid extraction (PFE). USEPA SW-846. Method 3545A, Update IV. Washington, D.C.

van Heukelem, W. F. 1991. Blue crab (Callinectes sapidus). Pages 6.1-6.24 in S. L. Funderburk, S.J. Jordan, J.A. Mihursky, and D. Riley, editors. Habitat requirements of Chesapeake Bay living resources. Chesapeake Research Consortium, Inc., Solomons, MD.

Vaughn, D.S. and J.W. Smith. 1988. Stock assessment of the Atlantic menhaden, Brevoortia tyrannus, fishery. NOAA Technical Report NMFS 63. 26p.

Waters, M. 1982. Chemical composition and frozen storage stability of spot, Leiostomus xanthurus. Marine Fisheries Review 44:14-22.

Zlatanos, S. and K. Laskaridis. 2007. Seasonal variation in the fatty acid composition of three Mediterranean fish - sardine (Sardina pilchardus), anchovy (Engraulis encrasicholus) and picarel (Spicara smaris). Food Chemistry 103:725-728. 
Table 1 . The library of prey species analyzed for fatty acid analysis. The values for length, weight, and lipid content represent the mean \pm 1 standard error of the mean. Lipid content is based upon gram of lipid per gram of fish.

\begin{tabular}{|c|c|c|c|c|c|c|c|}
\hline Species & Season & Bay location & River system & $\begin{array}{l}\text { Sample } \\
\text { size }\end{array}$ & $\begin{array}{l}\text { Length } \pm \text { SEM } \\
(\mathrm{mm})\end{array}$ & $\begin{array}{c}\text { Weight } \pm \text { SEM } \\
(\mathrm{g})\end{array}$ & $\begin{array}{l}\text { Lipid content } \pm \\
\text { SEM (\% ww) }\end{array}$ \\
\hline \multirow[t]{5}{*}{ Atlantic menhaden } & Spring & Upper & Choptank River & 8 & $78.00 \pm 1.69$ & $4.64 \pm 0.33$ & $4.95 \pm 0.22$ \\
\hline & Spring & Lower & York River & $36^{\Delta}$ & $51.30 \pm 1.25$ & $1.57 \pm 0.10$ & $8.65 \pm 1.16$ \\
\hline & Summer & Upper & Corsica River & 10 & $97.5 \pm 0.69$ & $8.37 \pm 0.15$ & $12.59 \pm 1.94$ \\
\hline & Summer & Lower & James River & 10 & $143.34 \pm 3.93$ & $39.57 \pm 2.25$ & $12.07 \pm 1.84$ \\
\hline & Fall & Upper & Choptank River & 9 & $127.56 \pm 2.84$ & $24.33 \pm 1.98$ & $12.46 \pm 1.17$ \\
\hline Atlantic menhaden adult & Summer & Upper & Nanticoke River & 10 & Ғ $233.08 \pm 10.53$ & Ғ $140.80 \pm 21.49$ & Ғ $11.75 \pm 1.91$ \\
\hline \multirow[t]{6}{*}{ Bay anchovy } & Spring & Upper & Patuxent River & 8 & $59.5 \pm 1.84$ & $1.37 \pm 0.09$ & $10.80 \pm 0.99$ \\
\hline & Spring & Lower & Main stem Chesapeake & 10 & $56.61 \pm 1.94$ & $1.97 \pm 0.17$ & $8.21 \pm 1.23$ \\
\hline & Summer & Upper & Magothy River & 15 & $73.41 \pm 1.74$ & $2.76 \pm 0.20$ & $14.93 \pm 3.90$ \\
\hline & Summer & Lower & Main stem Chesapeake & $23^{\Delta}$ & $65.25 \pm 1.43$ & $2.57 \pm 0.46$ & $5.89 \pm 0.44$ \\
\hline & Fall & Upper & Trappe River & $35^{\Delta}$ & $49.61 \pm 1.70$ & $1.47 \pm 0.31$ & $15.10 \pm 2.98$ \\
\hline & Fall & Lower & Main stem Chesapeake & $34^{\Delta}$ & $46.71 \pm 1.20$ & $1.30 \pm 0.15$ & $13.34 \pm 3.78$ \\
\hline \multirow[t]{2}{*}{ Blue crab } & Summer & Upper & Magothy River & 12 & $* 46.71 \pm 2.57$ & $7.21 \pm 1.45$ & $1.49 \pm 0.28$ \\
\hline & Fall & Upper & Chester River & 10 & $* 120.6 \pm 4.59$ & $89.1 \pm 7.41$ & $1.18 \pm 0.17$ \\
\hline \multirow[t]{2}{*}{ Spot } & Summer & Upper & Rhode River & 10 & $84.67 \pm 2.12$ & $7.97 \pm 0.58$ & $4.49 \pm 0.34$ \\
\hline & Fall & Upper & Chester River & 11 & $79.55 \pm 2.85$ & $6.05 \pm 0.82$ & $6.05 \pm 0.75$ \\
\hline
\end{tabular}

F Lengths and weights are measurements with head and tail present. The lipid content for this sample group was calculated based on the body with no head or tail.

*Length refers to carapace width, point to point.

$\Delta$ Several individuals were used in one sample due to low weight. 
Table 2. Summary of model selection statistics for lipid percent in samples; K represents the number of parameters in the model; $\Delta \mathrm{AIC}_{\mathrm{c}}$ represents the difference between the $\mathrm{AIC}_{\mathrm{c}}$ value for that model and the set's minimum $\mathrm{AIC}_{\mathrm{c}}$ value; W represents the Akaike weight of each model.

\begin{tabular}{|c|c|c|c|}
\hline Model & $\mathrm{K}$ & $\Delta \mathrm{AIC}_{\mathrm{C}}$ & $\mathrm{W}$ \\
\hline $\mathrm{We}+\mathrm{Sp}+\mathrm{Se}+\mathrm{We}^{*} \mathrm{Sp}^{\mathrm{A}}$ & 11 & 0 & 0.71 \\
\hline $\mathrm{We}+\mathrm{Sp}+\mathrm{Se}+\mathrm{We} * \mathrm{Sp}+\mathrm{We} * \mathrm{Se}+\mathrm{Sp} * \mathrm{Se}$ & 17 & 3.19 & 0.14 \\
\hline $\mathrm{We}+\mathrm{Sp}+\mathrm{Se}$ & 8 & 3.86 & 0.10 \\
\hline $\mathrm{We}+\mathrm{Sp}+\mathrm{Se}+\mathrm{We}{ }^{*} \mathrm{Sp}+\mathrm{We}{ }^{*} \mathrm{Se}+\mathrm{Sp}^{*} \mathrm{Se}+\mathrm{We}^{*} \mathrm{Se}{ }^{*} \mathrm{Sp}$ & 21 & 5.41 & 0.05 \\
\hline $\mathrm{We}+\mathrm{Sp}$ & 6 & 14.24 & 0 \\
\hline $\mathrm{We}$ & 3 & 156.82 & 0 \\
\hline Null model & 2 & 160.99 & 0 \\
\hline
\end{tabular}

${ }^{\mathrm{A}}$ Model terms are sample weight (We), species (Sp: Atlantic menhaden, bay anchovy, spot, and blue crab), and season (Se: spring, summer and fall). 
Table 3. Parameter estimates from the AIC model that included all factors (weight, species, and season) along with the second order interaction term of weight by season. The standard error (SE) of the estimate is given along with the p value. The weight of the model was 0.71 .

\begin{tabular}{lccc}
\hline Parameter & Estimate & SE & p value \\
\hline Intercept & 3.06 & 0.29 & $\mathbf{0 . 0 0 0 1}$ \\
Log weight & -0.47 & 0.21 & $\mathbf{0 . 0 2}$ \\
Blue crab & -2.27 & 0.40 & $\mathbf{0 . 0 0 0 1}$ \\
Menhaden & -0.57 & 0.28 & $\mathbf{0 . 0 4}$ \\
Spot & -0.62 & 0.67 & 0.36 \\
Spring & -0.75 & 0.19 & $\mathbf{0 . 0 0 0 1}$ \\
Summer & -0.20 & 0.11 & 0.07 \\
Log weight*Blue crab & 0.29 & 0.23 & 0.2 \\
Log weight*Menhaden & 0.49 & 0.19 & $\mathbf{0 . 0 1}$ \\
Log weight*Spot & 0.08 & 0.38 & 0.84 \\
\hline
\end{tabular}


Table 4. Parameter estimates from the AIC model that included all factors (weight, species, and season) along with the second order interaction terms of weight by species, weight by season, and species by season. The standard error (SE) of the estimate is given along with the p value. The weight of the model was 0.14 .

\begin{tabular}{lccc}
\hline Parameter & Estimate & SE & p value \\
\hline Intercept & 2.80 & 0.65 & $\mathbf{0 . 0 0 0 1}$ \\
Log weight & -0.27 & 0.47 & 0.57 \\
Blue crab & 1.61 & 1.60 & 0.31 \\
Menhaden & 1.40 & 0.94 & 0.14 \\
Spot & 0.09 & 0.79 & 0.90 \\
Spring & -0.56 & 0.62 & 0.37 \\
Summer & -1.10 & 0.55 & $\mathbf{0 . 0 5}$ \\
Log weight*Blue crab & -0.71 & 0.42 & 0.09 \\
Log weight*Menhaden & -0.28 & 0.34 & 0.42 \\
Log weight*Spot & -0.42 & 0.51 & 0.41 \\
Log weight*Spring & 0.06 & 0.45 & 0.89 \\
Log weight*Summer & 0.54 & 0.39 & 0.16 \\
Blue crab*Spring & NA & NA & NA \\
Menhaden*Spring & -1.20 & 0.84 & 0.15 \\
Spot*Spring & NA & NA & NA \\
Blue crab*Summer & -2.31 & 1.27 & 0.07 \\
Menhaden*Summer & -0.71 & 0.74 & 0.34 \\
Spot*Summer & -0.03 & 0.36 & 0.93 \\
\hline
\end{tabular}


Table 5. Parameter estimates from the AIC model that included all factors (weight, species, and season). The standard error (SE) of the estimate is given along with the $\mathrm{p}$ value. The weight of the model was 0.10 .

\begin{tabular}{lccc}
\hline Parameter & Estimate & $\mathrm{SE}$ & $\mathrm{p}$ value \\
\hline Intercept & 2.57 & 0.14 & $\mathbf{0 . 0 0 0 1}$ \\
Log weight & -0.09 & 0.06 & 0.13 \\
Blue crab & -2.08 & 0.17 & $\mathbf{0 . 0 0 0 1}$ \\
Menhaden & 0.16 & 0.15 & 0.29 \\
Spot & -0.73 & 0.14 & $\mathbf{0 . 0 0 0 1}$ \\
Spring & -0.60 & 0.16 & $\mathbf{0 . 0 0 0 2}$ \\
Summer & -0.16 & 0.10 & 0.13 \\
\hline
\end{tabular}


Table 6. Results from the classification and regression trees (CART) and discriminant function analysis (DFA) in this experiment. The discriminant function analysis was used on the $5 \mathrm{FA}$ with the highest variation and metrics consisting of saturated, monounsaturated, omega 3 , omega 6 , and co-eluted FAs. Sample size in each group is denoted by n, and the number correctly classified is listed under CART and the two DFA categories.

\begin{tabular}{|c|c|c|c|c|}
\hline \multirow[b]{2}{*}{ Sample } & & \multicolumn{3}{|c|}{ Number correctly classified } \\
\hline & $\mathrm{n}$ & $\begin{array}{l}\text { CART } \\
\text { (24 FA) }\end{array}$ & $\begin{array}{c}\text { DFA } \\
\text { (5 FA) }\end{array}$ & $\begin{array}{c}\text { DFA } \\
\text { (5 FA } \\
\text { sums) }\end{array}$ \\
\hline \multicolumn{5}{|l|}{ Bay Anchovy } \\
\hline Spring Upper & 8 & 8 & 3 & 4 \\
\hline Spring Lower & 8 & 7 & 8 & 8 \\
\hline Summer Upper & 9 & 8 & 6 & 2 \\
\hline Summer Lower & 10 & 10 & 9 & 9 \\
\hline Fall Upper & 10 & 10 & 9 & 8 \\
\hline Fall Lower & 10 & 9 & 9 & 6 \\
\hline \multicolumn{5}{|l|}{ Menhaden } \\
\hline Spring Upper & 8 & 6 & 8 & 8 \\
\hline Spring Lower & 10 & 10 & 10 & 10 \\
\hline Summer Upper (Choptank River) & 8 & 6 & 7 & 8 \\
\hline Summer Upper (Corsica River) & 9 & 9 & 7 & 8 \\
\hline \multicolumn{5}{|l|}{ Summer Upper (Adult-Nanticoke } \\
\hline River) & 9 & 9 & 4 & 2 \\
\hline Summer Lower & 10 & 10 & 9 & 7 \\
\hline Fall Upper & 6 & 3 & 1 & 0 \\
\hline \multicolumn{5}{|l|}{ Blue Crab } \\
\hline Summer Upper & 11 & 11 & 10 & 8 \\
\hline Fall Upper & 10 & 10 & 6 & 9 \\
\hline \multicolumn{5}{|l|}{ Spot } \\
\hline Summer Upper & 6 & 5 & 5 & 5 \\
\hline Fall Upper & 11 & 11 & 11 & 11 \\
\hline Total correct & & $142 / 153$ & $122 / 153$ & $113 / 153$ \\
\hline$\%$ Correctly classified & & 92.8 & 79.7 & 73.9 \\
\hline
\end{tabular}


Figure 1. Map of collection sites in the Chesapeake Bay. The black line represents a division between bay locations. Above the line, salinities ranged from 2-8 parts per thousand (ppt), and below the line samples salinities ranged from 10-16 ppt. The larger map is a representation of the box in the inset.

Figure 2. Natural log lipid percent (of wet weight) of samples collected in the a) spring, b) summer, and c) fall.

Figure 3. Major fatty acids in a) anchovy; and b) menhaden signatures. Solid bars represent samples collected from the upper Bay and patterned bars represent samples collected from the lower Bay.

Figure 4. Major fatty acids in a) spot; and b) blue crab signatures. Solid bars represent samples collected from the upper Bay and patterned bars represent samples collected from the lower Bay.

Figure 5. Classification and regression tree (CART) output for prey species classification. The frequency refers to which individual was classified at that terminal node. Letters in the legend correspond to letters at the end of each branch of the dendrogram.

Figure 6. Discriminant function analysis of the group mean centroids for the 5 fatty acids with the highest variation. The first 2 functions explained $70.5 \%$ of the variation. Arrows on the axes represent increases in that particular fatty acid in the direction noted. 
Figure 7. Discriminant function analysis of the group mean centroids for the 5 composite sums of fatty acids. The first 2 functions explained $71.5 \%$ of the variation. Arrows on the axes represent increases in that particular fatty acid metric in the direction noted.

Figure 8. Abundance of 4 fatty acids that exhibit differences based upon the size of menhaden analyzed $(n=26)$. The adult menhaden length refers to total length, with head and tail included. 
Figure 1.

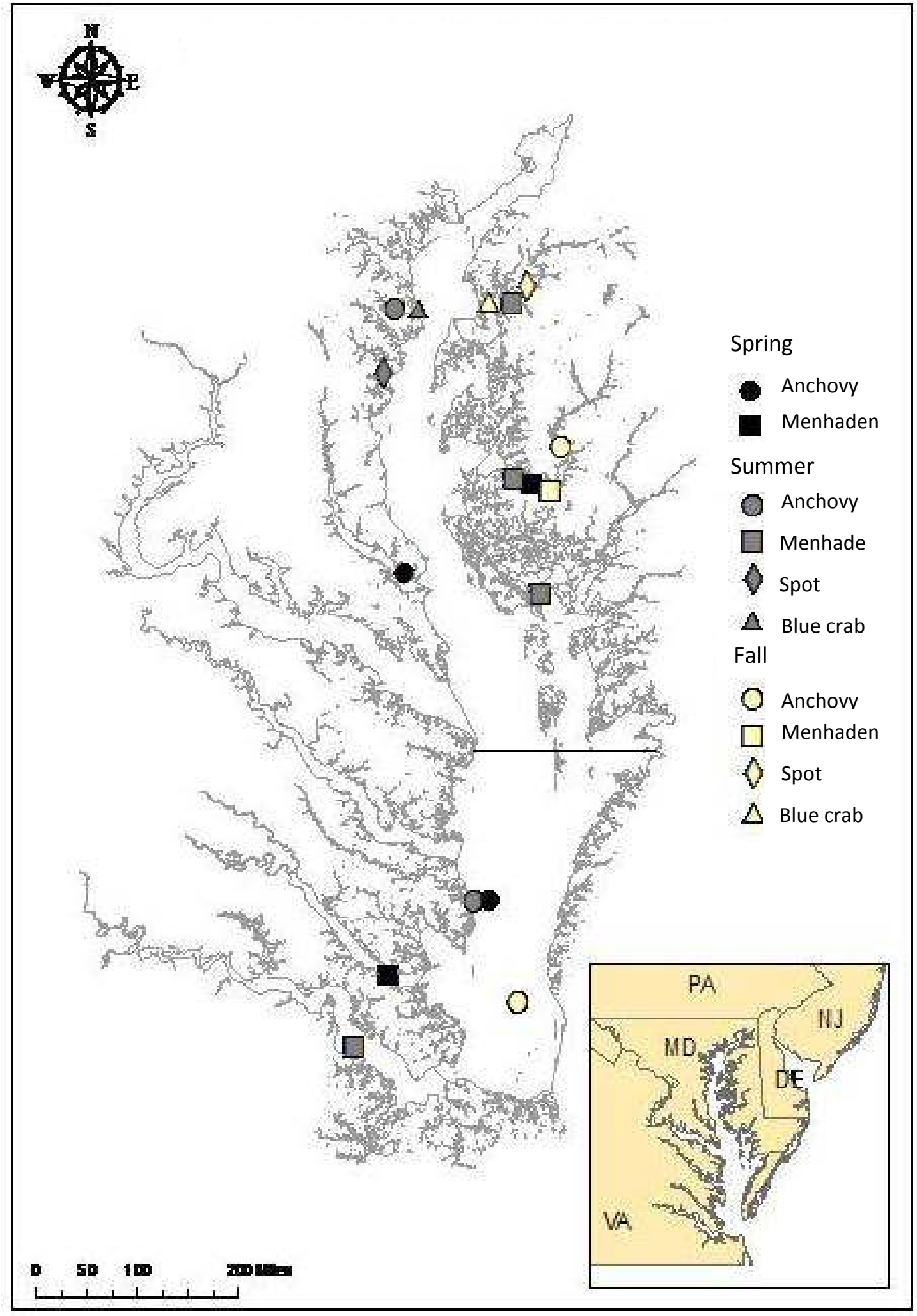


Figure 2.

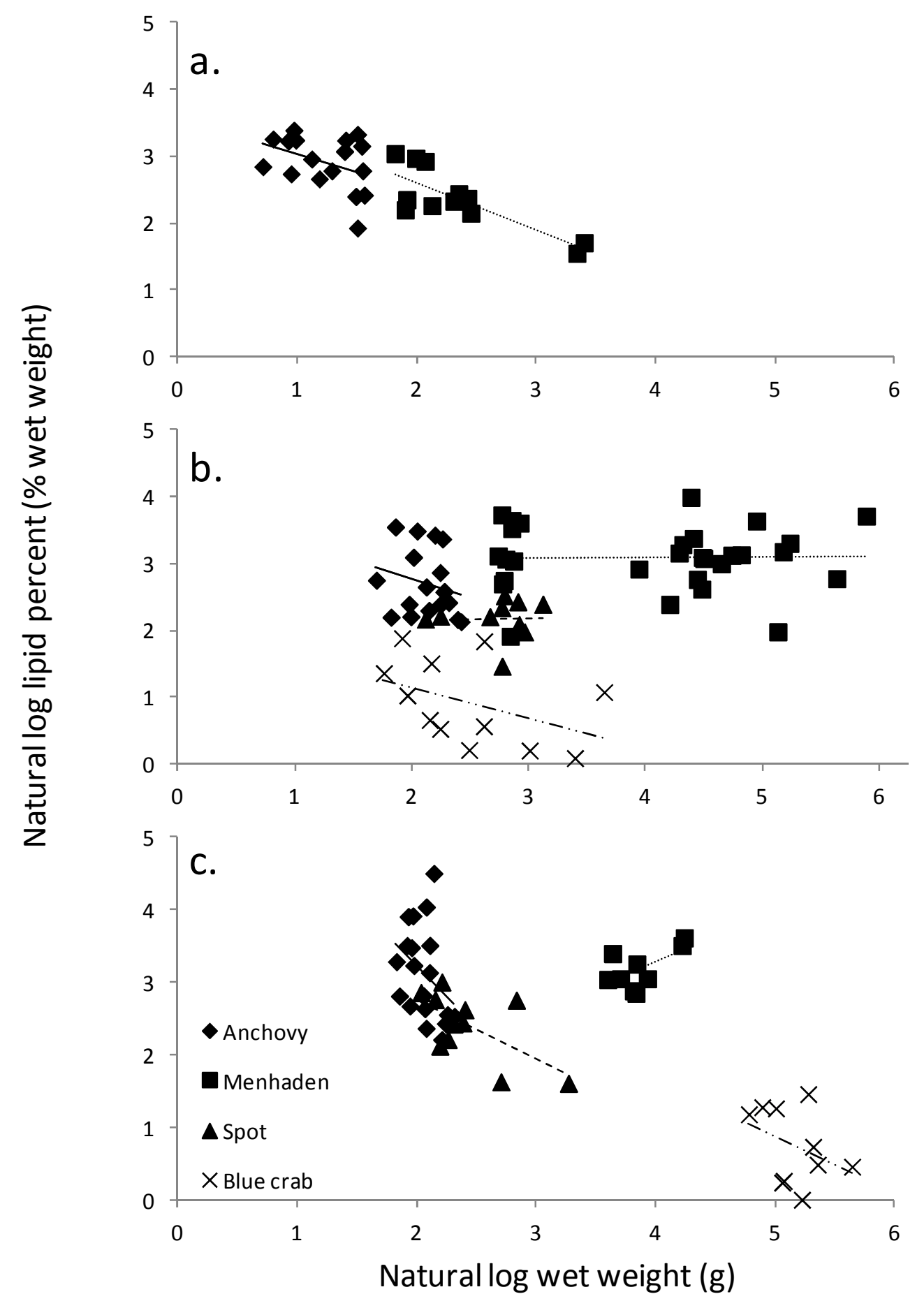


Figure 3.

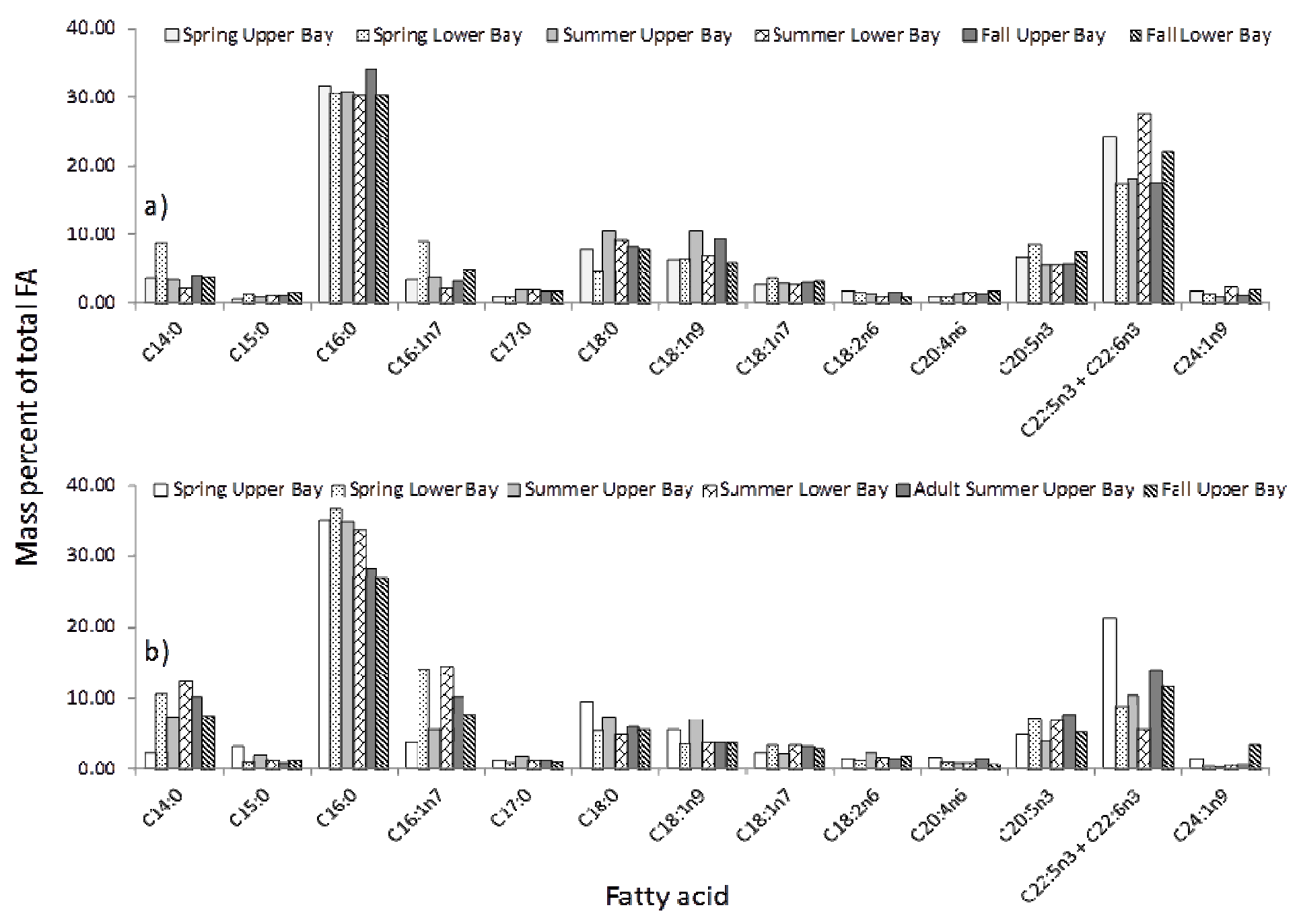


Figure 4.

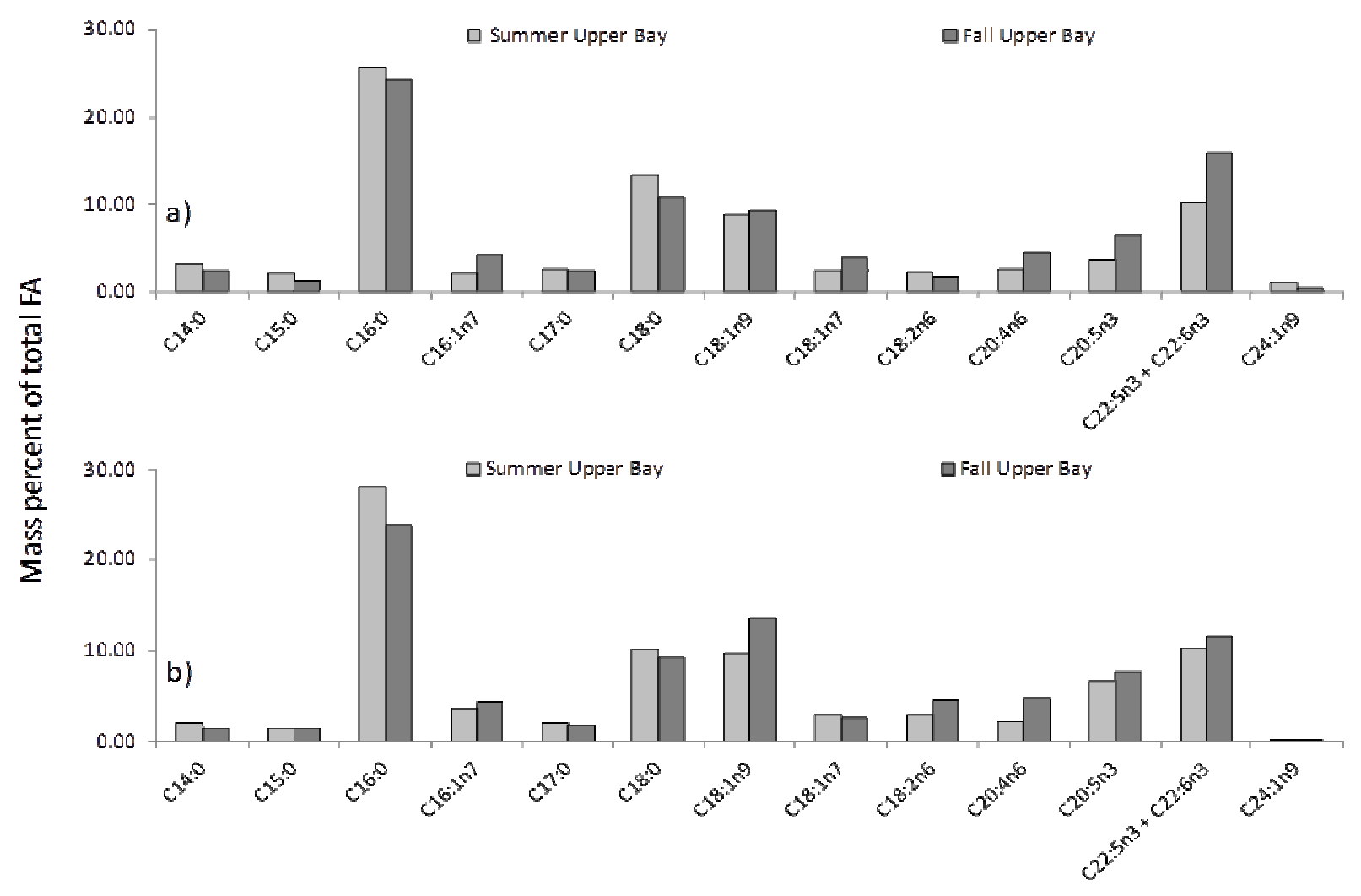

Fatty acid 
Figure 5.

Legend

$A=$ Anchovy, spring, lower bay

$\mathrm{J}=$ Menhaden, summer, upper bay

$B=A n c h o v y$, spring, upper bay

$\mathrm{K}=$ Menhaden, summer, upper bay

$\mathrm{C}=\mathrm{Anchovy}$, summer, lower bay

$\mathrm{L}=$ Menhaden (Adult), summer, upper bay

$D=$ Anchovy, summer upper bay

$\mathrm{M}=$ Menhaden, fall, upper bay

$\mathrm{E}=$ Anchovy, fall, lower bay

$\mathrm{N}=$ Blue crab, summer upper bay

$\mathrm{F}=$ Anchovy, fall, upper bay

$\mathrm{O}=$ Blue crab, fall, upper bay

$\mathrm{G}=$ Menhaden, spring, lower bay

$\mathrm{P}=$ Spot, summer, upper bay

$\mathrm{H}=$ Menhaden spring, upper bay

I=Menhaden, summer, lower bay

$Q=$ Spot, fall, upper bay

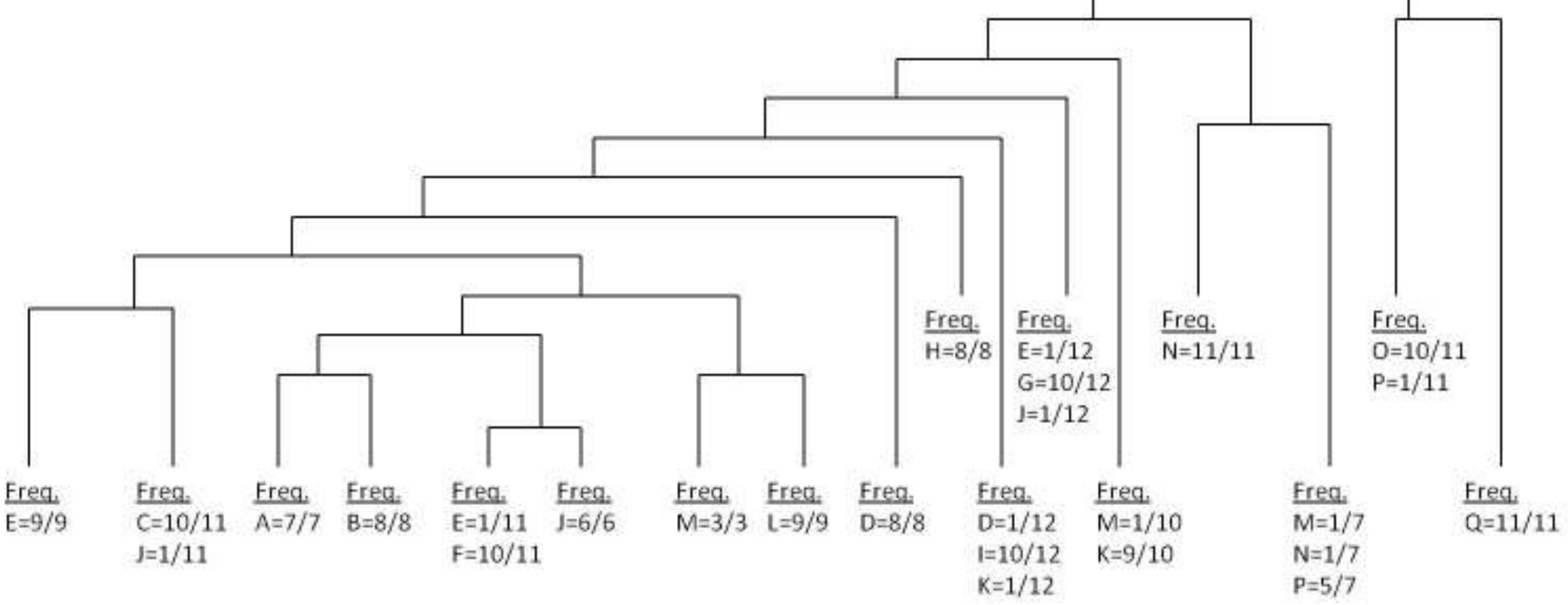


Figure 6.

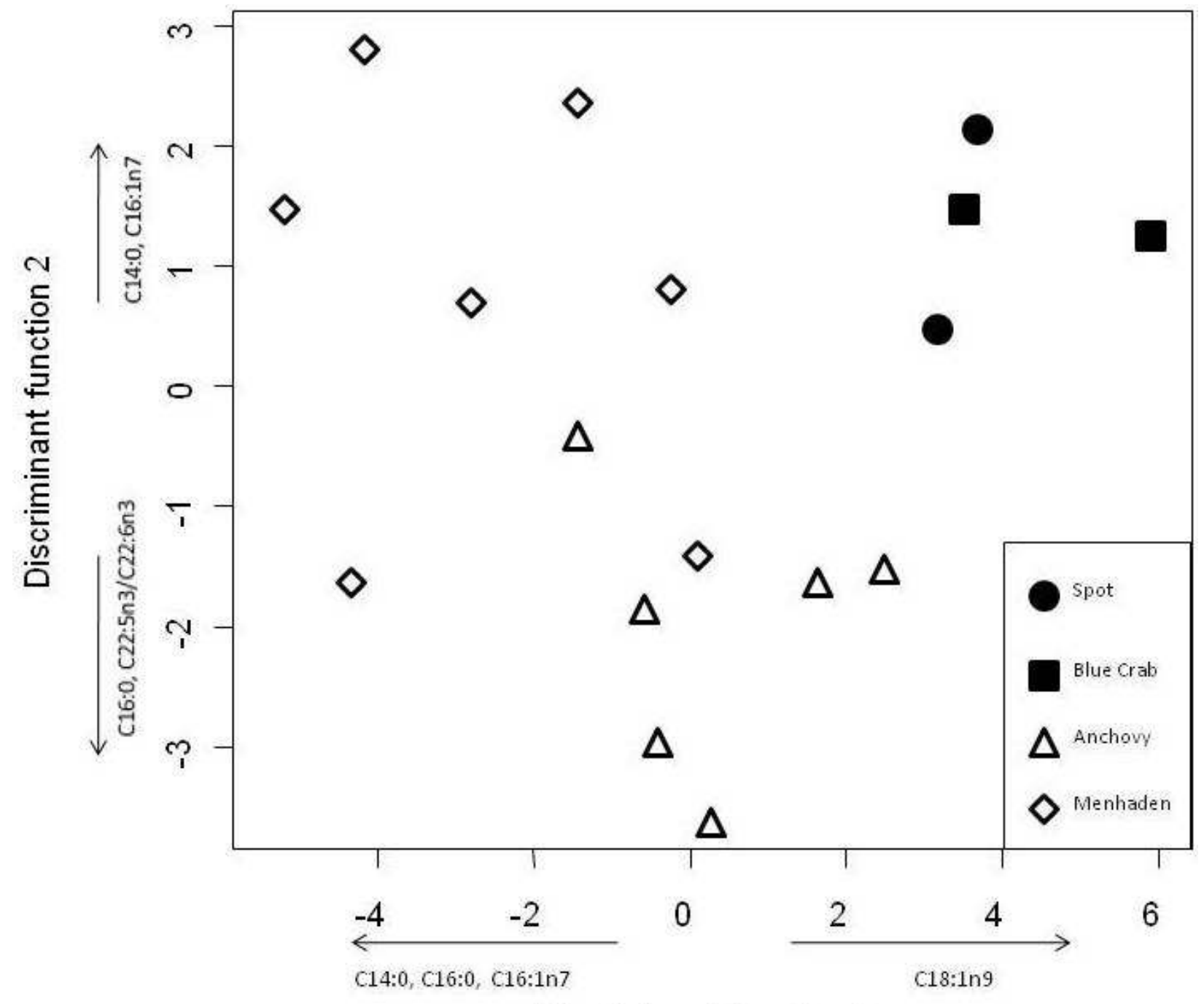

Discriminant function 1 
Figure 7.

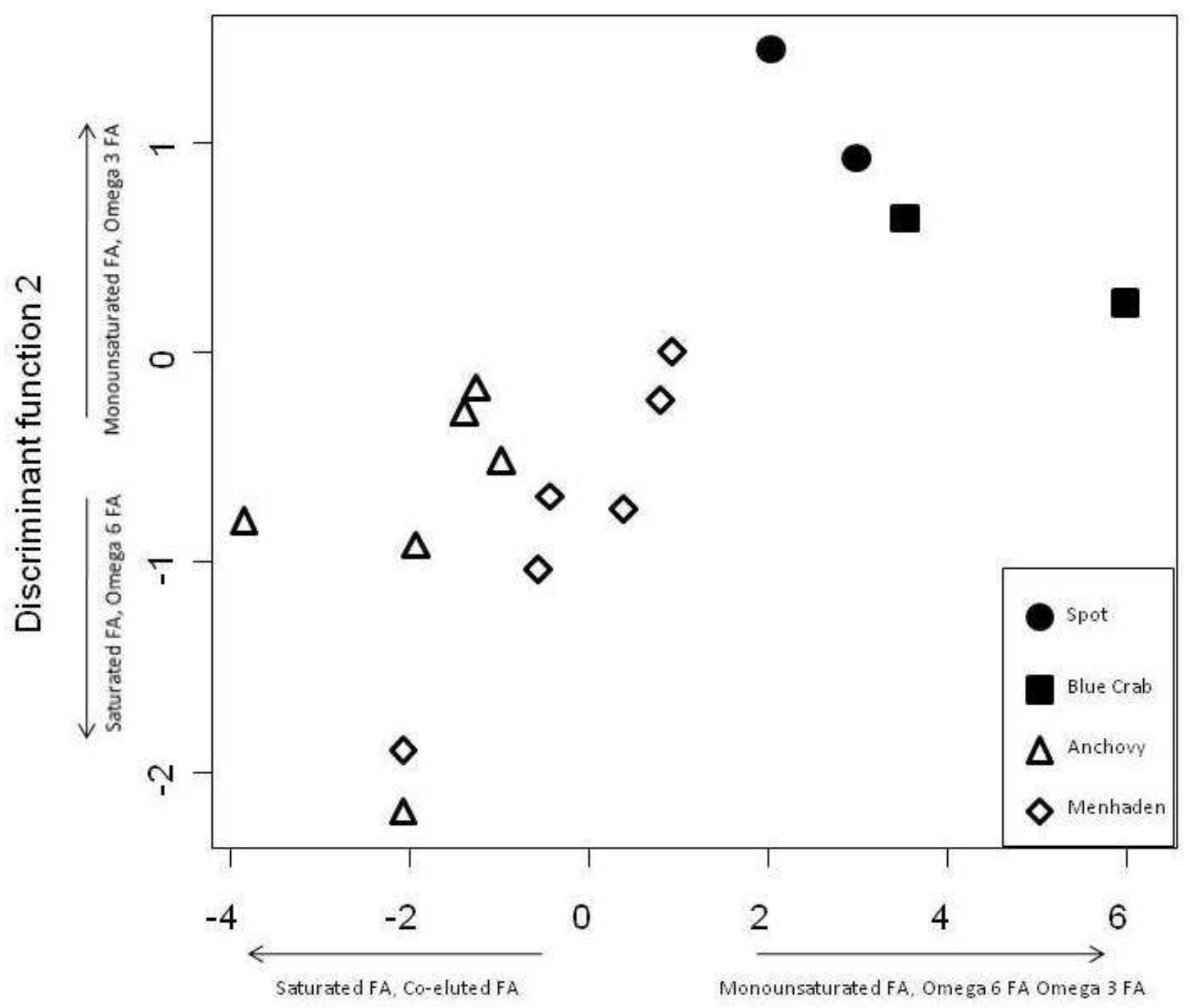

Discriminant function 1 
Figure 8.

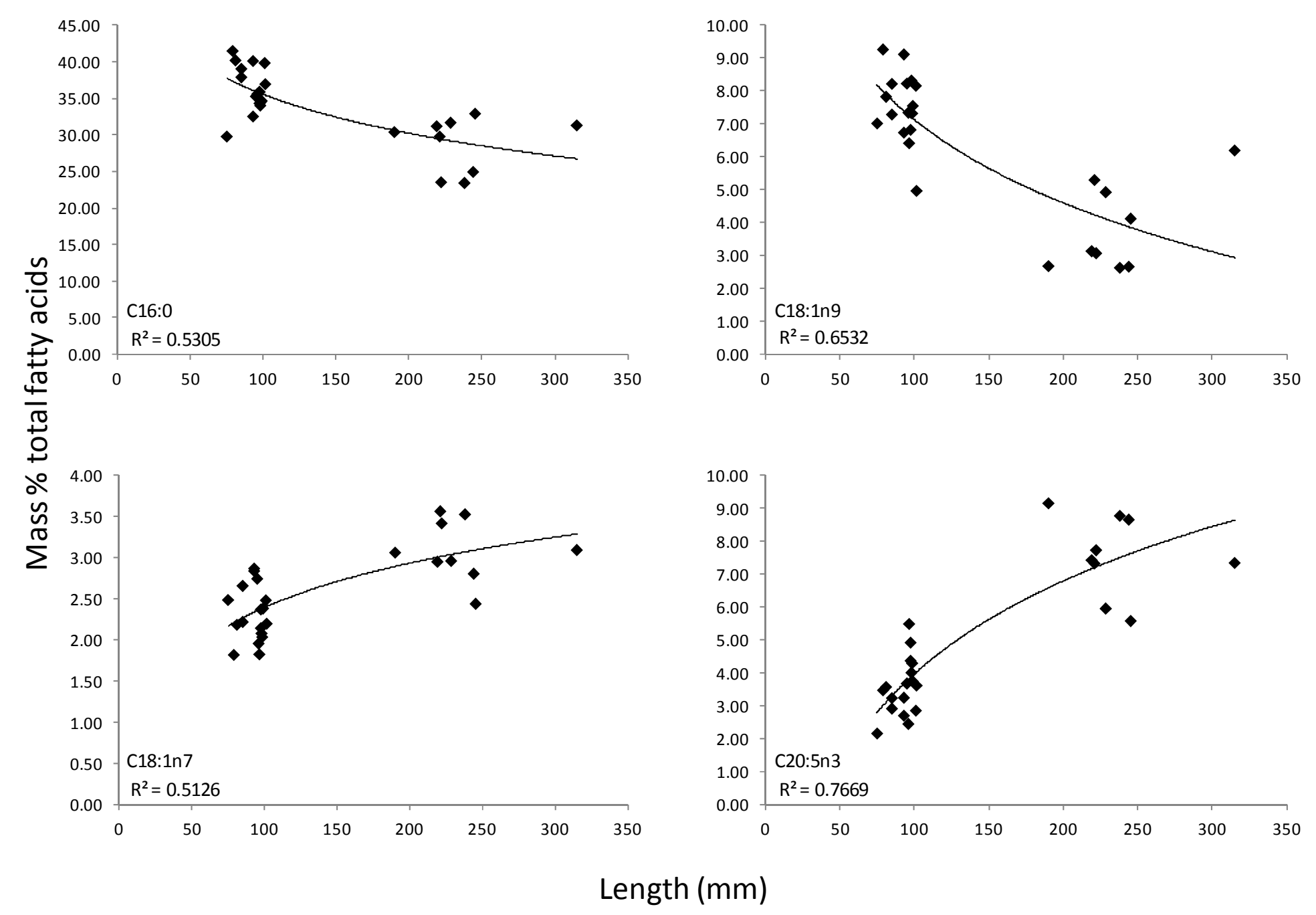


Chapter 3 - A comparison of liver and belly flap for evaluating striped bass diet using fatty acid signatures ${ }^{1}$

${ }^{1}$ This chapter is written in the style of the Journal of Fish Biology 


\begin{abstract}
The process of fatty acid conservation from prey to predator has been well studied in aquatic systems. Predators incorporate prey fatty acids, often with little to no modification into their own tissues. This fact has been the basis for trophic studies in many different systems because it removes the bias of examining stomach contents. However, there has been little research to determine which tissues in carnivorous fish offer the clearest picture of feeding history. The goal of this study was to compare fatty acid incorporation between liver and adipose tissue in striped bass Morone saxatilis. Striped bass were fed a diet of bay anchovy Anchoa mitchilli for four weeks to establish a baseline signature. Experimental feeding consisted of spot Leiostomus xanthurus for six weeks followed by a diet of Atlantic menhaden Brevoortia tyrannus for six weeks. Liver samples were consistently lower in lipids than belly flap regardless of the diet. Both tissues increased in lipid once the diet was switched to menhaden. Fatty acid signatures were different between the two prey types, and this difference was evident in both striped bass tissues tested. Proportions of discrete fatty acids, rather than the entire fatty acid profile, indicated the change in diet from spot to menhaden and were evident in striped bass tissues after a period of 31 days. Both tissues provide information on fatty acid incorporation and make good candidates for tracking diets; however belly flap tissue offers an easier and nonlethal sampling opportunity.
\end{abstract}

Keywords: Fatty acid trophic markers, lipid, Atlantic menhaden, spot 


\section{Introduction}

The feeding history of an organism is an important component of its overall ecology, and as such, has been widely studied in fish (Adams 1976, Currin et al. 1984). Striped bass Morone saxatilis (Walbaum 1792) specifically have been well studied due to their position as a top predator and an important recreational and commercial fishery (Schafer 1970, Hartman and Brandt 1995). Because any estimate of feeding history includes some biases, the results obtained can be skewed to varying degrees based upon the amount of error inherent in the method.

Traditionally, the method for analyzing stomach contents has been direct observation, whether by sacrificing the fish or manually removing the contents (Seaburg 1957). Estimations of diet were based on various metrics including (but not limited to): percent composition by weight or number and frequency of occurrence. From these metrics, indices of preference have been constructed based upon prey taxa prevalence in the stomach and the environment (Bowen 1996). Due to confounding factors such as the presence of chitinous material, prey size, and water temperature (Elliot 1972, Gannon 1976, He and Wurtsbaugh 1993), the rates of digestion for prey taxa are not identical. Therefore, estimations of diet and preference are likely biased, and a more accurate method is needed.

One alternative is fatty acid analysis, which is a method that focuses on biochemical markers for estimating diet history. Fatty acids are long chains of carbon and hydrogen atoms with a carboxylic acid functional group. Within organisms, excess energy in the form of fatty acids is stored as compounds known as acylglycerols. The most common form of energy storage involves three fatty acids esterified to a glycerol backbone (Gurr and Hardwood 1991). Fatty acids can be tracked as they are cycled through the food web (Iverson 1997a), and the diet can be estimated from the fatty acids present and their relative proportions with respect to other 
fatty acids (Iverson et al. 2004). Studies have also shown that a broader temporal history can be inferred from analyzing the fatty acids of an organism. Often, it is possible to determine diet items eaten over the past several weeks, versus the last meal (Iverson 1997b). These compounds are deposited from prey to predator largely unmodified (Iverson 1997a), providing a good candidate for eliminating the biases associated with analyzing stomach contents.

The fatty acid profile of the predator should begin to match that of the prey after a few weeks (Kirsch et al. 1998). Fatty acids are transported via lipoproteins within the lymphatic system (Tocher 2003) to storage sites after re-esterification into triacylglycerols (Iverson 2009). This process may not deliver fatty acids in equal quantities to every tissue. This process may be based more on the needs of the tissue for a particular fatty acid and differences in fatty acid delivery to specific tissues has been observed in fish (Montero et al. 2001, Njinkoue et al. 2002). It is imperative to understand the process of fatty acid incorporation in tissues that are intimately involved in fatty acid processing and storage.

Fatty acid analysis does have problems that need to be addressed for the technique to be a valuable resource. No fatty acid is completely unique to a species (Dalsgaard et al. 2003) and several fatty acids may be needed to distinguish between species (Recks and Seaborn 2008). This shortcoming requires several fatty acids present in the signature to be used to distinguish among prey items. A way to alleviate this problem is to design laboratory experiments that examine the process of lipid integration of a specific prey, and to examine how the signature changes when the diet is switched.

In order to determine the efficacy of fatty acid analysis for estimating striped bass diets, the pattern of incorporation must be determined first. Therefore, the aims of this study were to: 1) determine the rate at which striped bass tissues incorporated prey fatty acids; 2) examine if the 
entire prey fatty acid signature was incorporated into striped bass tissues; and 3) determine whether the liver or belly flap tissues were reliably mimicking the fatty acid signature of the prey. These two tissues were chosen because they hold little commercial value and represent areas largely responsible for storage (adipose) and processing (liver) of lipids.

\section{Materials and Methods}

\section{Experimental design}

Striped bass (Chesapeake Bay strain; total length $325 \pm 6.21 \mathrm{~mm}$ ) were obtained from West Virginia University's Aquaculture Extension Unit and were transported to the James J. Howard Marine Sciences Laboratory in Sandy Hook, New Jersey. Fish were randomly distributed among three 120 gallon tanks. The tanks were part of a flow through system with water pumped directly from the Sandy Hook Bay. Temperature ranged from $20.4-26.8^{\circ} \mathrm{C}$, and salinity ranged from 23.0 - 26.4 parts per thousand (ppt) during the feeding experiment. Striped bass were fed a diet of bay anchovy Anchoa mitchilli (Valenciennes 1848) every other day for four weeks prior to the experiment to establish a baseline fatty acid signature (Kirsch et al. 1998). At the start of the experiment (day 0), fish were fed a diet of spot Leiostomus xanthurus (Lacepede 1802) ad libitum every other day to approximate $1 / 2$ satiation. Four fish from each tank were sacrificed every two weeks starting on day 0 . On day 40 , the diet was switched to Atlantic menhaden Brevoortia tyrannus (Latrobe 1802) and four fish were sacrificed on days 71 and 88. Fish were weighed $(\mathrm{g})$ and measured (total length in $\mathrm{mm}$ ) and vacuum sealed with a FoodSaver vacuum sealer (Sunbeam Products, Inc., Niles, IL) and frozen at $-20^{\circ} \mathrm{C}$ until they could be analyzed. 


\section{Sample preparation}

Striped bass were thawed at the time of analysis, and tissue samples were weighed to the nearest 0.1 gram. The liver and a portion of the belly flap were removed. The belly flap (with skin intact) follows a line marked by the termination of the ribs and initiation of the peritoneum of the body wall (Jacobs et al. 2008).

All tissues were ground with a chemical drying agent, diatomaceous earth (Dionex, Sunnyvale, CA). Lipid was extracted with methylene chloride/methanol (3:1; v:v) under nitrogen using an Accelerated Solvent Extractor (ASE 300, Dionex, Sunnyvale, CA) according to Folch et al. (1957). Samples were extracted at $100^{\circ} \mathrm{C}$ and $1500 \mathrm{psi}$ (USEPA 2007). Three samples of tissue were extracted at both $100^{\circ} \mathrm{C}$ and $120^{\circ} \mathrm{C}$ to compare the yield in total lipid extracted (Schafer 1998) and create a correction factor. Total lipid extracted was determined gravimetrically for each sample and reported as a percent of wet weight.

Extracted lipid species containing fatty acids as various derivatives were transesterified using a solution of sulfuric acid and methanol (Christie 2003). Fatty acid methyl esters were run on a gas chromatograph (Agilent 6890N Network GC System, Santa Clara, CA) / mass spectrometer (GC/MS, Agilent, 5973 Network Mass selective detector, Santa Clara, CA). The chromatograph was equipped with a fused silica capillary column, DB-23 60m length X $0.250 \mathrm{~mm}$ OD X $0.25 \mu \mathrm{m}$ film thickness (Agilent, Santa Clara, CA) with hydrogen as a carrier gas. The temperature program was as follows: hold at an initial temperature of $50^{\circ} \mathrm{C}$ for 2 min, hold for $1 \mathrm{~min}$ at $150^{\circ} \mathrm{C}$ after ramping at $20^{\circ} \mathrm{C} \cdot \mathrm{min}^{-1}$, ramp to $215^{\circ} \mathrm{C}$ at $1.25^{\circ} \mathrm{C} \cdot \mathrm{min}^{-1}$. The fatty acid retention times were compared to known standards from Nu-Chek Prep (Elysian, MN), Cayman Chemical (Ann Arbor, MI), Matreya (Pleasant Gap, PA) and Restek (Bellefonte, PA). There were peaks which consisted of more than one fatty acid and it was impossible to determine 
which fatty acid was creating the peaks. Therefore, the term "fatty acid complex" was assigned to this peak. The complex refers to which fatty acid(s) could be responsible for the peak, e.g. $\mathrm{C} 22: 5 \mathrm{n} 3$ and $\mathrm{C} 22: 6 \mathrm{n} 3$.

\section{Statistical analyses}

To compare the effect of the prey species on growth, analysis of variance (ANOVA) was used to determine if there were differences in the weight of striped bass among all sample days (R Development Core Team 2010, Vienna, Austria). Residuals of the non-transformed data were normally distributed $(p>0.05)$ and therefore no transformation was performed. A Tukey's HSD post hoc test was performed to identify where the differences occurred.

Fatty acid methyl esters were expressed as the percent of the total fatty acid concentrations. These values were used to determine differences in the prey species. These values were then compared to tissues samples throughout the experiment to determine if striped bass tissues reflected prey values.

A permutational multivariate analysis of variance (PERMANOVA, Anderson 2005) was performed on the tissue samples and the two prey types, spot and menhaden, to determine if there were significant differences among the groups (R Development Core Team 2010, Vienna, Austria). This technique does not require variables constrained to a normal distribution and instead it creates a distribution based on permutations of the data.

Nonmetric multidimensional scaling (NMDS) was also performed on the data (R Development Core Team 2010, Vienna, Austria). This ordination technique is an iterative search for the best position of samples in multidimensional space, and uses the stress value as an indicator for the best solution. A distance matrix was calculated for the fatty acids, and the 
samples are ordinated based on the distances calculated (McCune and Grace 2002). This technique will allow visual confirmation of the PERMANOVA results.

\section{Results}

\section{Lipid content and growth}

The lipid content of liver tissue ranged from $2.14-13.45 \%(\mathrm{n}=45)$ and from $5.63-$ $25.67 \%(\mathrm{n}=46)$ for belly flap samples. Belly flap had consistently higher levels of lipid when compared to liver samples within a sampling day (Fig. 1). Although the average wet weight of fish increased throughout the experiment (Fig. 2), the lipid content of both tissues increased dramatically after the diet was switched to Atlantic menhaden (day 71 and 88), indicating the diet was the primary source of variation. The slope of weight gain in striped bass within this experiment increased starting on day 28 , which was prior to the diet switch to menhaden (Fig. 2).

\section{Fatty acids}

A total of 39 fatty acids, and one fatty acid complex were identified and quantified in this experiment. The 11 fatty acids: C14:0, C16:0, C16:1n7, C18:0, C18:1n9, C18:1n7c, C18:2n6, C20:4n6, C20:5n3, C22:5n3, and C22:6n3, accounted for $85-90 \%$ of all fatty acids seen in the liver and adipose tissue samples (Fig. 3). These fatty acids accounted for $83 \%$ of the total fatty acids in the spot samples (Fig. 3). These fatty acids were also abundant in livers and belly flaps removed from striped bass along with the menhaden used as the diet. The percent of total for these fatty acids ranged from $85-89 \%$ of the fatty acids identified in striped bass tissues on days 71 and 88 . However, in menhaden, the value was $77.54 \%$ and fatty acids others than those listed above were important, including $\mathrm{C} 18: 4 \mathrm{n} 3$ and $\mathrm{C} 18: 3 \mathrm{n} 3$. 
Fatty acid groupings (saturated, monounsaturated, omega-3, and omega-6) fluctuated throughout the experiment, regardless of the feed. When striped bass were fed spot, both liver and belly flap saturated fatty acids were at lower levels than those seen in spot. Monounsaturated fatty acids were at much higher levels in the striped bass than in spot (26-36\% and $22 \%$ respectively). Omega-3 fatty acids levels were similar between liver and spot, while belly flap levels increased throughout the experiment. Both tissues experienced an initial increase in omega 6 fatty acids from day 0 to 12 . Starting on day 28 , the proportion of these fatty acids decreased.

The diet switch from spot to menhaden also caused changes in the groups of fatty acids in striped bass tissues. The saturated fatty acids decreased in the liver, while increasing in the belly flap. Monounsaturated fatty acids were at much higher levels in striped bass tissues than spot. In both tissues, the omega-3 fatty abundance increased and omega 6 abundance levels decreased.

The PERMANOVA revealed a significant interaction between the sampling day and the type of tissue $\left(\mathrm{F}_{5,122}=6.76, \mathrm{p}<0.001\right)$. Therefore, comparisons were made based upon subsets of the data (Table I). Liver and belly flap were significantly different in fatty acid signature from one another on every sampling day $(6$ comparisons, $\mathrm{p}<0.01)$. Both tissues types were always significantly different than the diet of spot $(8$ comparisons, $\mathrm{p}<0.001)$ or menhaden $(4$ comparisons, $\mathrm{p}<0.01)$.

The patterns of change within a tissue were different between the liver and the belly flap (Table I). The liver fatty acid signature was not significantly different among days 0,12 , and 28 . The signature is also not significantly different between days 28 and 40, while day 40 is different than day 0 and 12 . This suggests that day 28 is a transition signature and that change is occurring. All liver samples collected during feeding of spot were significantly different than liver samples collected when striped bass were fed menhaden. For the belly flap, day 0 was 
significantly different than all other sample days. Days 12,28 , and 40 were not different from each other. After the diet was switched to menhaden, the belly flap samples were different than all samples collected when striped bass were fed spot. The fatty acid signature of liver and belly flap samples collected on day 71 and 88 were not different from each other, but were significantly different than all other sampling days.

The nonmetric multidimensional scaling (NMDS) demonstrates that the fatty acid signatures of the striped bass samples are changing during the experiment (Fig. 4, stress 10.42). Belly flap and liver samples exhibit different patterns from each other. However, the within tissue pattern is similar in plots of axis 1 vs. 2 and 1vs. 3. The belly flap signature changes as the experiment progresses. The belly flap changes to closer approximate spot during the first six weeks of the experiment, and when the diet is switched, the signature changes and starts to mimic that of menhaden. The signature of the liver samples is not as clear. The signature starts to change to closely approximate spot from day $0-12$. Signatures on day 28 and day 40 start to move away from the spot signature and back to the day 0 signature. Once the diet is switched to menhaden, the signature changes to approximate the fatty acid signature seen on day 0 , and then becomes distinct from all other samples, including the diet item.

Because the overall signature of striped bass tissues and prey were always significantly different, individual fatty acids were compared between menhaden and spot to establish unique marker fatty acids. Menhaden and spot contained the same component fatty acids, but the abundances differed between the two prey types (Fig. 5a). Striped bass tissues were then analyzed to determine if prey marker fatty acids were present (Figs. 5b and 5c). Although the tissue experienced fluctuations while being fed spot, the difference is clearly visible when the diet was switched to menhaden. The fatty acids C15:0, C18:3n3, C18:4n3, C19:0, C20:1n12, 
$\mathrm{C} 20: 1 \mathrm{n} 7$, and $\mathrm{C} 20: 2 \mathrm{n} 6$ exhibited differing values when spot and menhaden tissues were compared. These differences were then transferred to the striped bass tissues, and helped distinguish the diet switch. The fatty acid C19:0 was particularly useful because it was absent from menhaden samples. This fatty acid was removed from striped bass tissues within three weeks of the diet change. Some fatty acids are stored differently between the two tissue types. The liver exhibited lower levels of C15:0 than observed in spot, while the belly flap showed higher levels of $\mathrm{C} 18: 3 \mathrm{n} 3$ than seen in menhaden.

\section{Discussion}

Menhaden and spot have distinct and measurable affects on striped bass tissues. The fatty acid signature of striped bass liver and belly flap samples exhibited fatty acids indicative of a prey switch, from spot to menhaden, after a period of three weeks. Studies have shown that the fatty acids seen in the predator will mimic the fatty acids seen in the prey (Seaborn et al. 2000, Morias et al. 2001, Turner and Rooker 2005, Martinez et al. 2009). This change in fatty acid signature from one diet item to another has been quantified within a period of three weeks for cod Gadus morhua Linnaeus 1758 (Kirsch et al. 1998). Although change occurred in the fatty acids of striped bass throughout the experiment, regardless of the diet, certain fatty acids exhibited a distinct change within 31 days of when the diet was switched to menhaden.

Changes in lipid levels were evident in both tissues, and both tissues increased the percentage of lipid after the switch from spot to menhaden. Kirsch et al. (1998) found cod fed a low lipid diet item, squid ( $2.0 \%$ dry weight), did not increase the total fat levels. In our experiment, the lipid level of spot was $6.05 \%$ (wet weight) while the lipid level of menhaden was $11.75 \%$ (wet weight), and this change in prey lipid level was easily seen in striped bass 
tissues. Lipid storage depots vary among teleost fish, with possible locations including mesenteric fat, skeletal muscle, and liver (Sheridan 1988). While the pattern of lipid deposition is extremely similar between liver and belly flap in striped bass (both tissues increased lipid levels when fed menhaden), more lipid is stored in the belly flap than the liver.

Diet of striped bass appeared to be the main cause of lipid change within tissues tested. The lipid levels within the liver and belly flap appear to be relatively stable even while the fish is growing. The amount of lipid present in the tissue increases dramatically when the diet is switched to a high lipid prey which is a common result seen in fish (Refstie et al. 2001, Boujard et al. 2004). All energy not used immediately will go into storage for processes like metabolism and reproduction. This shows that the diet of striped bass and other top predators has a major impact on physiological processes. A less nutritious diet will lead to lower energy reserves, which in turn could lead to reduced growth, reduced reproductive output, and possibly mortality. Therefore, tracking the value of the diet becomes an important step along with tracking the diet itself.

The wet weight of striped bass increased dramatically starting on day 28 . This increase cannot be assigned to the diet switch from spot to menhaden, because the switch did not take place until day 40. Variables such as temperature and salinity did not change over the course of the experiment, and do not explain the difference seen. Striped bass were observed to be feeding for the duration of the experiment, and therefore were assumed to have been acclimated to the tank system. Water was constantly flowing through the tanks to limit build-up of waste products. Although the density of striped bass in the tanks was reduced as fish were sampled, the density of fish remained below $0.5 \mathrm{lbs} \mathrm{g}^{-1}$ (Lasordo et al. 1998); and was $0.1 \mathrm{lbs} \bullet \mathrm{g}^{-1}$ after day 28 , when 
the increase in growth was seen. Therefore, some factor other than density and water quality seems to have led to a change in weight gain in striped bass in this experiment.

The major fatty acids seen in both tissues were similar but there appears to be a difference in where certain fatty acids are located at increased concentrations. Even as the experiment progressed and fatty acid inputs were changing due to a new prey source, some patterns remained intact. For example, $\mathrm{C} 14: 0$ and $\mathrm{C} 16: 1 \mathrm{n} 7$ made a larger contributions to the belly flap fatty acid signature, while $\mathrm{C} 20: 4 \mathrm{n} 6$ and $\mathrm{C} 22: 6 \mathrm{n} 3$ had a higher mass percent in liver samples until the diet was switched to menhaden. The levels of $\mathrm{C} 22: 6 \mathrm{n} 3$ are similar in both spot and menhaden, but different values are present in the tissues depending on the prey type. The transport and storage of fatty acids may influence the tissue signature. Fatty acids are transported via lipoproteins within the lymphatic system (Tocher 2003) to storage sites after re-esterification into triacylglycerols (Iverson 2009). This process may not deliver fatty acids in equal quantities to every tissue; and this process may be based more on the needs of the tissue for a particular fatty acid.

Fatty acids will remain in storage tissue until needed for energy but the oxidation process is not uniform among all fatty acids. Selective metabolism of fatty acids is influenced by molecular structure, a process documented in rats (Leyton et al. 1987, Raclot and Groscolas 1993), humans (Delany et al. 2000), and rabbits (Connor et al. 1996). Although these studies were not focused on fish, the mechanisms are likely to be similar. This difference in oxidation may be responsible for the difference in abundance of certain fatty acids between the tissue types. Results from the literature that compared liver and muscle were not always consistent with the results from this experiment. Abundance values were similar between liver and muscle tissues in largemouth bass Micropterus salmoides (Lacepede 1802; Subhadra et al. 2006) and 
white seabream Diplodus sargus (Valenciennes 1830; Cejas et al. 2004). The gilthead sea bream Sparus aurata (Linnaeus 1758) did show differences similar to the values seen in this experiment when liver and muscle tissues were compared (Montero et al. 2001). The values obtained in this experiment suggest that certain fatty acids in adipose tissue, i.e. C22:6n3, may be oxidized more readily than other fatty acids and fatty acids such as $\mathrm{C} 18: \ln 9$ may not be as beneficial for energy as they are accumulated above the values seen in both prey items.

There was a clear pattern of change seen in each tissue from the start of the experiment through the terminus. It was expected that quantified fatty acids would change to match the fatty acid pattern seen in the prey (Pollierer et al. 2010). Studies suggest that predator signatures should mimic prey species around three weeks (Kirsch et al. 1998).This did not occur, as significant differences were always obtained when spot signatures were compared to both tissues sampled in striped bass. Despite significant differences in overall fatty acid signature, there are marker fatty acids which can help to identify a prey source within a period of about 31 days. The NMDS results indicate that there is a constant change occurring within both tissues regardless of prey type. When individual fatty acids are analyzed, we see that there are indeed differences within the tissues when the prey is changed. The fatty acid C19:0 provides the best example. Although this fatty acid is only present in small amounts in spot $(0.58 \%)$, these trace amounts are still seen in the striped bass tissue. This fatty acid is not present within menhaden, and we see this fatty acid removed from striped bass tissues within 31 days of fish being fed menhaden. This pattern also emerges when other fatty acids are analyzed but does not hold true for every fatty acid consumed.

Although neither tissue fully approximated the signature of the diet item, the possibility of identifying diet items from striped bass tissues does appear feasible. The entire fatty acid 
signature is not necessarily a good indicator of diet, although it does provide information on the change in signature in general. Both the liver and the belly flap exhibited changes in the fatty acid signature as the diet was changed. Although either tissue appears to be a candidate for fatty acid signature analysis, only the belly flap offers the possibility of non-lethal sampling. A technique would need to be developed to sample a small portion of the tissue without allowing for infection. This type of sampling has been performed on marine mammals where a sample of lipid is obtained by removing a tissue plug from the blubber layer (Bradshaw et al. 2003, Walton and Pomeroy 2003, Wetzel and Reynolds 2004). Laparoscopic surgery has been performed on shortnose sturgeon Acipenser brevirostrum (Lesueur 1818), Atlantic sturgeon A. oxyrinchus oxyrinchus (Mitchill 1815; Matsche et al. 2011) and on tench Tinca tinca (Linnaeus 1758; Macri et al. 2011) to sample reproductive tissues. This minimally invasive technique provides a method for internal tissue sampling and is non-lethal. Laparoscopic surgery may be adapted to sample fish tissues to track fatty acid changes, but may not be cost-effective.

Striped bass in the wild will not consume only one prey item. Thus, it becomes imperative to develop models that allow for multiple prey species within the diet. An important first step is to provide an accurate method for identifying the process of fatty acid incorporation into striped bass tissues, and how the signature changes during a diet shift. This study has shown that individual prey items contain fatty acid trophic markers (FATMs), which can be used to distinguish among items consumed. This information can be used to model the proportions of each diet item consumed (Iverson et al. 2004), and in turn, allow for more accurate estimates of diet. 


\section{Acknowledgments}

The authors would like to thank J. Councilman, A. Leight, J. Brush, and W. Lowery for assistance in collecting samples. We are also indebted to B. Dockum and L. Gonsalves for advice

and assistance in the chemical analysis of samples. E. Chambers provided invaluable help in the laboratory preparing and analyzing samples. We are grateful for the comments provided by anonymous reviewers. This research was made possible by funding from NOAA Chesapeake Bay Office Grant No. NA07NMF4570330 and all research was conducted under Animal Care and Use Protocol number 09-0102. 


\section{Literature cited}

Adams, S. M. (1976). Feeding ecology of eelgrass fish communities. Transactions of the American Fisheries Society 105, 514-519.

Anderson, M.J. (2005). PERMANOVA: a FORTRAN computer program for permutational multivariate analysis of variance. Department of Statistics, University of Auckland

Bowen, S.H. (1996). Quantitative description of the diet. In Fisheries Techniques (Murphy, B.R. and Willis, D.W., eds.), pp. 513-532. Bethesda, MD: American Fisheries Society

Boujard, T., A. Gelineau, G. Corraze, G. Dutto, E. Gasset, \& S. Kaushik. (2004). Regulation of feed intake, growth, nutrient, and energy utilization in European sea bass (Dicentrarchus labrax) fed high fat diets. Aquaculture 231, 529-545.

Bradshaw, C. J. A., M.A. Hindell, N.J. Best, K.L. Phillips, G. Wilson, \& P.D. Nichols. (2003).

You are what you eat: describing the foraging ecology of southern elephant seals (Mirounga leonina) using blubber fatty acids. Proceedings of the Royal Society of London B 270, 1283-1292.

Cejas, J.R., E. Almansa, S. Jẻrez, A. Bolańos, M. Samper, \& A. Lorenzo. (2004). Lipid and fatty acid composition of muscle and liver from wild and captive mature female broodstocks of white sea bream, Diplodus sargus. Comparative Biochemistry and Physiology Part B 138, 91-102.

Christie, W.M. (2003). Lipid Analysis. Bridgewater, England: PJ Barnes and Associates.

Connor, W.E., D.S. Lin, \& C. Colvis. (1996). Differential mobilization of fatty acids from adipose tissue. Journal of Lipid Research 37, 290-298. 
Currin, B. M., J.P. Reed, \& J.M. Miller. (1984). Growth, production, food consumption, and mortality of juvenile spot and croaker: a comparison of tidal and nontidal nursery areas. Estuaries 7, 451-459.

Dalsgaard, J. M. S. J., G. Kattner, D. Muller-Navarra, and W. Hagen. (2003). Fatty acid trophic markers in the pelagic marine environment. Advances in Marine Biology 46, 225-340.

Delany, J.P., M.M. Windhauser, C.M. Champagne, \& G.A. Bray. (2000). Differential oxidation of individual dietary fatty acids in humans. American Journal of Clinical Nutrition $\mathbf{7 2}$, 905-911.

Elliot, J.M. (1972). Rates of gastric evacuation in brown trout, Salmo trutta L. Freshwater Biology 2, 1-18.

Folch, J., M. Lees, \& G.H. Sloane Stanley. (1957). A simple method for the isolation and purification of total lipids from animal tissues. The Journal of Biological Chemistry 276, 497-509.

Gannon, J.E. (1976). The effects of differential digestion rates of zooplankton by alewife, Alosa pseudoharengus, on determinations of selective feeding. Transactions of the American Fisheries Society 105, 89-95.

Gurr, M.I. \& J.L. Hardwood. (1991). Lipid biochemistry: an introduction. $4^{\text {th }}$ edn. London, England: Chapman and Hall.

Hartman, K.J. \& S.B. Brandt. (1995). Trophic resource partitioning, diets, and growth of sympatric estuarine predators. Transactions of the American Fishery Society 124, 520537. 
He, E. \& W.A. Wurtsbaugh. (1993). An empirical model of gastric evacuation rates for fish and an analysis of digestion in piscivorous brown trout. Transactions of the American Fisheries Society 122, 717-730.

Iverson, S. J. (2009). Tracing aquatic food webs using fatty acids: from qualitative indicators to quantitative determination. In Lipids in aquatic ecosystems (Arts, M.T., M.T. Brett, \& M.J. Kainz eds). pp 281-307. New York, NY: Springer Science.

Iverson, S.J., J.P.Y. Arnold, \& I.L. Boyd. (1997b). Milk fatty acid signatures indicate both major and minor shifts in the diet of lactating Antarctic fur seals. Canadian Journal of Zoology 75, 1881-97.

Iverson, S.J., K.J. Frost, \& L.F. Lowry. (1997a). Fatty acid signatures reveal fine scale structure of foraging distribution of harbor seals and their prey in Prince William Sound, Alaska. Marine Ecology Progress Series 151, 255-271.

Iverson, S.J. C. Field, W.D. Bowen, \& W. Blanchard. (2004). Quantitative fatty acid signature analysis: a new method of estimating predator diets. Ecological Monographs 74, 211235.

Jacobs, J. M., M.R. Rhodes, B. Martin, D. McIntosh, W.F. Van Heukelem, \& R.M. Harrell. (2008). Tissue-specific sampling for estimation of striped bass whole-body proximate composition. Transactions of the American Fisheries Society 137, 386-392.

Jobling, M. (1994). Fish Bioenergetics. London, England: Chapman and Hall.

Kirsch, P. E., S.J. Iverson, W.D. Bowen, S.R. Kerr, \& R.G. Ackman. (1998). Dietary effects on the fatty acid signature of whole Atlantic cod (Gadus morhua). Canadian Journal of Fisheries and Aquatic Sciences 55, 1378-1386. 
Lasordo, T.M., M.P. Masser, and J. Rakocy. (1998). Recirculating aquaculture tank production systems: an overview of critical considerations. Southern Regional Aquaculture Center Publication No. 451. 6pgs.

Leyton, J., P.J. Drury, \& M.A. Crawford. (1987). Differential oxidation of saturated and unsaturated fatty acids in vivo in the rat. British Journal of Nutrition 57, 383-393.

Macri, F., G. Rapisarda, G. Marino, M. De Majo, \& G. Aiudi. (2011). Use of laparoscopy for the evaluation of the reproductive status of tench (Tinca tinca). Reproduction in Domestic Animals 46, 130-133.

Martinez, I., I.B. Standal, D.E. Axelson, B. Finstad, \& M. Aursand. (2009). Identification of the farm origin of salmon by fatty acid and $\mathrm{HR}{ }^{13} \mathrm{C}$ NMR profiling. Food Chemistry 116, 766-773.

Matsche, M.A., R.S. Bakal, \& K.M. Rosemary. (2011). Use of laparoscopy to determine sex and reproductive status of shortnose (Acipenser brevirostrum) and Atlantic sturgeon (Acipenser oxyrinchus oxyrinchus). Journal of Applied Ichthyology 27, 627-636.

McCune, B. \& J.B. Grace. (2002). Analysis of Ecological Communities. Gleneden Beach, OR: MjM Software Design.

Montero, D., L.E. Robaina, J. Socorro, J.M. Vergara, L. Tort, \& M.S. Izquierdo. (2001). Alteration of liver and muscle fatty acid composition in gilthead seabream (Sparus aurata) juveniles held at high stocking density and fed an essential fatty acid deficient diet. Fish Physiology and Biochemistry 24, 63-72.

Morias, S., J.G. Bell, D.A. Robertson, W.J. Roy, \& P.C. Morris. (2001). Protein/lipid ratios in extruded diets for Atlantic cod (Gadus morhua L.): effects on growth, feed utilization, muscle composition, and liver histology. Aquaculture 203, 101-119. 
Njinkoue, J.M., G. Barnathan, J. Miralles, E.M. Gaydou, \& A. Samb. (2002). Lipids and fatty acids in muscle, liver, and skin of three edible fish from the Senegalese coast: Sardinella maderensis, Sardinella aurita, and Cephalopholis taeniops. Comparative Biochemistry and Physiology Part B: Biochemistry and Molecular Biology 131, 395-402.

Pollierer, M.M., S. Scheu, \& D. Haubert. (2010). Taking it to the next level: trophic transfer of marker fatty acids from basal resources to predators. Soil Biology and Biochemistry $\mathbf{4 2 ,}$ 919-925.

Raclot, T. \& R. Groscolas. (1993). Differential mobilization of white adipose tissue fatty acids according to chain length, unsaturation, and positional isomerism. Journal of Lipid Research 34, 1515-1526.

Recks, M.J. and G.T. Seaborn. (2008). Variation in fatty acid composition among nine forage species from a southeastern US estuarine and nearshore coastal ecosystem. Fish Physiology and Biochemistry 34, 275-287.

Refstie, S., T. Storebakken, G. Baeverfjord, \& A.J. Roem. (2001). Long-term protein and lipid growth of Atlantic salmon (Salmo salar) fed diets with partial replacement o fish meal by soy protein products at medium or high lipid level. Aquaculture 193, 91-106.

Schafer, R. H. (1970). Feeding habits of striped bass from the surf waters of Long Island. New York Fish and Game Journal 17, 1-17.

Seaborn, G. T. M. L. J., \& T.I.J. Smith. (2000). Differentiation between cultured hybrid striped bass and wild striped bass and hybrid bass using fatty acid profiles. North American Journal of Fisheries Management 20, 618-626.

Seaburg, K. G. (1957). A stomach sampler for live fish. The Progressive Fish Culturist 19, 137139. 
Sheridan, M.A. (1988). Lipid dynamics in fish: aspects of absorption, transportation, deposition, and mobilization. Comparative Biochemistry and Physiology Part B 90, 679-690.

Subhadra, B., R. Lochmann, S. Rawles, \& R. Chen. (2006). Effect of dietary lipid source on the growth, tissue composition and hematological parameters of largemouth bass (Micropterus salmoides). Aquaculture 255, 210-222.

Tocher, D. R. (2003). Metabolism and functions of lipids and fatty acids in teleost fish. Reviews in Fisheries Science 11, 107-184.

Turner, J. P., \& J. R. Rooker. (2005). Effect of dietary fatty acids on the body tissues of larval and juvenile cobia and their prey. Journal of Experimental Marine Biology and Ecology 322, 13-27.

USEPA (United States Environmental Protection Agency). (2007). Pressurized fluid extraction (PFE). USEPA SW-846. Method 3545A, Update IV. Washington, D.C.

Walton, M., \& P. Pomeroy. (2003). Use of blubber fatty acid profiles to detect inter-annual variations in the diet of grey seals Halichoerus grypus. Marine Ecology Progress Series 248, 257-266.

Wetzel, D. L., \& I. J.E. Reynolds. (2004). Definitive identification of fatty acid constituents in marine mammal tissues. Canadian Journal of Fisheries and Aquatic Sciences 61, 554560.

\section{Electronic References}

R Development Core Team. 2010. R: A language and environment for statistical computing. R Foundation for Statistical Computing, Vienna, Austria. ISBN 3-900051-07-0, URL http://www.R-project.org. 
Table I. Results from the PERMANOVA performed on the fatty acid data from each sample. The entire fatty acid signature from each group was compare to all other groups. Asterisks represent a significant difference in overall signature.

\begin{tabular}{|c|c|c|c|c|c|c|c|c|c|c|c|c|c|}
\hline & Spot & Liv 0 & Liv 12 & Liv 28 & Liv 40 & Liv 71 & Liv 88 & BF 0 & BF 12 & BF 28 & BF 40 & BF 71 & BF 88 \\
\hline \multicolumn{14}{|l|}{ Spot } \\
\hline Liv 0 & $* * *$ & & & & & & & & & & & & \\
\hline Liv 28 & $* * *$ & ns & ns & & & & & & & & & & \\
\hline Liv 40 & $* * *$ & $* *$ & $* * *$ & ns & & & & & & & & & \\
\hline Liv 71 & $* * *$ & $* * *$ & $* * *$ & $*$ & $* * *$ & & & & & & & & \\
\hline Liv 88 & $* * *$ & $* * *$ & $* * *$ & $*$ & $* *$ & ns & & & & & & & \\
\hline BF 0 & $* * *$ & $* * *$ & & & & & & & & & & & \\
\hline BF 12 & $* * *$ & & $* * *$ & & & & & $* * *$ & & & & & \\
\hline BF 28 & $* * *$ & & & $* * *$ & & & & $* * *$ & ns & & & & \\
\hline BF 40 & $* * *$ & & & & $* * *$ & & & $* * *$ & ns & ns & & & \\
\hline BF 71 & $* * *$ & & & & & $* * *$ & & $* * *$ & $* * *$ & $* * *$ & $*$ & & \\
\hline Menhaden & $* * *$ & $* * *$ & $* * *$ & $* * *$ & $* * *$ & $* *$ & $* * *$ & $* * *$ & $* * *$ & $* * *$ & $* * *$ & $* *$ & $* *$ \\
\hline \multicolumn{14}{|l|}{$* \quad \mathrm{p}<0.05$} \\
\hline \multicolumn{14}{|l|}{$* * \quad p<0.01$} \\
\hline \multicolumn{14}{|l|}{$* * * \mathrm{P}<0.001$} \\
\hline $\begin{array}{l}\text { ns }=\text { not signif } \\
\text { A blank space }\end{array}$ & $m n$ & 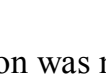 & tested & & & & & & & & & & \\
\hline
\end{tabular}


Figure 1. Fat contents of the liver ( $\bullet$ ) and belly flap ( $\bullet$ of striped bass analyzed. Spot was fed starting on day 0 until day 40 , and the diet was switched to menhaden on day 40 as indicated by the vertical line.

Figure 2. Average wet weight of striped bass from each sampling day. Spot was fed starting on day 0 until day 40 , and the diet was switched to menhaden on day 40 as indicated by the vertical line.

Figure 3. Average mass percent of the major fatty acids detected in menhaden ( $\square$ ) and spot ( $\square$ ) and striped bass tissues: a) liver samples, and b) belly flap samples on days 0 ( $⿴ 囗 0), 12$

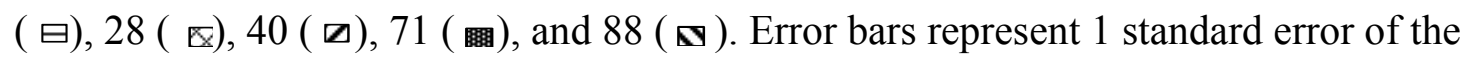
mean.

Figure 4. Non-metric multidimensional scaling (NMDS) plot of striped bass tissue samples and the prey items, spot and menhaden. A plot of a) axes 1 and 2 and b) axes 1 and 3 was needed to reduce the stress value (10.42). The alphanumeric code refers to the tissue $($ Liv $=$ liver and $\mathrm{BF}=$ belly flap) and the day on which the sample was collected (i.e. 0 $=$ day $0,40=$ day 40 , etc.). The two prey species are spot and menhaden $(\mathrm{MH})$.

Figure 5. Patterns in abundance of select fatty acids. Abundance is based upon mass percent of total fatty acids. The diet was changed from spot to menhaden on day 40 . Solid bars represent lipid masses during the time when striped bass were fed spot, while pattern bars represent lipid masses after switching the diet to menhaden. Part a) spot (solid 
bars) and menhaden (patterned bars) fatty acids, b) liver fatty acids for days $0,12,28$, 40,71 , and 88 and c) belly flap fatty acids for days $0,12,28,40,71$, and 88 . 
Figure 1.

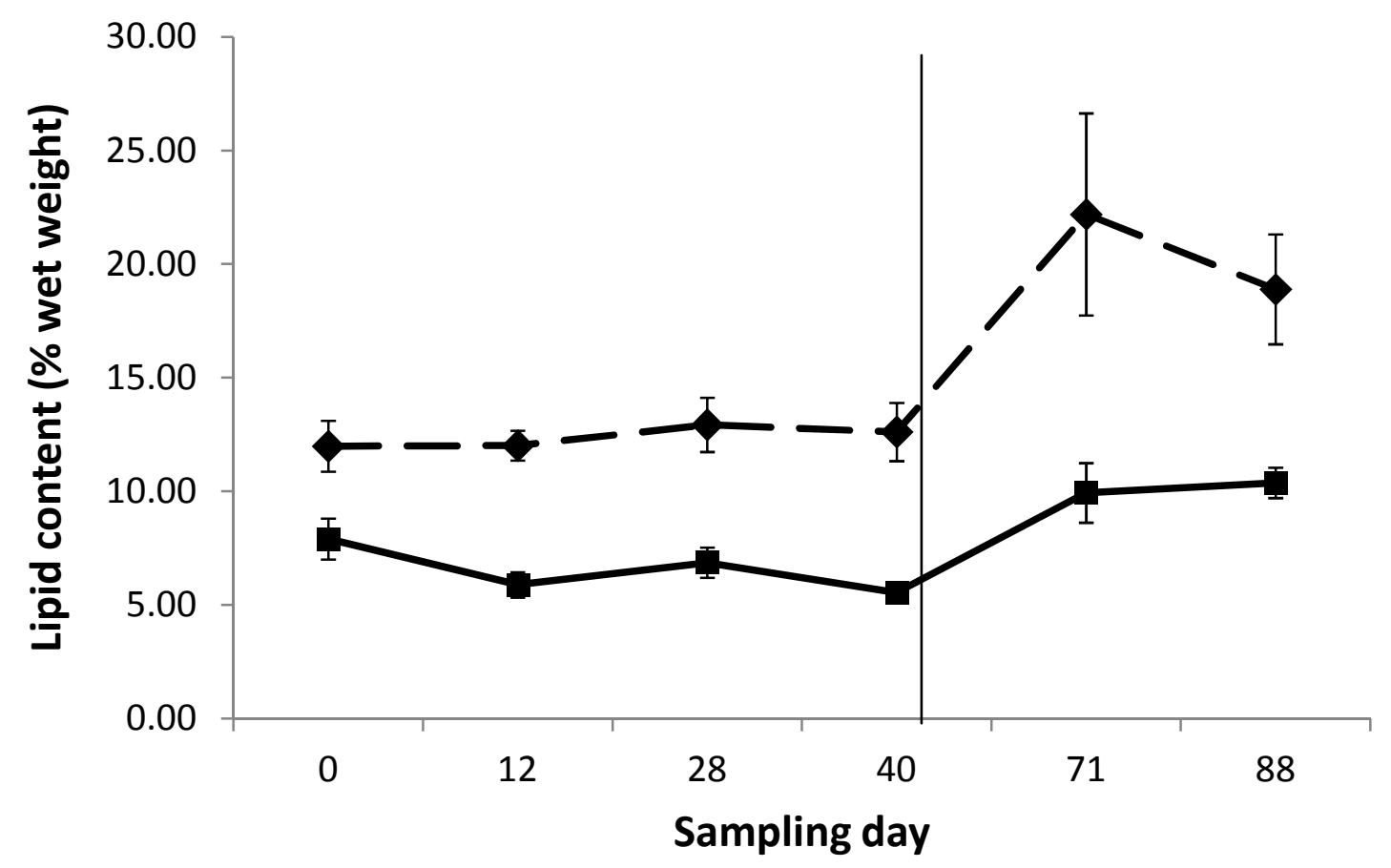


Figure 2.

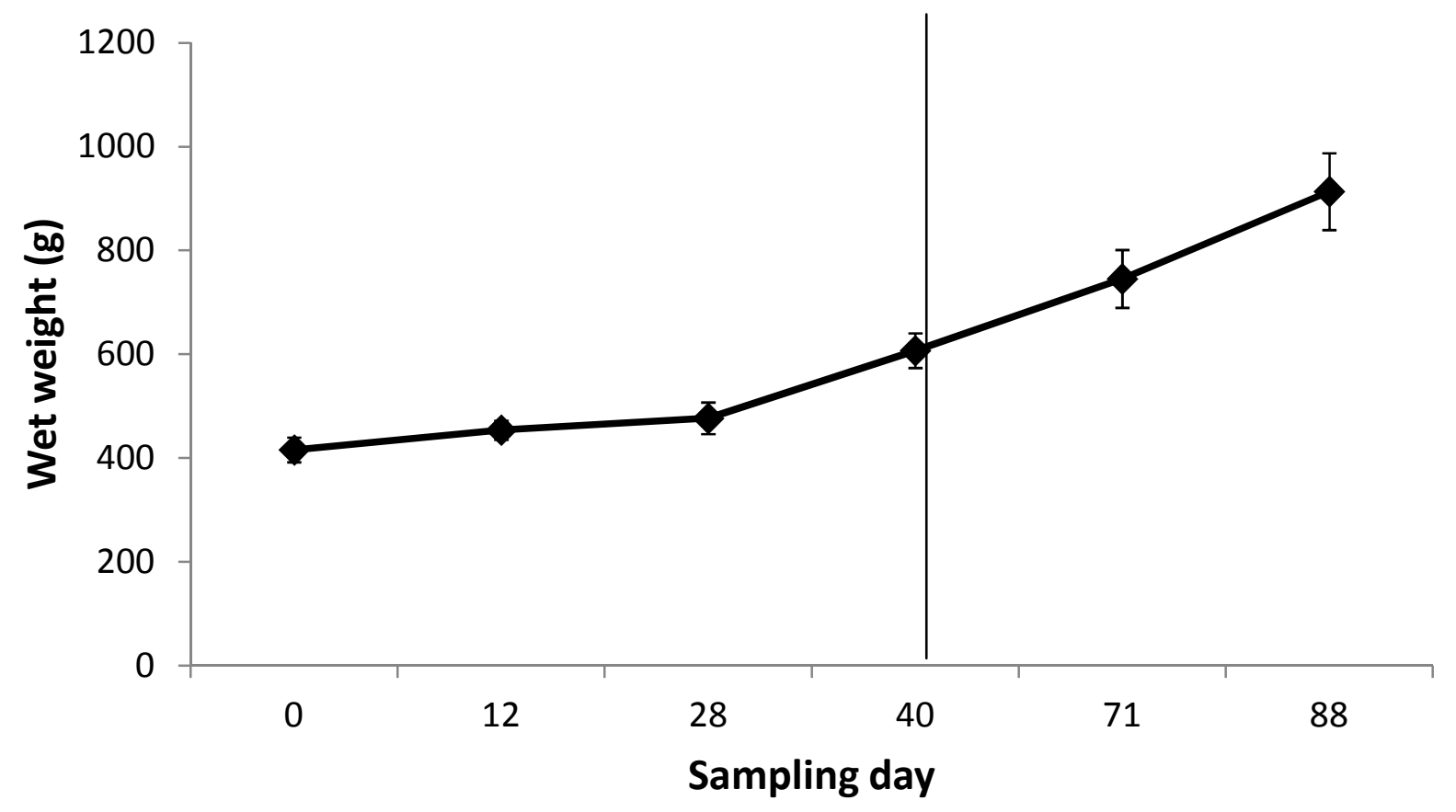


Figure 3.

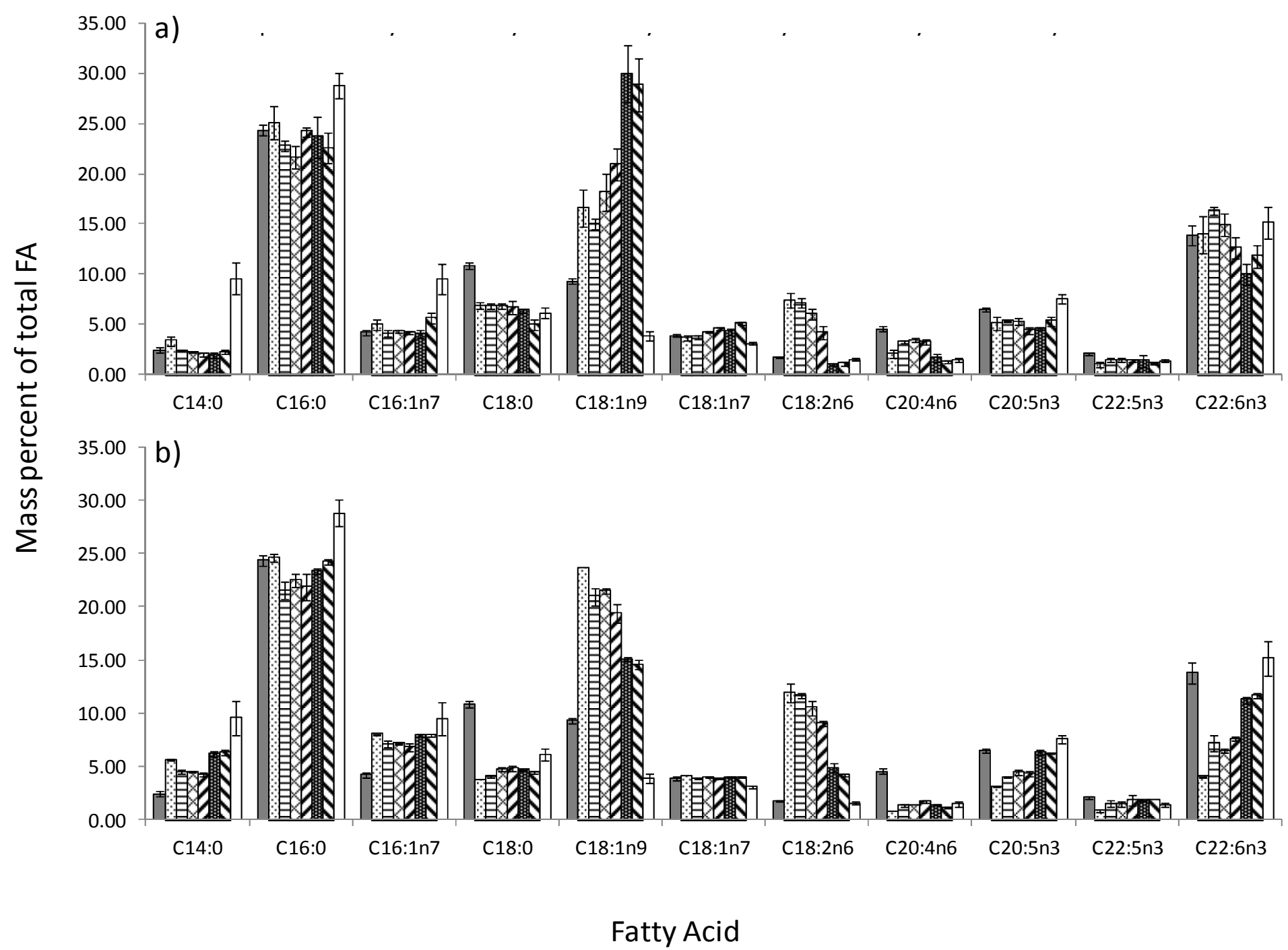


Figure 4.
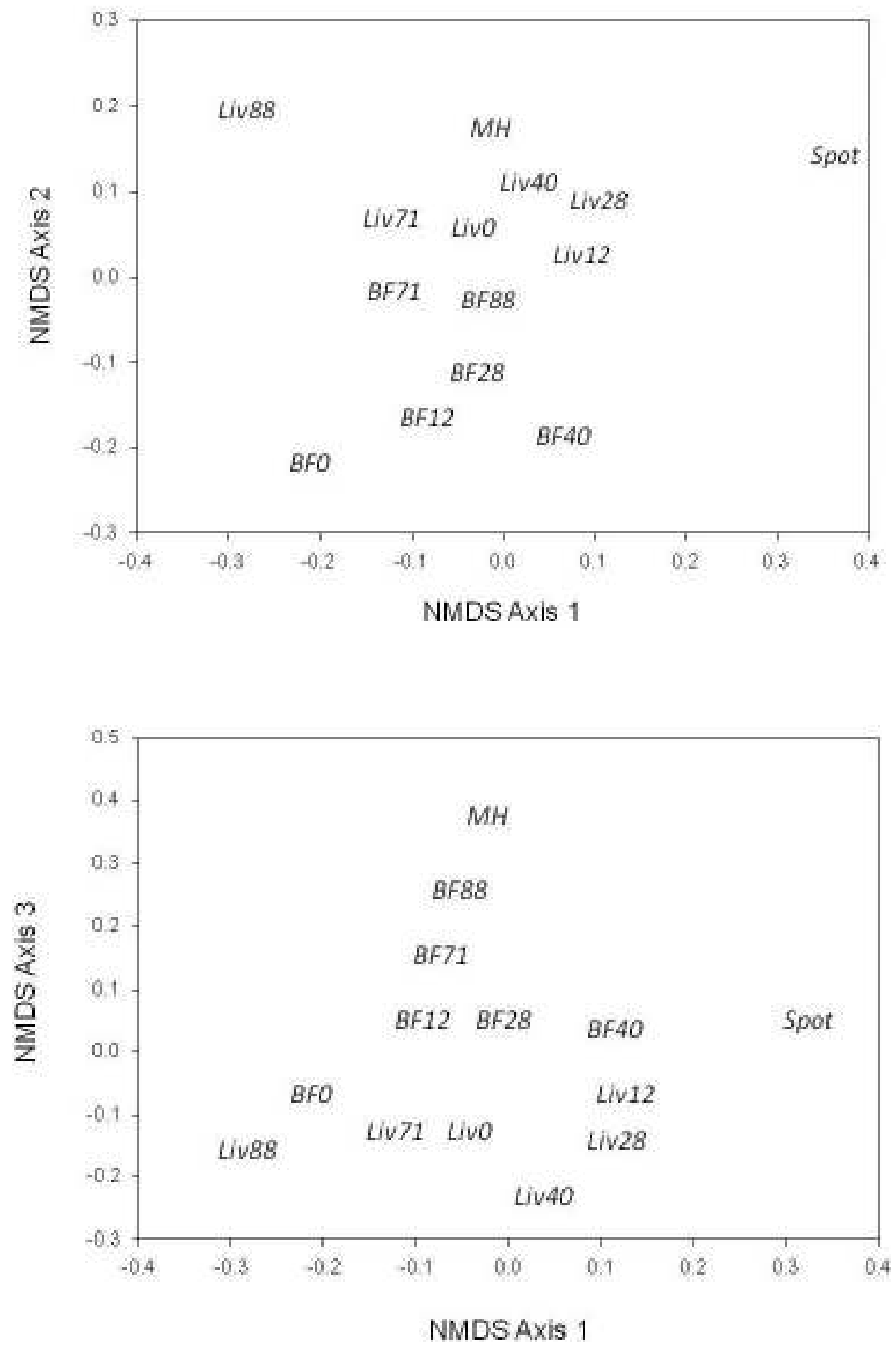
Figure 5.

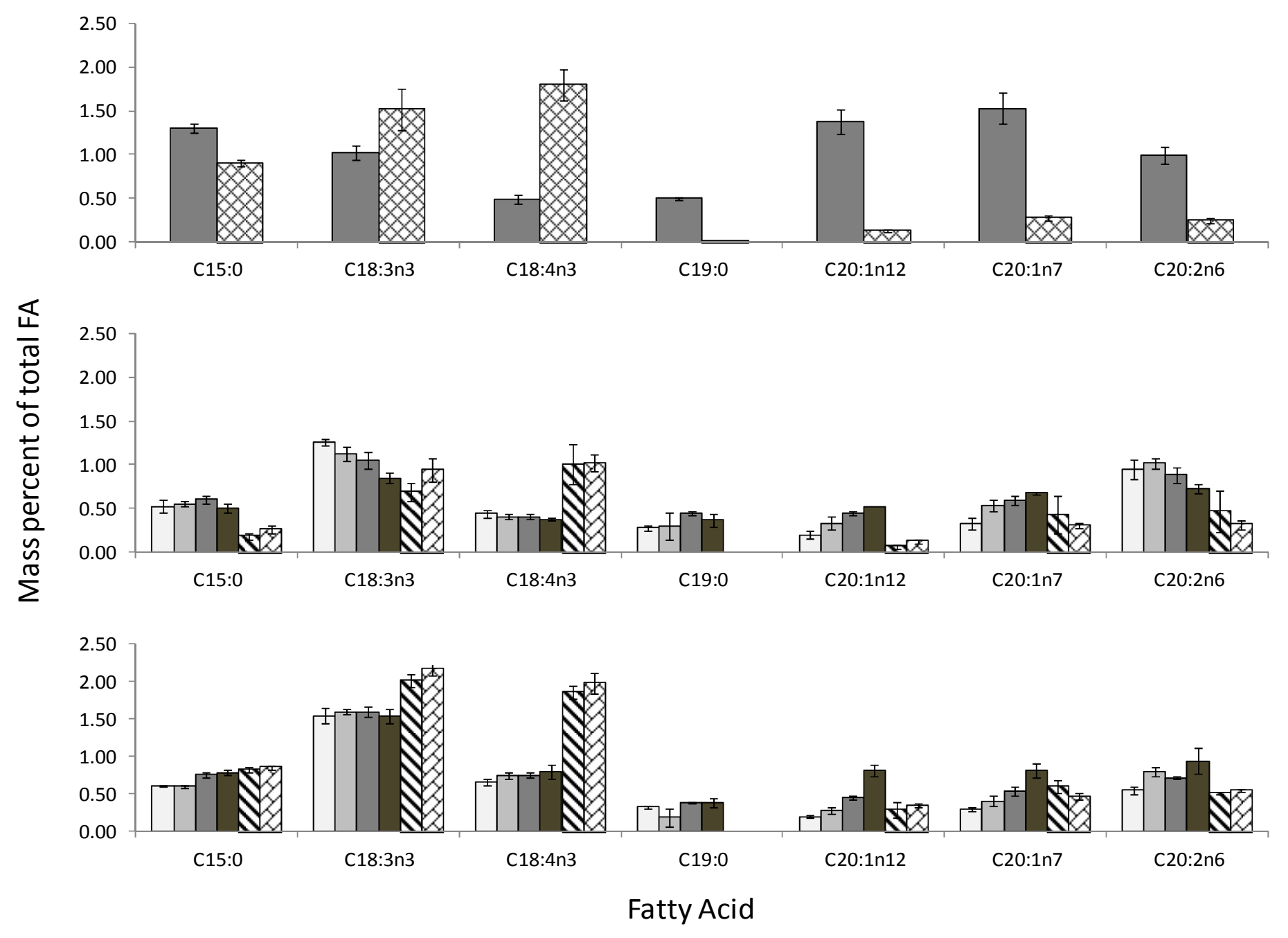


Chapter 4 - The effect of striped bass size on fatty acid signature incorporation 


\begin{abstract}
Fatty acids are a group of molecules that are transferred from prey to predator and deposited with little to no modification. Analysis of fatty acids has been used to elucidate the trophic web within aquatic systems. However, little research has been conducted to determine the effects of organism size on how fatty acids are incorporated within a species. Striped bass (Morone saxatilis) of three different sizes were fed a baseline diet of spot (Leiostomus xanthurus) for a period of four weeks then fed an experimental prey of Atlantic menhaden (Brevoortia tyrannus) for four weeks. All feeding was done every other day to satiation. Indicator fatty acids that distinguished menhaden from spot were unable to demonstrate a signature shift away from baseline within any of the striped bass size groups. A lack of feeding due to low temperatures for part of the experiment and a failure of larger fish to feed at adequate levels are most likely the causes for a lack of signature change. This experiment helps to demonstrate that fatty acid signature analysis may not provide an accurate record of recent diet when fish are feeding at low levels.
\end{abstract}

\title{
Introduction
}

The size of a fish will influence not only what is consumed, but how the diet is processed. Larger fish have larger mouths than their smaller conspecifics, allowing them to consume a broader range of prey items. Anadromous striped bass (Morone saxatilis) in the Chesapeake Bay provide a good example of different diet regimes for different life stages. Juveniles will consume prey indicative of the salinity regime, e.g. oligochaetes and insect larvae are more important in freshwater; and amphipods, mysids, and fish larvae are more important in higher salinity waters (Boynton et al. 1981). Striped bass will become primarily piscivorous by age 2 (Hartman and 
Brandt 1995a). Once the meal has been consumed, the energy derived is devoted to metabolic costs, including growth, and the remainder will be devoted to energy storage. Smaller fish tend to put more energy towards growth to escape predation while larger individuals will put more energy towards storage for use in stressful times (Jobling 1994).

Traditional methods for estimating diets in fish have involved sacrificing the fish or flushing the stomach with water and enumerating the prey items in the stomach (Seaburg 1957). Estimations of diet were based on various metrics including (but not limited to): percent composition by weight or number and frequency of occurrence. From these metrics, indices of preference have been constructed based upon prey taxa prevalence in the stomach and the environment (Bowen 1996). Due to confounding factors such as the presence of chitinous material, prey size, and water temperature (Elliot 1972, Gannon 1976, He and Wurtsbaugh 1993), the rates of digestion for prey taxa are not identical. Therefore, estimations of diet and preference are likely biased, and a more accurate method is needed.

The main constituents of lipids in fish are fatty acids, which hold promise as a chemical marker for tracking diets (Gurr and Hardwood 1991). These fatty acids are directly obtained through the diet and are deposited within the organism with little to no modification (Iverson 1997). They can be tracked as they are cycled through the food web (Iverson 1997), and prey taxa consumed can be identified from the fatty acids present and their relative proportions with respect to other fatty acids (Iverson 2004). Fatty acid analysis offers a good candidate for tracking feeding history for fishes.

One factor that may complicate diet studies is the nutritional needs of various age classes. Juvenile striped bass must consume enough energy to make it through the winter and at the same time grow quickly enough to escape predation by other species. In general, smaller fish put more 
energy towards growth rather than lipid deposition when compared with adult fish (Jobling 1994). Therefore, the fatty acids deposited in the lipid reserves of this species could vary between different age classes of striped bass. Iverson et al. (2002) showed that length of fish was an important indicator of the mass percent of C20:1n11 (gadoleic acid). Therefore, the question of how different size striped bass incorporate fatty acids needs to be clarified.

\section{Objectives}

Different sized fish allocate energy differentially to somatic and gonadal tissue. To evaluate how this may impact fatty acid signature incorporation, we conducted lab experiments with striped bass of three different sizes. Fish were fed the same prey type at the same relative ration (satiation every other day). By standardizing the feeding regime, the process of fatty acid storage across fish size can be determined.

\section{Materials and Methods}

\section{Sample collection and tank experiment}

Forty seven striped bass were placed into 800 gallon tanks based upon their length: 16 fish between 150 - 200 mm (Delmarva Aquatics: Chesapeake-Delaware strain), 16 fish between $300-380 \mathrm{~mm}$, and 15 fish greater than $460 \mathrm{~mm}$. The medium and large sizes of striped bass were collected from Chesapeake Bay tributaries near Oxford, Maryland by hook and line. These fish were transported by boat in a live well to the NOAA/NCCOS/Oxford laboratory in Oxford, Maryland. The tanks were flow through with water being pumped from the Tred Avon River. Water temperature was measured daily (Fig. 1). Fish in each tank were fed a diet of spot (Leiostomus xanthurus) ad libitum every other day for four weeks to approximate $50 \% \mathrm{C}_{\max }$ and 
homogenize the fatty acid signature among all sizes (Fig. 2). After four weeks, the striped bass were fed Atlantic menhaden (Brevoortia tyrannus) ad libitum every other day for four weeks. Four striped bass were sacrificed from each tank on day 0 and 13 with an overdose of tricaine methanesulfonate (MS-222; Western Chemical, Ferndale, WA), weighed (g) and measured (total length in mm), and vacuum sealed with a FoodSaver vacuum sealer (Sunbeam Products, Inc., Niles, IL) and frozen at $-20^{\circ} \mathrm{C}$ until they could be analyzed. Remaining fish in each tank were sampled on day 28 (eight small fish, eight medium fish, and seven large fish).

\section{Sample preparation}

Striped bass were thawed at the time of analysis, and tissue samples were weighed to the nearest 0.1 gram. One sample consisted of three to five grams of adipose tissue located beneath the ribs on the ventral surface, hereafter referred to as belly flap (Jacobs et al. 2008). This tissue has been shown to provide an accurate record of diet in striped bass (Chapter 3). All samples were ground with a chemical drying agent, diatomaceous earth (Dionex, Sunnyvale, CA), and had a known amount of internal standard (C13:0 triacylglycerol) added to determine the efficiency of the extraction process.

Lipids were extracted under nitrogen using an Accelerated Solvent Extractor (ASE 300, Dionex, Sunnyvale, CA) with a mixture of $3: 1(\mathrm{v} / \mathrm{v})$ dichloromethane:methanol and $0.1 \%$ butylated hydroxytoluene (BHT) as an antioxidant. Samples were extracted at $100^{\circ} \mathrm{C}$ and 1500 psi (United States Environmental Protection Agency 2007). Samples were then back-extracted using a $0.88 \%$ potassium chloride solution in deionized water to remove non-lipid materials from extracts (Folch et al. 1957). Total lipid extracted was determined gravimetrically for each sample and reported as a percent of wet weight. 
Extracted lipid species containing fatty acids as various derivatives were transesterified using a solution of sulfuric acid and methanol. In this process, aclyglycerols are broken apart to their constituents: glycerol and fatty acids methyl esters (FAMEs). Free fatty acids present in the lipid mixture are also converted to FAMEs using this process (Christie 2003). Sample extracts were cleaned with silica gel and anhydrous sodium sulfate to remove polar components and water, which may degrade the performance of the gas chromatograph column. The silica column was conditioned with hexane and the sample was added along with hexane and diethyl ether, 95:5, v/v (Christie 2003). The mixture was concentrated to $5 \mathrm{ml}$ and diluted to a final total lipid concentration of $100 \mu \mathrm{g} / \mathrm{ml}$. Finished samples were run on a gas chromatograph (Agilent $6890 \mathrm{~N}$ Network GC System, Santa Clara, CA) / mass spectrometer (GC/MS, Agilent, 5973 Network Mass selective detector, Santa Clara, CA) in select ion monitoring mode.

The GC/MS was used to identify and quantify fatty acid methyl esters in each sample. FAMEs were injected into a fused capillary column, DB-23 $60 \mathrm{~m}$ length X $0.250 \mathrm{~mm}$ OD X $0.25 \mu \mathrm{m}$ film thickness (Agilent, Santa Clara, CA) using an autosampler (Agilent 7683 Series Auto Sampler). Hydrogen was used as a carrier gas. The temperature program was as follows: hold at an initial temp of $50^{\circ} \mathrm{C}$ for $2 \mathrm{~min}$, hold at $150^{\circ} \mathrm{C}$ for $1 \mathrm{~min}$ after ramping at $20^{\circ} \mathrm{C} \cdot \mathrm{min}^{-1}$, ramp at $1.25^{\circ} \mathrm{C} \cdot \min ^{-1}$ until $215^{\circ} \mathrm{C}$. The fatty acid retention times were compared to known standards from Nu-Chek Prep (GLC MIX 85, 411, 642, 632, Elysian, MN). These four standard mixtures were combined along with stearidonic acid (C18:4n3, Cayman Chemical, Ann Arbor, MI) to make a total FAME standard solution of $12.25 \mu \mathrm{g} / \mathrm{ml}$. Matreya 25 FAME mixture (Pleasant Gap, PA) was used to obtain retention times for $\mathrm{C} 18: \ln 9$ trans and $\mathrm{C} 18: 2 \mathrm{n} 6$ trans. Restek cis/trans FAME mixture (Bellefonte, PA) was used to obtain retention times for C20:1n7. These standards and an internal standard of C13:0 $(100 \mu \mathrm{g} / \mathrm{ml})$ were added to quantify the 
amount of each fatty acid methyl ester present. The GC/MS tracks the select ion signature of each compound and was used to verify the identity of each peak. There were peaks which consisted of more than one fatty acid and it was impossible to determine which fatty acid(s) constituted the peaks. Therefore, a term fatty acid "complex" was assigned to this peak. The complex refers to which fatty acids could be responsible for the peak, e.g. C22:3n3 and C22:5n6.

\section{Statistical analyses}

We used an a priori model building (generalized linear model in program $\mathrm{R}[\mathrm{R}$ Development Core Team 2010]) strategy to determine the effects of sampling day, fish weight, and water temperature on the lipid content (as percent of wet weight) of each sample. Models included: 1) a global of all three predictor variables and all interaction terms (including the three interaction term), 2) predictor variables and a single interaction term, 3) a single predictor variable, and 4) a null model that included no predictor variables (Table 1). The Akaike information criterion for small sample size ( $\mathrm{AIC}_{\mathrm{C}}$; Burnham and Anderson 2002) was used to select the best model. A plot of residuals demonstrated that the data violated the assumption of normality. Both the continuous variables weight and lipid content were natural log transformed which corrected the violation of normality. All model building and selection was performed in $\mathrm{R}$ (R Development Core Team 2010).

Indicator fatty acids were identified for the prey types using the relative mass percent of the total. These values were then compared to tissues samples throughout the experiment to determine if striped bass tissues reflected prey values. This technique distinguished the diet switch from spot to menhaden in an earlier chapter (Chapter 3).

Nonmetric multidimensional scaling (NMDS) was also performed on the data (R Development Core Team 2010). This ordination technique is an iterative search for the best 
position of samples in multidimensional space, and uses the stress value as an indicator for the best solution. A distance matrix was calculated for the fatty acids, and the samples are ordinated based on the distances calculated (McCune and Grace 2002).

\section{Results}

\section{Lipid content}

Lipid content (percent wet weight) in striped bass ranged from $2.64-24.66 \%(n=42$, Fig. 3). Lipid levels decreased from day 0 to 13 for the medium and large striped bass, while the small fish showed an increased in lipid content during this same interval. All three size classes showed an increase in lipid content from day 13 to day 28. Large striped bass had the biggest change, with slight increases in both small and medium striped bass. The regression model with the most weight for explaining lipid content was the null model meaning no factor measured adequately predicted lipid levels (Table 1). Temperature and weight were each better models than sampling day.

A difference in weight within a striped bass size class was difficult to discern as the experiment progressed (Fig. 4). Small and large striped bass showed a small increase in weight from day 0 to 13 , followed by slight decrease to day 28. Medium striped bass remained at constant weight from day 0 to 13 , and decreased slightly from day 13 to 28 .

\section{Fatty acids}

A total of 40 fatty acids and one fatty acid complex (C22:3n3 and C22:5n6) were identified in striped bass lipids. The 12 fatty acids C14:0, C16:0, C16:1n7, C18:0, C18:1n9, $\mathrm{C} 18: 1 \mathrm{n} 7 \mathrm{c}, \mathrm{C} 18: 2 \mathrm{n} 6, \mathrm{C} 20: 4 \mathrm{n} 6, \mathrm{C} 20: 5 \mathrm{n} 3, \mathrm{C} 22: 0, \mathrm{C} 22: 5 \mathrm{n} 3$, and $\mathrm{C} 22: 6 \mathrm{n} 3$ accounted for $76.05-$ $88.41 \%$ of the mass percent of fatty acids. These fatty acids accounted for $84.72 \%$ of the mass 
percent of fatty acids present in menhaden tissues fed to striped bass (Table 1). These fatty acids decreased in abundance from day 0 to day 28 for all size classes; 87.82 to $76.05 \%$ for small fish, 88.41 to $83.76 \%$ for medium fish, and 87.09 to $77.27 \%$ for large striped bass.

The nonmetric multidimensional scaling indicated that no discernible change was evident in striped bass belly flap tissue as they were fed menhaden (Fig. 5). The samples from each size class were clustered in one area regardless of the sampling day. Samples moving away from the cluster appear to move neither towards menhaden or spot. Two samples, a small striped bass from day 28 and a large fish from day 13, are extreme outliers compared to the rest of the samples.

Relative abundances of certain fatty acids have the ability to distinguish a diet switch in striped bass from a diet of spot to one of menhaden (Chapter 3). When the striped bass tissues were analyzed for these marker fatty acids, no pattern of fatty acid incorporation was apparent (Fig. 6). Many of these indicator fatty acids did not change between the sampling days for all three size classes of striped bass. The fatty acid complex C22:3n3 and C22:5n6 changed its relative abundance for medium striped bass in the opposite direction that the diet fatty acids would indicate. This same fatty acid complex did follow a decreasing pattern in large striped bass.

\section{Discussion}

Energy that is yielded from the diet is used for metabolic processes and the remainder is stored within the organism. These storage molecules will contain fatty acid trophic markers (FATMs; Graeve et al. 1994, Dalsgaard et al. 2003) indicative of feeding history, and they should change based upon the prey being consumed (Iverson 2009). Fatty acids within striped 
bass belly flap tissue should have recorded the diet change from spot to menhaden during our experiment. It is apparent that other factors, e.g. reduced feeding or temperature, prevented definitive conclusions from being made in this experiment. However, we still were able to gain valuable insight into fatty acid incorporation within varying sizes of striped bass.

Lipid stores accumulate once the energetic needs of the organism have been met first. The Atlantic menhaden feed had higher lipid content (11.75\% wet weight) than spot (6.05\% wet weight) which should have resulted in lipid content increases in striped bass tissues (Refstie et al. 2001). Decreases in lipid content were evident after the experiment had progressed for a period of 13 days for two size classes of fish. Removal of lipid stores would suggest that feeding is reduced or absent, and the fish is relying on stored lipids for metabolic costs (Maddock and Burton 1994). Fish that are fed ad libitum should have stable lipid levels, if not show an increase. Jacobs et al. (2008) fed striped bass ad libitum three times a week while keeping the temperature constant at $19^{\circ} \mathrm{C}$, and whole body lipid levels increased on each subsequent sampling period (21 and 42 days). Fish that had a decrease in lipids were fish that were starved for the duration of the experiment. The European seabass (Dicentrarchus labrax), also a member of the family Moronidae, exhibited progressive declines in lipids as starvation set in (Stirling 1976). These studies indicate fish that are not feeding will show a concomitant decrease in lipid levels within the body. The results seen in our experiment demonstrate decreases in lipid levels for part of the experiment, which means striped bass were relying on stored lipids. The increase after day 13 suggests that fish began to replace the depleted lipid stores.

According to Hartman and Brandt (1995b), water temperature affects the specific growth rate of striped bass fed at maximum consumption, regardless of size, although larger fish seem to have a broader range of temperatures at which they experience optimal growth. Cox and Coutant 
found that juvenile striped bass fed at $60 \%$ ration and $16^{\circ} \mathrm{C}$ still experienced positive growth rates. The incidence of lower growth suggests that temperature may not have been the reason for lack of lipid accumulation and weight gain. Rather, the reduced or absence of feeding may be responsible.

Previous studies of fatty acid signature incorporation have suggested that the predator fatty acids should begin to mimic that of the prey (Seaborn et al. 2000, Turner and Rooker 2005). The change of signature has been shown to occur within two to three weeks (Kirsch et al. 1998). Several fatty acids were at similar levels as they were within spot tissues on day 0 (Fig. 2), but not all fatty acids. This suggests that the signature of the prey was never completely expressed within the predator tissue. We have demonstrated that the entire fatty acid signature of striped bass tissues did not change under the conditions tested, but rather marker fatty acids are indicative of a prey switch (Chapter 3). However, in this experiment, when looking at those marker fatty acids that distinguish between the two prey types, there is not a clear pattern of change in the proportions of these fatty acids in any size of striped bass. There is an exception with two fatty acids, $\mathrm{C} 22: 3 \mathrm{n} 3+\mathrm{C} 22: 5 \mathrm{n} 6$ in large fish and $\mathrm{C} 20: 2 \mathrm{n} 6$ in medium fish. It is difficult to ascertain what constitutes normal fluctuations within each size group without knowing the degree to which individual fish were eating and how temperature affected the fish.

Water visibility within the tanks was low due to unfiltered water being pumped in directly from the Tred Avon River. The initiation and cessation of feeding was difficult to determine due to this factor. Because some of these fish were wild caught, they may never have taken to feeding while housed in the tanks, although it is possible for hook and line captured fish to be habituated to feeding in captivity, e.g. white bass Morone chrysops (Kohler et al. 1994). This difficulty highlights a problem that may be prevalent within the bay ecosystem. Wild fish 
often will experience degraded conditions or periods of low temperature, in which feeding becomes diminished. Unlike marine mammals which have a large blubber layer, and hence a large fatty acid deposit to call upon, piscivorous fish lipid supplies are most likely not as extensive. This would not be an issue if all fatty acids were used equally. However, during periods of starvation, fatty acids will be differentially mobilized depending on the tissue (Jezierska et al. 1982) which could explain the decreases in striped bass fatty acids that were abundant in menhaden tissues. As the lipid supplies are relied upon more heavily, the signature will become skewed farther away from the original signature.

While the experiment did not yield discernible patterns of fatty acid incorporation, it does offer an opportunity for further research. All three size classes of striped bass were exposed to the same temperature, and provided with the same proportion of food, but they did not respond in a similar manner. Medium and large size classes lost lipid from day 13 to 28 while small fish were able to maintain a slight increase throughout the experiment.

The practice of using fatty acids in food web studies has been used successfully in other studies, including fish. The limiting step of this technique appears to be that fish need to be feeding at sufficiently high rates in order for the fatty acid signature of the prey taxa to become incorporated into predator tissue. Periods of low feeding will cause signatures to be skewed away from the prey, leading to erroneous conclusions about the diet. It is suggested that this technique only be used during bouts of known feeding until more research can be done to determine correction factors for lowered feeding due to stress and low temperatures. 


\section{Acknowledgments}

The authors would like to thank J. Price, J. Councilman, A. Leight, J. Brush, and W. Lowery for assistance in collecting samples. We are also indebted to B. Dockum and L. Gonsalves for advice and assistance in the chemical analysis of samples. E. Chambers provided invaluable help in the laboratory preparing and analyzing samples. We are grateful for the comments provided by anonymous reviewers. This research was made possible by funding from NOAA Chesapeake Bay Office Grant No. NA07NMF4570330 and all research was conducted under Animal Care and Use Protocol number 09-0102. 


\section{Literature cited}

Boynton, R.W., T.T. Polgar, and H. Zion. 1981. Importance of juvenile striped bass food habits in the Potomac Estuary. Transactions of the American Fisheries Society 110:56-63.

Burnham, K.P., and D.R. Anderson. 2002. Model selection and multi-model inference. $2^{\text {nd }}$ ed. Springer, Berlin, Germany. 496pp.

Christie, W.M. 2003. Lipid Analysis. PJ Barnes and Associates. Bridgewater, England.

Cox, D. K., and C. C. Coutant. 1981. Growth dynamics of juvenile striped bass as functions of temperature and ration. Transactions of the American Fisheries Society 110:226-238.

Dalsgaard, J. M. S. J., G. Kattner, D. Muller-Navarra, and W. Hagen. 2003. Fatty acid trophic markers in the pelagic marine environment. Advances in Marine Biology 46.

Folch, J., M. Lees, and G.H. Sloane Stanley. 1957. A simple method for the isolation and purification of total lipids from animal tissues. The Journal of Biological Chemistry:497509.

Graeve, M., G. Kattner, and W. Hagen. 1994. Diet-induced changes in the fatty acid composition of Arctic herbivorous copepods: experimental evidence of trophic markers. Journal of Experimental Marine Biology and Ecology 182:97-110.

Gurr, M.I. and J.L. Hardwood. 1991. Lipid biochemistry: an introduction. $4^{\text {th }}$ ed. Chapman and Hall. London, England.

Hartman, K. J., and S. B. Brandt. 1995a. Trophic resource partioning, diets, and growth of sympatric estuarine predators. Transactions of the American Fisheries Society 124:520537. 
Hartman, K. J., and S. B. Brandt. 1995b. Comparative energetics and the development of bioenergetics models for sympatric estuarine piscivores. Canadian Journal of Fisheries and Aquatic Sciences 52:1647-1666.

Iverson, S. J. 2009. Tracing aquatic food webs using fatty acids: from qualitative indicators to quantitative determination. Pages 281-307 in M. T. Arts, editor. Lipids in aquatic ecosystems. Springer Science.

Iverson, S.J., K.J. Frost, and L.L. Lowry. 1997. Fatty acid signatures reveal fine scale structure of foraging distribution of harbor seals and their prey in Prince William Sound, Alaska. Marine Ecology Progress Series 151: 255-271.

Iverson, S. J., K.J. Frost, and S.L.C. Lang. 2002. Fat content and fatty acid composition of forage fish and invertebrates in Prince William Sound, Alaska: factors contributing to among and within species variability. Marine Ecology Progress Series 241:161-181.

Iverson, S. J., C. Field, W.D. Bowen, and W. Blanchard. 2004. Quantitative fatty acid signature analysis: a new method of estimating predator diets. Ecological Monographs 74:211-235.

Jacobs, J. M., M.R. Rhodes, B. Martin, D. McIntosh, W.F. Van Heukelem, and R.M. Harrell. 2008. Tissue-specific sampling for estimation of striped bass whole-body proximate composition. Transactions of the American Fisheries Society 137:386-392.

Jezierska, B., J.R. Hazel, and S.D. Gerking. 1982. Lipid mobilization during starvation in the rainbow trout, Salmo gairdneri, with attention to fatty acids. Journal of Fish Biology 21:681-692.

Jobling, M. 1994. Fish Bioenergetics. Chapman and Hall. London, England. 
Jones, P.W., J.S. Wilson, R.P. Morgan, H.R. Lunsford, and J. Lawson. 1977. Potomac River fisheries study - striped bass spawning stock assessment - interpretative report for 1974 through 1976. Chesapeake Biological Lab. UMCEES Ref. No. 77-55 CBL.

Kirsch, P. E., S.J. Iverson, W.D. Bowen, S.R. Kerr, and R.G. Ackman. 1998. Dietary effects on the fatty acid signature of whole Atlantic cod (Gadus morhua). Canadian Journal of Fisheries and Aquatic Sciences 55:1378-1386.

Kohler, C.C., R.J. Sheehan, C. Habicht, J.A. Malison, and T.B. Kayes. 1994. Habituation to captivity and controlled spawning of white bass. Transactions of the American Fisheries Society 123:964-974.

Maddock, D.M. and M.P.M. Burton. 1994. Some effects of starvation on the lipid and skeletal muscle layers of the winter flounder, Pleuronectes americanus. Canadian Journal of Zoology 72:1672-1679.

Maryland Department of Natural Resources (MD DNR). 1987. Maryland striped bass research. Final report: Project AFC - 15 Segment 1. September 1987. Tidewater Administration, Fisheries Division, Annapolis, MD.

McCune, B. and J.B. Grace. 2002. Analysis of Ecological Communities. MjM Software Design, Gleneden Beach, OR.

R Development Core Team (2008). R: A language and environment for statistical computing. R Foundation for Statistical Computing, Vienna, Austria. ISBN 3-900051-07-0, URL http://www.R-project.org.

Refstie, S. T. Storebakken, G. Baeverfjord, and A.J. Roem. 2001. Long-term protein and lipid growth of Atlantic salmon (Salmo salar) fed diets with partial replacement of fish meal by soy protein products at medium or high lipid level. Aquaculture 193:91-106. 
Seaborn, G. T. M. L. J., and T.I.J. Smith. 2000. Differentiation between cultured hybrid striped bass and wild striped bass and hybrid bass using fatty acid profiles. North American Journal of Fisheries Management 20:618-626.

Setzler-Hamilton, E. M., and L. H. H. Jr. 1991. Striped bass (Morone saxitilis). Pages 13.1113.27 in S. L. Funderburk, S.J. Jordan, J.A. Mihursky, and D. Riley, editor. Habitat requirements for Chesapeake Bay living resources. Chesapeake Research Consortium, Solomons, MD.

Stirling, H.P. 1976. Effects of experimental feeding and starvation on the proximate composition of the European bass Dicentrarchus labrax. Marine Biology 35:85-91.

Turner, J. P., and J. R. Rooker. 2005. Effect of dietary fatty acids on the body tissues of larval and juvenile cobia and their prey. Journal of Experimental Marine Biology and Ecology $322: 13-27$.

Uphoff Jr., J. H. 2003. Predator-prey analysis of striped bass and Atlantic menhaden in upper Chesapeake Bay. Fisheries Management and Ecology 10:313-322.

United States Environmental Protection Agency (USEPA). 2007. Pressurized fluid extraction (PFE). USEPA SW-846. Method 3545A, Update IV. Washington, D.C. 
Table 1. Summary of model selection statistics for lipid percent in samples; K represents the number of parameters in the model; $\Delta \mathrm{AIC}_{\mathrm{c}}$ represents the difference between the $\mathrm{AIC}_{\mathrm{c}}$ value for that model and the set's minimum $\mathrm{AIC}_{\mathrm{c}}$ value; W represents the Akaike weight of each model.

\begin{tabular}{lccc}
\hline Model & $\mathrm{K}$ & $\Delta \mathrm{AICc}$ & $\mathrm{W}$ \\
\hline Null & 2 & 0 & 0.5 \\
$\mathrm{~T}^{\mathrm{A}}$ & 3 & 2.24 & 0.16 \\
$\mathrm{We}$ & 3 & 2.3 & 0.16 \\
$\mathrm{D}$ & 4 & 3.21 & 0.1 \\
$\mathrm{D}+\mathrm{T}$ & 5 & 5.53 & 0.03 \\
$\mathrm{D}+\mathrm{We}$ & 5 & 5.73 & 0.03 \\
$\mathrm{D}+\mathrm{We}+\mathrm{T}$ & 6 & 8.24 & 0.01 \\
$\mathrm{D}+\mathrm{We}+\mathrm{T}+\mathrm{D}{ }^{*} \mathrm{We}$ & 8 & 13.52 & 0 \\
$\mathrm{D}+\mathrm{We}+\mathrm{T}+\mathrm{D} * \mathrm{We}+\mathrm{D} * \mathrm{~T}+\mathrm{W} * \mathrm{~T}$ & 11 & 22.03 & 0 \\
$\mathrm{D}+\mathrm{We}+\mathrm{T}+\mathrm{D} * \mathrm{We}+\mathrm{D} * \mathrm{~T}+\mathrm{We} \mathrm{T}+\mathrm{D} * \mathrm{We} \mathrm{T}$ & 13 & 28.49 & 0 \\
${ }^{\mathrm{A}}$ Model terms are temperature $(\mathrm{T})$, weight $(\mathrm{We})$, and sampling day $(\mathrm{D})$.
\end{tabular}


Table 2. Mean fatty acid concentrations expressed as a mass percent of all fatty acids present \pm 1 standard error of the mean; nd $=$ not detected. The fatty acids shown are for the prey item, spot, and the tissues collected from striped bass days 0 through 40 . Unless specified, all unsaturated fatty acids have cis configuration.

\begin{tabular}{|c|c|c|c|c|c|c|c|c|c|c|}
\hline \multirow[b]{2}{*}{ Fatty acid } & \multirow[b]{2}{*}{ Menhaden } & \multicolumn{3}{|c|}{$\underline{\text { Small }}$} & \multicolumn{3}{|c|}{$\underline{\text { Medium }}$} & \multicolumn{3}{|c|}{$\underline{\text { Large }}$} \\
\hline & & Day 0 & Day 13 & Day 28 & Day 0 & Day 13 & Day 28 & Day 0 & Day 13 & Day 28 \\
\hline $\mathrm{C} 12: 0$ & $0.26 \pm 0.04$ & $0.15 \pm 0.04$ & $0.06 \pm 0.03$ & $0.44 \pm 0.33$ & $0.06 \pm 0.02$ & $0.06 \pm 0.03$ & $0.10 \pm 0.03$ & $0.07 \pm 0.04$ & $0.18 \pm 0.13$ & $0.10 \pm 0.02$ \\
\hline C13:0 & $0.40 \pm 0.07$ & $0.40 \pm 0.03$ & $0.11 \pm 0.07$ & $0.38 \pm 0.24$ & $0.26 \pm 0.08$ & $0.16 \pm 0.11$ & $0.53 \pm 0.19$ & $0.53 \pm 0.33$ & $0.09 \pm 0.09$ & $5.74 \pm 5.39$ \\
\hline $\mathrm{C} 14: 0$ & $7.30 \pm 0.51$ & $4.36 \pm 0.28$ & $4.43 \pm 0.14$ & $3.08 \pm 0.62$ & $3.68 \pm 0.08$ & $3.99 \pm 0.12$ & $3.40 \pm 0.29$ & $4.12 \pm 0.27$ & $3.97 \pm 0.47$ & $3.31 \pm 0.81$ \\
\hline $\mathrm{C} 14: \ln 5$ & $0.05 \pm 0.02$ & $0.13 \pm 0.02$ & $0.07 \pm 0.04$ & $0.08 \pm 0.03$ & $0.14 \pm 0.03$ & $0.19 \pm 0.03$ & $0.19 \pm 0.06$ & $0.09 \pm 0.05$ & $0.46 \pm 0.25$ & $0.14 \pm 0.03$ \\
\hline C15:0 & $2.07 \pm 0.3$ & $1.37 \pm 0.11$ & $1.39 \pm 0.12$ & $1.25 \pm 0.14$ & $1.19 \pm 0.05$ & $1.32 \pm 0.05$ & $1.23 \pm 0.18$ & $1.30 \pm 0.08$ & $1.44 \pm 0.18$ & $0.87 \pm 0.20$ \\
\hline C16: 0 DMA & $0.51 \pm 0.1$ & $0.39 \pm 0.03$ & $0.69 \pm 0.31$ & $0.45 \pm 0.12$ & $0.36 \pm 0.09$ & $0.41 \pm 0.05$ & $0.53 \pm 0.10$ & $0.41 \pm 0.07$ & $0.64 \pm 0.22$ & $0.60 \pm 0.20$ \\
\hline C16:0 & $34.82 \pm 0.42$ & $26.52 \pm 0.23$ & $27.14 \pm 1.55$ & $23.83 \pm 3.07$ & $27.11 \pm 0.46$ & $27.77 \pm 0.67$ & $26.27 \pm 1.71$ & $26.94 \pm 1.15$ & $25.44 \pm 1.88$ & $23.54 \pm 3.02$ \\
\hline $\mathrm{C} 16: \ln 7$ & $5.51 \pm 0.16$ & $7.00 \pm 0.37$ & $6.79 \pm 0.14$ & $5.06 \pm 0.65$ & $6.59 \pm 0.23$ & $6.62 \pm 0.23$ & $6.16 \pm 0.56$ & $7.55 \pm 0.32$ & $5.44 \pm 0.88$ & $6.38 \pm 1.34$ \\
\hline $\mathrm{C} 17: 0$ & $1.81 \pm 0.16$ & $1.27 \pm 0.06$ & $1.48 \pm 0.16$ & $1.19 \pm 0.09$ & $1.13 \pm 0.03$ & $1.30 \pm 0.05$ & $1.13 \pm 0.11$ & $1.18 \pm 0.07$ & $2.00 \pm 0.60$ & $1.11 \pm 0.14$ \\
\hline C18:0 & $7.31 \pm 0.37$ & $6.40 \pm 0.26$ & $7.24 \pm 0.34$ & $6.70 \pm 0.87$ & $6.09 \pm 0.33$ & $6.55 \pm 0.21$ & $6.79 \pm 0.32$ & $6.59 \pm 0.44$ & $9.10 \pm 1.22$ & $6.20 \pm 0.28$ \\
\hline $\mathrm{C} 18: \ln 12 \mathrm{t}$ & $0.15 \pm 0.05$ & $0.88 \pm 0.11$ & $0.82 \pm 0.23$ & $0.49 \pm 0.19$ & $0.62 \pm 0.11$ & $0.52 \pm 0.02$ & $0.62 \pm 0.03$ & $0.67 \pm 0.04$ & $0.47 \pm 0.17$ & $0.46 \pm 0.09$ \\
\hline $\mathrm{C} 18: \ln 9 \mathrm{t}$ & $0.14 \pm 0.05$ & nd & nd & $0.33 \pm 0.12$ & $0.19 \pm 0.11$ & $0.09 \pm 0.09$ & $0.19 \pm 0.07$ & $0.10 \pm 0.10$ & nd & $1.38 \pm 1.05$ \\
\hline $\mathrm{C} 18: \ln 7 \mathrm{t}$ & nd & $0.04 \pm 0.04$ & $0.14 \pm 0.14$ & nd & nd & $0.03 \pm 0.03$ & $0.04 \pm 0.02$ & nd & nd & $0.19 \pm 0.19$ \\
\hline C18:1n9 & $6.98 \pm 0.31$ & $14.34 \pm 0.18$ & $15.70 \pm 0.54$ & $11.92 \pm 1.73$ & $15.78 \pm 1.20$ & $16.25 \pm 0.40$ & $15.94 \pm 1.16$ & $17.32 \pm 0.79$ & $12.90 \pm 1.29$ & $15.61 \pm 2.44$ \\
\hline $\mathrm{C} 18: \ln 7$ & $2.21 \pm 0.10$ & $4.22 \pm 0.17$ & $3.53 \pm 0.06$ & $4.67 \pm 1.44$ & $3.88 \pm 0.12$ & $3.55 \pm 0.04$ & $3.92 \pm 0.25$ & $4.07 \pm 0.16$ & $3.91 \pm 0.52$ & $3.49 \pm 0.71$ \\
\hline $\mathrm{C} 18: 2 \mathrm{n} 6 \mathrm{t}$ & nd & nd & $0.39 \pm 0.39$ & $0.60 \pm 0.46$ & nd & nd & nd & nd & nd & nd \\
\hline C18:2n6 & $2.42 \pm 0.25$ & $2.52 \pm 0.30$ & $2.37 \pm 0.35$ & $1.54 \pm 0.17$ & $1.57 \pm 0.11$ & $1.93 \pm 0.16$ & $1.52 \pm 0.29$ & $1.75 \pm 0.43$ & $2.46 \pm 1.31$ & $1.86 \pm 0.37$ \\
\hline C18:3n6 & $0.42 \pm 0.20$ & nd & $0.06 \pm 0.04$ & $0.24 \pm 0.10$ & $0.03 \pm 0.03$ & $0.12 \pm 0.04$ & $0.11 \pm 0.04$ & $0.03 \pm 0.03$ & $0.05 \pm 0.05$ & $0.29 \pm 0.15$ \\
\hline C18:3n3 & $1.15 \pm 0.18$ & $0.92 \pm 0.07$ & $0.97 \pm 0.04$ & $0.69 \pm 0.14$ & $0.88 \pm 0.04$ & $0.96 \pm 0.09$ & $0.81 \pm 0.12$ & $1.00 \pm 0.14$ & $0.80 \pm 0.36$ & $0.71 \pm 0.18$ \\
\hline $\mathrm{C} 18: 4 \mathrm{n} 3$ & $2.81 \pm 0.19$ & $0.69 \pm 0.07$ & $0.82 \pm 0.29$ & $1.31 \pm 0.50$ & $0.53 \pm 0.02$ & $0.72 \pm 0.07$ & $0.62 \pm 0.13$ & $0.56 \pm 0.05$ & $0.73 \pm 0.29$ & $0.98 \pm 0.32$ \\
\hline C19:2n6 & $0.24 \pm 0.22$ & nd & $0.02 \pm 0.02$ & $0.40 \pm 0.30$ & nd & $0.01 \pm 0.01$ & $0.06 \pm 0.02$ & nd & $0.58 \pm 0.43$ & $0.69 \pm 0.63$ \\
\hline C20:0 & $1.14 \pm 0.19$ & $1.14 \pm 0.01$ & $1.43 \pm 0.10$ & $2.05 \pm 0.69$ & $1.17 \pm 0.03$ & $1.29 \pm 0.07$ & $1.28 \pm 0.07$ & $1.32 \pm 0.02$ & $1.95 \pm 0.45$ & $1.46 \pm 0.28$ \\
\hline C20:1n15 & nd & $0.02 \pm 0.02$ & $0.22 \pm 0.20$ & $0.36 \pm 0.23$ & nd & $0.05 \pm 0.03$ & $0.12 \pm 0.06$ & nd & nd & $0.45 \pm 0.39$ \\
\hline $\mathrm{C} 20: \ln 12$ & $0.01 \pm 0.01$ & nd & nd & $1.07 \pm 0.80$ & nd & nd & nd & nd & nd & nd \\
\hline C20:1n9 & $0.01 \pm 0.01$ & $1.34 \pm 0.11$ & $1.85 \pm 0.08$ & $2.06 \pm 0.04$ & $1.38 \pm 0.03$ & $1.69 \pm 0.03$ & $1.89 \pm 0.13$ & $1.70 \pm 0.08$ & $1.65 \pm 0.56$ & $1.78 \pm 0.38$ \\
\hline $\mathrm{C} 20: \ln 7$ & $0.03 \pm 0.02$ & $1.38 \pm 0.16$ & $1.73 \pm 0.13$ & $1.23 \pm 0.15$ & $1.13 \pm 0.06$ & $1.38 \pm 0.07$ & $1.36 \pm 0.11$ & $1.36 \pm 0.16$ & $1.29 \pm 0.47$ & $1.42 \pm 0.17$ \\
\hline
\end{tabular}


Table 2 continued.

\begin{tabular}{|c|c|c|c|c|c|c|c|c|c|c|}
\hline \multirow[b]{2}{*}{ Fatty acid } & \multirow[b]{2}{*}{ Menhaden } & \multicolumn{3}{|c|}{$\underline{\text { Small }}$} & \multicolumn{3}{|c|}{$\underline{\text { Medium }}$} & \multicolumn{3}{|c|}{$\underline{\text { Large }}$} \\
\hline & & Day 0 & Day 13 & Day 28 & Day 0 & Day 13 & Day 28 & Day 0 & Day 13 & Day 28 \\
\hline C20:2n6 & $0.01 \pm 0.01$ & $0.66 \pm 0.05$ & $1.10 \pm 0.34$ & $0.66 \pm 0.24$ & $0.59 \pm 0.00$ & $0.76 \pm 0.04$ & $0.77 \pm 0.07$ & $0.64 \pm 0.05$ & $0.62 \pm 0.21$ & $0.73 \pm 0.09$ \\
\hline C20:3n6 & $0.08 \pm 0.04$ & $0.09 \pm 0.03$ & $0.07 \pm 0.04$ & $0.91 \pm 0.40$ & $0.12 \pm 0.02$ & $0.28 \pm 0.05$ & $0.17 \pm 0.05$ & $0.06 \pm 0.04$ & $1.01 \pm 0.82$ & $0.17 \pm 0.06$ \\
\hline $\mathrm{C} 20: 4 \mathrm{n} 6$ & $1.04 \pm 0.12$ & $2.36 \pm 0.08$ & $2.27 \pm 0.06$ & $1.48 \pm 0.34$ & $2.11 \pm 0.19$ & $2.05 \pm 0.12$ & $2.33 \pm 0.19$ & $2.30 \pm 0.08$ & $1.78 \pm 0.60$ & $1.65 \pm 0.36$ \\
\hline $\mathrm{C} 20: 3 \mathrm{n} 3$ & nd & $0.39 \pm 0.04$ & $0.34 \pm 0.13$ & $0.43 \pm 0.19$ & $0.38 \pm 0.03$ & $0.38 \pm 0.01$ & $0.39 \pm 0.03$ & $0.29 \pm 0.04$ & $0.47 \pm 0.18$ & $0.75 \pm 0.48$ \\
\hline $\mathrm{C} 20: 5 \mathrm{n} 3$ & $7.18 \pm 0.34$ & $5.27 \pm 0.22$ & $3.79 \pm 0.22$ & $2.66 \pm 0.71$ & $4.91 \pm 0.18$ & $3.79 \pm 0.41$ & $3.60 \pm 0.21$ & $4.17 \pm 0.28$ & $2.29 \pm 0.82$ & $3.47 \pm 0.51$ \\
\hline $\mathrm{C} 22: 0$ & $0.15 \pm 0.05$ & $1.77 \pm 0.13$ & $1.68 \pm 0.08$ & $3.18 \pm 1.15$ & $2.00 \pm 0.09$ & $1.74 \pm 0.06$ & $1.94 \pm 0.26$ & $1.72 \pm 0.06$ & $1.40 \pm 0.47$ & $2.04 \pm 0.29$ \\
\hline $\mathrm{C} 22: \ln 9$ & nd & $0.16 \pm 0.03$ & $0.28 \pm 0.14$ & $1.36 \pm 0.47$ & $0.23 \pm 0.01$ & $0.29 \pm 0.07$ & $0.48 \pm 0.17$ & nd & $0.70 \pm 0.30$ & $0.32 \pm 0.05$ \\
\hline $\mathrm{C} 22: 2 \mathrm{n} 6$ & $0.22 \pm 0.09$ & nd & $0.11 \pm 0.11$ & $0.64 \pm 0.27$ & $0.01 \pm 0.01$ & $0.17 \pm 0.09$ & $0.17 \pm 0.10$ & nd & $0.77 \pm 0.71$ & $0.35 \pm 0.24$ \\
\hline $\mathrm{C} 22: 4 \mathrm{n} 6$ & nd & $0.63 \pm 0.02$ & $0.47 \pm 0.16$ & $1.69 \pm 0.57$ & $0.45 \pm 0.13$ & $0.76 \pm 0.18$ & $0.90 \pm 0.27$ & $0.79 \pm 0.11$ & $2.55 \pm 1.79$ & $0.80 \pm 0.19$ \\
\hline $\mathrm{C} 22: 3 \mathrm{n} 3+\mathrm{C} 22: 5 \mathrm{n} 6$ & $0.14 \pm 0.04$ & $0.73 \pm 0.05$ & $0.13 \pm 0.13$ & $1.53 \pm 0.69$ & $0.53 \pm 0.15$ & $1.10 \pm 0.34$ & $1.46 \pm 0.61$ & $0.66 \pm 0.05$ & $0.83 \pm 0.36$ & $0.54 \pm 0.11$ \\
\hline $\mathrm{C} 22: 5 \mathrm{n} 3$ & $1.31 \pm 0.09$ & $1.96 \pm 0.03$ & $2.02 \pm 0.17$ & $3.39 \pm 1.24$ & $2.44 \pm 0.06$ & $1.87 \pm 0.22$ & $2.41 \pm 0.60$ & $1.77 \pm 0.58$ & $3.36 \pm 2.02$ & $1.41 \pm 0.46$ \\
\hline C22:6n3 & $8.64 \pm 0.88$ & $11.09 \pm 0.58$ & $7.87 \pm 0.68$ & $8.54 \pm 2.19$ & $12.25 \pm 1.35$ & $8.86 \pm 0.49$ & $9.48 \pm 2.22$ & $8.77 \pm 0.60$ & $6.62 \pm 1.61$ & $8.31 \pm 1.62$ \\
\hline C24:1n9 & $0.25 \pm 0.08$ & $0.31 \pm 0.02$ & $0.30 \pm 0.10$ & $0.76 \pm 0.42$ & $0.43 \pm 0.08$ & $0.70 \pm 0.30$ & $1.03 \pm 0.85$ & $0.16 \pm 0.06$ & $1.07 \pm 0.65$ & $0.37 \pm 0.08$ \\
\hline
\end{tabular}


Figure 1. Water temperature for the experimental tanks throughout the experiment. The dashed line represents the day on which the diet was switched from the baseline prey of spot to that of the experimental prey of menhaden.

Figure 2. Baseline fatty acid signature of all three size classes of striped bass after four weeks of being fed spot.

Figure 3. Lipid content of the three size classes of striped bass analyzed. Spot was fed as a baseline prey for four weeks prior to the start of the experiment. Starting on day zero, menhaden was used as the experimental prey. Error bars represent 1 standard error of the mean.

Figure 4. Wet weight of striped bass from each sampling day. Error bars represent 1 standard error of the mean.

Figure 5. Nonmetric multidimensional scaling of fatty acid signatures for striped bass, the baseline prey, spot, and the experimental prey, menhaden. Size class of fish is denoted as Sm for small, Med for medium, and Lg for large. The sampling days for each size class are denoted as 0 is day 0,13 is day 13 , and 28 is day 28 . MH refers to menhaden fed as the experimental prey. 
Figure 6. Patterns in abundance of select fatty acids for the three sizes of striped bass and the prey species fed during this experiment. Abundance is based upon mass percent of total fatty acids. 
Figure 1.

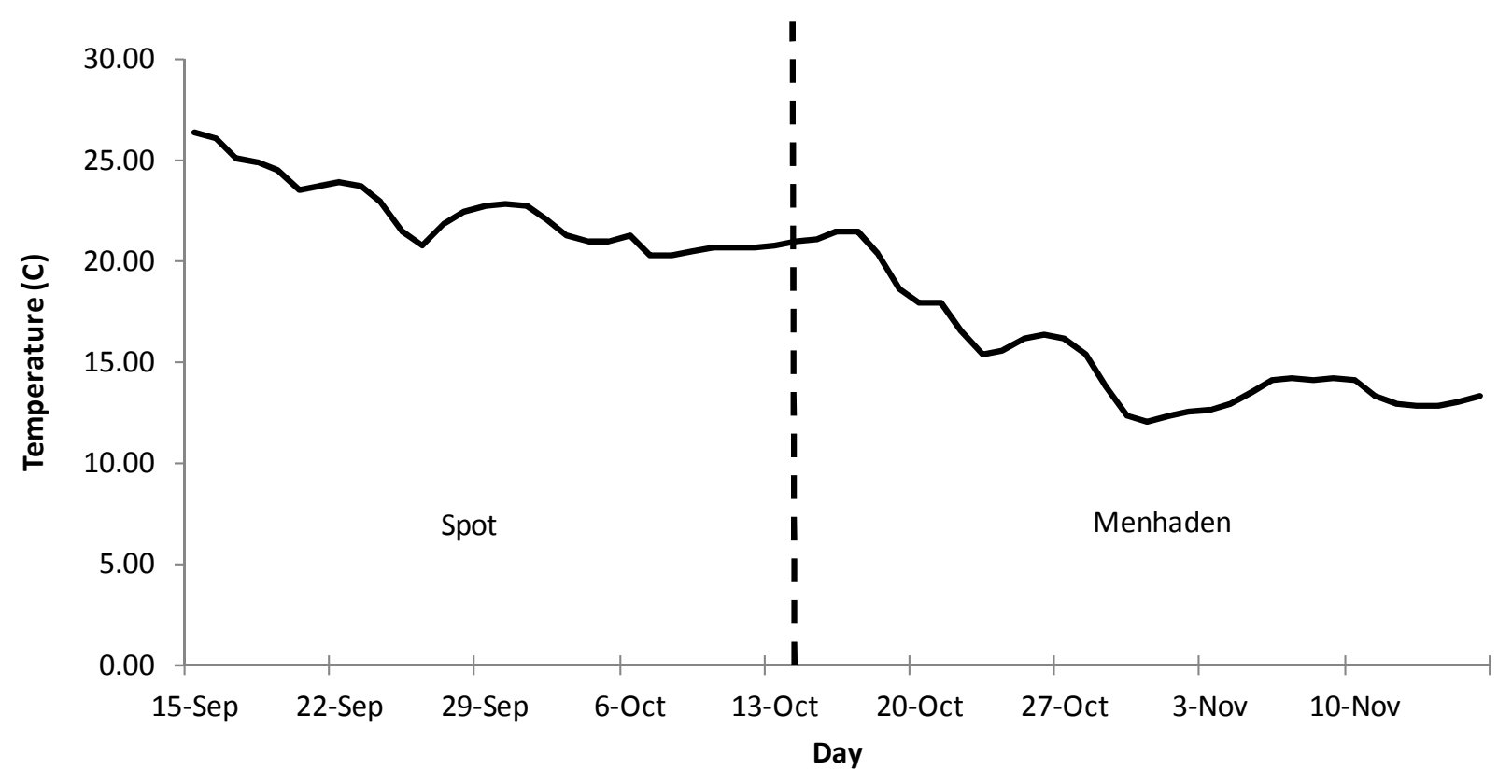


Figure 2.

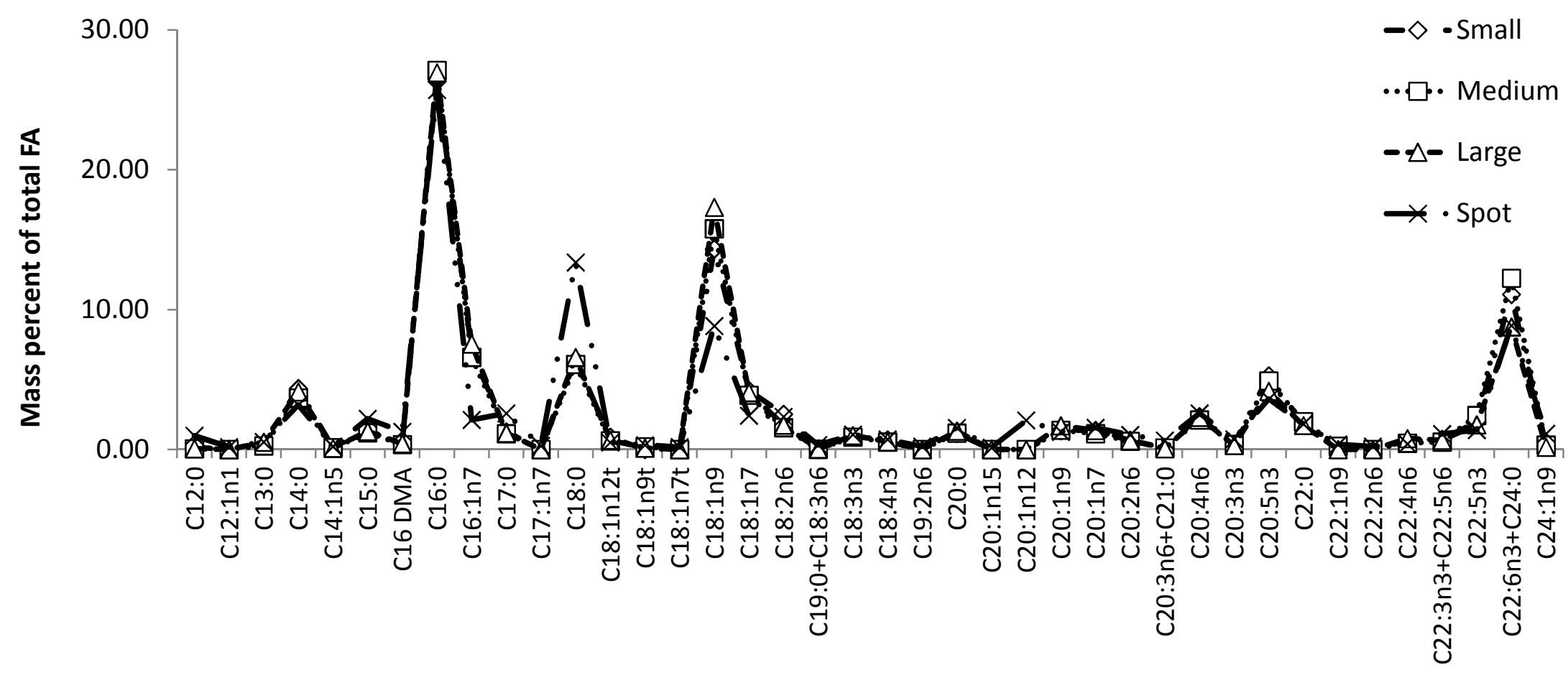

Fatty acid 
Figure 3.

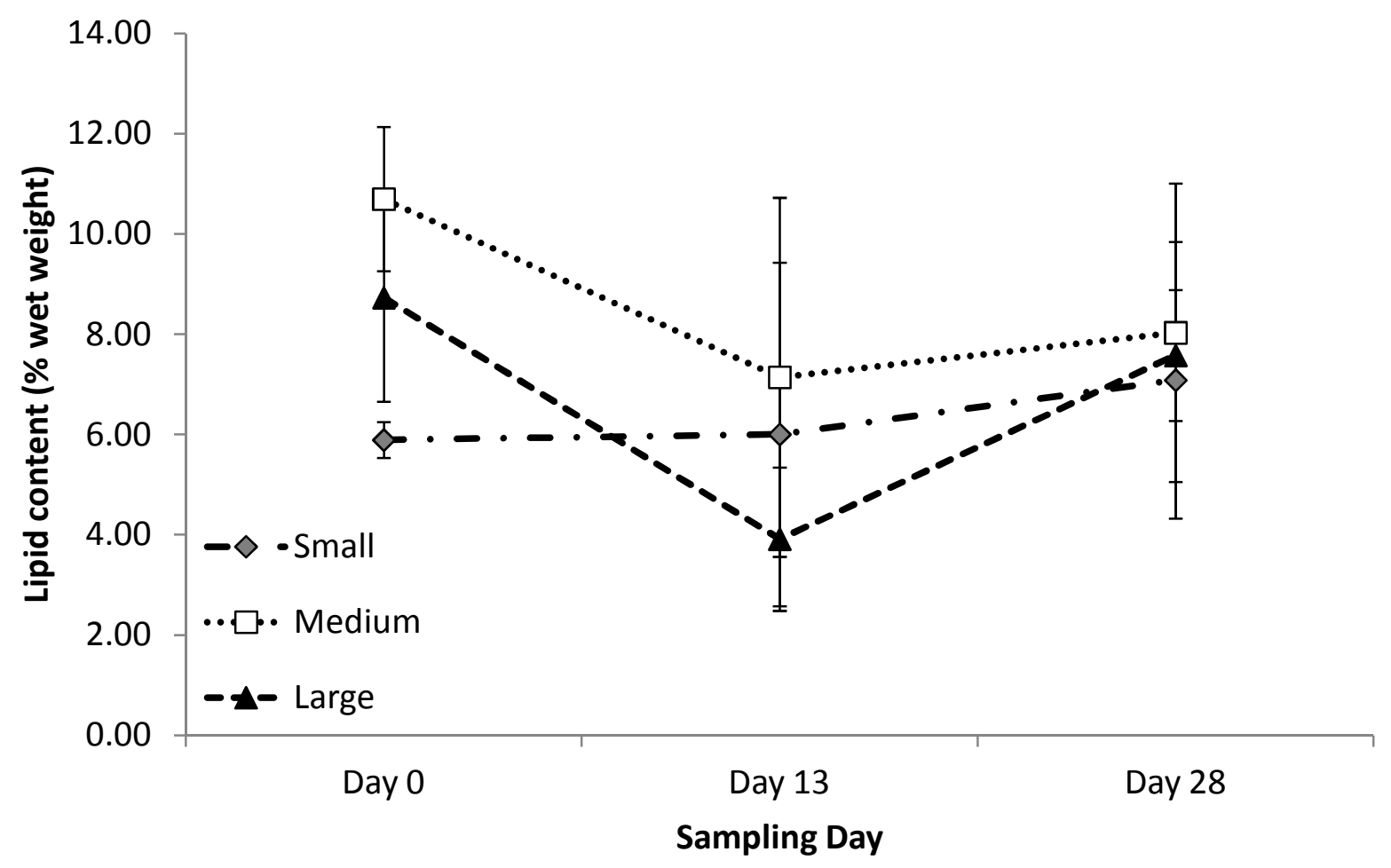


Figure 4.

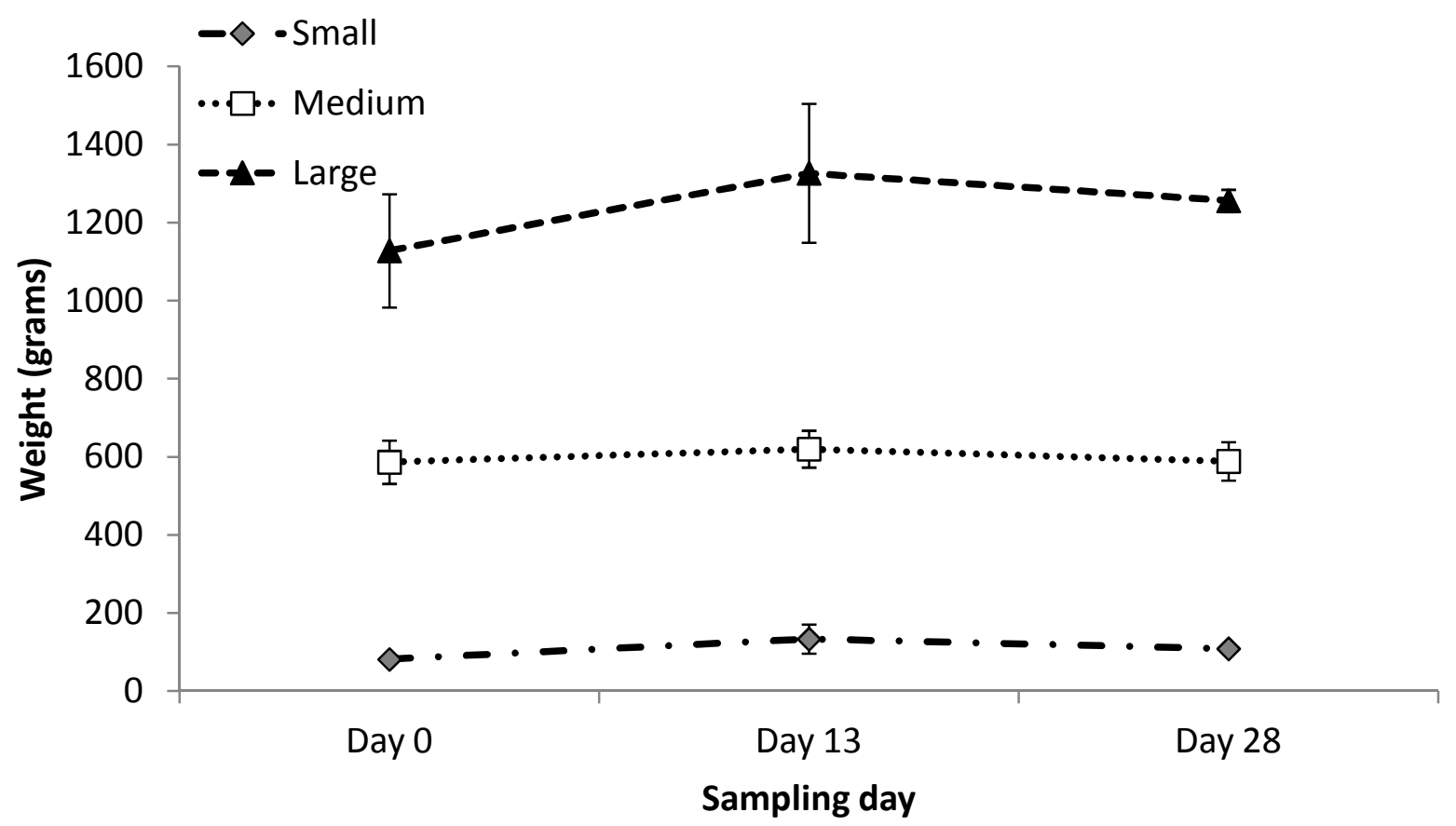


Figure 5.

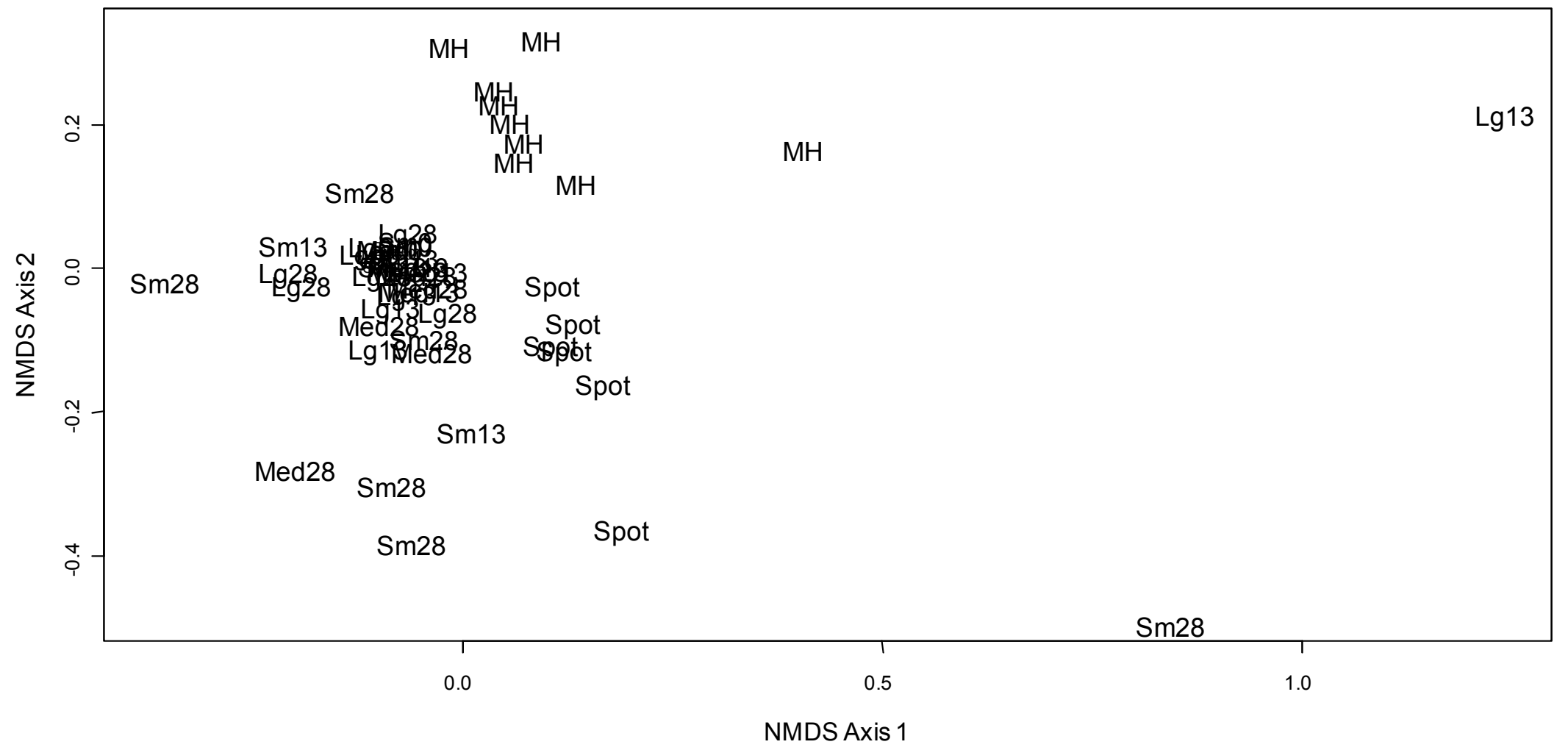


Figure 6.

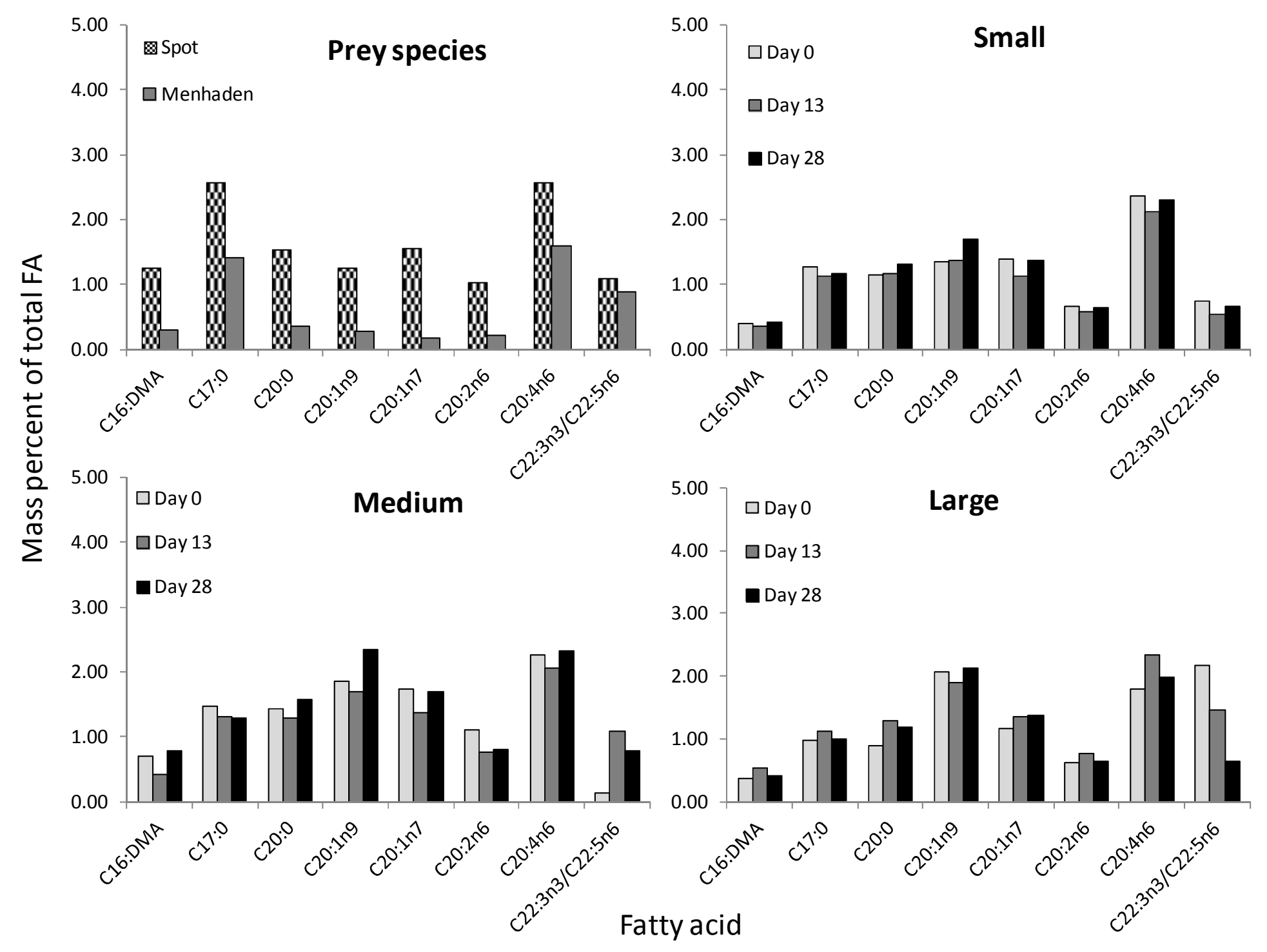


Chapter 5 - Evaluation of quantitative fatty acid signature analysis (QFASA) to estimate diets of striped bass 


\begin{abstract}
The process of studying diets has relied on analysis of prey items present in the stomach.
\end{abstract} Due to unequal digestion rates, temperature effects, and changes in feeding patterns, there may be significant error or bias associated with analyzing stomach contents. Alternative methods, e.g. stable isotopes and fatty acids, rely on the chemical signatures associated with the prey items rather than the prey items themselves. Fatty acid analysis specifically has the potential to estimate the proportional contribution of prey species by using a technique known as quantitative fatty acid analysis (QFASA). This model estimates what combination of prey results in the fatty acid signature present in predator tissues. The goal of this study was to evaluate the utility of using the QFASA model to estimate the contribution of spot (Leiostomus xanthurus) and Atlantic menhaden (Brevoortia tyrannus) fed to striped bass (Morone saxatilis) under controlled laboratory conditions. All striped bass were fed spot for six weeks to calculate calibration coefficients and establish a baseline signature. Calibration coefficients are values that correct for predator metabolism of fatty acids derived from the prey. Starting at day 0 , three experimental diets (100\% menhaden; $70 \%$ menhaden 30\% spot; and 30\% menhaden $70 \%$ spot) were fed to striped bass for six weeks. Liver and belly flap were removed from striped bass on day 0,21 , and 48 and analyzed for fatty acids. The QFASA model underestimated the contribution of menhaden throughout the experiment, but performed better with a truncated fatty acid dataset consisting of fatty acids derived mainly from the diet. Estimated contributions of menhaden averaged $18-20 \%$ for fish fed the $100 \%$ menhaden diet, $10-20 \%$ menhaden for fish fed the $70 \%$ menhaden $30 \%$ spot diet, and $5-20 \%$ menhaden for fish fed the $30 \%$ menhaden $70 \%$ spot diet. Striped bass grew better and had higher lipid levels in the liver and belly flap tissues in striped bass fed menhaden than either one of the diet mixtures. At this point, it appears that 
QFASA is not a viable technique to use to estimate striped bass feeding history. Most previous QFASA studies have focused on homeotherms, e.g. seabirds and marine mammals, and therefore fish may represent a more difficult species to model feeding history.

\section{Introduction}

Construction of food webs often relies on estimates of feeding history derived from stomach contents. However, analyzing stomach contents has well documented biases associated with it, e.g. variation in retention times of hard material (Hyslop 1980), temperature effects on digestion (He and Wurtsbaugh 1993), shearing of prey items leading to incomplete ingestion of the entire prey item (Scharf et al. 1997), and inconsistent methodology limiting comparisons among studies (Cortes 1997). These samples represent an estimation that goes back only as far as when these prey items were consumed (Iverson et al. 2004) and no information can be inferred over a longer period of time.

Fatty acids have been used extensively in marine settings for a variety of purposes: to identify farm raised versus wild fish (Ackman and Takeuchi 1986), to assess the health of hatchery reared fish (Brett et al. 1997), and for formulation of beneficial diets for hatchery fish (Sargent et al. 1997). The most promising aspect of studying fatty acids is the ability to track diets of organisms.

Recent advances in trophic ecology have tried to use fatty acid analysis, stable isotopes, or both in an effort to provide information on feeding history over a longer time period (Smith et al. 1996, Hooker et al. 2001. Ruess et al. 2005, Herman et al. 2005). Fatty acids are stored as triacylglycerols and represent a storage depot of energy for an organism (Gurr and Hardwood 1991). When an organism ingests organic material, the fatty acids that comprise the prey species 
are transferred to the predator with little or no modification, allowing these molecules to be used as tracers of the diet (Iverson 2009).

Studies focused on estimating which prey item is important in the diet by comparing the fatty acid signature of the prey item to the predator in question have been conducted for fish (Ratanayake and Ackman 1979, Kuusipalo 2000, Jobling 2003) and marine mammals (Bradshaw et al. 2003, Beck et al. 2005). Metabolism of the predator will prevent its fatty acid signature from exactly matching that of the prey (Budge et al. 2006); however, the key components are often identifiable (Dalsgaard 2003).

The qualitative estimation of what is being consumed may not always be straightforward. Wild organisms are often opportunistic and will consume a variety of prey items (Hartman and Brandt 1995). Therefore the fatty acids present in the predator will represent a mixture of all the prey items. Quantitative fatty acid signature analysis (QFASA) is a multivariate optimization model that estimates proportions of prey in a predator's diet based upon prey and predator fatty acid signatures and lipid content of the prey (Iverson et al. 2004). The metabolism of the predator is taken into account with calibration coefficients, values that are designed to correct for predator deposition and mobilization of various fatty acids (Iverson et al. 2004). To date, studies have focused on using marine mammals (Nordstrom et al. 2008, Tucker et al. 2009, Meynier et al. 2010) with few studies focusing on birds (Iverson et al. 2007) or fish (Budge et al. 2011).

Striped bass (Morone saxatilis) is one of the first fish species to have their diets estimated using this model. Striped bass are large anadromous fish that historically represented an important commercial and recreational fishery in the Chesapeake Bay (Chesapeake Bay Fisheries Ecosystem Advisory Panel 2006). During the 1970s and 1980s striped bass in Chesapeake Bay experienced a well documented decline (ASMFC 1981). Through a moratorium 
placed on the fishery, this species rebounded and was declared a recovered species in the 1990s (ASMFC 1995). Starting in the early 2000s, striped bass were found emaciated and infected with lesions linked to mycobacteriosis (Overton et al. 2003). One theory suggested that the recovered population may have outgrown its prey base (Uphoff 2003). When resources are not present for an organism to meet its metabolic demands, it will be more susceptible to disease. Therefore, an accurate method is needed to estimate feeding history of striped bass to determine if a dietary shift has occurred.

The purpose of this study was to evaluate the QFASA model for striped bass. Specifically, our objectives were: 1) to establish calibration coefficients (corrections for predator metabolism) for striped bass liver and belly flap tissues; 2) to use the QFASA model to estimate the contribution of two prey taxa (spot [Leiostomus xanthurus] and menhaden [Brevoortia tyrannus]) to the signatures of striped bass fed a known mixture of these two prey items; and 3) to use the QFASA model to estimate the proportion of menhaden to the signatures of striped bass after the diet was completely switched from spot to menhaden.

\section{Materials and Methods}

\section{Feeding study}

Striped bass (total length $325 \pm 6.21 \mathrm{~mm}$ ) were obtained from West Virginia University's Aquaculture Extension Unit and were transported to the James J. Howard Marine Sciences Laboratory in Sandy Hook, New Jersey. Eighty fish were randomly distributed among three 120 gallon tanks. The tanks were part of a flow through system with water pumped directly from the Sandy Hook Bay. Temperature ranged from $20.4-26.8^{\circ} \mathrm{C}$, and salinity ranged from 23 26.4 parts per thousand (ppt) during the feeding experiment. 
Fish were fed a diet of spot (Leiostomus xanthurus; collected from the Chester River, Maryland in fall) every other day for six weeks prior to the experiment to establish calibration coefficients of predator metabolism for striped bass (see below) and to establish a baseline fatty acid signature (Kirsch et al. 1998). At the start of the experiment (day 0), tank one was fed a diet of menhaden (Brevoortia tyrannus; collected from the Naticoke River, Maryland in the summer), tank two was fed a mixture of menhaden and spot $(70: 30 \mathrm{w}: \mathrm{w})$, and tank three was fed a mixture of menhaden and spot (30/70 w:w). Individual spot and menhaden were weighed together prior to homogenizing based upon the $70: 30$ or 30:70 treatments. The combination of fish was then placed in a food processor to mix the fish tissues. The homogenate was combined into pellets that could be consumed whole by striped bass. The pellets were stored in a $-20^{\circ} \mathrm{C}$ walk-in freezer in air tight bags until feeding. Ten samples of each homogenate were kept for lipid and fatty acid analysis.

Four striped bass were sacrificed from each tank on days 21 and 48. Fish were weighed (g) and measured (total length in $\mathrm{mm}$ ), and vacuum sealed with a FoodSaver vacuum sealer (Sunbeam Products, Inc., Niles, IL) and frozen at $-20^{\circ} \mathrm{C}$ until they could be analyzed.

\section{Sample preparation}

Striped bass were thawed at the time of analysis and tissue samples were weighed to the nearest 0.1 gram. The liver and a portion of the belly flap were removed. The belly flap (with skin intact) follows a line marked by the termination of the ribs and initiation of the peritoneum of the body wall (Jacobs et al. 2008). All tissues were ground with a chemical drying agent, diatomaceous earth (Dionex, Sunnyvale, CA) and a known amount of internal standard (C13:0 triacylglycerol) was added to determine the efficiency of the extraction process. A sample with just the internal standard (the method blank) was also analyzed. 
Lipids were extracted under nitrogen using an Accelerated Solvent Extractor (ASE 300, Dionex, Sunnyvale, CA) with a mixture of 3:1 (v/v) dichloromethane:methanol and $0.1 \%$ butylated hydroxytoluene (BHT) as an antioxidant. Samples were extracted once at $100^{\circ} \mathrm{C}$ and 1500 psi (USEPA 2007). Samples were back-extracted using a 0.88\% potassium chloride solution in deionized water to remove non-lipid materials from the extracts (Folch et al. 1957). Total lipid extracted was determined gravimetrically for each sample and reported as a percent of wet weight.

Extracted lipid species containing fatty acids as various derivatives were transesterified using a solution of sulfuric acid and methanol. In this process, aclyglycerols are broken apart to their constituents: glycerol and fatty acids methyl esters (FAMEs). Free fatty acids present in the lipid mixture are also converted to FAMEs (Christie 2003). Sample extracts were cleaned with silica gel and anhydrous sodium sulfate to remove polar components and water, which may degrade the performance of the gas chromatograph column. The silica column was conditioned with hexane and the sample was added along with hexane and diethyl ether, 95:5, v/v (Christie 2003). The mixture was concentrated to $5 \mathrm{ml}$ and diluted to a final total lipid concentration of $100 \mu \mathrm{g} / \mathrm{ml}$. Finished samples were run on a gas chromatograph (Agilent $6890 \mathrm{~N}$ Network GC System, Santa Clara, CA) / mass spectrometer (GC/MS, Agilent, 5973 Network Mass selective detector, Santa Clara, CA) in select ion monitoring mode.

The GC/MS was used to identify and quantify fatty acid methyl esters in each sample. FAMEs were injected into a fused capillary column, DB-23 $60 \mathrm{~m}$ length X $0.250 \mathrm{~mm}$ OD X $0.25 \mu \mathrm{m}$ film thickness (Agilent, Santa Clara, CA) using an autosampler (Agilent 7683 Series Auto Sampler). Hydrogen was used as a carrier gas. The temperature program was as follows: hold at an initial temperature of $50^{\circ} \mathrm{C}$ for $2 \mathrm{~min}$, hold for $1 \mathrm{~min}$ at $150^{\circ} \mathrm{C}$ after ramping at 
$20^{\circ} \mathrm{C} \cdot \mathrm{min}^{-1}$, ramp to $215^{\circ} \mathrm{C}$ at $1.25^{\circ} \mathrm{C} \cdot \mathrm{min}^{-1}$. The fatty acid retention times were compared to known standards from Nu-Chek Prep (GLC MIX 85, 411, 642, 632, Elysian, MN). These four standard mixtures were combined along with stearidonic acid (C18:4n3, Cayman Chemical, Ann Arbor, MI) to make a total FAME standard solution of $12.25 \mu \mathrm{g} / \mathrm{ml}$. Matreya 25 FAME mixture (Pleasant Gap, PA) was used to obtain retention times for C20:1n7. Restek cis/trans FAME mixture (Bellefonte, PA) was used to obtain retention times for C18:1n9 trans and C18:2n6 trans. These standards and an internal standard of C13:0 FAME $(100 \mu \mathrm{g} / \mathrm{ml})$ were added to quantify the amount of each fatty acid methyl ester present. The GC/MS tracks the select ion signature of each compound and was used to verify the identity of each peak. There were peaks which consisted of more than one fatty acid and it was impossible to determine which fatty acid(s) constituted the peaks. Therefore, a term fatty acid "complex" was assigned to this peak. The complex refers to which fatty acids could be responsible for the peak, e.g. C22:3n3 and C22:5n6.

\section{Calibration coefficients and fatty acid subsets}

Calibration coefficients were calculated by dividing the proportion of a FA in a predator by the value of that same FA in the prey (Iverson et al. 2004). During the baseline feeding, all three tanks of striped bass were fed spot for a period of 6 weeks. At the end of the six weeks, 12 striped bass were sacrificed and the fatty acid signature of the liver and belly flap was analyzed. Eleven samples of spot were also analyzed for their fatty acid signature, resulting in 132 calibration coefficients for each fatty acid in both the liver and belly flap. The six highest and lowest values were removed before the mean was calculated (10\% trimmed mean; Iverson et al. 2004).

A subset of the fatty acids is used for the QFASA model, which excludes fatty acids that may arise from biosynthesis, or fatty acids inconsistently detected. In our experiment, we used an 
extended fatty acid subset including all fatty acids that had a proportion $>0.1 \%(n=30$; Table 1$)$.

A dietary subset was also constructed to mimic the dataset presented in Iverson et al. (2004).

This subset consisted of fatty acids derived primarily from the diet $(n=16$; Table 1$)$. Once fatty

acids were removed from the dataset, the proportions were renormalized to $100 \%$.

\section{Diet estimation}

The diet of striped bass was estimated using the QFASA model (Iverson et al. 2004).

The model uses the prey FA signatures and tries to estimate which mixture of prey comes closest to matching the predator's actual signature. The best mixture of prey FAs is then weighted by the fat content of the prey species. Species that have a higher fat content will have more FAs to contribute to the signature seen in the predator, and the weighting algorithm takes this into account. The model uses an optimization procedure which aims to minimize the distance between the predicted and observed predator signature, the Kullback-Liebler (KL) distance. The optimization uses a quasi-Newton algorithm with a Broyden-Fletcher-Goldfarb-Shanno formula and was carried out with a package developed at Massey University, New Zealand (Fatty acid solution - Dr. R. Sheriff and A/Prof P.C.H. Morel).

\section{Statistical analyses}

Fatty acid methyl esters were expressed as the percent of the total fatty acid concentrations. These values were used to determine differences in the prey species and were then compared to tissues samples throughout the experiment to determine if striped bass tissues reflected prey values.

Nonmetric multidimensional scaling (NMDS) was also performed on the data ( $\mathrm{R}$ Development Core Team 2010, Vienna, Austria). This ordination technique is an iterative search for the best position of samples in multidimensional space, and uses the stress value as an 
indicator for the best solution. A distance matrix was calculated for the fatty acids, and the samples were ordinated based on the distances calculated (McCune and Grace 2002).

\section{Results}

\section{Mixed diet feed}

The fatty acids of spot and menhaden were markedly different, however, the fatty acids present in the two mixed diets (70MH:30SP and 30MH:70MH) did not represent a continuum between spot and menhaden as intended (Table 2). The fatty acids detected in the diet mixtures should have intermediate values when compared to the contributing tissues of spot and menhaden, however there were several instances of values for the mixed diets being out of the range, e.g. $\mathrm{C} 18: 3 \mathrm{n} 3$ and $\mathrm{C} 20: 3 \mathrm{n} 3$. There are also several instances in which the 70MH:30SP diet has proportions more similar to spot than menhaden, e.g. C14:0, C16:1n7, C18:0, and C18:1n7. The same type of pattern holds true for 30MH:70SP, e.g. C14:0, C16:0, C18:0, and C18:4n3. Despite these anomalies, the NMDS plot revealed that both mixtures were intermediate between spot and menhaden, with the 70MH:30SP mixture being more similar to menhaden and the 30MH:70SP being more similar to spot (Fig.1).

\section{Growth}

The lengths and weights, as well as the lipid content of both the liver and belly flap samples changed depending on the feeding regime (Table 3). Striped bass fed menhaden alone obtained larger sizes, based on length and weight, than striped bass fed either of the mixtures. The lipid content of both the liver and belly flap of striped bass fed menhaden increased above the starting lipid levels. The results for the mixed diets were variable. Striped bass fed the 70MH:30SP mixture obtained a larger final length, weight, and belly flap lipid content. Striped 
bass fed the 30MH:70SP mixture obtained larger final liver lipid content. Overall, the standard errors were high for many of the measurements due to low sample size ( $n=4$ samples per group).

\section{Fatty acid composition}

The fatty acid signature of striped bass fed the various diets did not show distinct variation in their signatures (Fig.1). There was a general pattern of signatures moving towards those of the various diets as the experiment progressed. However, there was a large degree of overlap of the three diets in both the liver and belly flap tissues and a separation from the initial diet of spot. The NMDS also indicates that the striped bass fed spot for six weeks prior to the start of the experimental feeding were more dissimilar versus spot than the striped bass fed experimental diets. Liver samples were more similar to each other than belly flap samples in terms of their respective fatty acid signatures regardless of the diet $(100 \%$ menhaden or either mixed diet; Fig. 1).

Individual striped bass fatty acids did not show a consistent pattern of change from the initial diet to that of the 70MH:30SP mixture (Fig. 2) or the 30MH:70SP mixture (Fig. 3).

Certain fatty acids were often higher in striped bass tissues from day 0 through day 48 , despite the initial and mixture diets having lower proportions, e.g. C18:2n6 and C18:1n9 (Fig. 2b), C18:1n9 (Fig. 3a), and C18:1n9 (Fig. 3b). Certain striped bass fatty acids remained at the level of the initial diet, e.g. C16:1n7 (Fig. 2a) and C14:0 (Fig. 3a). Other fatty acids remained at levels of the mixture diet and showed no change, e.g. C20:4n6 (Fig. 2b) and C18:0 (Fig. 3a).

\section{QAFSA model}

Calibration coefficients were calculated for both striped bass liver and belly flap tissues (Table 3). There were apparent differences in the metabolism and storage of fatty acids in liver and belly flap tissues, therefore calibration coefficients were only used for the tissue in which 
they were calculated. Two different sets of fatty acid datasets were used in the QFASA model (Table 3) and these were adopted from Iverson et al. (2004).

Striped bass samples fed the baseline diet of spot were analyzed with the QFASA model to determine the duration needed before the diet consisted of $100 \%$ spot (Fig. 4). The anchovy signature was still present when the baseline feeding was initiated. The proportional contribution of spot increased throughout the six weeks until the signature of striped bass tissues consisted of 95-98\% spot fatty acids.

Samples from both tissues sampled on day 0, 21, and 48 during the experiment for each diet were run with the QAFSA model and appropriate calibration coefficients. The model was run once with the full fatty acid dataset (Fig. 5) and the dietary dataset (Fig. 6).

Liver and belly flap samples run using the full dataset yielded slightly different results, although both instances were not able to correctly identify the diet mixture fed. On day 0 , the model indicated that the spot signature accounted for $95-98 \%$ of the prey consumed by striped bass. Samples from striped bass switched to a diet of menhaden estimated the contribution of menhaden to be small, decreasing slightly from $20 \%$ on day 21 to $18 \%$ on day 48 (Fig. 5 b). The contribution of menhaden to liver signatures was $10 \%$ on day 21 and $20 \%$ on day 48 (Fig. 5a). The contribution of menhaden estimated by QFASA was incorrect for both tissues fed the 70MH:30SP and the 30MH:70SP diets. All results estimated menhaden contributing $\sim 5-20 \%$ of the diet, with lower values for the 30MH:70SP diet. In both mixed diet treatments, the contribution of menhaden decreased from day 21 to day 48 .

Running the QFASA model with the dietary dataset yielded better results than the full dataset, but the estimated contribution of menhaden was lower than the actual. Results from liver samples from striped bass fed menhaden estimated the contribution of menhaden to be $50 \%$ on 
day 21 and $80 \%$ on day 48 (Fig. 6a). Estimates from belly flap samples indicated the contribution of menhaden to be $45 \%$ on day 21 and $40 \%$ on day 48 (Fig $6 \mathrm{~b}$ ). The proportion of menhaden in striped bass fed the $70 \mathrm{MH}: 30 \mathrm{SP}$ yielded $10 \%$ on day 21 and $18 \%$ on day 48 for liver, while belly flap samples had $10 \%$ menhaden in their signatures on both day 21 and 48 . The proportion of menhaden in striped bass fed 30MH:70SP was $15 \%$ on day 21 and $10 \%$ on day 48 for liver, while belly flap samples had $20 \%$ menhaden on day 21 and $8 \%$ on day 48 .

\section{Discussion}

The QAFSA model performed poorly in regards to all captive feeding trials in this study. The model had problems with estimating the contribution of menhaden alone to the fatty acid signatures of liver and belly flap tissues from striped bass fed this prey species for six weeks. Model estimates derived from the liver yielded more accurate results as the liver represents a processing organ for fatty acids recently consumed while adipose tissue is a long term storage site for fatty acids. The model also consistently underestimated the proportion of menhaden fatty acids in the signature of striped bass fed a known mix of spot and menhaden.

In order to run the QFASA model, inputs of prey fatty acids, predator fatty acids, and calibration coefficients are needed. Calibration coefficients are based on the incorporation of a specific prey fatty acid into a predator's tissue (Iverson et al. 2004) and need to be estimated by captive feeding experiments. Captive feeding trials can also be used to test the model before applying it to wild populations; such studies have lasted for 42 days (Iverson et al. 2007, Nordstrom et al. 2008) and 50 days (Wang et al. 2010). Based upon these studies and the fact that predator tissues should begin to mimic prey species after a period of approximately three weeks (Kirsch et al. 1998), we fed striped bass for a period of six weeks to calculate calibration 
coefficients. We also ran the captive feeding trials that the QFASA model was based on for another six weeks. However, the data indicated that the switch from spot to menhaden was not complete after the period of six weeks. Liver tissue showed an increase in the proportion of menhaden from day 21 - 48 for both datasets (although more pronounced in the dietary dataset), but the highest value obtained was $\sim 80 \%$. There is little research to suggest the appropriate duration for a captive feeding study of fish for QAFSA validation. Despite the fact that a fish predator will mimic its prey signature after a period of three weeks, Atlantic salmon (Salmo salar) required 12 weeks for the proportions of fatty acids in the muscle and belly flap to completely change substantially and remain stable (Budge et al. 2011). The comparisons among taxonomic groups may confound the issue. Fish are poikilothermic while seabirds and mammals are homeothermic, necessitating the use of more energy for homeostasis in homeotherms, and in turn using more fatty acids. Therefore, an experiment lasting six weeks for a fish species may be enough to distinguish fatty acid signatures in a predator tissue qualitatively, but not quantitatively.

The model results overestimated the contribution of spot to the striped bass signature. The mixed diets should have represented a continuum of fatty acids between the two components (Budge et al. 2011). However, the values for several fatty acids were outside the range of spot and menhaden. The fat content of the 70MH:30SP diet mixture had a lower fat content than the 30MH:70SP mixture, possibly indicating a disproportionate contribution of spot in the diet formulated to be higher in menhaden. This combination of fatty acids resulted in the model recognizing spot as more prevalent than it actually was. In this study, prey species were weighed, homogenized, and frozen prior to feeding. Previous studies have combined fish and krill oil to a standard lipid content (14\% wet weight) and pelleted using an industrial steam pellet mill (Budge 
et al. 2011), or combined fish species, e.g. silverside (Menida menida), rainbow smelt (Osmerus mordax), and herring (Clupea harengus) with no information about how the prey species were combined (Iverson et al. 2007). The lack of a standardized procedure for mixed diet formulation may have led to heterogeneous diet mixtures being fed to striped bass. This fact along with the length of the experiment could have led to the poor performance of the QFASA model.

Striped bass fed a diet of menhaden alone led to larger fish and a higher lipid content of the liver and belly flap tissues than either of the mixed diets. The lipid content of the menhaden diet $(11.75 \%)$ was higher than either the $70 \mathrm{MH}: 30 \mathrm{SP}(6.56 \%)$ or $30 \mathrm{MH}: 70 \mathrm{SP}(7.32 \%)$ mixtures. Due to the possibility of non-uniform mixtures in both the mixed diet treatments, it is difficult to reach a conclusion on the effect of a lowered ratio of menhaden in the diet on growth parameters and lipid deposition. However, it is obvious that the removal of a preferred prey (menhaden) leads to reduced growth and lowered lipid stores, although high standard errors due to low sample size prevent definitive conclusions. This becomes an important biological ramification in relation to the possible overfishing of menhaden (NOAA 2009). Studies have shown that the proportion of menhaden in the diet has decreased since the recovery of the striped bass population (Overton et al. 2000). More research is needed to assess the long term effects of diet mixtures of high- and lower-lipid prey on the growth and health of striped bass.

Based upon the findings of Budge et al. (2011) on the incorporation of prey fatty acids, including diet mixtures, fish may need longer time periods (12 weeks) in which to reach a plateau in terms of fatty acid turnover; however, this situation may not be realistic for wild fish populations. Studies that have examined striped bass diets using stomach contents have shown that there are several prey items that comprise the diets (Hartman and Brandt 1995, Overton et al. 2000, Rudershausen et al. 2005). This suggests that there are new prey signatures being added to 
striped bass tissues constantly, precluding the dominance of just one prey signature. Although much work has been done with marine mammals (Beck et al. 2007, Thiemann et al. 2007, Thiemann et al. 2008, Meynier et al. 2010), this technique is relatively new to fisheries management. QFASA models may prove to be useful for fish populations, but more research needs to be done to verify that the model is capable of estimating diets without the focal species needing to feed on one prey item for an extended period of time.

\section{Acknowledgments}

The authors would like to thank J. Councilman, A. Leight, J. Brush, and W. Lowery for assistance in collecting samples. We are also indebted to B. Dockum and L. Gonsalves for advice and assistance in the chemical analysis of samples. E. McGinley provided invaluable help in the laboratory preparing and analyzing samples. We are grateful for the comments provided by anonymous reviewers. This research was made possible by funding from NOAA Chesapeake Bay Office Grant No. NA07NMF4570330 and all research was conducted under West Virginia University Animal Care and Use Protocol number 09-0102. 


\section{Literature cited}

Ackman, R.G. and T. Takeuchi. 1986. Comparison of fatty acids and lipids of smolting hatcheryfed and wild Atlantic salmon Salmo salar. Lipids 21: 117-120.

ASMFC (Atlantic States Marine Fisheries Commission). 1981. Interstate fisheries management plan for the striped bass. Fisheries Management Report No. 1, Washington, D.C.

ASMFC (Atlantic States Marine Fisheries Commission). 1995. Amendment \#5 to the interstate fishery management plan for Atlantic striped bass. ASMFC. Fisheries Management Report 24, Washington, D.C.

Beck, C. A., S.J. Iverson, and W.D. Bowen. 2005. Blubber fatty acids of gray seals reveal sex differences in the diet of a size-dimorphic marine carnivore. Canadian Journal of Zoology $83: 377-388$.

Beck, C.A., S.J. Iverson, W.D. Bowen, and W. Blanchard. 2007. Sex differences in grey seal diet reflect seasonal variation in foraging behaviour and reproductive expenditure: evidence from quantitative fatty acid signature analysis. Journal of Animal Ecology 76:490-502.

Bradshaw, C. J. A., M.A. Hindell, N.J. Best, K.L. Phillips, G. Wilson, and P.D. Nichols. 2003. You are what you eat: describing the foraging ecology of southern elephant seals (Mirounga leonina) using blubber fatty acids. Proceedings of the Royal Society of London B 270:1283-1292.

Brett, M. and D. Muller-Navarra. 1997. The role of highly unsaturated fatty acids in aquatic foodweb processes. Freshwater Biology, 38: 483-499.

Budge, S.M., S.J. Iverson, and H.N. Koopman. 2006. Studying trophic ecology in marine ecosystems using fatty acids: a primer on analysis and interpretation. Marine Mammal Science 22:759-801. 
Budge, S.M., S.N. Penney, S.P. Lall. 2011. Response of tissue lipids to diet variation in Atlantic salmon (Salmo salar): implications for estimating diets with fatty acid analysis. Journal of Experimental Marine Biology and Ecology 409:267-274.

Chesapeake Bay Fisheries Ecosystem Advisory Panel (National Oceanic and Atmospheric Administration Chesapeake Bay Office). 2006. Fisheries ecosystem planning for Chesapeake Bay. American Fisheries Society, Trends in Fisheries Science and Management 3, Bethesda, Maryland.

Christie, W.M. 2003. Lipid Analysis. PJ Barnes and Associates. Bridgewater, England.

Cortes, E. 1997. A critical review of methods of studying fish feeding based on analysis of stomach contents: application to elasmobranch fishes. Canadian Journal of Fisheries and Aquatic Sciences 54:726-738.

Dalsgaard, J., M. St. John, G. Kattner, D. Muller-Navarra, and W. Hagen. 2003. Fatty acid trophic markers in the pelagic marine environment. Advances in Marine Biology 46:224340.

Folch, J., M. Lees, and G.H.S. Stanley. 1957. A simple method for the isolation and purification of total lipids from animal tissues. Journal of Biological Chemistry 226:497-509.

Gurr, M.I. \& J.L. Hardwood. 1991. Lipid biochemistry: an introduction. $4^{\text {th }}$ edn. London, England: Chapman and Hall.

Hartman, K.J. and S.B. Brandt. 1995. Trophic resource partitioning, diets, and growth of sympatric estuarine predators. Transactions of the American Fishery Society 124:520537. 
He, E. \& W.A. Wurtsbaugh. 1993. An empirical model of gastric evacuation rates for fish and an analysis of digestion in piscivorous brown trout. Transactions of the American Fisheries Society $122,717-730$.

Herman, D.P., D.G. Burrow, P.R. Wade, J.W. Durban, C.O. Matkin, R.G. Leduc, L.G. BarrettLennard, and M.M. Krahn. 2005. Feeding ecology of eastern North Pacific killer whales Orcinus orca from fatty acid, stable isotope, and organochlorine analyses of blubber biopsies. Marine Ecology Progress Series 302:275-291.

Hooker, S.K., S.J. Iverson, P. Ostrom, and S.C. Smith. 2001. Diet of northern bottlenose whales inferred from fatty acid and stable isotope analyses of biopsy samples. Canadian Journal of Zoology 79:1442-1454.

Hyslop, E.J. 1980. Stomach contents analysis - a review of methods and their application. Journal of Fish Biology 17:411-429.

Iverson, S. J. 2009. Tracing aquatic food webs using fatty acids: from qualitative indicators to quantitative determination. In Lipids in aquatic ecosystems (Arts, M.T., M.T. Brett, \& M.J. Kainz eds). pp 281-307. New York, NY: Springer Science.

Iverson, S.J., A.M. Springer, and A. Kitaysky. 2007. Seabirds as indicators of food web structure and ecosystem variability: qualitative and quantitative diet analyses using fatty acids. Marine Ecology Progress Series 352:235-244.

Iverson, S.J., C. Field, W.D. Bowen, and W. Blanchard. 2004. Quantitative fatty acid signature analysis: a new method of estimating predator diets. Ecological Monographs 74:211-235.

Jacobs, J. M., M.R. Rhodes, B. Martin, D. McIntosh, W.F. Van Heukelem, and R.M. Harrell. 2008. Tissue-specific sampling for estimation of striped bass whole-body proximate composition. Transactions of the American Fisheries Society 137:386-392. 
Jobling, M. 2003. Do changes in Atlantic salmon, Salmo salar L., fillet fatty acids following a dietary switch represent wash-out or dilution? Test of a dilution model and its application. Aquaculture Research 34:1215-1221.

Kirsch, P.E., S.J. Iverson, W.D. Bowen, S.R. Kerr, and R.G. Ackman. 1998. Dietary effects on the fatty acid signature of whole Atlantic cod (Gadus morhua). Canadian Journal of Fisheries and Aquatic Sciences 55:1378-1386.

Kuusipalo, L. 2000. Muscle fatty acids as indicators of niche and habitat in Malawian cichlids. Limnology and Oceanography 45:996-1000.

McCune, B. and J.B. Grace. 2002. Analysis of Ecological Communities. MjM Software Design, Gleneden Beach, OR.

Meynier, L., P.C.H. Morel, B.L. Chilvers, D.D.S. Mackenzie, and P.J. Duignan. 2010. Quantitative fatty acid signature analysis on New Zealand sea lions: model sensitivity and diet estimates. Journal of Mammalogy 91:1484-1495.

NOAA (National Oceanic and Atmospheric Administration). 2009. Forecast for the 2009 Gulf and Atlantic menhaden purse-seine fisheries and review of the 2008 fishing season. Sustainable Fisheries Branch, NMFS Beaufort, NC.

Nordstrom, C.A., L.J. Wilson, S.J. Iverson, and D.J. Tollit. 2008. Evaluating fatty acid signature analysis (QFASA) using harbor seals Phoca vitulina richardsi in captive feeding studies. Marine Ecology Progress Series 360:245-263.

Overton, A.S., E.B. May, J. Griffin, F.J. Margraf. 2000. A bioenergetics approach for determining the effect of increased striped bass population on its prey and health in the Chesapeake Bay. Report to: Maryland Department of Natural Resources. Maryland 
Cooperative Fish and Wildlife Research Unit, University of Maryland Eastern Shore, Princess Anne, MD.

Overton, A.S., F.J. Margraf, C.A. Weedon, L.H. Pieper, E.B. May. 2003. The prevalence of mycobacterial infections in striped bass in Chesapeake Bay. Fisheries Management and Ecology 10:301-308.

R Development Core Team. 2010. R: A language and environment for statistical computing. R Foundation for Statistical Computing, Vienna, Austria. ISBN 3-900051-07-0, URL http://www.R-project.org.

Ratanayake, W. M., and R. G. Ackman. 1979. Fatty alcohols in capelin, herring, and mackerel oils and muscle lipids: I. Fatty alcohol details dietary copepod fat with certain fish depot fats. Lipids 14:795-803.

Rudershausen, P.J., J.E. Tuomikoski, and J.A. Buckel. 2005. Prey selectivity and diet of striped bass in western Albemarle Sound, North Carolina. Transactions of the American Society 134:1059-1074.

Ruess, L., A. Tiunov, D. Haubert, H.H. Richnow, M.H. Haggblom, and S. Scheu. 2005. Carbon stable isotope fractionation and trophic transfer of fatty acids in fungal based soil food chains. Soil Biology and Biochemistry 37: 945-953.

Sargent, J.R., L.A. McEvoy, and J.G. Bell. 1997. Requirements, presentation, and sources of polyunsaturated acids in marine fish larval feeds. Aquaculture 155:117-127.

Scharf, F.S., J.A. Buckel, F. Juanes, and D.O. Conover. 1997. Estimating piscine prey size from partial remains: testing for shifts in foraging mode by juvenile bluefish. Environmental Biology of Fishes 49:377-388. 
Smith, R.J., K.A. Hobson, H.N. Koopman, and D.M. Lavigne. 1996. Distinguishing between populations of fresh- and salt-water harbor seals (Phoca vitulina) using stable-isotope ratios and fatty acid profiles. Canadian Journal of Fisheries and Aquatic Sciences 53:272279.

Thiemann, G., S.J. Iverson, and I. Sterling. 2008. Polar bear diets and arctic marine food webs: insights from fatty acid analysis. Ecological Monographs 78:591-613.

Thiemann, G., S.M. Budge, S.J. Iverson, and I. Sterling. 2007. Unusual fatty acid biomarkers reveal age- and sex-specific foraging in polar bears (Ursus maritimus). Canadian Journal of Zoology85:505-517.

Tucker, S., W.D. Bowen, S.J. Iverson, W. Blanchard, and G.B. Stenson. 2009. Sources of variation in diets of harp and hooded seals estimated from quantitative fatty acid signature analysis (QFASA). Marine Ecology Progress Series 384:287-302.

Uphoff Jr., J.H. 2003. Predator-prey analysis of striped bass and Atlantic menhaden in upper Chesapeake Bay. Fisheries Management and Ecology 10:313-322.

USEPA (United States Environmental Protection Agency). 2007. Pressurized fluid extraction (PFE). USEPA SW-846. Method 3545A, Update IV. Washington, D.C.

Wang, S.W., T.E. Hollmen, and S.J. Iverson. 2010. Validating quantitative fatty acid signature analysis to estimate diets of spectacled and Stellar's eiders (Somateria fischeri and Polysticta setlleri). Journal of Comparative Physiology B 180:125-139. 
Table 1. Calibration coefficients calculated for fatty acids in the liver and belly flap samples. Fatty acid datasets represent the variables included in the QFASA models.

\begin{tabular}{|c|c|c|c|c|}
\hline \multirow[b]{2}{*}{ Fatty acid } & \multicolumn{2}{|c|}{$\underline{\text { Calibration coefficients }}$} & \multicolumn{2}{|c|}{ Fatty acid datasets } \\
\hline & Liver & Belly flap & Full & Dietary \\
\hline $\mathrm{C} 14: 0$ & 0.91 & 1.87 & $\mathrm{X}$ & \\
\hline $\mathrm{C} 15: 0$ & 0.40 & 0.60 & $\mathrm{X}$ & \\
\hline C16:0 & 0.99 & 0.88 & $\mathrm{X}$ & \\
\hline $\mathrm{C} 16: \ln 7$ & 1.01 & 1.62 & $\mathrm{X}$ & \\
\hline $\mathrm{C} 17: 0$ & 0.54 & 0.41 & $\mathrm{X}$ & \\
\hline C18:0 & 0.65 & 0.44 & $\mathrm{X}$ & \\
\hline $\mathrm{C} 18: \ln 9 \mathrm{t}$ & 1.00 & 0.61 & $\mathrm{X}$ & \\
\hline $\mathrm{C} 18: \ln 9$ & 2.23 & 2.06 & $\mathrm{X}$ & \\
\hline $\mathrm{C} 18: 1 \mathrm{n} 7 \mathrm{c}$ & 1.22 & 1.02 & $\mathrm{X}$ & \\
\hline $\mathrm{C} 18: 2 \mathrm{n} 6$ & 2.42 & 5.26 & $\mathrm{X}$ & $\mathrm{X}$ \\
\hline C18:3n6 & 1.32 & 1.84 & $\mathrm{X}$ & $\mathrm{X}$ \\
\hline $\mathrm{C} 18: 3 \mathrm{n} 3+\mathrm{C} 19: 0$ & 0.88 & 1.64 & $\mathrm{X}$ & $\mathrm{X}$ \\
\hline $\mathrm{C} 18: 4 \mathrm{n} 3$ & 0.86 & 1.90 & $\mathrm{X}$ & $\mathrm{X}$ \\
\hline C20:0 & 0.54 & 0.97 & $\mathrm{X}$ & \\
\hline $\mathrm{C} 20: \ln 12$ & 0.43 & 0.68 & $\mathrm{X}$ & \\
\hline $\mathrm{C} 20: \ln 9$ & 2.88 & 1.82 & $\mathrm{X}$ & $\mathrm{X}$ \\
\hline $\mathrm{C} 20: \ln 7$ & 0.51 & 0.65 & $\mathrm{X}$ & $X$ \\
\hline $\mathrm{C} 20: 2 \mathrm{n} 6$ & 0.81 & 1.10 & $\mathrm{X}$ & $X$ \\
\hline $\mathrm{C} 20: 3 \mathrm{n} 6+\mathrm{C} 21: 0$ & 0.84 & 1.27 & $\mathrm{X}$ & $X$ \\
\hline $\mathrm{C} 20: 4 \mathrm{n} 6$ & 0.72 & 0.39 & $\mathrm{X}$ & $\mathrm{X}$ \\
\hline $\mathrm{C} 20: 3 \mathrm{n} 3$ & 0.56 & 1.11 & $\mathrm{X}$ & $\mathrm{X}$ \\
\hline $\mathrm{C} 20: 5 \mathrm{n} 3$ & 0.67 & 0.67 & $\mathrm{X}$ & $X$ \\
\hline $\mathrm{C} 22: 0$ & 0.38 & 0.95 & $\mathrm{X}$ & \\
\hline $\mathrm{C} 22: \ln 9$ & 1.15 & 1.38 & $\mathrm{X}$ & $X$ \\
\hline $\mathrm{C} 22: 2 \mathrm{n} 6$ & 0.92 & 2.39 & $\mathrm{X}$ & $\mathrm{X}$ \\
\hline $\mathrm{C} 22: 4 \mathrm{n} 6$ & 0.42 & 0.61 & $\mathrm{X}$ & $X$ \\
\hline $\mathrm{C} 22: 3 \mathrm{n} 3+\mathrm{C} 22: 5 \mathrm{n} 6$ & 0.51 & 0.66 & $\mathrm{X}$ & $X$ \\
\hline $\mathrm{C} 22: 5 \mathrm{n} 3$ & 0.68 & 0.94 & $\mathrm{X}$ & \\
\hline $\mathrm{C} 24: 0+\mathrm{C} 22: 6 \mathrm{n} 3$ & 0.93 & 0.57 & $\mathrm{X}$ & $\mathrm{X}$ \\
\hline $\mathrm{C} 24: 1 \mathrm{n} 9$ & 0.90 & 1.44 & $\mathrm{X}$ & \\
\hline
\end{tabular}


Table 2. Mean fatty acid concentrations expressed as a mass percent of all fatty acids present \pm 1 standard error of the mean; nd = not detected. The fatty acids shown are for the menhaden and spot, the two prey taxa that comprised the mixed diets: $70 \%$ menhaden and $30 \%$ spot (70MH:30SP) and 30\% menhaden and 70\% spot (30MH:70SP).

\begin{tabular}{|c|c|c|c|c|}
\hline & $\begin{array}{l}\text { Menhaden } \\
(\mathrm{n}=10)\end{array}$ & $\begin{array}{c}70 \mathrm{MH}: 30 \mathrm{SP} \\
(\mathrm{n}=8)\end{array}$ & $\begin{array}{c}\text { 30MH:70SP } \\
(\mathrm{n}=7)\end{array}$ & $\begin{array}{c}\text { Spot } \\
(\mathrm{n}=11)\end{array}$ \\
\hline Fat content & $11.75 \pm 1.91$ & $6.56 \pm 0.48$ & $7.32 \pm 0.84$ & $6.05 \pm 0.18$ \\
\hline \multicolumn{5}{|l|}{ Fatty acid } \\
\hline C12:0 & $0.11 \pm 0.01$ & $0.11 \pm 0.00$ & $0.12 \pm 0.01$ & $0.05 \pm 0.04$ \\
\hline $\mathrm{C} 12: \ln 1$ & $0.35 \pm 0.05$ & $0.02 \pm 0.00$ & $0.04 \pm 0.01$ & $0.02 \pm 0.03$ \\
\hline C13:0 & $0.18 \pm 0.03$ & $0.24 \pm 0.01$ & $0.21 \pm 0.04$ & $0.26 \pm 0.26$ \\
\hline C14:0 & $10.28 \pm 1.53$ & $5.81 \pm 0.17$ & $8.34 \pm 0.98$ & $2.42 \pm 0.81$ \\
\hline $\mathrm{C} 14: \ln 5$ & $0.05 \pm 0.01$ & $0.09 \pm 0.01$ & $0.11 \pm 0.01$ & $0.03 \pm 0.01$ \\
\hline C15:0 & $0.90 \pm 0.04$ & $1.69 \pm 0.05$ & $1.18 \pm 0.13$ & $1.30 \pm 0.17$ \\
\hline C16:0 & $28.26 \pm 1.21$ & $26.39 \pm 1.53$ & $27.87 \pm 2.08$ & $24.36 \pm 1.69$ \\
\hline $\mathrm{C} 16: \ln 7$ & $10.25 \pm 1.41$ & $6.97 \pm 0.13$ & $7.53 \pm 0.81$ & $4.21 \pm 0.81$ \\
\hline $\mathrm{C} 17: 0$ & $1.22 \pm 0.08$ & $2.56 \pm 0.09$ & $1.74 \pm 0.11$ & $2.48 \pm 0.42$ \\
\hline C18:0 & $5.91 \pm 0.51$ & $9.03 \pm 0.30$ & $6.98 \pm 0.42$ & $10.83 \pm 1.00$ \\
\hline $\mathrm{C} 18: \ln 12 \mathrm{t}$ & $0.23 \pm 0.05$ & nd & $0.13 \pm 0.05$ & $0.06 \pm 0.14$ \\
\hline C18:1n9t & $0.02 \pm 0.02$ & nd & $0.04 \pm 0.04$ & $0.06 \pm 0.14$ \\
\hline C18:1n9 & $3.82 \pm 0.47$ & $10.46 \pm 0.42$ & $7.52 \pm 0.28$ & $9.30 \pm 0.80$ \\
\hline $\mathrm{C} 18: \ln 7$ & $3.17 \pm 0.10$ & $3.82 \pm 0.11$ & $3.47 \pm 0.16$ & $3.88 \pm 0.52$ \\
\hline $\mathrm{C} 18: 2 \mathrm{n} 6 \mathrm{t}$ & nd & nd & $0.01 \pm 0.01$ & $0.03 \pm 0.06$ \\
\hline C18:2n6 & $1.54 \pm 0.13$ & $1.75 \pm 0.05$ & $1.63 \pm 0.06$ & $1.75 \pm 0.21$ \\
\hline C18:3n6 & $0.47 \pm 0.03$ & $0.18 \pm 0.02$ & $0.27 \pm 0.05$ & $0.13 \pm 0.02$ \\
\hline C19:0 & nd & $0.52 \pm 0.02$ & $0.45 \pm 0.08$ & $0.50 \pm 0.07$ \\
\hline C18:3n3 & $1.51 \pm 0.25$ & $1.71 \pm 0.13$ & $2.19 \pm 0.26$ & $1.02 \pm 0.27$ \\
\hline $\mathrm{C} 18: 4 \mathrm{n} 3$ & $1.87 \pm 0.17$ & $1.27 \pm 0.09$ & $1.73 \pm 0.13$ & $0.49 \pm 0.16$ \\
\hline C19:2n6 & nd & $0.03 \pm 0.01$ & $0.12 \pm 0.10$ & $0.05 \pm 0.01$ \\
\hline C20:0 & $0.25 \pm 0.02$ & $0.47 \pm 0.03$ & $0.46 \pm 0.07$ & $0.47 \pm 0.16$ \\
\hline C20:1n15 & $0.02 \pm 0.01$ & $0.04 \pm 0.01$ & $0.02 \pm 0.01$ & $0.04 \pm 0.03$ \\
\hline $\mathrm{C} 20: \ln 12$ & $0.13 \pm 0.02$ & $2.08 \pm 0.11$ & $0.80 \pm 0.10$ & $1.38 \pm 0.48$ \\
\hline C20:1n9 & $0.39 \pm 0.09$ & $1.07 \pm 0.04$ & $1.22 \pm 0.19$ & $0.90 \pm 0.24$ \\
\hline $\mathrm{C} 20: \ln 7$ & $0.28 \pm 0.03$ & $1.96 \pm 0.11$ & $0.98 \pm 0.11$ & $1.53 \pm 0.59$ \\
\hline $\mathrm{C} 20: 2 \mathrm{n} 6$ & $0.24 \pm 0.03$ & $0.67 \pm 0.11$ & $0.60 \pm 0.14$ & $0.99 \pm 0.32$ \\
\hline $\mathrm{C} 20: 3 \mathrm{n} 6$ & $0.27 \pm 0.03$ & $0.17 \pm 0.03$ & $0.27 \pm 0.11$ & $0.17 \pm 0.07$ \\
\hline
\end{tabular}


Table 1 continued.

\begin{tabular}{lcccc}
\hline Fatty acid & Menhaden & 70MH30SP & 30MH70SP & Spot \\
\hline $\mathrm{C} 20: 4 \mathrm{n} 6$ & $1.45 \pm 0.22$ & $1.68 \pm 0.07$ & $1.04 \pm 0.13$ & $4.56 \pm 0.75$ \\
$\mathrm{C} 20: 3 \mathrm{n} 3$ & $0.30 \pm 0.05$ & $0.50 \pm 0.08$ & $0.53 \pm 0.14$ & $0.44 \pm 0.06$ \\
$\mathrm{C} 20: 5 \mathrm{n} 3$ & $7.80 \pm 0.35$ & $5.23 \pm 0.20$ & $6.13 \pm 0.34$ & $6.52 \pm 0.65$ \\
$\mathrm{C} 22: 0$ & $0.52 \pm 0.11$ & $0.39 \pm 0.07$ & $0.71 \pm 0.29$ & $0.38 \pm 0.09$ \\
$\mathrm{C} 22: 1 \mathrm{n} 9$ & $0.22 \pm 0.08$ & $0.25 \pm 0.07$ & $0.69 \pm 0.37$ & $0.28 \pm 0.08$ \\
$\mathrm{C} 22: 2 \mathrm{n} 6$ & $0.11 \pm 0.07$ & $0.12 \pm 0.07$ & $0.09 \pm 0.06$ & $0.15 \pm 0.09$ \\
$\mathrm{C} 22: 4 \mathrm{n} 6$ & $0.36 \pm 0.12$ & $0.63 \pm 0.12$ & $0.68 \pm 0.33$ & $1.15 \pm 0.29$ \\
$\mathrm{C} 22: 3 \mathrm{n} 3+\mathrm{C} 22: 5 \mathrm{n} 6$ & $1.38 \pm 0.20$ & $0.94 \pm 0.14$ & $1.15 \pm 0.40$ & $1.34 \pm 0.48$ \\
$\mathrm{C} 22: 5 \mathrm{n} 3$ & $1.44 \pm 0.18$ & $1.66 \pm 0.17$ & $1.72 \pm 0.36$ & $2.10 \pm 0.38$ \\
$\mathrm{C} 24: 0+\mathrm{C} 22: 6 \mathrm{n} 3$ & $13.87 \pm 1.02$ & $8.88 \pm 0.40$ & $10.09 \pm 0.82$ & $13.83 \pm 3.30$ \\
$\mathrm{C} 24: 1 \mathrm{n} 9$ & $0.74 \pm 0.16$ & $0.62 \pm 0.14$ & $1.13 \pm 0.32$ & $0.56 \pm 0.27$ \\
\hline
\end{tabular}


Table 3. Length, weight, and lipid levels of liver and belly flap samples for each diet fed during the experiment. Values represent the mean and 1 standard error of the mean.

\begin{tabular}{llcccc}
\hline & & & \multicolumn{2}{c}{ Lipid content } \\
Week & Diet & Length $(\mathrm{mm})$ & Weight $(\mathrm{g})$ & Liver $(\% \mathrm{WW})$ & Belly flap (\% WW) \\
\hline 0 & - & $352.83 \pm 6.59$ & $607.00 \pm 33.50$ & $5.54 \pm 0.34$ & $12.62 \pm 1.28$ \\
21 & Menhaden & $360.75 \pm 7.43$ & $745.25 \pm 55.68$ & $9.93 \pm 1.31$ & $22.19 \pm 4.45$ \\
48 & Menhaden & $390.50 \pm 6.89$ & $913.50 \pm 74.15$ & $10.37 \pm 0.67$ & $18.89 \pm 2.42$ \\
21 & $70 \mathrm{MH}: 30 \mathrm{SP}$ & $355.50 \pm 9.15$ & $593.00 \pm 50.40$ & $5.64 \pm 0.45$ & $8.10 \pm 0.59$ \\
48 & 70MH:30SP & $369.25 \pm 43.20$ & $801.25 \pm 120.31$ & $5.14 \pm 0.12$ & $11.36 \pm 2.01$ \\
21 & 30MH:70SP & $358.00 \pm 27.00$ & $629.50 \pm 133.50$ & $6.49 \pm 0.24$ & $10.10 \pm 0.41$ \\
48 & 30MH:70SP & $361.25 \pm 6.98$ & $744.28 \pm 64.02$ & $6.43 \pm 0.66$ & $9.47 \pm 2.40$ \\
\hline
\end{tabular}


Figure 1. NMDS plot of fatty acids identified in the diets, liver, and belly flap tissue in striped bass during the experiment. Fish were fed a diet of spot for six weeks and sampled on day 0. Striped bass were fed three diets: menhaden in tank 1 (T1), 70\% menhaden:30\% spot in tank 2 (T2), and 30\% spot:70\% menhaden in tank 3 (T3). These fish were sampled after a period of 6 weeks.

Figure 2. Mean values of select fatty acids from striped bass fed a mixed diet of $70 \%$ menhaden $30 \%$ spot for a) liver samples and b) belly flap samples. Error bars represent 1 standard error of the mean.

Figure 3. Mean values of select fatty acids from striped bass fed a mixed diet of $30 \%$ menhaden $70 \%$ spot for a) liver samples and b) belly flap samples. Error bars represent 1 standard error of the mean.

Figure 4. Proportional contributions of spot and anchovy to the fatty acid signature of striped bass during the baseline feeding of spot as calculated by the QFASA model. Anchovy was used as the feed during the acclimation of striped bass to the tank system. The dietary dataset of fatty acids variables was used to evaluate contributions. 
Figure 5. Proportional contributions of spot and menhaden to the fatty acid signature of striped bass as calculated by the QFASA model. The full dataset of fatty acids variables was used to evaluate contributions. Day refers to when the striped bass was sacrificed, $\mathrm{MH}$ is the $100 \%$ menhaden diet, $70 \mathrm{MH}: 30 \mathrm{SP}$ is the $70 \%$ menhaden $30 \%$ spot diet, and 30MH:70SP is the $30 \%$ menhaden $70 \%$ spot diet.

Figure 6. Proportional contributions of spot and menhaden to the fatty acid signature of striped bass as calculated by the QFASA model. The dietary dataset of fatty acids variables was used to evaluate contributions. Day refers to when the striped bass was sacrificed, $\mathrm{MH}$ is the $100 \%$ menhaden diet, $70 \mathrm{MH}: 30 \mathrm{SP}$ is the $70 \%$ menhaden $30 \%$ spot diet, and 30MH:70SP is the $30 \%$ menhaden $70 \%$ spot diet. 
Figure 1.

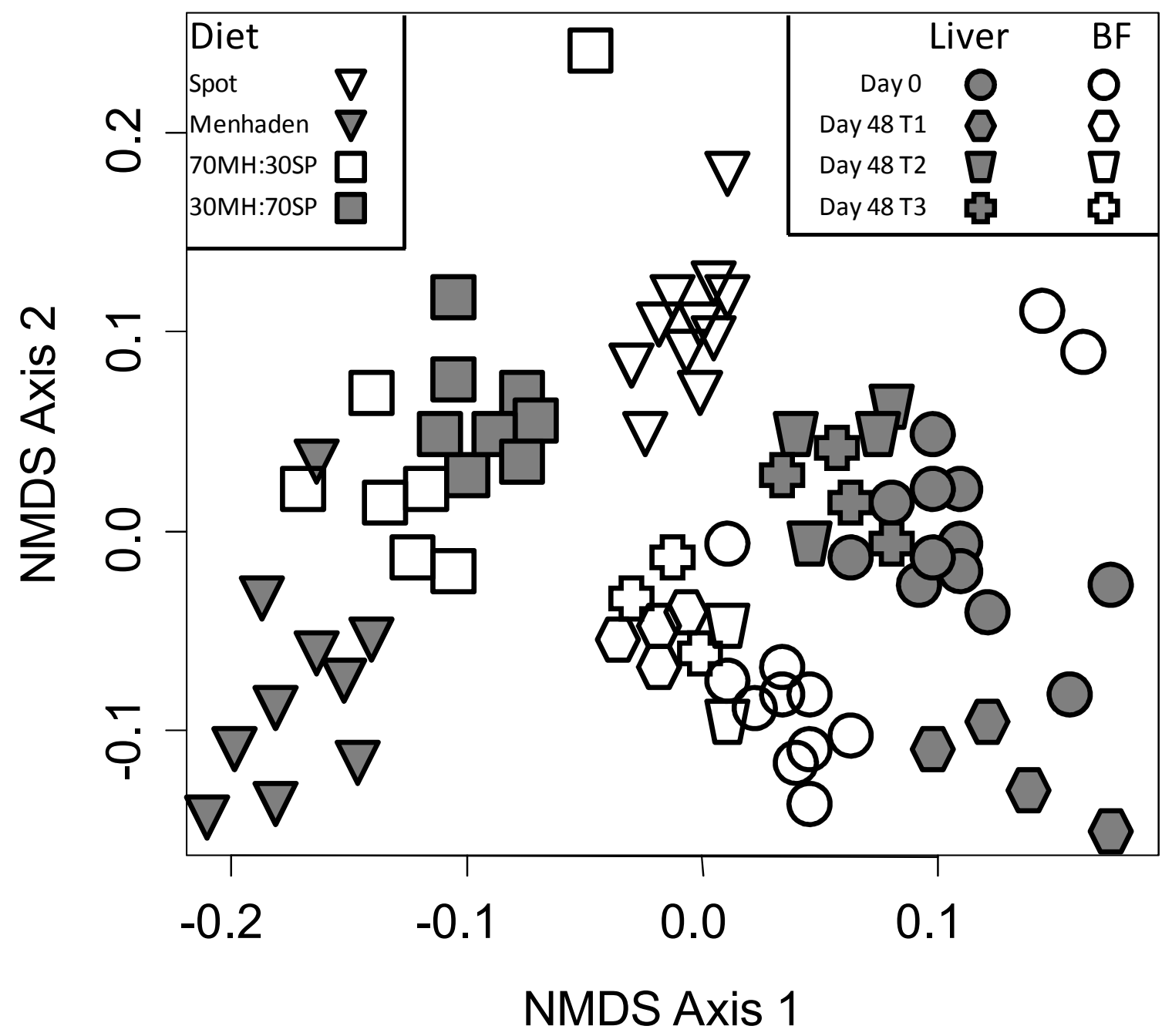


Figure 2.

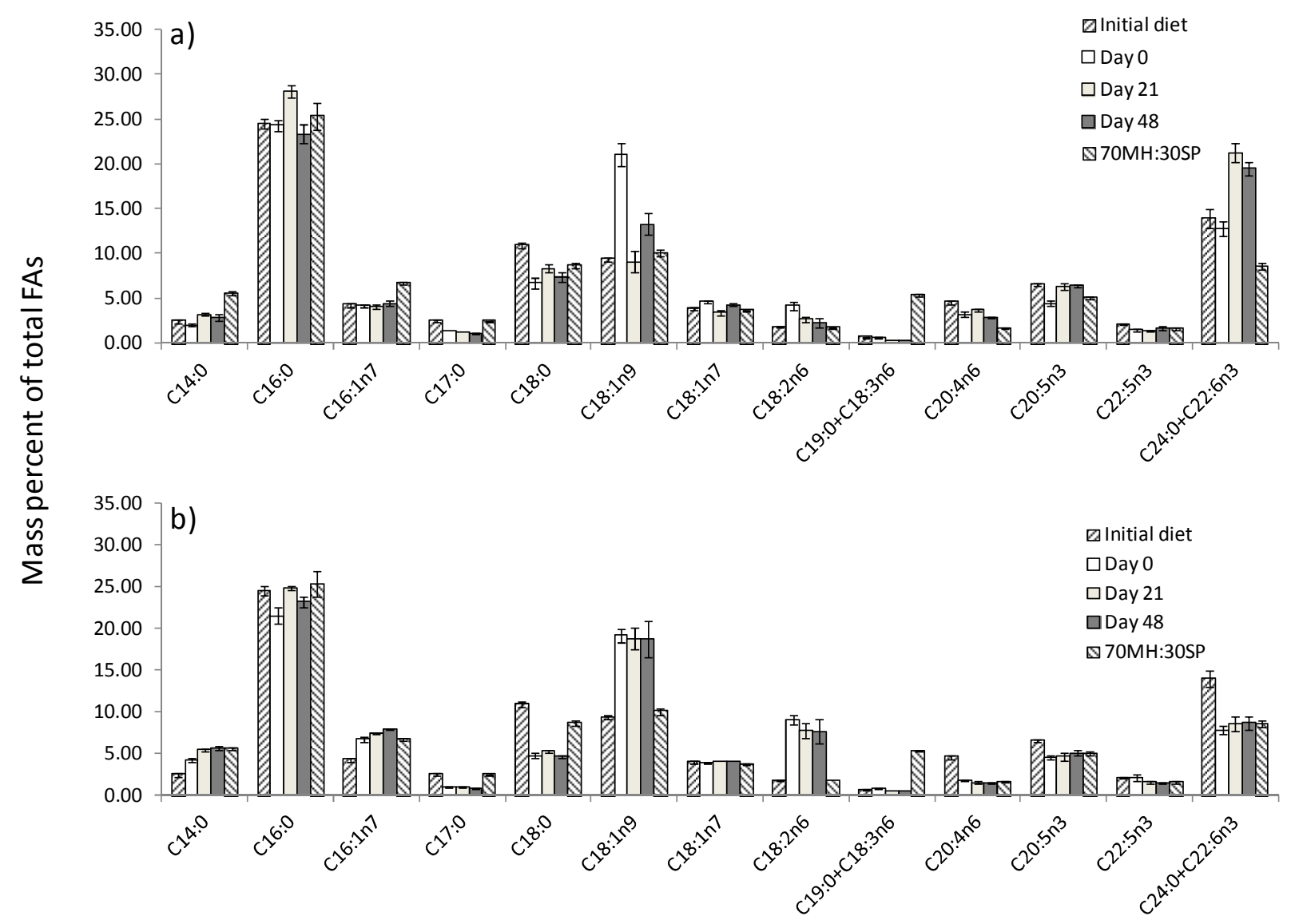

Fatty acid 
Figure 3.

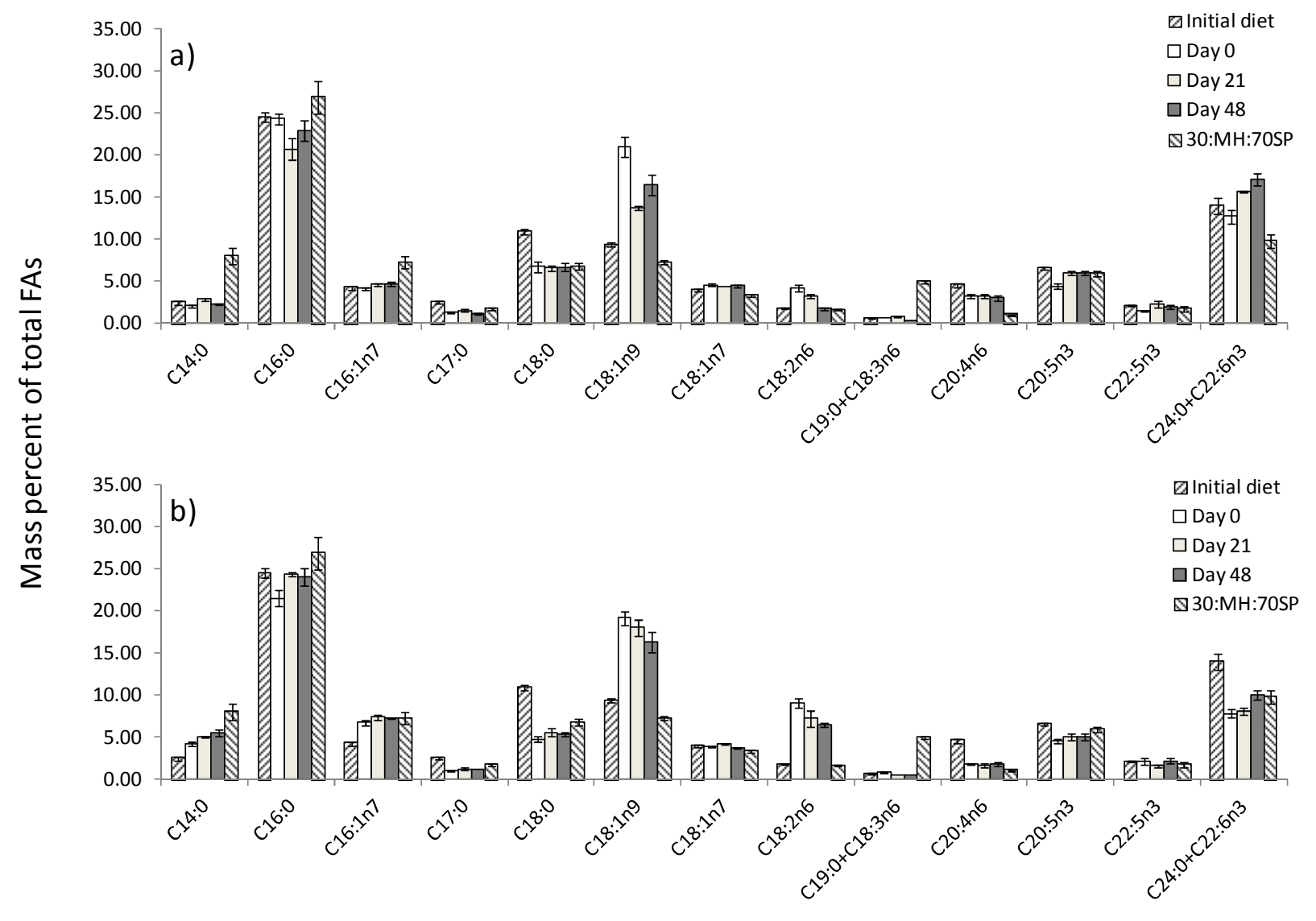

Fatty acid 
Figure 4.

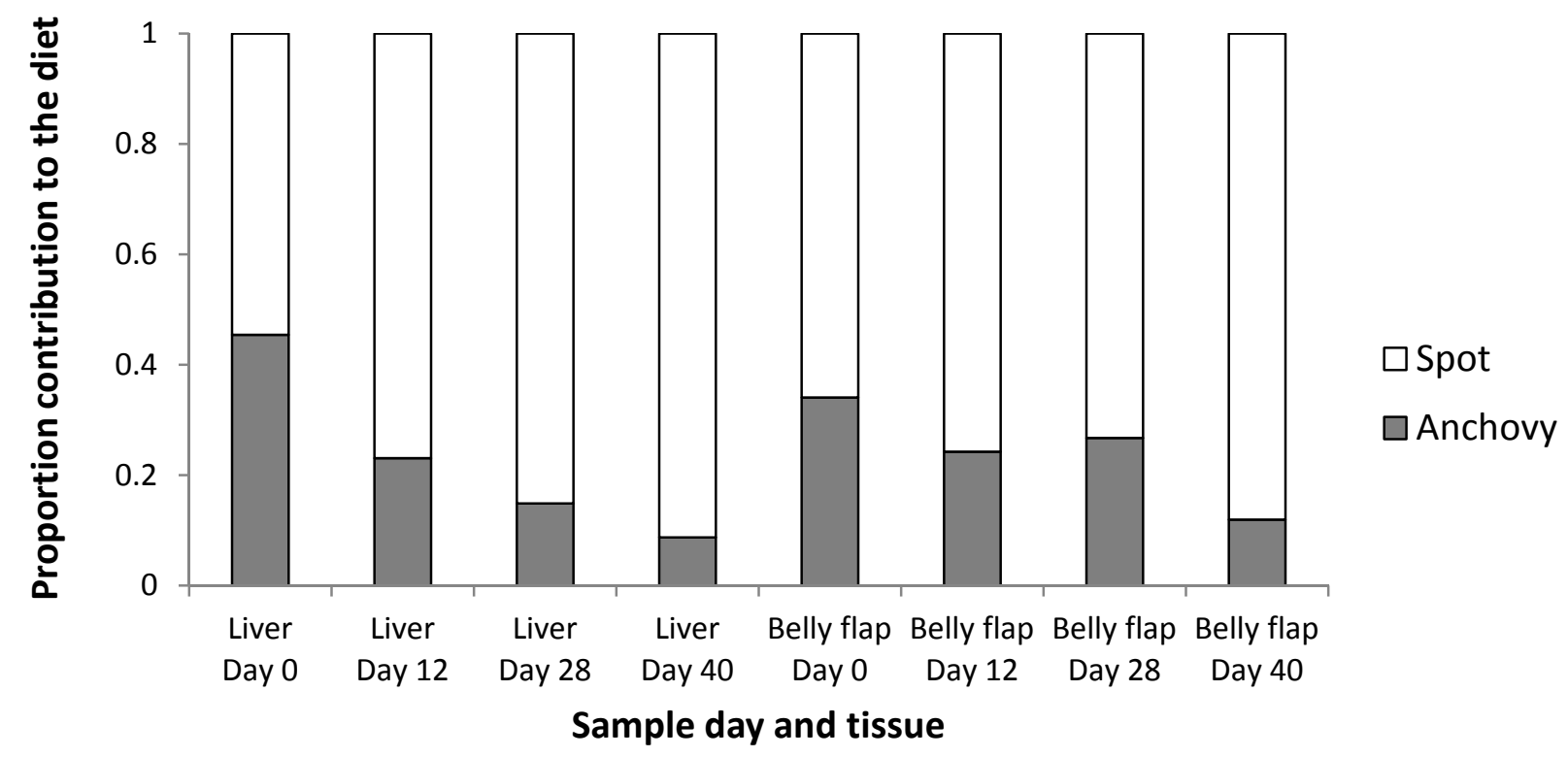


Figure 5.

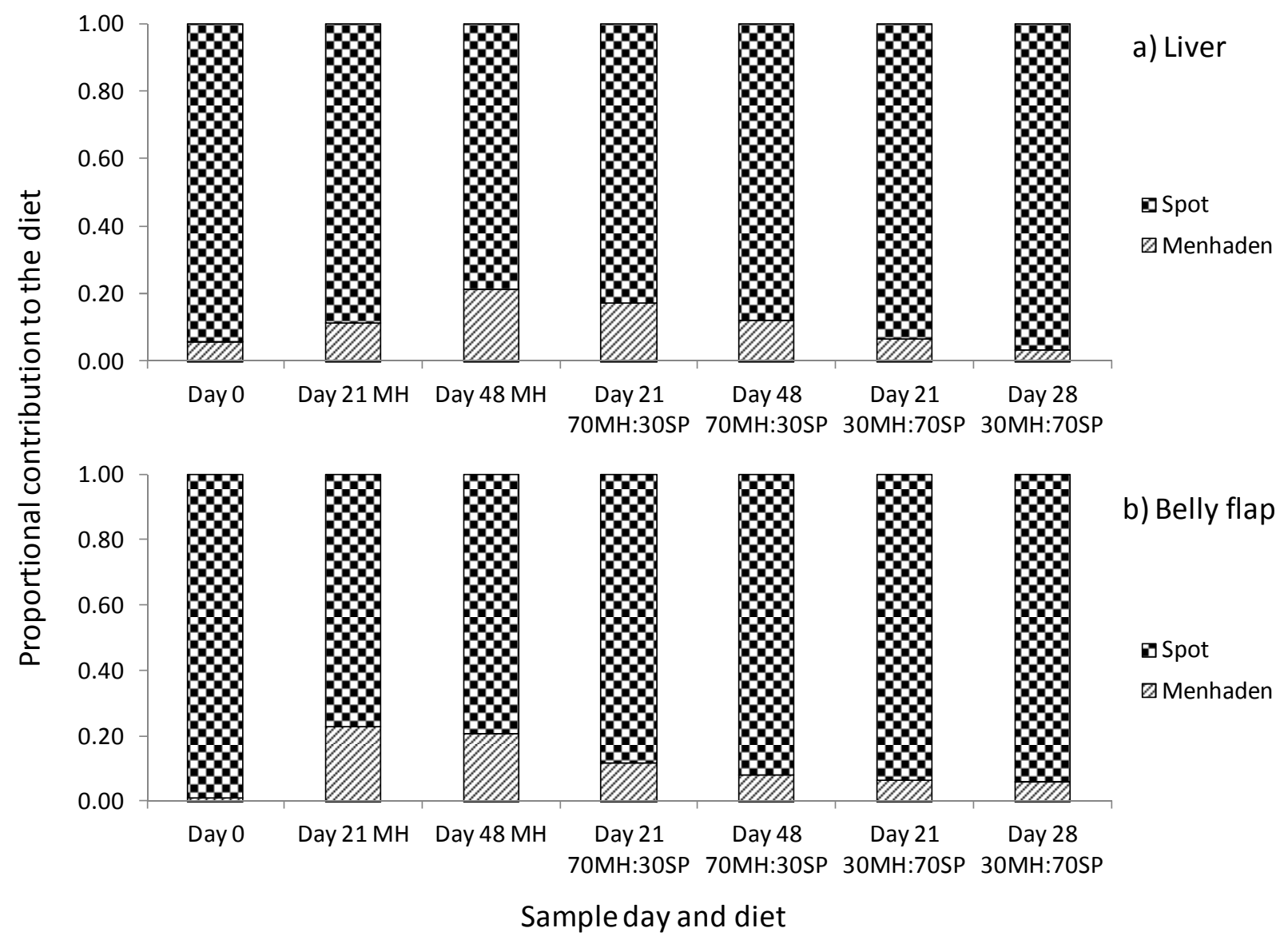


Figure 6.

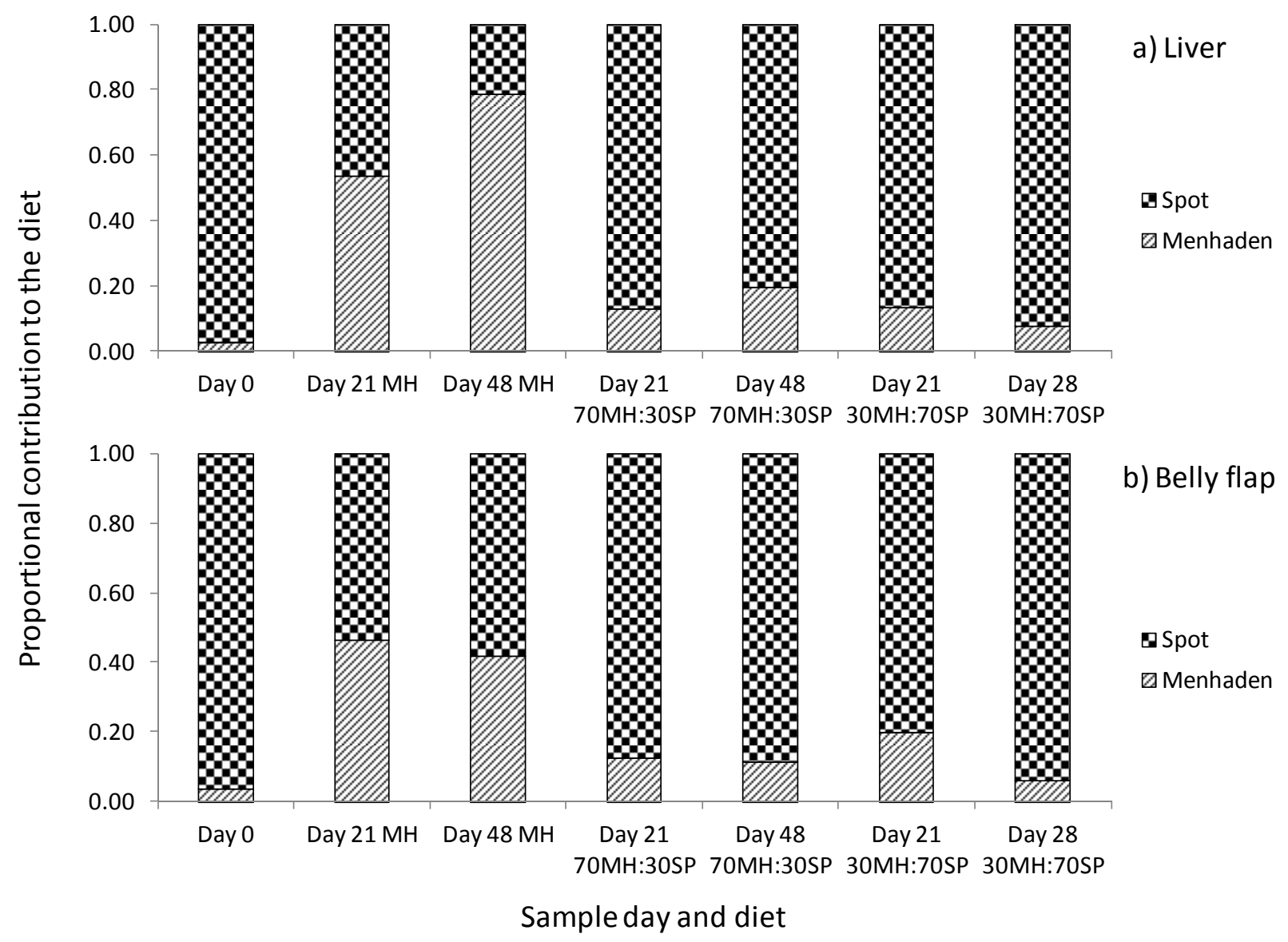


Chapter 6 - Field validation of quantitative fatty acid signature analysis (QFASA) for Chesapeake Bay striped bass 


\begin{abstract}
Food web models are constructed based upon information gathered from analyzing stomach contents of the candidate species. These methods have well known biases, e.g. shorter retention time for prey items in the gut at elevated temperatures, over estimation of prey with digestion resistant hard parts, and metrics skewed towards the last meal. A biochemical alternative, fatty acid (FA) analysis, has been shown in previous studies to give a more accurate estimation of the feeding history. Recently, a quantitative model based on FAs has been developed. Quantitative FA signature analysis (QFASA) can estimate proportions of prey items consumed. The goal of this study was to corroborate the findings of the QFASA model and stomach contents for wild caught striped bass. Seventy-eight striped bass (Morone saxatilis) were caught in the Choptank River during October 2009. During the fall, the QFASA model should have the highest chance of success due to high and continued feeding on Atlantic menhaden (Brevoortia tyrannus), which provides a simple natural condition on which to test the model. These fish were analyzed for FAs and prey species caught in the upper Chesapeake Bay in fall were used as the possible prey items. Stomach contents revealed that striped bass were indeed feeding predominantly on menhaden, however, the QFASA model using the dietary dataset (16 FA) and the extended dataset (30 FA) determined that bay anchovy (Anchoa mitchilli) and spot (Leiostomus xanthurus) were the major constituents of the diet. Studies using QFASA on homeotherms (marine mammals and sea birds) have produced reliable and verifiable prey structure in the wild. However, the results of the present study indicate that the QFASA model needs to be further optimized for fish species in a laboratory setting before it can employed in the field.
\end{abstract}




\section{Introduction}

The interactions between predator and prey and the subsequent construction of food webs are important themes in the ecology of fishes (Baird and Ulanowicz 1989). These food webs provide links among the various species modeled, and are often based on estimates of the diet from the recovery of prey items in the stomachs of the predator (e.g., Berg 1979, Durbin et al. 1983, Blanco et al. 2003, Harvey et al. 2003). The effects of predation become increasingly important when the prey species are also commercially harvested (Yodzis 2001). Although the idea of connectedness of species is not a new one (Paine 1980), it is only recently that this concept has been incorporated into management strategies, e.g. ecosystem based fisheries management (Pikitch et al. 2004). These models attempt to include species interactions rather than modeling each species as an individual unit (Brodziak and Link 2002). However, these models are all based upon estimates of diet from stomach contents analysis, which has well known biases (Pierce and Boyle 1991).

An analysis of stomach contents often provides information on the recent feeding history. The rate of digestion is not equal for all items consumed. Hard parts associated with prey items may be more resistant to digestion (Hyslop 1980), leading to an overestimation of these particular prey species. The digestive capacity of a predator is not uniform and is influenced by

temperature. Warmer temperatures will lead to higher metabolic activities and reduce the time in which prey items are retained in the gut (He and Wurtsbaugh 1993). These biases have the potential to insert a large degree of error when calculating diets for fish, and this error will be carried through the construction of food web models.

Alternative methods for estimating diet include the use of fatty acids (FAs; Desvilettes et al. 1997, Kharlamenko et al. 1995, Alfaro et al. 2006) or stable isotopes (Hansson et al. 1997, 
Pinnegar and Polumin 2000, Sotiropoulos et al. 2004) as trophic markers. FAs are a large constituent of lipids and undergo little to no modification when incorporated into a predator's tissue (Tocher 2003). Therefore, it can be argued that the FAs present in a predator should mimic those of the prey species consumed (Kirsch et al. 1998). Studies that have attempted to use FA analysis with fish have focused on using prey FA signatures (a compilation of all FAs identified within an individual) to estimate what species a predator was consuming (Budge et al. 2002, Kainz et al. 2004, Alfaro et al. 2006). This qualitative estimate of diet is limited because proportions of different prey groups consumed cannot be inferred.

A model developed recently, quantitative FA signature analysis (QFASA; Iverson et al. 2004), allows the proportion of each diet item to be estimated by comparing the signatures of prey versus the signature of the predator. Predator FA metabolism is accounted for with calibration coefficients (CC), which are calculated in captive feeding trials (Iverson et al. 2004). These values account for the differential mobilization and use of fatty acids in a predator. The values will be one if there is an exact match between prey abundance and predator abundance of that fatty acid, less than one if that fatty acid is more prevalent in prey tissues and greater than one if the fatty acid is more prevalent in the predator's tissues. This model has been used for marine mammals (Thiemann et al. 2008, Tucker et al. 2009, Meynier et al. 2010) and sea birds (Iverson et al. 2007), with little research performed on fish species (Budge et al. 2011).

Constructing food web models in the Chesapeake Bay has been performed, but difficulties are abundant. Striped bass (Morone saxatilis), for example, are apex predators that spawn in the bay. The spawning population returns to the coastal stocks after breeding, while immature fish will remain in the bay for the first two to eight years of life, depending on the sex of the fish (Setzler-Hamilton and Hall 1991). The Chesapeake Bay is categorized as a continuum 
of salinity with oligohaline ( $0-6$ parts of thousand $[\mathrm{ppt}])$, mesohaline (6-18 ppt), and polyhaline (>18 ppt) regions (Stroup and Lynn 1963). Salinity structures the fish community in each of these regions which leads to different community compositions (Jung and Houde 2003). The effects of season and salinity make modeling food webs for the entire Chesapeake Bay troublesome. Baird and Ulanowicz (1989), for example, were only able to model species interactions for the mesohaline region of the bay in summer.

Accurate estimates for an apex predator like striped bass are necessary to properly manage the population. This fish has been an important commercial and recreational resource (Chesapeake Bay Fisheries Ecosystem Advisory Panel 2006), but due to overfishing, the population began a rapid decline in the 1970s (ASMFC 1981). This reduction in population resulted in a moratorium being placed on the species in Maryland and Virginia during the 1980s, which led to a population recovery in the 1990s (ASMFC 1995), and stock assessments have shown the population is stable. However, there have been observations of emaciated fish with external lesions and internal granulomas (Baya 1998, Uphoff 2003). These symptoms are linked to the infectious bacteria mycobacteriosis (Heckert et al. 2001, Rhodes et al. 2004). Theories suggest that striped bass might be competing for their preferred prey, menhaden, with other fish species and humans. Hartman (2003) demonstrated that striped bass feeding demand in the Hudson River has exceeded the supply of prey species. A similar situation may be occurring in the Chesapeake Bay which could lead to an increased susceptibility to bacterial infections. Malnutrition in fish can lead to suppressed immune systems, which in turn make the fish susceptible to infectious agents like Mycobacterium spp. (Jacobs et al. 2009).

The goal of this study was to use the QFASA model on wild caught Chesapeake Bay striped bass to estimate the contribution of prey species to the diet. To reach this goal, our 
specific objectives were: 1) to estimate striped bass diets using stomach contents, and 2) to compare the stomach contents to the results of the QFASA model to determine if and to what proportion spot (Leiostomus xanthurus), menhaden, bay anchovy (Anchoa mitchilli), and blue crab (Callinectes sapidus) collected in the same season as the striped bass contributed to the striped bass FA signature in the belly flap tissue.

\section{Materials and Methods}

\section{Sample collection and preparation}

Seventy-eight striped bass were collected in October 2009 by hook and line, with the help of a local fisherman (J. Price), in the vicinity of the Choptank River, Maryland. Fish were vacuum sealed and stored at $-20^{\circ} \mathrm{C}$ once returned to the lab. Striped bass were thawed at the time of analysis, weighed to the nearest 0.1 gram, and measured to the nearest millimeter (total length). A sample of the belly flap was removed for lipid extraction and FA analysis. The belly flap (with skin intact) follows a line marked by the termination of the ribs and initiation of the peritoneum of the body wall (Jacobs et al. 2008). The belly flap represents a depot of fat storage and a tissue with little commercial value, making it an ideal candidate for estimating diet with FAs. All tissues were ground with a chemical drying agent, diatomaceous earth (Dionex, Sunnyvale, CA) and had a known amount of internal standard (C13:0 triacylglycerol) added to determine the efficiency of the extraction process.

Lipids were extracted under nitrogen using an Accelerated Solvent Extractor (ASE 300, Dionex, Sunnyvale, CA) with a mixture of 3:1 (v/v) dichloromethane:methanol and $0.1 \%$ butylated hydroxytoluene (BHT) as an antioxidant. Samples were extracted once at $100^{\circ} \mathrm{C}$ and 1500 psi (USEPA 2007). Samples were back-extracted using a $0.88 \%$ potassium chloride 
solution in deionized water to remove non-lipid materials from the extracts (Folch et al. 1957). Total lipid extracted was determined gravimetrically for each sample and reported as a percent of wet weight.

Extracted lipid species containing FAs as various derivatives were transesterified using a solution of sulfuric acid and methanol. In this process, acylglycerols are broken apart to their constituents: glycerol and FAs methyl esters (FAMEs). Free FAs present in the lipid mixture are also converted to FAMEs (Christie 2003). Sample extracts were cleaned with silica gel and anhydrous sodium sulfate to remove polar components and water, which may degrade the performance of the gas chromatograph column. The silica column was conditioned with hexane and the sample was added along with hexane and diethyl ether, 95:5, v/v (Christie 2003). The mixture was concentrated to $5 \mathrm{ml}$ and diluted to a final total lipid concentration of $100 \mu \mathrm{g} / \mathrm{ml}$. Finished samples were run on a gas chromatograph (Agilent 6890N Network GC System, Santa Clara, CA) / mass spectrometer (GC/MS, Agilent, 5973 Network Mass selective detector, Santa Clara, CA) in select ion monitoring mode.

The GC/MS was used to identify and quantify FA methyl esters in each sample. FAMEs were injected into a fused capillary column, DB-23 $60 \mathrm{~m}$ length X $0.250 \mathrm{~mm}$ OD X $0.25 \mu \mathrm{m}$ film thickness (Agilent, Santa Clara, CA) using an autosampler (Agilent 7683 Series Auto Sampler). Hydrogen was used as a carrier gas. The temperature program was as follows: hold at an initial temp of $50^{\circ} \mathrm{C}$ for $2 \mathrm{~min}$, hold at $150^{\circ} \mathrm{C}$ for $1 \mathrm{~min}$ after ramping at $20^{\circ} \mathrm{C} \cdot \mathrm{min}^{-1}$, ramp at $1.25^{\circ} \mathrm{C} \cdot \min ^{-1}$ until $215^{\circ} \mathrm{C}$. The FA retention times were compared to known standards from $\mathrm{Nu}-$ Chek Prep (GLC MIX 85, 411, 642, 632, Elysian, MN). These four standard mixtures were combined along with stearidonic acid (C18:4n3, Cayman Chemical, Ann Arbor, MI) to make a total FAME standard solution of $12.25 \mu \mathrm{g} / \mathrm{ml}$. Matreya 25 FAME mixture (Pleasant Gap, PA) 
was used to obtain retention times for C20:1n7. Restek cis/trans FAME mixture (Bellefonte, PA) was used to obtain retention times for $\mathrm{C} 18: 1 \mathrm{n} 9$ trans and $\mathrm{C} 18: 2 \mathrm{n} 6$ trans. These standards and an internal standard of C13:0 FAME $(100 \mu \mathrm{g} / \mathrm{ml})$ were added to quantify the amount of each FA methyl ester present. The GC/MS tracks the select ion signature of each compound and was used to verify the identity of each peak. There were peaks which consisted of more than one FA and it was impossible to determine which FA(s) constituted the peaks. Therefore, the term "FA complex" was assigned to this peak. The complex refers to which FAs could be responsible for the peak, e.g. C22:3n3 and C22:5n6.

\section{Statistical analyses}

Nonmetric multidimensional scaling (NMDS) was performed on the data (R Development Core Team 2010, Vienna, Austria). This ordination technique is an iterative search for the best position of samples in multidimensional space, and uses the stress value as an indicator for the best solution. A distance matrix was calculated for the FAs, and the samples are ordinated based on the distances calculated (McCune and Grace 2002).

\section{Calibration coefficients and FA subsets}

Calibration coefficients were calculated during a captive feeding study with striped bass and spot. The values account for the metabolism of a FA by striped bass, as different FAs may have different fates when they are digested. Twelve striped bass were sacrificed after being fed spot for six weeks, and the FA signature of the belly flap was analyzed. Eleven samples of spot were also analyzed for their FA signature. The coefficients were obtained by dividing the proportion of a FA in striped bass by the proportion of that same FA in spot (Iverson et al. 2004). Each striped bass is compared to each prey item, resulting in 132 calibration coefficients for each 
FA. The six highest and lowest values were removed before the mean was calculated to remove any extreme outliers (10\% trimmed mean; Iverson et al. 2004).

A subset of the FAs is used for the QFASA model. In our experiment, two FA datasets were created. The first, an extended FA dataset, included all FAs that had a proportion $>0.1 \%$ $(\mathrm{n}=30)$. The second dataset, a dietary dataset, consisted of FAs derived primarily from the diet $(\mathrm{n}=16)$. For a list of these calibration coefficients and fatty acid subsets, see Chapter 5: Table 1. Once FAs the datasets were constructed, the proportions were renormalized to $100 \%$.

\section{Diet estimation}

Stomach contents of striped bass were examined and a percent of occurrence for each prey taxa was calculated. Vertebrae of digested fish were counted in order to classify the fish species (K. Hartman; personal communication). The diet of striped bass was estimated using the QFASA model (Iverson et al. 2004). The model uses the prey FA signatures and tries to estimate which mixture of prey comes closest to matching the predator's actual signature. The best mixture of prey FAs is weighted by the fat content of the prey species, as fish with higher lipid levels will contribute a larger concentration of FAs. The model uses an optimization procedure which aims to minimize the distance between the predicted and observed predator signature, the Kullback-Liebler (KL) distance. The optimization uses a quasi-Newton algorithm with a Broyden-Fletcher-Goldfarb-Shanno formula and was carried out with a package developed at Massey University, New Zealand (FA solution - Dr. R. Sheriff and A/Prof P.C.H. Morel). 


\section{Results}

The prey analyzed in this experiment differed in their fat content, with menhaden and bay anchovy having higher lipid levels than blue crab and spot. Striped bass belly flap tissue had an average lipid content of $5.24 \%$ by wet weight (Table 1 ).

The complete FA signature for striped bass and the prey items are given in Table 2 . There were marked differences among the prey species in regards to the proportions of individual FAs (Fig. 2). For example, blue crab had approximately twice the relative amount of C18:2n6, while menhaden had the highest levels of $\mathrm{C} 16: 1 \mathrm{n} 7$ and $\mathrm{C} 24: 1 \mathrm{n} 9$. There were also differences related to whether the prey taxa were benthic or pelagic, e.g. menhaden and bay anchovy (pelagic) had higher levels of C14:0 and C16:0 compared to spot and blue crab (benthic).

\section{Diet estimation}

The percent biomass of prey in the stomachs was calculated for striped bass in this experiment. Of the 78 striped bass $(505.91 \pm 5.27 \mathrm{~mm}$; Table 1$)$ analyzed, 36 had empty stomachs. The diet of striped bass specimens that had full stomachs consisted of menhaden (93.12\%), blue crab (1.25\%) and unidentified fish (5.63\%; not included in Fig. 3). Unidentified fish consisted of vertebral columns that were incomplete, preventing positive identification. Diet estimations (as percent biomass of prey) from Hartman and Brandt (1995) and Overton et al. (2000) are provided for age three striped bass in the middle Chesapeake during the fall (September - October) for comparison.

A qualitative approach was taken with the FA signatures from each taxa, and ordinated using NMDS (Fig. 2). Based upon the spacing of species and the $95 \%$ confidence interval around them, spot contributed the highest proportion to striped bass FA signatures, followed by bay 
anchovy. There was a minimal degree of overlap between menhaden and striped bass, and blue crab and striped bass.

Quantitative estimates of diet based on stomach contents and the QFASA model were not in agreement (Fig. 3). According to the model, spot contributed the highest proportion to the diet, followed by bay anchovy. Menhaden and blue crab made minor contributions to the diet. The results from the $16 \mathrm{FA}$ dataset and $30 \mathrm{FA}$ dataset yielded different results. The truncated dataset estimated the contribution of spot and bay anchovy to by 59.22 and $37.61 \%$, respectively; while the full dataset estimated the contribution of spot and bay anchovy to be 80.66 and $16.34 \%$, respectively. The results from both models had high KL distances: 30.32 for the 16 FA model and 27.32 for the 30 FA model.

\section{Discussion}

The results of this study indicate that the QFASA model was unable to correctly characterize the diets of striped bass collected from the Chesapeake Bay. FA incorporation into a predator's signature takes several weeks (Kirsch et al. 1998). Striped bass were sampled in October based upon the findings of previous studies in which striped bass were feeding heavily on menhaden between August and December (Hartman and Brandt 1995, Overton et al. 2000). This suggested that by collecting striped bass in October, sufficient time would be allowed for the menhaden signature to become incorporated into striped bass tissues. The stomach contents reinforced this notion due to the higher number of menhaden present in the diet.

Lipid levels in the wild caught striped bass indicate that these fish have been feeding for an extended period. Jacobs et al. (2008) found that age-1 striped bass (mean length $=241.8 \mathrm{~mm}$ ) had belly flap lipid levels of $8.67 \%$ by wet weight for fed fish and $3.72 \%$ by wet weight for 
starved fish after a period of 42 days. Larger fish tend to store more lipid than smaller fish, and the striped bass in our experiment were around age- 3 fish. A lipid level of $5.24 \%$ by wet weight would point to a situation where striped bass have been feeding below satiation, but were not being starved.

Striped bass in this experiment were caught within days of each other in order to limit the variation in the feeding regime. The stomach contents of the striped bass collected indicated that the predominant prey item was Atlantic menhaden. Hartman and Brandt (1995) and Overton et al. (2000) found comparable diets for similar sized fish in the fall. While other prey items were found in the diets for our study, the unidentified group may have been menhaden whose spinal columns were separated during the digestive process.

The switch to a new prey item in fish is detectable after a period of three weeks (Kirsch et al. 1998) but the signature may not be completely stable until 12 to 14 weeks (Jobling 2003, Budge et al. 2011). The instability of the FAs in the signature of fish may prevent quantitative estimates of diet using QFASA. The diet of a fish may need to be constant for a period of months rather than weeks or days in order for the QFASA model to be utilized. This situation is not likely, as striped bass are known to change their feeding throughout the year (Manooch 1973, Overton et al. 2009). However, based upon the findings of this study, striped bass may have been feeding on spot and bay anchovy for the past several weeks, prior to the sampling period.

Some striped bass are known to move to different areas over small temporal scales, e.g. one to four weeks (Mansueti 1961). These different areas may be a different river system in which prey species are the same, but the FA signature of the prey is different (Chapter 2). The movements of striped bass would prevent researchers from knowing from which system prey species originated, possibly leading to using an erroneous dataset of FAs to represent potential 
prey species. While this would still be an issue if FA signatures were incorporated over a period of three weeks, it becomes a serious obstacle to overcome if FAs need 12 to 14 weeks to stabilize in fish tissues.

The results of the QFASA model indicated that spot and bay anchovy were the predominant prey of striped bass; with blue crab and menhaden making small contributions to the diet. The proportional contribution of spot was less in the model that used the dietary FA dataset (16 FA) versus the full dataset ( $30 \mathrm{FA})$. Studies have shown that the dataset based only on FAs obtained from the diet yields better results (Iverson et al. 2004, Beck et al. 2007). We have also found that even when the model was incorrect, better results were obtained from this truncated dataset (Chapter 5).

Studies have shown that the FA signature of fish species is affected by season (Bandarra et al. 2001) and location (Recks and Seaborn 2008). Therefore, prey samples analyzed were collected in the same season (often in the same month) as the striped bass. However, due to logistical constraints, prey samples were collected from areas in the upper bay as close to the Choptank River as possible, but not necessarily from the same system. No discernible pattern in FA signature was detected for anchovy and menhaden in the upper bay versus the lower bay (Chapter 2), and it becomes difficult to determine whether collecting samples from areas different than collection of striped bass affected the results seen in this experiment. It would be advisable for future studies to collect all species at the same time in the same location (if possible) to try and remove any spatial error.

The process by which the FA profile changes in striped bass could provide insight into the shortcomings of the QFASA model. A dilution model worked well with Atlantic salmon (Salmo salar) to document the change of FAs from one diet to another (Jobling 2003). In this 
model, the FAs from the original diet become diluted or lowered in prevalence as the new diet is consumed. FA signatures from both diets would be present in the tissues until FAs from the new diet have finally diluted the concentrations of fatty acids from the previous diet. Striped bass in this study may not have been feeding on menhaden long enough to allow for the dilution of spot signatures.

The FA model QFASA does not appear feasible for estimating the diets of striped bass in the Chesapeake Bay at this time. The results indicate the diet was dominated by a prey that was not present in the stomachs. There is a possibility that the FA signature did not have adequate time to stabilize and reflect the current diet. In order for this technique to be viable in estimating diets of wild fish, there must be a minimal lag time between the corroboration of FA incorporation and stomach contents. Further laboratory studies are needed to determine whether FAs present in striped bass represent an amalgam of all prey taxa, or if the previous signature is washed out completely replaced by the new signature. More work also needs to be done to determine which tissue represents the best candidate for the QFASA model. The belly flap is a long term storage depot, and it may be difficult to overwrite the fatty acid signature. Other areas of the fish that contain mobile fatty acids, e.g. the liver of the blood, may represent a better alternative to further test this model.

\section{Acknowledgements}

The authors would like to thank J. Price J. Councilman, A. Leight, J. Brush, and W. Lowery for assistance in collecting samples. We are also indebted to B. Dockum and L. Gonsalves for advice and assistance in the chemical analysis of samples. Em. McGinley provided invaluable help in the laboratory preparing and analyzing samples and L. Meynier provided access to the statistical 
program. We are grateful for the comments provided by anonymous reviewers. This research was made possible by funding from NOAA Chesapeake Bay Office Grant No. NA07NMF4570330 and all research was conducted under West Virginia University Animal Care and Use Protocol number 09-0102. 


\section{Literature cited}

Alfaro, A.C., F. Thomas, L. Sergent, and M. Duxbury. 2006. Identification of trophic interactions within an estuarine food web (northern New Zealand) using FA biomarkers and stable isotopes. Estuarine, Coastal and Shelf Science 70:271-286.

ASMFC (Atlantic States Marine Fisheries Commission). 1981. Interstate fisheries management plan for the striped bass. Fisheries Management Report No. 1, Washington, D.C.

ASMFC (Atlantic States Marine Fisheries Commission). 1995. Amendment \#5 to the interstate fishery management plan for Atlantic striped bass. ASMFC. Fisheries Management Report 24, Washington, D.C.

Baird, D., and R. E. Ulanowicz. 1989. The seasonal dynamics of the Chesapeake Bay ecosystem. Ecological Monographs 59:329-364.

Bandarra, N., I. Batista, M.L. Nunes, and J.M. Empis. 2001. Seasonal variation in the chemical composition of horse-mackerel (Trachurus trachurus). European Food Resources and Technology 212:535-539.

Baya, A.M. 1998. Gram positive bacteria and skin lesions in Chesapeake Bay fish. Proc Workshop Causes and Effects of Ulcerative Lesions in Fish, Easton, MD. Maryland Department of Natural Resources, Oxford, MD. p 11.

Beck, C.A., S.J. Iverson, W.D. Bowen, and W. Blanchard. 2007. Sex differences in grey seal diet reflect seasonal variation in foraging behavior and reproductive expenditure: evidence from quantitative FA signature analysis. Journal of Animal Ecology 76:490-502.

Berg, J. 1979. Discussion of methods of investigating the food of fishes, with reference to a preliminary study of the prey of Gobiusculus flavescens (Gobiidae). Marine Biology 50:263-273. 
Blanco, S., S. Romo, M.J. Villena, and S. Martinez. 2003. Fish communities and food web interactions in some shallow Mediterranean lakes. Hydrobiologia 506-509:473-480.

Brodziak, J. and J. Link. 2002. Ecosystem-based fishery management: what is it and how can we do it? Bulletin of Marine Science 70:589-611.

Budge, S. M., Iverson, S. J., Bowen, W. D and Ackman, R. G. 2002. Among- and within-species variability in the FA signatures of marine fish and invertebrates on the Scotian Shelf, Georges Bank, and southern Gulf of St. Lawrence. Canadian Journal of Fisheries and Aquatic Sciences 59, 886-898.

Budge, S.M., S.N. Penney, S.P. Lall. 2011. Response of tissue lipids to diet variation in Atlantic salmon (Salmo salar): implications for estimating diets with FA analysis. Journal of Experimental Marine Biology and Ecology 409:267-274.

Chesapeake Bay Fisheries Ecosystem Advisory Panel (National Oceanic and Atmospheric Administration Chesapeake Bay Office). 2006. Fisheries ecosystem planning for Chesapeake Bay. American Fisheries Society, Trends in Fisheries Science and Management 3, Bethesda, Maryland.

Christie, W.M. 2003. Lipid Analysis. PJ Barnes and Associates. Bridgewater, England. Desvilettes, C., G. Bourdier, C. Amblard, and B. Barth. 1997. Use of FAs for the assessment of zooplankton grazing on bacteria, protozoans, and microalgae. Freshwater Biology 38:629-637.

Durbin, E.G., A.G. Durbin, R.W. Langton, and R.E. Bowman. 1983. Stomach contents of silver hake, Merluccius bilinearis, and Atlantic cod, Gadus morhua, and estimation of their daily rations. Fishery Bulletin 81:437-454. 
Folch, J., M. Lees, and G.H. Sloane Stanley. 1957. A simple method for the isolation and purification of total lipids from animal tissues. The Journal of Biological Chemistry:497509.

Hansson, S., J.E. Hobbie, R. Elmgren, U. Larsson, B. Fry, and S. Johansson. 1997. The stable nitrogen isotope ratio as a marker of food-web interactions and fish migration. Ecology $78: 2249-2257$.

Hartman, K.J. 2003. Population-level consumption by Atlantic coastal striped bass and the influence of population recovery upon prey communities. Fisheries Management and Ecology 10:281-288.

Hartman, K. J., and S. B. Brandt. 1995. Trophic resource partioning, diets, and growth of sympatric estuarine predators. Transactions of the American Fisheries Society 124:520537.

Harvey, C.J., S.P. Cox, T.E. Essington, S. Hansson, and J.F. Kitchell. 2003. An ecosystem model of food web and fisheries interactions in the Baltic Sea. ICES Journal of Marine Science 60:939-950.

He, E. and W.A. Wurtsbaugh. 1993. An empirical model of gastric evacuation rates for fish and an analysis of digestion in piscivorous brown trout. Transactions of the American Fisheries Society 122:717-730.

Heckert, R.A., S. Elankumaran, A. Milani, and A. Baya. 2001. Detection of a new Mycobacterium species in wild striped bass in the Chesapeake Bay. Journal of Clinical Microbiology 39:710-715.

Hyslop, E.J. 1980. Stomach contents analysis - a review of methods and their application. Journal of Fish Biology 17:411-429. 
Iverson, S.J. C. Field, W.D. Bowen, and W. Blanchard. 2004. Quantitative FA signature analysis: a new method of estimating predator diets. Ecological Monographs 74:211235.

Iverson, S.J., A.M. Springer, and A. Kitaysky. 2007. Seabirds as indicators of food web structure and ecosystem variability: qualitative and quantitative diet analyses using FAs. Marine Ecology Progress Series 352:235-244.

Jacobs, J. M., M.R. Rhodes, B. Martin, D. McIntosh, W.F. Van Heukelem, and R.M. Harrell. 2008. Tissue-specific sampling for estimation of striped bass whole-body proximate composition. Transactions of the American Fisheries Society 137:386-392.

Jacobs, J.M., M.R. Rhodes, A. Baya, R. Reimschuessel, H. Townsend, and R.M. Harrell. 2009. Influence of nutritional state on the progression and severity of mycobacteriosis in striped bass Morone saxatilis. Diseases of Aquatic Organisms 87:183-197.

Jobling, M. 2003. Do changes in Atlantic salmon, Salmo salar L., fillet FAs following a dietary switch represent wash-out or dilution? Test of a dilution model and its application. Aquaculture Research 34:1215-1221.

Jung, S. and E.D. Houde. 2003. Spatial and temporal variabilities of pelagic fish community structure and distribution in Chesapeake Bay, USA. Estuarine, Coastal, and Shelf Science 58:335-351.

Kainz, M., M.T. Arts, and A. Mazumder. 2004. Essential FAs in the planktonic food web and their ecological role for higher trophic levels. Limnology and Oceanography 49:17841793.

Kharlamenko, V.I., N.V. Zhukova, S.V. Khotimchenko, V.I. Svetashev, and G.M. Kamenev. 1995. FAs as markers of food sources in a shallow-water hydrothermal ecosystem 
(Kraternaya Bight, Yankich Island, Kurile Islands). Marine Ecology Progress Series 120:231-241

Kirsch, P. E., S.J. Iverson, W.D. Bowen, S.R. Kerr, and R.G. Ackman. 1998. Dietary effects on the FA signature of whole Atlantic cod (Gadus morhua). Canadian Journal of Fisheries and Aquatic Sciences 55:1378-1386.

Manooch III, C. S. 1973. Food habits of yearling and adult striped bass, Morone saxatilis

(Walbaum), from Albemarle Sound, North Carolina. Chesapeake Science 14:73-86.

Mansueti, R. J. 1961. Age, growth, and movements of the striped bass, Roccus saxatilis, taken in size selective fishing gear in Maryland. Chesapeake Science 2:9-36.

McCune, B. \& J.B. Grace. 2002. Analysis of Ecological Communities. Gleneden Beach, OR: MjM Software Design.

Meynier, L., P.C.H. Morel, B.L. Chilvers, D.D.S. Mackenzie, and P.J. Duignan. 2010. Quantitative FA signature analysis on New Zealand sea lions: model sensitivity and diet estimates. Journal of Mammalogy 91:1484-1495.

Overton, A. S., E.B. May, J. Griffin, and F.J. Margraf. 2000. A bioenergetics approach for determining the effect of increased striped bass population on its prey and health in the Chesapeake Bay. Maryland Department of Natural Resources, Annapolis.

Overton, A. S., F.J. Margraf, and E.B. May. 2009. Spatial and temporal patterns in the diet of striped bass in Chesapeake Bay. Transactions of the American Fisheries Society 138:915-926.

Paine, R.T. 1980. Food webs: linkage, interaction strength and community infrastructure. Journal of Animal Ecology 49:666-685. 
Pierce, G.J. and P.R. Boyle. 1991. A review of methods for diet analysis in piscivorous marine mammals. Oceanography Marine Biology: An Annual Review 29:409-486.

Pikitch, E.K., C. Santora, E.A. Babcock, A. Bakun, R. Bonfil, D.O. Conover, P. Dayton, P. Doukakis, D. Fluharty, B. Heneman, E.D. Houde, J. Link, P.A. Livingston, M. Mangel, M.K. McAllister, J. Pope, and K.J. Sainsbury. 2004. Ecosystem-based fishery management. Science 305:346-347.

Pinnegar, J.K. and N.V.C. Polumin. 2000. Contributions of stable-isotope data to elucidating food webs of Mediterranean rocky littoral fishes. Oecologia 122:399-409.

R Development Core Team. 2010. R: A language and environment for statistical computing. $\mathrm{R}$ Foundation for Statistical Computing, Vienna, Austria. ISBN 3-900051-07-0, URL http://www.R-project.org.

Recks, M. A., and G. T. Seaborn. 2008. Variation in FA composition among nine forage species from a southeastern US estuarine and nearshore coastal ecosystem. Fish Physiology and Biochemistry 34:275-287.

Rhodes, M.W., H. Kator, I. Kaattari, D. Gauthier, W. Vogelbein, and C.A. Ottinger. 2004. Isolation and characterization of mycobacteria from striped bass Morone saxatilis from the Chesapeake Bay. Diseases of Aquatic Organisms 61:41-51.

Setzler-Hamilton, E. M., and L. H. Hall Jr. 1991. Striped bass (Morone saxitilis). Pages 13.1113.27 in S. L. Funderburk, S.J. Jordan, J.A. Mihursky, and D. Riley, editor. Habitat requirements for Chesapeake Bay living resources. Chesapeake Research Consortium, Solomons, MD. 
Sotiropoulos, M.A., W.M. Tonn, and L.I. Wassenaar. 2004. Effects of lipid extraction on stable carbon and nitrogen isotope analyses of fish tissues: potential consequences for food webs. Ecology of Freshwater Fish 13:155-160.

Stroup, E.D. and R.J. Lynn. 1963. Atlas of salinity and temperature distributions in Chesapeake Bay 1951 - 1961 and seasonal averages 1949 - 1961. The Chesapeake Bay Institute, Graphical Summary Report, Ref. 63-1. Johns Hopkins University, Baltimore, Maryland, USA.

Thiemann, G., S.J. Iverson, and I. Sterling. 2008. Polar bear diets and arctic marine food webs: insights from FA analysis. Ecological Monographs 78:591-613.

Tocher, D.R. 2003. Metabolism and functions of lipids and FAs in teleost fish. Reviews in Fisheries Science 11:107-184.

Tucker, S., W.D. Bowen, S.J. Iverson, W. Blanchard, and G.B. Stenson. 2009. Sources of variation in diets of harp and hooded seals estimated from quantitative FA signature analysis (QFASA). Marine Ecology Progress Series 384:287-302.

USEPA (United States Environmental Protection Agency). 2007. Pressurized fluid extraction (PFE). USEPA SW-846. Method 3545A, Update IV. Washington, D.C.

Uphoff Jr., J.H. 2003. Predator-prey analysis of striped bass and Atlantic menhaden in upper Chesapeake Bay. Fisheries Management and Ecology 10:313-322.

Yodzis, P. 2001. Must top predators be culled for the sake of fisheries? Trends in Ecology and Evolution 16:78-84. 
Table 1. Length, weight, and fat content of striped bass and the four prey species collected in the upper bay during the fall (September - October). Values represent the mean \pm 1 standard error of the mean, $\mathrm{N}$ refers to the samples size of each group.

\begin{tabular}{lcccc}
\hline Species & $\mathrm{N}$ & Length $(\mathrm{mm})$ & Weight $(\mathrm{g})$ & Fat content $(\% \mathrm{WW})$ \\
\hline Striped bass & 78 & $505.91 \pm 5.27$ & $1271.29 \pm 39.08$ & $5.24 \pm 0.54$ \\
Menhaden & 9 & $127.56 \pm 2.84$ & $23.33 \pm 1.98$ & $12.46 \pm 1.17$ \\
Bay anchovy & 9 & $50.12 \pm 1.87$ & $3.81 \pm 0.15$ & $15.10 \pm 2.98$ \\
Spot & 11 & $79.55 \pm 2.85$ & $6.04 \pm 0.82$ & $6.05 \pm 0.75$ \\
Blue crab & 10 & $120.60 \pm 4.59$ & $89.10 \pm 7.41$ & $1.18 \pm 0.17$ \\
\hline
\end{tabular}


Table 2. Mean FA concentrations expressed as a mass percent of all FAs present \pm 1 standard error of the mean; nd = not detected. FAs shown are for striped bass and the four prey species analyzed in the QFASA model. All species were collected in the upper bay in fall (September-October). FAs listed are in the cis configuration unless otherwise noted.

\begin{tabular}{|c|c|c|c|c|c|}
\hline Fatty acid & Striped bass & Menhaden & Bay anchovy & Spot & Blue crab \\
\hline C12:0 & $0.15 \pm 0.04$ & $0.19 \pm 0.05$ & $0.09 \pm 0.03$ & $0.05 \pm 0.01$ & $0.09 \pm 0.01$ \\
\hline $\mathrm{C} 12: \ln 1$ & $0.04 \pm 0.01$ & $0.02 \pm 0.02$ & nd & $0.02 \pm 0.03$ & $0.07 \pm 0.05$ \\
\hline C13:0 & $0.13 \pm 0.02$ & $0.60 \pm 0.20$ & $0.50 \pm 0.03$ & $0.26 \pm 0.08$ & $0.13 \pm 0.04$ \\
\hline $\mathrm{C} 14: 0$ & $3.46 \pm 0.18$ & $7.91 \pm 0.75$ & $3.60 \pm 0.19$ & $2.42 \pm 0.24$ & $1.49 \pm 0.13$ \\
\hline C14:1n5 & $0.11 \pm 0.02$ & $0.29 \pm 0.22$ & $0.04 \pm 0.02$ & $0.03 \pm 0.001$ & $0.04 \pm 0.01$ \\
\hline C15:0 & $0.81 \pm 0.02$ & $1.39 \pm 0.13$ & $1.4 \pm 0.07$ & $1.30 \pm 0.05$ & $1.41 \pm 0.06$ \\
\hline C15:1n5 & nd & $0.01 \pm 0.01$ & $0.33 \pm 0.03$ & nd & $0.24 \pm 0.03$ \\
\hline C16 DMA & nd & $0.42 \pm 0.12$ & $0.40 \pm 0.02$ & nd & $0.01 \pm 0.01$ \\
\hline C16:0 & $27.74 \pm 0.52$ & $29.63 \pm 2.45$ & $30.10 \pm 0.49$ & $24.36 \pm 0.51$ & $23.81 \pm 0.69$ \\
\hline $\mathrm{C} 16: \ln 7$ & $5.50 \pm 0.23$ & $7.79 \pm 1.96$ & $4.71 \pm 0.35$ & $4.21 \pm 0.24$ & $4.40 \pm 0.24$ \\
\hline $\mathrm{C} 17: 0$ & $1.16 \pm 0.07$ & $1.00 \pm 0.07$ & $1.64 \pm 0.05$ & $2.48 \pm 0.13$ & $1.76 \pm 0.12$ \\
\hline $\mathrm{C} 17: \ln 7$ & $0.02 \pm 0.02$ & $0.13 \pm 0.08$ & nd & nd & nd \\
\hline C18:0 & $6.89 \pm 0.19$ & $6.25 \pm 0.37$ & $7.74 \pm 0.14$ & $10.83 \pm 0.30$ & $9.19 \pm 0.44$ \\
\hline $\mathrm{C} 18: \ln 12 \mathrm{t}$ & nd & $0.19 \pm 0.05$ & $0.19 \pm 0.09$ & $0.06 \pm 0.14$ & $0.55 \pm 0.11$ \\
\hline $\mathrm{C} 18: \ln 9 \mathrm{t}$ & $0.26 \pm 0.02$ & $0.31 \pm 0.16$ & $0.03 \pm 0.02$ & $0.06 \pm 0.04$ & $0.23 \pm 0.04$ \\
\hline $\mathrm{C} 18: \ln 9$ & $10.79 \pm 0.55$ & $4.19 \pm 0.30$ & $5.97 \pm 0.19$ & $9.30 \pm 0.24$ & $13.55 \pm 1.02$ \\
\hline $\mathrm{C} 18: \ln 7$ & $3.57 \pm 0.09$ & $2.90 \pm 0.12$ & $3.06 \pm 0.04$ & $3.88 \pm 0.16$ & $2.61 \pm 0.09$ \\
\hline $\mathrm{C} 18: 2 \mathrm{n} 6$ & $1.27 \pm 0.09$ & $1.65 \pm 0.17$ & $0.95 \pm 0.05$ & $1.75 \pm 0.06$ & $4.45 \pm 0.48$ \\
\hline $\mathrm{C} 18: 3 \mathrm{n} 6+\mathrm{C} 19: 0$ & $0.46 \pm 0.05$ & $0.47 \pm 0.10$ & $0.35 \pm 0.01$ & $0.63 \pm 0.03$ & $0.39 \pm 0.03$ \\
\hline $\mathrm{C} 18: 3 \mathrm{n} 3$ & $1.01 \pm 0.08$ & $2.08 \pm 0.15$ & $0.96 \pm 0.10$ & $1.02 \pm 0.08$ & $0.55 \pm 0.02$ \\
\hline $\mathrm{C} 18: 4 \mathrm{n} 3$ & $1.13 \pm 0.08$ & $2.43 \pm 0.38$ & $1.09 \pm 0.11$ & $0.49 \pm 0.05$ & $0.39 \pm 0.04$ \\
\hline C19:2n6 & $0.21 \pm 0.04$ & $0.14 \pm 0.11$ & $0.01 \pm 0.01$ & $0.05 \pm 0.001$ & nd \\
\hline C20:0 & $0.32 \pm 0.04$ & $1.43 \pm 0.54$ & $0.44 \pm 0.02$ & $0.47 \pm 0.05$ & $0.38 \pm 0.04$ \\
\hline $\mathrm{C} 20: \ln 15$ & $0.07 \pm 0.02$ & $0.30 \pm 0.13$ & $0.02 \pm 0.01$ & $0.04 \pm 0.01$ & $0.02 \pm 0.01$ \\
\hline $\mathrm{C} 20: \ln 12$ & $0.71 \pm 0.05$ & $0.54 \pm 0.23$ & $0.19 \pm 0.02$ & $1.38 \pm 0.14$ & $2.64 \pm 0.48$ \\
\hline $\mathrm{C} 20: \ln 9$ & $1.58 \pm 0.07$ & $0.33 \pm 0.09$ & $0.28 \pm 0.02$ & $0.90 \pm 0.07$ & $1.23 \pm 0.05$ \\
\hline $\mathrm{C} 20: \ln 7$ & $0.79 \pm 0.07$ & $0.69 \pm 0.32$ & $0.29 \pm 0.02$ & $1.53 \pm 0.18$ & $3.33 \pm 0.43$ \\
\hline $\mathrm{C} 20: 2 \mathrm{n} 6$ & $0.64 \pm 0.09$ & $0.28 \pm 0.09$ & $0.34 \pm 0.03$ & $0.99 \pm 0.10$ & $1.25 \pm 0.08$ \\
\hline $\mathrm{C} 20: 3 \mathrm{n} 6+\mathrm{C} 21: 0$ & $0.27 \pm 0.05$ & $0.68 \pm 0.21$ & $0.19 \pm 0.02$ & $0.19 \pm 0.04$ & $0.31 \pm 0.04$ \\
\hline C20:4n6 & $2.67 \pm 0.12$ & $0.80 \pm 0.04$ & $1.67 \pm 0.07$ & $4.56 \pm 0.23$ & $4.75 \pm 0.35$ \\
\hline $\mathrm{C} 20: 3 \mathrm{n} 3$ & $0.37 \pm 0.07$ & $0.68 \pm 0.36$ & $0.23 \pm 0.03$ & $0.44 \pm 0.02$ & $0.30 \pm 0.07$ \\
\hline $\mathrm{C} 20: 5 \mathrm{n} 3$ & $5.78 \pm 0.21$ & $5.36 \pm 0.84$ & $7.39 \pm 0.12$ & $6.52 \pm 0.20$ & $7.68 \pm 0.54$ \\
\hline $\mathrm{C} 22: 0$ & $0.54 \pm 0.15$ & $1.79 \pm 0.34$ & $0.59 \pm 0.03$ & $0.38 \pm 0.03$ & $0.42 \pm 0.07$ \\
\hline $\mathrm{C} 22: \ln 9$ & $0.50 \pm 0.06$ & $0.67 \pm 0.33$ & $0.08 \pm 0.01$ & $0.28 \pm 0.03$ & $0.11 \pm 0.05$ \\
\hline $\mathrm{C} 22: 2 \mathrm{n} 6$ & $0.17 \pm 0.06$ & $0.57 \pm 0.33$ & nd & $0.15 \pm 0.09$ & $0.08 \pm 0.19$ \\
\hline
\end{tabular}


Table 2 continued.

\begin{tabular}{lccccc}
\hline Fatty acid & Striped bass & Menhaden & Bay anchovy & Spot & Blue crab \\
\hline $\mathrm{C} 22: 4 \mathrm{n} 6$ & $0.68 \pm 0.06$ & $0.63 \pm 0.37$ & $0.44 \pm 0.10$ & $1.15 \pm 0.09$ & $0.47 \pm 0.15$ \\
$\mathrm{C} 22: 3 \mathrm{n} 3+\mathrm{C} 22: 5 \mathrm{n} 6$ & $1.14 \pm 0.11$ & $1.35 \pm 0.42$ & $0.88 \pm 0.07$ & $1.34 \pm 0.14$ & $1.08 \pm 0.21$ \\
$\mathrm{C} 22: 5 \mathrm{n} 3$ & $1.97 \pm 0.11$ & $0.33 \pm 0.33$ & $1.92 \pm 0.14$ & $2.10 \pm 0.11$ & $0.84 \pm 0.14$ \\
$\mathrm{C} 22: 6 \mathrm{n} 3+\mathrm{C} 24: 0$ & $16.24 \pm 0.62$ & $10.14 \pm 0.37$ & $19.98 \pm 0.64$ & $13.83 \pm 1.00$ & $10.67 \pm 0.44$ \\
$\mathrm{C} 24: 1 \mathrm{n} 9$ & $0.85 \pm 0.08$ & $2.50 \pm 1.18$ & $1.85 \pm 0.16$ & $0.56 \pm 0.08$ & $0.06 \pm 0.04$ \\
\hline
\end{tabular}


Figure 1. FA proportions for the four prey taxa examined in this study. Values represent the mean of each FA; errors bars represent one standard error of the mean.

Figure 2. NMDS of FA signatures from striped bass and the four prey taxa collected in the fall (September-October). Symbols represent the group centroid mean of each taxon, and ellipses are the $95 \%$ confidence intervals around the mean.

Figure 3. Proportional contribution of the four prey taxa to the diets of striped bass. QFASA model results from a 16 FA dataset and a 30 FA dataset are based on the contribution of each prey taxa fatty signature to striped bass FA signatures in the belly flap. Values for stomachs are the percent biomass of each prey taxa in striped bass samples in this experiment. Values from Hartman and Brandt (1995) and Overton et al. (2000) are contribution of each prey taxa based upon percent biomass to the diets of age 3 striped bass in the middle portion of the Chesapeake Bay during the fall (September October). 
Figure 1.

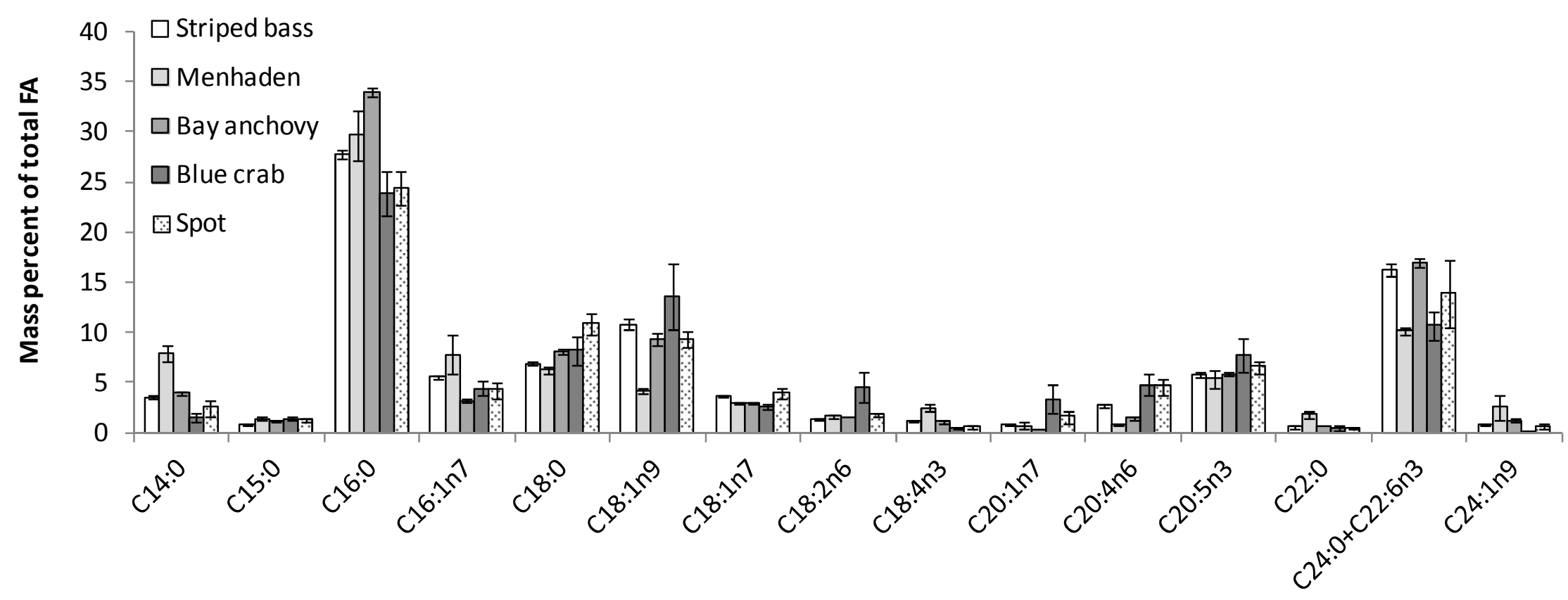

Fatty acid 
Figure 2.

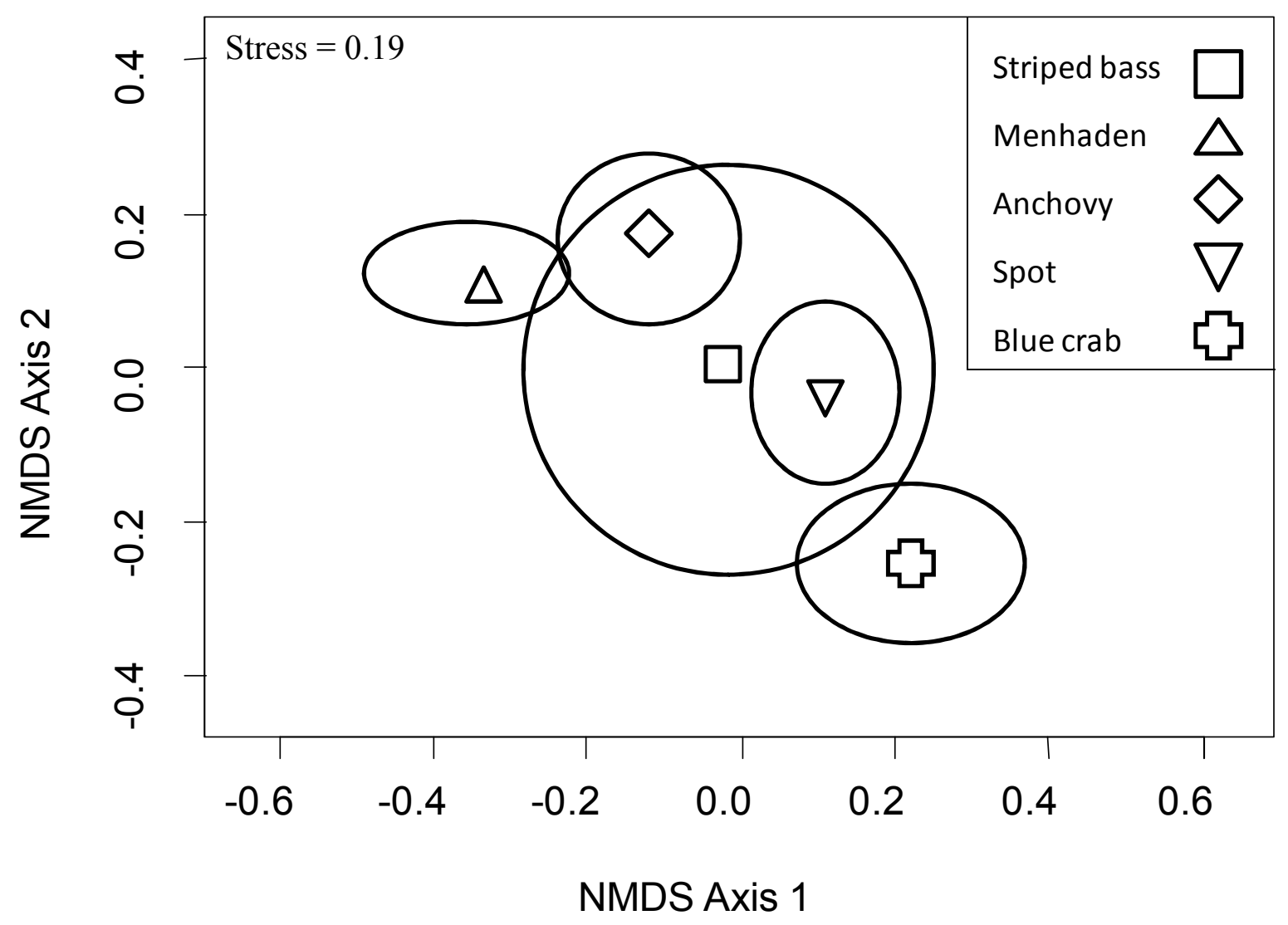


Figure 3.

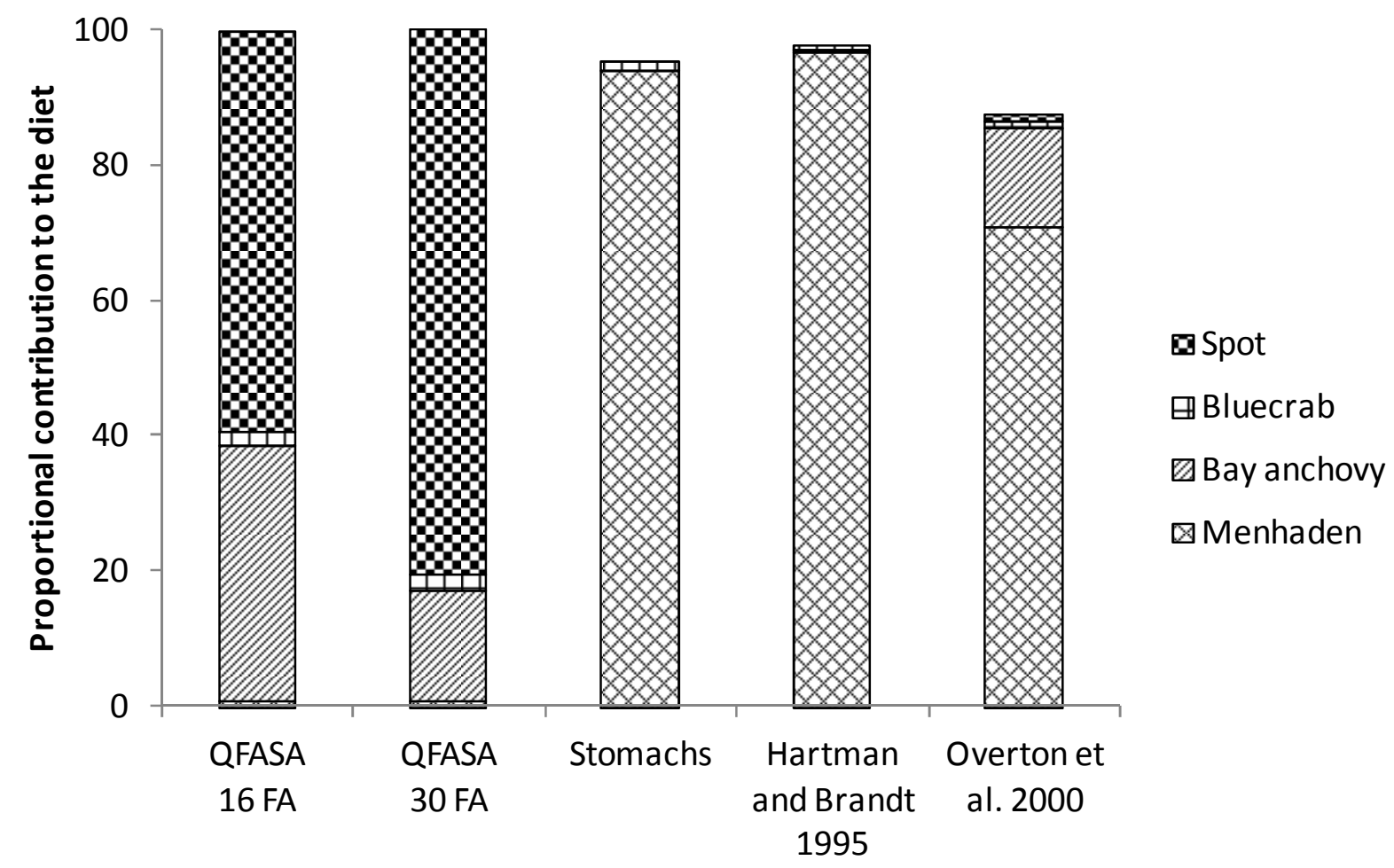




\section{Chapter 7: Dissertation summary}

The goal of this project was to determine the efficacy of using fatty acids to track striped bass diets. To achieve this goal, I had several objectives. First, I established a library of FA signatures and lipid contents for commonly consumed striped bass prey species in multiple seasons and locations in the Chesapeake Bay. My findings indicated that demersal prey species, spot (Leiostomus xanthurus) and blue crab (Callinectes sapidus), and pelagic prey species, Atlantic menhaden (Brevoortia tyrannus) and bay anchovy (Anchoa mitchilli) differed in their fatty acid signatures. Spot and blue crab were readily differentiated from each other and were grouped according to season and not species. Bay anchovy and menhaden did not exhibit clear patterns in terms of season or location in the bay.

Lipid content for striped bass prey items indicated that there were patterns with regards to season and species. Bay anchovy and menhaden consistently had the highest lipid content, spot had the next highest lipid content, and blue crab had the lowest lipid levels. Seasonal impacts on lipid content for menhaden, bay anchovy, and spot yielded an increase throughout the year, while blue crab lipid levels decreased from summer to fall.

These results highlight the importance of sampling prey species at the same time as predator species being studied. Fatty acids proportions and lipid levels will vary throughout the year and this fluctuation prevents using data on prey species collected in a different season than a predator.

The role that different tissues play in the deposition and storage of fatty acids in fish has been an area lacking in research. I tested both liver and belly flap (adipose tissue) from striped bass and documented how the fatty acid signature changed as the diet was switched from spot to menhaden. Striped bass were fed spot for a period of six weeks and menhaden for a period of six 
weeks. Fish were serially sacrificed and had their fatty acid signatures recorded. There was a definitive change in the lipid levels once striped bass were changed to a diet of menhaden. The entire fatty acid signature in striped bass liver and belly flap did not change to match the prey as the literature suggests. However, certain marker fatty acids were able to distinguish the diet of striped bass.

Therefore, it becomes imperative to have very detailed information regarding the fatty acid signature of prey species in question. The fatty acids tested in this experiment (a suite of approximately 40) were sufficient to delineate the change in diet. Prey items that have very similar diets may require more information on fatty acids, e.g. branched fatty acids. A period of six weeks is not long enough for the entire striped bass signature to match that of the prey, but it is sufficient time for certain fatty acids to become present in levels that can point to the current diet being eaten.

Another factor that may influence the process of fatty acid deposition is predator size. To test the effect of this variable, I obtained striped bass of three different sizes and fed them the same diet to satiation. It became apparent when analyzing this data that feeding was reduced or absent entirely for all size classes of striped bass. Water temperature or stress from handling may have caused striped bass to fail to consume the offered prey, preventing analysis of how size affects fatty acid signature incorporation. No growth was recorded, lipid levels remained the same or decreased, and fatty acid markers that worked in the previous experiment were unable to highlight the diet switch. Size may be an important factor in influencing fatty acid incorporation but no conclusions could be made from this experiment.

One of the most promising areas of research that involve fatty acids is the ability to estimate the proportion of different prey items consumed. The model, quantitative fatty acid 
signature analysis (QFASA), requires information on prey fatty acids and lipid levels, predator fatty acids, and information on how predators metabolize different fatty acids (calibration coefficients). Most studies have focused on homeotherms such as seabirds and marine mammals, and as such, this study represented one of the first attempts to try and apply the model to a poikilotherm.

To test the QFASA model, striped bass were fed a baseline diet of spot before being fed mixtures of spot and menhaden. As a control, another set of striped bass were fed a diet of solely menhaden. The model was able to correctly identify spot as the diet item after the baseline feeding regime. However, in all instances (menhaden alone, and spot and menhaden mixtures), the model consistently overestimated the contribution of spot to the diet. Problems may have arisen from the formulation of the diet due to lipid levels. However, menhaden is higher in lipid than spot, and any overestimation should have been skewed to the higher lipid prey: menhaden. A recent study that tried to also apply the model to poikilotherms (salmon) found that stabilization of fatty acids may take as long as $12-14$ weeks in fish (Budge et al. 2011). This time frame begins to present issues of striped bass remaining in one area of this long. As I have stated, prey species need to be collected at the time of predator capture. Striped bass are mobile predators and sampling prey becomes problematic over such an extended time period. The second issue becomes striped bass consuming the same diet over this time period. As more species are included into the diet at different proportions, the signature is constantly changed. Results begin to become difficult to interpret and unreliable.

As a concurrent experiment with the QFASA model development, I wanted to capture wild striped bass to determine the degree of corroboration between the model and items information collected from striped bass stomachs. Wild striped bass were collected with hook 
and line in the fall from the Choptank River. This time of year represents a season in which reliance on menhaden as a primary food source is extremely high. Therefore, the fatty acids from menhaden should have had ample time to become deposited within striped bass tissues. Data from the stomachs and other studies conducted on similarly aged striped bass (age-3) during the same season indicated that menhaden was the dominant prey item. However, results from the QFASA model pointed to spot and bay anchovy making large contributions to the diet, with very little contribution coming from menhaden.

Fatty acid analysis has been used as a tool to garner more information about the diet of an organism. At this time, it is my recommendation that quantitative methods for establishing feeding history with fatty acids are not ready to be employed in the fisheries field. The results from the model did not match the known diet fed to striped bass. A longer study should be conducted to determine how long striped bass need to be fed the same diet before the QFASA model can estimate diet. While qualitative estimates have been shown to work in this experiment, the same level of information can be gathered from looking at stomach contents for a fraction of the cost. Until the problems with QFASA are adequately researched for poikilotherms, other methods should be employed to estimate the diet. 


\section{Literature cited}

Budge, S.M., S.N. Penney, S.P. Lall. 2011. Response of tissue lipids to diet variation in Atlantic salmon (Salmo salar): implications for estimating diets with FA analysis. Journal of Experimental Marine Biology and Ecology 409:267-274. 


\section{Chapter 2 Raw Data}

Values for length ( $\mathrm{mm}$ ), weight ( $\mathrm{g}$ ), lipid content (\% wet weight) and fatty acids routinely identified for the prey species analyzed in Chapter 2 of this experiment. Average total length is presented when several prey species were used in the sample. Samples that are designated with an $A$ and $B$ were samples that were extracted twice on the Accelerated Solvent Extractor (ASE).

Table A1. Bay anchovy collected from the upper bay in spring.

\begin{tabular}{|c|c|c|c|c|c|c|c|c|c|c|c|c|}
\hline & \multicolumn{12}{|c|}{ Sample number } \\
\hline & $1 \mathrm{~A}$ & $1 \mathrm{~B}$ & $2 A \& B$ & $3 \mathrm{~A}$ & $3 \mathrm{~B}$ & $4 A \& B$ & $5 \mathrm{~A}$ & $5 \mathrm{~B}$ & $6 A \& B$ & $7 \mathrm{~A}$ & $7 \mathrm{~B}$ & $8 A \& B$ \\
\hline Total length (mm) & 53.00 & - & 65.50 & 63.5 & - & 59.5 & 58.5 & - & 64 & 61 & - & 51.0 \\
\hline Weight (g) & 1.01 & - & 1.52 & 1.62 & - & 1.31 & 1.33 & - & 1.80 & 1.25 & - & 1.10 \\
\hline Lipid content (\%) & 8.58 & - & 9.60 & 7.12 & - & 14.75 & 12.72 & - & 8.07 & 12.58 & - & 12.96 \\
\hline $\mathrm{C} 12: 0$ & 0.10 & 1.37 & nd & 0.10 & 1.06 & 0.14 & 0.08 & nd & 0.08 & 0.05 & 1.63 & 0.06 \\
\hline C13:0 & nd & nd & nd & nd & nd & nd & 0.17 & nd & 0.06 & 0.12 & nd & nd \\
\hline C14:0 & 1.80 & 3.49 & 2.49 & 3.73 & 6.63 & 3.97 & 5.00 & 6.56 & 3.78 & 3.85 & nd & 4.04 \\
\hline C14:1n5 & nd & 3.08 & nd & 0.04 & 3.03 & nd & nd & 2.69 & 0.04 & 0.02 & 6.55 & 0.06 \\
\hline C15:0 & 0.50 & 0.82 & 0.55 & 0.76 & 2.11 & 0.88 & 0.93 & nd & 0.65 & 0.69 & 1.85 & 0.06 \\
\hline C15:1n5 & 0.06 & nd & nd & 0.03 & nd & nd & nd & nd & 0.01 & 0.01 & nd & 0.04 \\
\hline C16:0 DMA & 0.58 & 1.15 & 0.53 & 0.54 & 2.61 & 0.50 & 0.40 & nd & 0.39 & 0.38 & nd & 0.55 \\
\hline C16:0 & 31.48 & 32.71 & 29.63 & 32.91 & 30.94 & 30.86 & 32.66 & 37.45 & 30.77 & 32.14 & 32.56 & 30.84 \\
\hline $\mathrm{C} 16: 1 \mathrm{n} 7$ & 2.24 & 2.40 & 2.52 & 4.67 & nd & 4.21 & 4.13 & 5.80 & 3.29 & 2.69 & 2.28 & 3.95 \\
\hline $\mathrm{C} 17: 0$ & 0.84 & 1.07 & 1.17 & 0.85 & 1.01 & 1.17 & 1.20 & nd & 0.97 & 1.14 & 1.01 & 1.04 \\
\hline C17:1n7 & nd & nd & 0.30 & 0.17 & nd & 0.35 & 0.17 & nd & 0.10 & 0.08 & nd & nd \\
\hline C18:0 & 7.56 & 12.56 & 7.99 & 7.55 & 11.64 & 7.51 & 6.69 & 12.28 & 7.28 & 8.95 & 17.69 & 8.30 \\
\hline C18:1n9t & nd & nd & nd & 0.14 & nd & nd & nd & nd & nd & nd & nd & nd \\
\hline C18:1n9 & 6.43 & 6.64 & 6.76 & 7.42 & 8.84 & 6.72 & 5.56 & 7.11 & 5.94 & 5.30 & 6.41 & 6.61 \\
\hline C18:1n7 & 2.12 & 2.87 & 2.64 & 3.29 & 4.09 & 2.48 & 2.49 & nd & 2.31 & 2.01 & 2.06 & 3.06 \\
\hline C18:2n6 & 1.44 & 1.93 & 1.84 & 1.80 & 2.56 & 2.12 & 1.91 & nd & 1.38 & 1.32 & 2.55 & 1.62 \\
\hline C19:0 + C18:3n6 & 0.16 & nd & nd & 0.28 & nd & 0.26 & 0.24 & nd & 0.20 & 0.20 & nd & 0.26 \\
\hline C18:3n3 & 1.09 & 1.03 & 1.51 & 1.81 & 1.72 & 1.99 & 2.03 & nd & 1.12 & 1.07 & 1.11 & 1.14 \\
\hline
\end{tabular}


Table A1 continued. Bay anchovy collected from the upper bay in spring.

\begin{tabular}{|c|c|c|c|c|c|c|c|c|c|c|c|c|}
\hline & \multicolumn{12}{|c|}{ Sample number } \\
\hline & $1 \mathrm{~A}$ & $1 \mathrm{~B}$ & $2 A \& B$ & $3 \mathrm{~A}$ & $3 \mathrm{~B}$ & $4 A \& B$ & $5 A$ & $5 B$ & $6 A \& B$ & $7 \mathrm{~A}$ & $7 B$ & $8 A \& B$ \\
\hline C18:4n3 & 0.96 & 0.83 & 1.61 & 1.31 & 1.07 & 2.16 & 2.50 & nd & 1.37 & 1.29 & 1.53 & 1.38 \\
\hline C19:2n6 & nd & nd & nd & nd & nd & nd & nd & nd & nd & nd & nd & nd \\
\hline C20:0 & 0.21 & nd & 0.32 & 0.41 & nd & 0.35 & 0.33 & nd & 0.35 & 0.35 & nd & 0.36 \\
\hline C20:1n12 & 0.20 & nd & nd & 0.23 & nd & 0.35 & 0.45 & nd & 0.28 & 0.26 & nd & 0.50 \\
\hline C20:0 & 0.21 & nd & 0.32 & 0.41 & nd & 0.35 & 0.33 & nd & 0.35 & 0.35 & nd & 0.36 \\
\hline C20:1n12 & 0.20 & nd & nd & 0.23 & nd & 0.35 & 0.45 & nd & 0.28 & 0.26 & nd & 0.50 \\
\hline C20:1n9 & 0.25 & nd & 0.36 & 0.35 & nd & 0.52 & 0.37 & nd & 0.26 & 0.20 & nd & 0.37 \\
\hline $\mathrm{C} 20: 1 \mathrm{n} 7$ & 0.12 & nd & nd & 0.30 & nd & 0.48 & 0.55 & nd & 0.33 & 0.24 & nd & 0.67 \\
\hline$C 20: 2 n 6$ & 0.46 & nd & 0.50 & 0.60 & nd & 0.62 & 0.59 & nd & 0.46 & 0.43 & nd & 0.59 \\
\hline$C 20: 3 n 6+C 21: 0$ & nd & nd & nd & 0.14 & nd & nd & nd & nd & 0.08 & 0.07 & nd & 0.11 \\
\hline$C 20: 4 n 6$ & 0.99 & 0.91 & 1.22 & 1.52 & 1.11 & 1.14 & 0.67 & nd & 0.93 & 0.75 & 0.56 & 0.96 \\
\hline$C 20: 3 n 3$ & 0.25 & nd & nd & 0.27 & nd & nd & 0.23 & nd & 0.20 & 0.18 & nd & 0.23 \\
\hline C20:5n3 & 6.03 & 5.33 & 7.26 & 6.42 & 5.74 & 6.93 & 7.45 & 7.99 & 7.04 & 6.16 & 4.71 & 5.84 \\
\hline $\mathrm{C} 22: 0$ & 0.45 & nd & 0.40 & 0.59 & nd & 0.70 & 0.60 & nd & 0.66 & 0.70 & nd & 0.52 \\
\hline C22:1n9 & nd & nd & nd & 0.07 & nd & nd & nd & nd & 0.08 & 0.07 & nd & 0.07 \\
\hline $\mathrm{C} 22: 2 \mathrm{n} 6$ & nd & nd & nd & nd & nd & nd & nd & nd & 0.02 & nd & nd & nd \\
\hline C23:0 & 0.23 & nd & nd & 0.19 & nd & 0.23 & 0.15 & nd & 0.17 & 0.17 & nd & 0.30 \\
\hline$C 22: 4 n 6$ & nd & nd & nd & nd & nd & 0.13 & 0.12 & nd & 0.10 & 0.10 & nd & 0.12 \\
\hline$C 22: 5 n 6$ & 0.59 & nd & 0.72 & 0.92 & 0.82 & 0.49 & 0.38 & nd & 0.50 & 0.44 & nd & 0.51 \\
\hline C22:5n3 & 0.48 & nd & 0.46 & 0.61 & 0.93 & 0.54 & 0.62 & nd & 0.47 & 0.52 & 0.70 & 0.60 \\
\hline$C 24: 0$ & 0.91 & 1.55 & 0.89 & 0.98 & 0.95 & 1.08 & 0.68 & nd & 0.95 & 0.71 & 0.78 & 1.20 \\
\hline$C 22: 6 n 3$ & 28.50 & 21.62 & 26.76 & 16.68 & 13.12 & 19.42 & 18.52 & 20.11 & 25.32 & 24.66 & 15.26 & 22.17 \\
\hline C24:1n9 & 1.57 & 0.61 & 1.57 & 1.12 & nd & 1.70 & 1.49 & nd & 2.05 & 1.80 & 0.74 & 1.86 \\
\hline
\end{tabular}


Table A2. Bay anchovy collected from the lower bay in spring.

\begin{tabular}{|c|c|c|c|c|c|c|c|c|}
\hline & \multicolumn{8}{|c|}{ Sample number } \\
\hline & 1 & 2 & 4 & 5 & 6 & 7 & 8 & 9 \\
\hline Total length (mm) & 60 & 58 & 64 & 61 & 59 & 58 & 57 & 51 \\
\hline Weight (g) & 2.31 & 2.33 & 2.23 & 2.02 & 2.23 & 2.36 & 2.20 & 1.28 \\
\hline Lipid content (\%) & 11.68 & 8.04 & 13.88 & 12.69 & 3.43 & 5.58 & 5.49 & 7.67 \\
\hline $\mathrm{C} 12: 0$ & 0.13 & 0.18 & 0.14 & 0.15 & nd & 1.25 & 0.18 & 1.07 \\
\hline C12:1n1 & nd & nd & nd & nd & nd & 0.07 & nd & nd \\
\hline C13:0 & 0.27 & 0.16 & 0.14 & 0.24 & nd & 0.17 & 0.20 & 0.31 \\
\hline C14:0 & 8.36 & 8.35 & 10.14 & 9.60 & 7.55 & 7.72 & 8.83 & 8.41 \\
\hline C14:1n5 & 0.10 & 0.07 & 0.08 & 0.14 & nd & 0.08 & 0.12 & 0.10 \\
\hline C15:0 & 1.09 & 1.25 & 1.21 & 1.31 & 1.12 & 1.29 & 1.12 & 1.19 \\
\hline C16:0 DMA & 0.29 & 0.34 & 0.30 & 0.39 & nd & 0.35 & 0.29 & 0.36 \\
\hline C16:0 & 27.96 & 30.34 & 31.50 & 27.78 & 34.37 & 29.72 & 30.20 & 30.60 \\
\hline $\mathrm{C} 16: 1 \mathrm{n} 7$ & 8.58 & 7.96 & 8.69 & 11.39 & 8.03 & 8.32 & 9.62 & 7.83 \\
\hline $\mathrm{C} 17: 0$ & 0.83 & 0.82 & 0.80 & 0.82 & 0.64 & 1.10 & 0.86 & 1.19 \\
\hline C18:0 & 4.08 & 3.57 & 4.12 & 3.58 & 6.82 & 5.25 & 4.25 & 4.98 \\
\hline $\mathrm{C} 18: 1 \mathrm{n} 12 \mathrm{t}$ & 0.46 & 0.21 & 0.16 & nd & nd & 0.21 & nd & nd \\
\hline C18:1n9 & 6.37 & 5.82 & 5.65 & 6.40 & 7.06 & 6.93 & 6.36 & 6.12 \\
\hline C18:1n7 & 3.21 & 3.14 & 3.06 & 3.61 & 4.47 & 3.68 & 3.27 & 3.64 \\
\hline C18:2n6 & 1.20 & 1.59 & 1.32 & 1.29 & 1.71 & 1.50 & 1.38 & 1.38 \\
\hline$C 19: 0+C 18: 3 n 6$ & 0.25 & 0.20 & 0.23 & 0.27 & nd & 0.29 & 0.26 & 0.27 \\
\hline C18:3n3 & 0.98 & 1.02 & 0.95 & 0.82 & 0.81 & 0.85 & 1.01 & 0.75 \\
\hline C18:4n3 & 1.39 & 1.46 & 1.47 & 1.42 & 1.34 & 1.02 & 1.29 & 1.22 \\
\hline C20:0 & 0.32 & 0.29 & 0.35 & 0.39 & nd & 0.35 & 0.28 & 0.30 \\
\hline $\mathrm{C} 20: 1 \mathrm{n} 12$ & 0.31 & 0.14 & 0.26 & 0.34 & nd & 0.42 & 0.35 & 0.53 \\
\hline C20:1n9 & 0.49 & 0.61 & 0.52 & 0.88 & nd & 0.68 & 0.74 & 0.74 \\
\hline C20:1n7 & 0.64 & 0.42 & 0.55 & 0.55 & nd & 0.67 & 0.68 & 0.84 \\
\hline$C 20: 2 n 6$ & 0.32 & 0.42 & 0.38 & 0.33 & nd & 0.49 & 0.44 & 0.45 \\
\hline$C 20: 3 n 6+C 21: 0$ & nd & nd & 0.10 & nd & nd & 0.10 & 0.12 & 0.16 \\
\hline
\end{tabular}


Table A2 continued. Bay anchovy collected from the lower bay in spring.

\begin{tabular}{lcccccccc}
\hline & \multicolumn{8}{c}{ Sample number } \\
\hline \hline C20:4n6 & 1 & 2 & 4 & 5 & 6 & 7 & 8 \\
C20:3n3 & 1.00 & 0.64 & 0.66 & 1.20 & 1.11 & 1.13 & 0.85 & 0.70 \\
C20:5n3 & nd & nd & 0.12 & nd & nd & 0.09 & 0.10 & 0.13 \\
C22:0 & 10.06 & 8.71 & 8.08 & 8.93 & 7.91 & 7.72 & 8.49 & 7.32 \\
C22:1n11 & 0.49 & 0.35 & 0.45 & nd & nd & 0.41 & 0.22 & 0.47 \\
C22:1n9 & 0.28 & 0.53 & 0.43 & nd & nd & 0.56 & 0.52 & 0.67 \\
C22:2n6 & nd & nd & 0.13 & nd & nd & nd & 0.13 & 0.13 \\
C22:4n6 & nd & nd & 0.01 & nd & nd & nd & nd & nd \\
C22:5n6 & nd & nd & 0.11 & 0.19 & nd & 0.13 & 0.11 & 0.15 \\
C22:5n3 & 0.52 & 0.32 & nd & 0.52 & nd & nd & 0.36 & 0.33 \\
C24:0 & 0.53 & 0.50 & 0.43 & 0.59 & nd & 0.49 & 0.47 & 0.49 \\
C22:6n3 & 0.47 & 0.45 & 0.30 & 0.36 & nd & 0.59 & 0.53 & 0.57 \\
C24:1n9 & 17.99 & 18.92 & 15.75 & 15.55 & 15.82 & 15.15 & 15.26 & 15.47 \\
& 1.05 & 1.22 & 1.40 & 0.96 & 1.24 & 1.20 & 1.08 & 1.15 \\
\hline
\end{tabular}


Table A3. Bay anchovy collected from the upper bay in summer.

\begin{tabular}{lccccccccc}
\hline & \multicolumn{1}{c}{ Sample number } \\
\hline & 1 & 2 & 3 & 4 & 5 & 6 & 7 & 8 & 9 \\
\hline Average total length (mm) & 81.30 & 63.03 & 69.20 & 85.55 & 81.50 & 77.40 & 68.78 & 70.18 & 72.50 \\
Weight (g) & 3.72 & 3.84 & 2.71 & 3.64 & 3.19 & 3.07 & 4.77 & 4.47 & 5.18 \\
Lipid content (\%) & 11.00 & 16.30 & 7.80 & 4.51 & 17.29 & 4.47 & 14.44 & 15.29 & 43.30 \\
C12:0 & 0.13 & 0.15 & 0.28 & 0.29 & 0.45 & 0.10 & 0.18 & 0.51 & 0.43 \\
C13:0 & nd & 0.33 & 0.47 & 0.44 & 0.93 & 0.77 & 0.35 & 0.29 & nd \\
C14:0 & 5.89 & 3.68 & 2.70 & 2.53 & 2.32 & 1.59 & 3.35 & 3.99 & 3.75 \\
C14:1n5 & 0.82 & nd & nd & nd & nd & nd & nd & nd & nd \\
C15:0 & 0.69 & 1.01 & 1.01 & 1.07 & 1.03 & 0.74 & 0.95 & 1.39 & 1.24 \\
C15:1n5 & nd & nd & 0.11 & 0.08 & nd & 0.11 & nd & nd & nd \\
C16:0 DMA & 1.23 & 0.49 & 0.61 & 0.63 & 0.69 & 0.92 & 0.57 & 0.60 & 0.06 \\
C16:0 & 32.05 & 30.27 & 28.79 & 31.17 & 31.62 & 30.24 & 28.62 & 31.66 & 32.37 \\
C16:1n7 & 14.04 & 2.82 & 1.66 & 2.02 & 1.91 & 2.12 & 2.52 & 2.62 & 2.79 \\
C17:0 & 0.90 & 1.59 & 1.98 & 2.26 & 2.03 & 1.91 & 2.13 & 2.01 & 2.35 \\
C17:1n7 & 0.38 & 0.53 & nd & nd & nd & nd & nd & nd & nd \\
C18:0 & 8.54 & 8.57 & 11.22 & 11.26 & 12.26 & 10.54 & 10.79 & 10.13 & 10.87 \\
C18:1n12t & nd & 0.73 & nd & nd & nd & nd & nd & nd & nd \\
C18:1n9 & 17.77 & 9.27 & 8.23 & 8.94 & 10.33 & 9.37 & 8.35 & 9.46 & 10.95 \\
C18:1n7 & 5.17 & 2.59 & 2.67 & 2.72 & 2.57 & 2.74 & 2.09 & 2.52 & 2.76 \\
C18:2n6 & 0.53 & 1.66 & 1.54 & 1.22 & 1.11 & 1.36 & 1.80 & 1.52 & 1.54 \\
C19:0+ C18:3n6 & nd & 0.37 & 0.37 & 0.40 & 0.56 & 0.35 & 0.41 & 0.36 & 0.53 \\
C18:3n3 & nd & 1.09 & 0.73 & 0.64 & 0.57 & 0.47 & 0.89 & 0.97 & 0.74 \\
C18:4n3 & nd & 1.48 & 0.76 & 0.43 & 0.67 & 0.32 & 1.09 & 1.03 & 0.96 \\
C20:0 & 0.23 & nd & 0.48 & 0.54 & 0.62 & 0.42 & 0.51 & 0.54 & 0.67 \\
C20:1n15 & nd & nd & nd & nd & nd & nd & nd & nd & nd \\
C20:1n12 & 1.02 & 0.87 & 0.89 & 0.54 & 0.65 & 0.52 & 1.20 & 0.93 & 0.95 \\
C20:1n9 & 3.73 & 0.42 & 0.46 & 0.45 & 0.35 & 0.38 & 0.58 & 0.54 & nd \\
\hline & & & & & & & & &
\end{tabular}


Table A3 continued. Bay anchovy collected from the upper bay in summer.

\begin{tabular}{lccccccccc}
\hline & \multicolumn{10}{c}{ Sample number } \\
\hline \hline C20:1n7 & 1 & 2 & 3 & 4 & 5 & 6 & 7 & 8 & 9 \\
C20:2n6 & 0.33 & 0.24 & 0.25 & 0.43 & 0.42 & 0.49 & 0.58 & 0.26 & 0.40 \\
C20:3n6 + C21:0 & nd & nd & 0.18 & 0.18 & nd & nd & nd & nd & nd \\
C20:4n6 & nd & 0.94 & 1.59 & 2.14 & 1.83 & 1.77 & 1.27 & 1.29 & 1.00 \\
C20:3n3 & nd & 0.22 & 0.37 & 0.38 & 0.38 & 0.26 & 0.46 & 0.31 & nd \\
C20:5n3 & 0.36 & 7.17 & 6.94 & 5.95 & 4.27 & 5.52 & 6.65 & 6.77 & 6.96 \\
C22:0 & nd & 0.51 & 0.50 & 0.58 & 0.46 & 0.47 & 0.48 & 0.40 & nd \\
C22:1n11 & 2.80 & nd & nd & nd & nd & nd & nd & nd & nd \\
C22:1n9 & 0.75 & nd & nd & nd & nd & nd & nd & nd & nd \\
C22:4n6 & nd & 0.24 & 0.33 & 0.32 & nd & 0.30 & 0.41 & 0.34 & nd \\
C22:5n6 & nd & 0.51 & 0.51 & 0.56 & 0.77 & 0.45 & 0.27 & 0.47 & nd \\
C22:5n3 & 0.28 & 1.99 & 1.31 & 0.71 & 0.81 & 0.58 & 1.20 & 0.93 & 0.38 \\
C24:0 & 0.11 & 0.93 & 0.89 & 1.22 & 1.68 & 1.29 & 1.16 & 0.74 & 0.97 \\
C22:6n3 & 1.48 & 17.79 & 20.16 & 17.82 & 16.87 & 21.47 & 19.13 & 15.69 & 16.06 \\
C24:1n9 & 0.53 & 0.87 & 0.98 & 1.40 & 1.08 & 1.71 & 1.03 & 0.79 & nd \\
\hline
\end{tabular}


Table A4. Bay anchovy collected from the lower bay in summer.

\begin{tabular}{lcccccccccc}
\hline & \multicolumn{10}{c}{ Sample number } \\
\hline & 1 & 2 & 3 & 4 & 5 & 6 & 7 & 8 & 9 & 10 \\
\hline \hline Average total length (mm) & 66.13 & 88.70 & 60.98 & 61.95 & 63.53 & 63.35 & 65.28 & 63.85 & 70.70 & 60.62 \\
Weight (g) & 3.58 & 5.43 & 4.68 & 4.85 & 4.83 & 4.15 & 5.59 & 5.03 & 4.69 & 4.25 \\
Lipid content (\%) & 5.44 & 4.35 & 8.76 & 6.57 & 6.55 & 7.05 & 4.21 & 5.60 & 5.43 & 4.95 \\
C12:0 & 0.08 & 0.07 & 0.12 & 0.06 & nd & 0.19 & 0.13 & 0.15 & 0.00 & 0.03 \\
C12:1n1 & 0.03 & 0.05 & nd & 0.03 & nd & 0.04 & nd & 0.02 & 0.02 & 0.03 \\
C13:0 & 0.57 & 0.51 & 0.42 & 0.44 & 0.61 & 0.43 & 0.35 & 0.36 & 0.38 & 0.53 \\
C14:0 & 1.42 & 0.99 & 2.53 & 2.19 & 1.39 & 2.77 & 1.95 & 3.14 & 2.42 & 1.88 \\
C14:1n5 & 0.02 & nd & 0.02 & 0.04 & nd & 0.02 & 0.04 & 0.03 & nd & 0.03 \\
C15:0 & 1.08 & 0.79 & 1.31 & 1.08 & 0.89 & 1.36 & 1.18 & 0.96 & 1.15 & 1.03 \\
C15:1n5 & 0.36 & 0.38 & 0.34 & 0.34 & 0.46 & 0.23 & 0.29 & 0.22 & 0.26 & 0.38 \\
C16:0 DMA & 0.55 & 0.46 & 0.43 & 0.50 & 0.50 & 0.48 & 0.46 & 0.38 & 0.38 & 0.41 \\
C16:0 & 29.82 & 28.68 & 29.10 & 29.88 & 27.87 & 32.97 & 31.68 & 30.45 & 29.24 & 31.33 \\
C16:1n7 & 1.88 & 1.64 & 1.91 & 1.76 & 1.69 & 2.32 & 1.92 & 2.82 & 1.70 & 1.66 \\
C17:0 & 1.80 & 1.53 & 1.94 & 1.77 & 1.89 & 1.93 & 1.79 & 1.48 & 1.72 & 1.65 \\
C18:0 & 8.92 & 7.86 & 9.55 & 9.28 & 9.58 & 9.73 & 9.02 & 8.05 & 8.82 & 9.52 \\
C18:1n12t & nd & nd & nd & nd & nd & nd & 0.22 & nd & nd & nd \\
C18:1n9 & 7.48 & 7.30 & 6.32 & 6.35 & 6.96 & 7.35 & 6.76 & 6.84 & 5.47 & 6.66 \\
C18:1n7 & 2.83 & 2.82 & 2.53 & 2.49 & 2.63 & 2.69 & 2.50 & 2.62 & 2.31 & 2.46 \\
C18:1n9t & nd & nd & nd & nd & 0.17 & nd & nd & nd & nd & nd \\
C18:2n6 & 0.87 & 0.89 & 0.93 & 0.90 & 0.92 & 1.05 & 0.86 & 1.08 & 0.98 & 0.86 \\
C19:0 + C18:3n6 & 0.30 & 0.25 & 0.28 & 0.27 & 0.34 & 0.35 & 0.28 & 0.29 & 0.28 & 0.28 \\
C18:3n3 & 0.49 & 0.45 & 0.63 & 0.66 & 0.52 & 0.61 & 0.57 & 0.73 & 0.73 & 0.60 \\
C18:4n3 & 0.23 & 0.23 & 0.47 & 0.55 & 0.35 & 0.39 & 0.34 & 0.60 & 0.74 & 0.39 \\
C20:0 & 0.35 & 0.27 & 0.37 & 0.32 & 0.36 & 0.43 & 0.35 & 0.37 & 0.40 & 0.35 \\
C20:1n15 & 0.05 & 0.01 & 0.03 & nd & nd & 0.02 & 0.01 & 0.02 & 0.01 & nd \\
C20:1n12 & 0.23 & 0.12 & 0.31 & 0.25 & 0.22 & 0.37 & 0.23 & 0.35 & 0.21 & 0.17 \\
\hline & & & & & & & & & &
\end{tabular}


Table A4 continued. Bay anchovy collected from the lower bay in summer.

\begin{tabular}{lcccccccccc}
\hline & \multicolumn{10}{c}{ Sample number } \\
\hline & 1 & 2 & 3 & 4 & 5 & 6 & 7 & 8 & 9 & 10 \\
\hline \hline C20:1n9 & 0.45 & 0.37 & 0.41 & 0.36 & 0.34 & 0.44 & 0.35 & 0.40 & 0.28 & 0.28 \\
C20:1n7 & 0.31 & 0.24 & 0.40 & 0.29 & 0.37 & 0.40 & 0.29 & 0.47 & 0.26 & 0.25 \\
C20:2n6 & 0.46 & 0.39 & 0.45 & 0.43 & 0.42 & 0.45 & 0.41 & 0.44 & 0.39 & 0.39 \\
C20:3n6 + C21:0 & 0.19 & 0.14 & 0.17 & 0.02 & 0.15 & 0.17 & 0.17 & 0.14 & 0.16 & 0.15 \\
C20:4n6 & nd & 2.36 & 1.66 & 1.53 & 1.36 & 1.83 & 1.60 & 1.61 & 1.35 & 1.51 \\
C20:3n3 & 0.20 & 0.27 & 0.22 & 0.19 & 0.18 & 0.23 & 0.19 & 0.20 & 0.19 & 0.18 \\
C20:5n3 & 6.12 & 7.39 & 5.40 & 5.15 & 4.44 & 5.49 & 5.17 & 6.12 & 5.37 & 4.83 \\
C22:0 & 0.58 & 0.44 & 0.53 & 0.50 & 0.50 & 0.47 & 0.42 & 0.45 & 0.60 & 0.53 \\
C22:1n9 & 0.14 & 0.10 & 0.18 & 0.15 & nd & 0.17 & 0.12 & 0.13 & 0.23 & 0.13 \\
C22:2n6 & 0.05 & nd & nd & 0.02 & 0.03 & 0.02 & 0.01 & 0.02 & 0.04 & 0.01 \\
C23:0 & 0.07 & 0.05 & 0.13 & 0.08 & 0.10 & 0.06 & 0.11 & 0.09 & 0.15 & 0.09 \\
C22:4n6 & 0.20 & 0.23 & 0.51 & 0.25 & 0.75 & 0.32 & 0.77 & 0.27 & 0.59 & 0.40 \\
C22:3n3 & 0.74 & 0.91 & 1.13 & 0.91 & 1.61 & 0.67 & 1.15 & 0.96 & 1.41 & 1.07 \\
C22:5n3 & 0.76 & 0.68 & 0.80 & 0.57 & 0.68 & 0.71 & 0.57 & 0.78 & 0.60 & 0.48 \\
C24:0 & 1.42 & 1.30 & 1.46 & 1.40 & 2.14 & 0.96 & 1.33 & 1.33 & 1.46 & 1.32 \\
C22:6n3 & 26.77 & 27.70 & 24.77 & 26.78 & 26.43 & 20.26 & 24.32 & 23.43 & 27.11 & 26.15 \\
C24:1n9 & 2.18 & 2.11 & 2.23 & 2.19 & 3.11 & 1.56 & 2.06 & 2.18 & 2.59 & 2.38 \\
\hline
\end{tabular}


Table A5. Bay anchovy collected from the upper bay in fall.

\begin{tabular}{|c|c|c|c|c|c|c|c|c|c|c|}
\hline & \multicolumn{10}{|c|}{ Sample number } \\
\hline & 1 & 2 & 3 & 4 & 5 & 6 & 7 & 8 & 9 & 10 \\
\hline Average total length (mm) & 46.83 & 46.63 & 75.60 & 64.95 & 48.78 & 54.88 & 57.93 & 56.48 & 41.31 & 47.88 \\
\hline Weight (g) & 3.54 & 4.09 & 3.87 & 3.97 & 3.41 & 3.17 & 3.57 & 3.96 & 4.73 & 4.56 \\
\hline Lipid content (\%) & 25.03 & 16.70 & 8.36 & 28.33 & 24.79 & 8.30 & 12.64 & 5.34 & 6.43 & 1.65 \\
\hline $\mathrm{C} 12: 0$ & 0.45 & 0.20 & 0.50 & 0.51 & 0.17 & 0.17 & 0.45 & 0.27 & 0.33 & 0.44 \\
\hline C12:1n1 & nd & nd & nd & nd & nd & nd & nd & nd & nd & nd \\
\hline C13:0 & 0.30 & 0.21 & 0.28 & 0.21 & 0.19 & 0.19 & 0.27 & 0.23 & 0.38 & 0.29 \\
\hline C14:0 & 3.75 & 5.36 & 3.23 & 3.85 & 4.38 & 4.40 & 3.45 & 2.55 & 4.30 & 3.88 \\
\hline $\mathrm{C} 14: 1 \mathrm{n} 5$ & nd & nd & nd & nd & nd & 0.04 & 0.05 & nd & nd & nd \\
\hline C15:0 & 1.27 & 1.09 & 1.43 & 1.23 & 1.06 & 1.07 & 1.11 & 1.05 & 1.02 & 1.30 \\
\hline $\mathrm{C} 15: \ln 5$ & nd & nd & nd & 0.04 & 0.05 & 0.06 & 0.03 & 0.07 & nd & nd \\
\hline C16:0 DMA & 0.49 & 0.51 & 0.64 & 0.53 & 0.51 & 0.52 & 0.48 & 0.74 & 0.52 & 0.53 \\
\hline C16:0 & 34.17 & 34.02 & 32.78 & 35.00 & 32.88 & 33.06 & 37.53 & 33.53 & 33.93 & 33.33 \\
\hline C16:1n7 & 2.56 & 3.02 & 4.41 & 3.12 & 2.94 & 2.96 & 3.61 & 2.46 & 2.78 & 3.22 \\
\hline C17:0 & 1.70 & 1.46 & 2.46 & 1.88 & 1.44 & 1.45 & 1.55 & 1.50 & 1.40 & 1.65 \\
\hline C17:1n7 & 0.53 & 0.13 & 0.81 & 0.64 & 0.49 & nd & nd & nd & nd & nd \\
\hline C18:0 & 7.88 & 8.30 & 6.85 & 7.50 & 8.12 & 8.16 & 7.11 & 9.03 & 10.06 & 8.02 \\
\hline $\mathrm{C} 18: 1 \mathrm{n} 12 \mathrm{t}$ & 0.49 & 0.41 & 0.74 & 0.24 & nd & nd & nd & nd & nd & nd \\
\hline C18:1n9 & 8.81 & 6.91 & 11.89 & 10.85 & 7.18 & 7.22 & 11.73 & 9.82 & 7.94 & 10.56 \\
\hline C18:1n7 & 3.01 & 2.53 & 3.34 & 3.15 & 2.67 & 2.69 & 3.20 & 2.92 & 3.11 & 3.20 \\
\hline C18:2n6 & 1.43 & 1.60 & 1.50 & 1.47 & 1.62 & 1.63 & 1.17 & 1.24 & 1.33 & 1.52 \\
\hline $\mathrm{C} 19: 0+\mathrm{C} 18: 3 n 6$ & 0.32 & 0.27 & 0.36 & 0.34 & 0.29 & 0.29 & 0.31 & 0.35 & 0.37 & 0.36 \\
\hline C18:3n3 & 1.34 & 1.93 & 0.90 & 0.93 & 1.64 & 1.65 & 0.88 & 0.78 & 1.70 & 1.14 \\
\hline C18:4n3 & 0.97 & 1.59 & 0.45 & 0.77 & 1.36 & 1.37 & 0.71 & 0.59 & 2.15 & 1.05 \\
\hline$C 19: 2 n 6$ & nd & nd & nd & nd & nd & nd & nd & nd & nd & nd \\
\hline C20:0 & 0.53 & 0.51 & 0.46 & 0.55 & 0.47 & 0.47 & 0.57 & 0.53 & 0.45 & 0.57 \\
\hline C20:1n12 & 0.29 & 0.34 & 0.54 & 0.33 & 0.32 & 0.32 & 0.34 & 0.35 & 0.32 & 0.36 \\
\hline
\end{tabular}


Table A5 continued. Bay anchovy collected from the upper bay in fall.

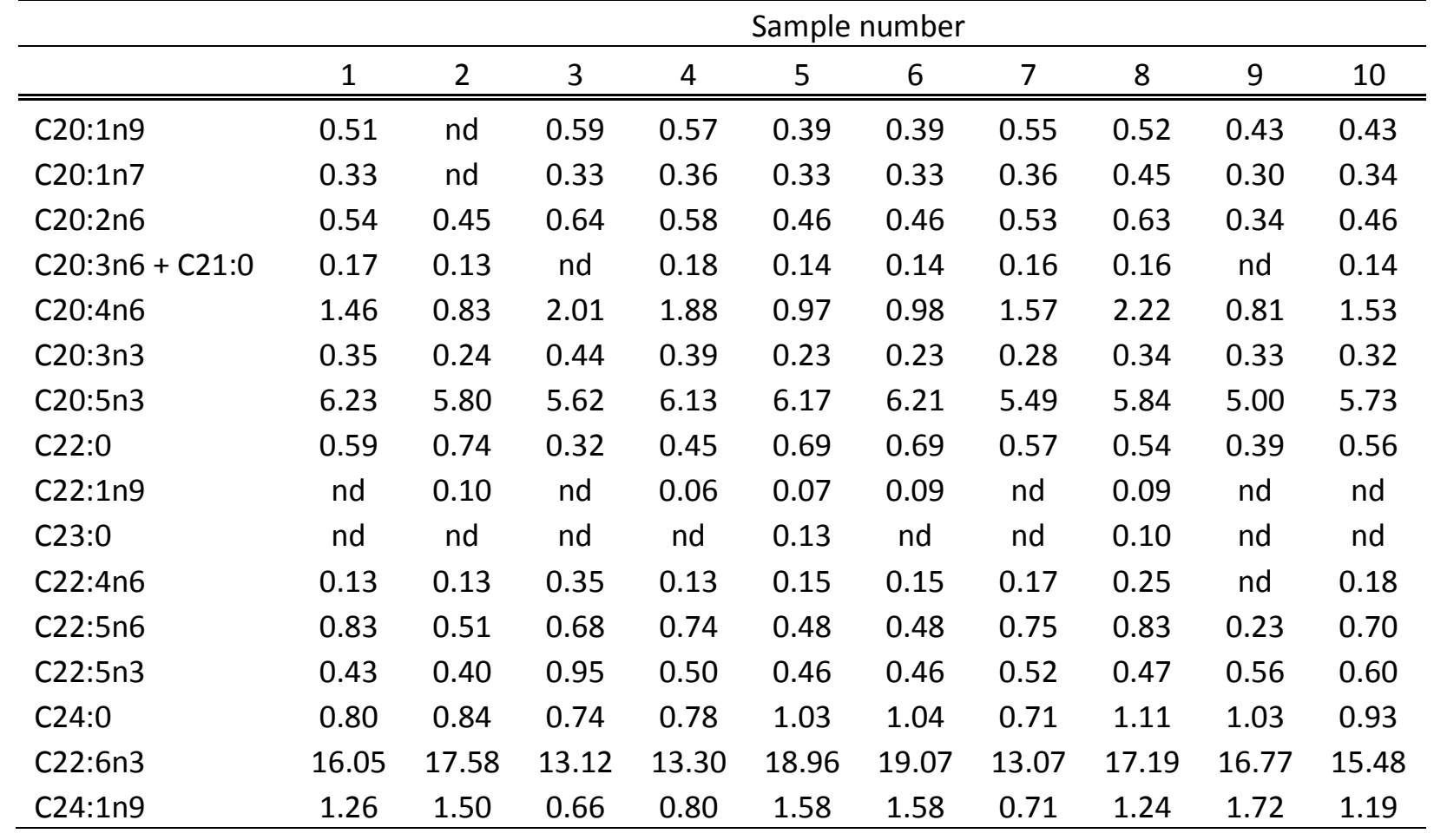


Table A6. Bay anchovy collected from the lower bay in fall.

\begin{tabular}{|c|c|c|c|c|c|c|c|c|c|c|}
\hline & \multicolumn{10}{|c|}{ Sample number } \\
\hline & 1 & 2 & 3 & 4 & 5 & 6 & 7 & 8 & 9 & 10 \\
\hline Total length (mm) & 55 & 67 & 60 & 46 & 62 & 52 & 52 & 62 & 51 & 55 \\
\hline Weight (g) & 3.51 & 4.52 & 4.23 & 4.65 & 5.02 & 3.46 & 3.92 & 3.38 & 4.07 & 3.09 \\
\hline Lipid content (\%) & 16.20 & 4.55 & 44.97 & 5.70 & 6.28 & 7.26 & 6.98 & 16.65 & 11.49 & 13.37 \\
\hline $\mathrm{C} 12: 0$ & 0.15 & 0.26 & nd & nd & 0.14 & 0.09 & 0.13 & nd & 0.03 & 0.07 \\
\hline C12:1n1 & nd & nd & nd & nd & nd & 0.06 & 0.06 & nd & 0.06 & 0.09 \\
\hline $\mathrm{C} 13: 0$ & 0.48 & 0.37 & 0.45 & 0.46 & 0.37 & 0.51 & 0.45 & 0.68 & 0.55 & 0.66 \\
\hline C14:0 & 3.57 & 3.43 & 3.87 & 4.64 & 3.33 & 3.16 & 3.99 & 2.95 & 2.76 & 4.20 \\
\hline C14:1n5 & 0.04 & nd & nd & nd & 0.03 & 0.03 & 0.04 & 0.13 & 0.02 & 0.15 \\
\hline C15:0 & 1.19 & 1.22 & 1.59 & 1.72 & 1.07 & 1.30 & 1.53 & 1.51 & 1.17 & 1.66 \\
\hline C15:1n5 & 0.31 & 0.30 & 0.46 & 0.27 & 0.20 & 0.29 & 0.20 & 0.52 & 0.35 & 0.35 \\
\hline C16:0 DMA & 0.36 & 0.39 & 0.47 & 0.55 & 0.35 & 0.38 & 0.37 & 0.38 & 0.32 & 0.38 \\
\hline C16:0 & 29.22 & 28.24 & 28.29 & 29.85 & 32.49 & 31.47 & 32.26 & 28.99 & 28.79 & 30.58 \\
\hline C16:1n7 & 4.06 & 3.47 & 5.43 & 6.81 & 3.54 & 4.39 & 5.71 & 3.87 & 4.12 & 5.56 \\
\hline C17:0 & 1.70 & 1.93 & 1.76 & 1.65 & 1.57 & 1.49 & 1.51 & 1.76 & 1.44 & 1.56 \\
\hline C18:0 & 7.96 & 7.77 & 7.92 & 7.32 & 7.98 & 7.51 & 6.95 & 8.51 & 7.83 & 7.43 \\
\hline $\mathrm{C} 18: 1 \mathrm{n} 12 \mathrm{t}$ & nd & 0.30 & nd & 0.14 & 0.25 & nd & nd & nd & nd & 0.19 \\
\hline C18:1n9 & 5.88 & 6.77 & 6.90 & 5.23 & 6.05 & 5.50 & 5.07 & 6.32 & 5.93 & 5.82 \\
\hline C18:1n7 & 3.05 & 2.92 & 3.25 & 3.10 & 2.93 & 3.06 & 2.95 & 3.12 & 2.87 & 3.28 \\
\hline C18:1n9t & nd & nd & nd & 0.14 & nd & nd & nd & 0.18 & nd & nd \\
\hline C18:2n6 & 0.78 & 0.81 & 0.96 & 1.21 & 0.80 & 0.93 & 1.08 & 0.90 & 0.88 & 1.16 \\
\hline $\mathrm{C} 19: 0+\mathrm{C} 18: 3 \mathrm{n} 6$ & 0.34 & 0.37 & 0.42 & 0.43 & 0.34 & 0.33 & 0.33 & 0.35 & 0.31 & 0.31 \\
\hline C18:3n3 & 0.81 & 0.60 & 0.88 & 1.43 & 0.69 & 0.95 & 1.26 & 0.67 & 0.85 & 1.41 \\
\hline $\mathrm{C} 18: 4 \mathrm{n} 3$ & 1.13 & 0.85 & 0.93 & 1.78 & 0.75 & 1.08 & 1.41 & 0.65 & 1.02 & 1.29 \\
\hline C19:2n6 & nd & nd & nd & nd & nd & nd & nd & nd & 0.05 & nd \\
\hline$C 20: 0$ & 0.48 & 0.49 & 0.54 & 0.46 & 0.43 & 0.37 & 0.40 & 0.46 & 0.33 & 0.47 \\
\hline C20:1n15 & nd & nd & nd & 0.07 & 0.02 & nd & 0.01 & nd & nd & 0.10 \\
\hline
\end{tabular}


Table A6 continued. Bay anchovy collected from the lower bay in fall.

\begin{tabular}{lcccccccccc}
\hline & \multicolumn{1}{c}{ Sample number } \\
\hline & 1 & 2 & 3 & 4 & 5 & 6 & 7 & 8 & 9 & 10 \\
\hline \hline C20:1n12 & 0.25 & 0.18 & 0.25 & 0.27 & 0.17 & 0.13 & 0.16 & 0.17 & 0.11 & 0.18 \\
C20:1n9 & 0.30 & 0.29 & 0.36 & 0.27 & 0.26 & 0.22 & 0.20 & 0.36 & 0.21 & 0.31 \\
C20:1n7 & 0.34 & 0.22 & 0.29 & 0.39 & 0.27 & 0.26 & 0.27 & 0.21 & 0.25 & 0.41 \\
C20:2n6 & 0.35 & 0.36 & 0.41 & 0.21 & 0.35 & 0.31 & 0.30 & 0.52 & 0.31 & 0.28 \\
C20:3n6 + C21:0 & 0.17 & 0.16 & 0.27 & 0.26 & 0.15 & 0.15 & 0.16 & 0.29 & 0.14 & 0.14 \\
C20:4n6 & 1.62 & 1.59 & 2.08 & 1.29 & 1.77 & 1.85 & 1.40 & 1.78 & 1.67 & 1.57 \\
C20:3n3 & 0.16 & 0.16 & 0.40 & 0.36 & 0.16 & 0.18 & 0.18 & 0.24 & 0.19 & 0.22 \\
C20:5n3 & 7.31 & 6.64 & 7.13 & 7.51 & 7.36 & 8.04 & 7.12 & 7.60 & 7.23 & 7.71 \\
C22:0 & 0.64 & 0.64 & 0.63 & 0.66 & 0.54 & 0.55 & 0.54 & 0.76 & 0.42 & 0.52 \\
C22:1n11 & 0.07 & 0.25 & 0.43 & 0.56 & 0.02 & 0.08 & 0.06 & 0.63 & 0.27 & 0.12 \\
C22:1n9 & 0.10 & nd & 0.13 & 0.12 & 0.08 & 0.07 & 0.08 & nd & 0.09 & 0.10 \\
C22:2n6 & 0.08 & 0.09 & 0.08 & nd & 0.03 & 0.02 & 0.03 & nd & nd & nd \\
C23:0 & 0.24 & 0.21 & 0.22 & 0.16 & 0.14 & 0.10 & 0.09 & 0.15 & 0.15 & 0.14 \\
C22:4n6 & 0.57 & 0.59 & 1.23 & 0.20 & 0.26 & 0.25 & 0.27 & 0.18 & 0.54 & 0.32 \\
C22:3n3 & 0.92 & 1.33 & 1.19 & 0.72 & 0.67 & 0.73 & 0.79 & 0.62 & 1.00 & 0.84 \\
C22:5n3 & 0.85 & 1.08 & 0.63 & 0.61 & 0.59 & 0.59 & 0.55 & 0.52 & 0.73 & 0.57 \\
C24:0 & 1.50 & 1.71 & 1.25 & 0.93 & 0.90 & 1.07 & 0.97 & 1.30 & 1.58 & 1.12 \\
C22:6n3 & 20.73 & 21.20 & 17.63 & 16.89 & 21.25 & 20.82 & 19.51 & 20.92 & 22.98 & 17.30 \\
C24:1n9 & 2.29 & 2.83 & 1.29 & 1.32 & 1.71 & 1.67 & 1.62 & 1.80 & 2.47 & 1.43 \\
\hline
\end{tabular}


Table A7. Blue crab collected from the upper bay in summer.

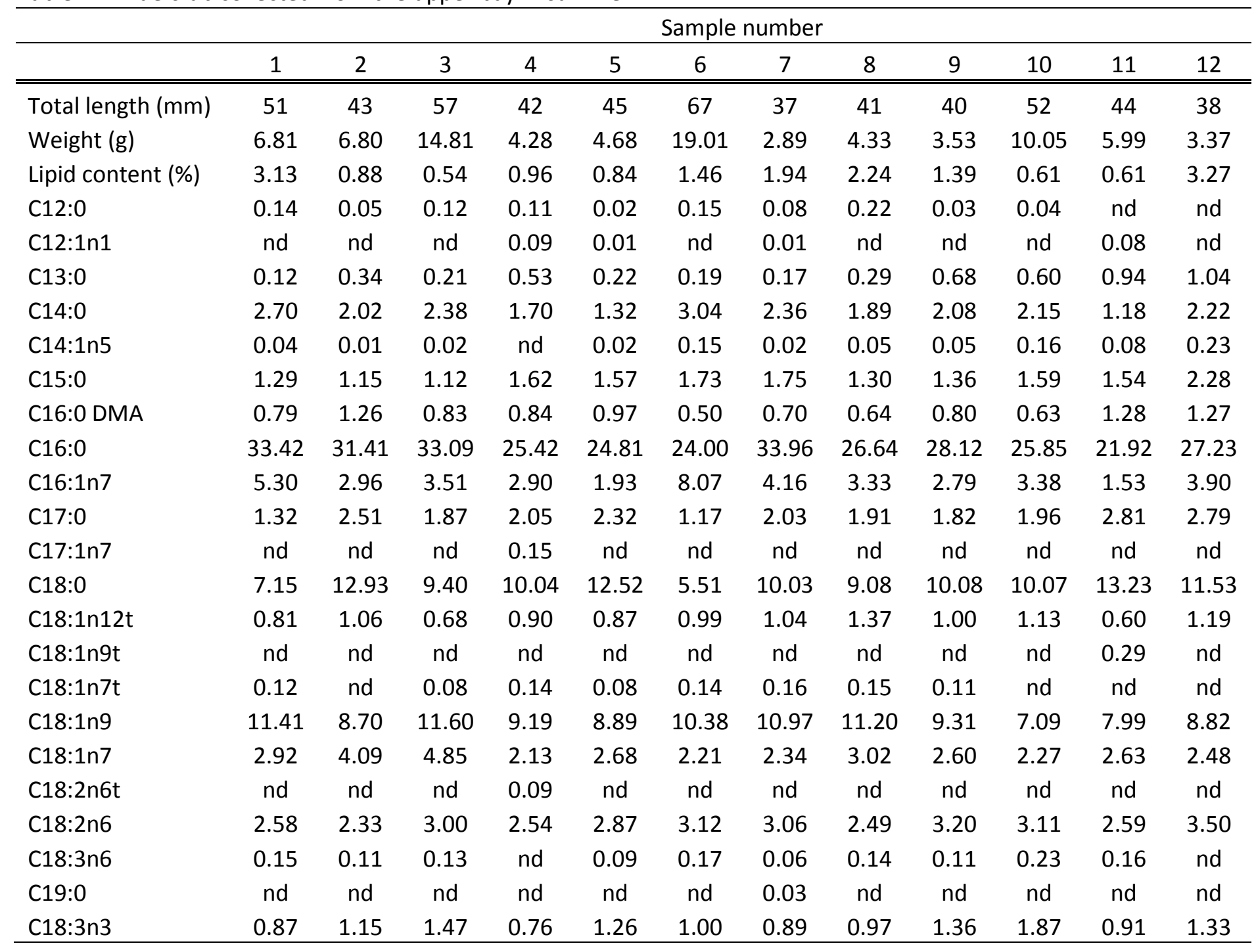


Table A7 continued. Blue crab collected from the upper bay in summer.

\begin{tabular}{lcccccccccccc}
\hline & \multicolumn{10}{c}{ Sample number } \\
\hline & 1 & 2 & 3 & 4 & 5 & 6 & 7 & 8 & 9 & 10 & 11 & 12 \\
\hline C18:4n3 & 1.17 & 0.42 & 0.62 & 0.78 & 0.25 & 1.33 & 0.44 & 0.72 & 0.82 & 0.79 & 0.27 & nd \\
C19:2n6 & 0.03 & 0.01 & nd & 0.11 & nd & 0.09 & 0.06 & nd & 0.05 & nd & nd & nd \\
C20:0 & 1.29 & 1.39 & 1.46 & 1.99 & 1.50 & 1.61 & 1.64 & 1.63 & 1.59 & 1.90 & 1.64 & 2.31 \\
C20:1n15 & nd & 0.10 & 0.10 & 0.18 & 0.11 & 0.18 & 0.13 & 0.07 & 0.08 & 0.14 & nd & 0.42 \\
C20:1n12 & 2.82 & 1.15 & 1.63 & 4.63 & 1.43 & 4.22 & 4.21 & 2.34 & 2.26 & 3.47 & 1.68 & 3.42 \\
C20:1n9 & 1.17 & 1.06 & 1.49 & 1.43 & 1.06 & 1.20 & 1.34 & 1.12 & 1.04 & 1.04 & 1.10 & 1.94 \\
C20:1n7 & 2.69 & 1.14 & 0.92 & 4.63 & 1.31 & 4.35 & 4.33 & 1.84 & 2.14 & 3.57 & 1.42 & 2.93 \\
C20:2n6 & 1.02 & 1.36 & 1.63 & 1.70 & 1.94 & 1.30 & 1.45 & 1.82 & 1.62 & 1.79 & 2.16 & 2.48 \\
C20:3n6 & 0.10 & 0.13 & 0.14 & 0.18 & 0.17 & 0.18 & 0.09 & 0.15 & 0.14 & 0.27 & 0.30 & 0.27 \\
C21:0 & 0.15 & 0.17 & 0.22 & 0.28 & 0.13 & 0.21 & 0.22 & 0.20 & 0.19 & 0.24 & 0.27 & 1.32 \\
C20:4n6 & 1.59 & 2.82 & 2.25 & 2.29 & 3.17 & 1.65 & 1.35 & 2.04 & 2.11 & 1.97 & 3.07 & 1.98 \\
C20:3n3 & 0.26 & 0.36 & 0.50 & 0.34 & 0.40 & 0.37 & 0.25 & 0.30 & 0.42 & 0.40 & 0.41 & 0.55 \\
C20:5n3 & 6.52 & 8.69 & 6.63 & 5.97 & 10.02 & 4.58 & 4.35 & 6.74 & 7.50 & 5.84 & 8.75 & 4.47 \\
C22:0 & 1.21 & 1.15 & 1.20 & 1.28 & 1.31 & 1.19 & 0.93 & 2.06 & 1.74 & 1.74 & 1.30 & 1.86 \\
C22:1n11 & nd & nd & nd & 0.23 & nd & nd & nd & nd & nd & 0.11 & nd & 0.28 \\
C22:1n9 & 0.14 & 0.15 & 0.16 & nd & 0.24 & 0.28 & 0.22 & 0.20 & 0.17 & 0.26 & 0.37 & nd \\
C22:2n6 & 0.02 & 0.04 & 0.03 & 0.75 & nd & nd & 0.04 & nd & 0.03 & 0.31 & nd & nd \\
C22:4n6 & 0.12 & 0.36 & 0.18 & nd & 0.56 & 0.13 & 0.10 & 0.60 & 0.30 & 0.35 & 0.85 & nd \\
C22:3n3 + C22:5n6 & 0.37 & 0.20 & 0.27 & 1.22 & 0.57 & 0.37 & 0.16 & 0.55 & 0.45 & 0.54 & 0.50 & 0.56 \\
C22:5n3 & 0.45 & 0.92 & 0.45 & 1.78 & 3.40 & 3.58 & 0.43 & 1.86 & 1.31 & 3.06 & 5.65 & 0.82 \\
C22:6n3 + C24:0 & 7.84 & 6.19 & 5.61 & 9.05 & 9.99 & 10.25 & 4.29 & 10.92 & 10.40 & 9.86 & 9.80 & 4.60 \\
C24:1n9 & 0.07 & 0.11 & 0.16 & nd & nd & 0.36 & 0.14 & 0.14 & 0.10 & 0.22 & 0.54 & nd \\
\hline
\end{tabular}


Table A8. Blue crab collected from the upper bay in fall.

\begin{tabular}{lcccccccccc}
\hline & \multicolumn{1}{c}{ Sample number } \\
\hline & 1 & 2 & 3 & 4 & 5 & 6 & 7 & 8 & 9 & 10 \\
\hline Total length (mm) & 114 & 119 & 154 & 116 & 99 & 111 & 115 & 126 & 130 & 122 \\
Weight (g) & 101.9 & 78.5 & 140.8 & 59.9 & 66.4 & 74.6 & 79.6 & 97.8 & 105.5 & 92.4 \\
Lipid content (\%) & 1.04 & 0.64 & 0.79 & 1.63 & 1.80 & 1.77 & 0.65 & 2.15 & 0.82 & 0.50 \\
C12:0 & 0.07 & 0.05 & 0.10 & 0.09 & 0.07 & 0.12 & 0.06 & 0.17 & 0.08 & 0.06 \\
C12:1n1 & 0.08 & nd & 0.10 & 0.12 & 0.08 & 0.07 & 0.09 & 0.16 & nd & nd \\
C13:0 & 0.30 & nd & 0.28 & 0.20 & 0.12 & 0.13 & nd & 0.23 & nd & nd \\
C14:0 & 1.37 & 1.29 & 1.42 & 1.51 & 1.39 & 2.19 & 1.17 & 2.25 & 1.32 & 1.02 \\
C14:1n5 & 0.05 & 0.03 & 0.03 & 0.08 & 0.04 & 0.06 & 0.02 & 0.04 & 0.07 & 0.01 \\
C15:0 & 1.55 & 1.50 & 1.41 & 1.28 & 1.29 & 1.88 & 1.28 & 1.38 & 1.31 & 1.27 \\
C15:1n5 & 0.32 & 0.41 & 0.23 & 0.22 & 0.20 & 0.24 & 0.30 & 0.22 & 0.29 & nd \\
C16:0 DMA & nd & 0.07 & nd & nd & nd & nd & nd & nd & nd & nd \\
C16:0 & 23.08 & 23.58 & 23.50 & 24.00 & 20.04 & 26.99 & 25.42 & 26.80 & 23.24 & 21.48 \\
C16:1n7 & 4.55 & 3.88 & 4.59 & 5.70 & 3.90 & 5.16 & 3.66 & 4.13 & 5.07 & 3.37 \\
C17:0 & 1.33 & 2.09 & 2.23 & 1.11 & 1.39 & 1.70 & 2.07 & 1.80 & 1.64 & 2.22 \\
C18:0 & 7.11 & 10.19 & 7.83 & 6.39 & 6.29 & 7.87 & 9.11 & 8.12 & 8.71 & 10.26 \\
C18:1n12t & 0.51 & 0.70 & 0.58 & 0.44 & 0.57 & 0.55 & 0.44 & 0.76 & 0.49 & 0.42 \\
C18:1n9t & 0.22 & nd & 0.18 & 0.47 & 0.19 & 0.35 & 0.17 & 0.08 & 0.26 & 0.37 \\
C18:1n7t & nd & nd & nd & nd & nd & nd & nd & 0.08 & nd & nd \\
C18:1n9 & 18.48 & 14.03 & 10.98 & 19.15 & 11.07 & 11.42 & 11.51 & 13.00 & 15.62 & 10.22 \\
C18:1n7 & 2.90 & 2.56 & 2.29 & 2.96 & 2.23 & 2.33 & 2.52 & 2.94 & 2.77 & 2.55 \\
C18:2n6 & 6.00 & 3.20 & 2.85 & 7.51 & 5.09 & 3.72 & 3.44 & 4.42 & 5.20 & 3.06 \\
C18:3n6 & 0.38 & 0.39 & 0.35 & 0.31 & 0.62 & 0.35 & 0.35 & 0.39 & 0.44 & 0.36 \\
C18:3n3 & 0.47 & 0.47 & 0.54 & 0.52 & 0.64 & 0.52 & 0.53 & 0.56 & 0.58 & 0.66 \\
C18:4n3 & 0.38 & 0.21 & 0.50 & 0.32 & 0.60 & 0.46 & 0.29 & 0.54 & 0.30 & 0.36 \\
C19:2n6 & 0.02 & 0.01 & nd & nd & nd & nd & nd & nd & nd & nd \\
C20:0 & 0.29 & 0.37 & 0.32 & 0.22 & 0.68 & 0.34 & 0.39 & 0.34 & 0.38 & 0.43 \\
\hline & & & & & & & & & &
\end{tabular}


Table A8 continued. Blue crab collected from the upper bay in fall.

\begin{tabular}{lcccccccccc}
\hline & \multicolumn{10}{c}{ Sample number } \\
\hline \hline C20:1n15 & 1 & 2 & 3 & 4 & 5 & 6 & 7 & 8 & 9 & 10 \\
C20:1n12 & nd & 0.03 & nd & 0.06 & nd & 0.08 & nd & nd & 0.04 & nd \\
C20:1n9 & 2.87 & 0.00 & 4.66 & 2.33 & 3.50 & 3.87 & 3.10 & 3.25 & nd & 2.83 \\
C20:1n7 & 1.15 & 1.52 & 1.22 & 0.97 & 1.33 & 1.23 & 1.15 & 1.09 & 1.19 & 1.41 \\
C20:2n6 & 3.02 & nd & 4.99 & 2.43 & 3.92 & 4.26 & 3.41 & 3.64 & 4.23 & 3.44 \\
C20:3n6 & 1.08 & 1.64 & 1.09 & 1.01 & 1.57 & 1.08 & 1.14 & 1.06 & 1.32 & 1.54 \\
C21:0 & 0.29 & 0.32 & 0.28 & 0.24 & 0.67 & 0.22 & 0.27 & 0.25 & 0.28 & 0.26 \\
C20:4n6 & nd & nd & nd & nd & nd & 0.01 & nd & nd & 0.02 & nd \\
C20:3n3 & 4.19 & 6.43 & 4.93 & 3.39 & 4.41 & 3.83 & 5.45 & 3.43 & 4.97 & 6.44 \\
C20:5n3 & 0.17 & 0.25 & 0.24 & 0.18 & 0.97 & 0.23 & 0.29 & 0.27 & 0.20 & 0.24 \\
C22:0 & 6.32 & 9.25 & 8.00 & 6.09 & 6.25 & 6.44 & 9.43 & 6.63 & 7.38 & 11.05 \\
C22:1n9 & 0.29 & 0.36 & 0.32 & 0.32 & 1.02 & 0.37 & 0.37 & 0.29 & 0.38 & 0.47 \\
C22:2n6 & 0.05 & 0.08 & 0.06 & 0.05 & 0.60 & 0.05 & 0.05 & 0.03 & 0.06 & 0.06 \\
C22:4n6 & 0.02 & 0.02 & nd & 0.01 & 0.61 & 0.02 & 0.02 & 0.01 & 0.03 & 0.03 \\
C22:3n3 + C22:5n6 & 0.33 & 0.45 & 0.28 & 0.30 & 1.85 & 0.30 & 0.36 & 0.28 & 0.33 & 0.27 \\
C22:5n3 & 1.36 & 0.84 & 0.62 & 2.90 & 0.97 & 0.80 & 0.68 & 0.99 & 0.84 \\
C22:6n3 + C24:0 & 0.64 & 1.22 & 0.65 & 0.83 & 1.68 & nd & 0.69 & 0.96 & 0.72 & 0.99 \\
C24:1n9 & 9.30 & 12.03 & 12.13 & 8.28 & 12.21 & 10.60 & 10.63 & 9.38 & 10.08 & 12.04 \\
\hline
\end{tabular}


Table A9. Menhaden collected from the upper bay in spring.

Sample number

\begin{tabular}{|c|c|c|c|c|c|c|c|c|c|c|c|}
\hline & $1 \mathrm{~A}$ & $1 \mathrm{~B}$ & $2 A \& B$ & $3 \mathrm{~A}$ & $3 B$ & $4 \mathrm{~A}$ & $5 A \& B$ & $6 \mathrm{~A}$ & $7 \mathrm{~A}$ & $7 \mathrm{~B}$ & $8 A \& B$ \\
\hline Total length (mm) & 71 & - & 76 & 78 & - & 73 & 86 & 81 & 80 & - & 79 \\
\hline Weight (g) & 3.33 & & 4.16 & 4.65 & & 3.43 & 5.76 & 5.20 & 5.20 & & 4.99 \\
\hline Lipid content (\%) & 4.47 & - & 4.80 & - & - & - & 4.26 & 5.72 & - & 5.35 & 5.11 \\
\hline C12:0 & nd & nd & 0.04 & 0.04 & 0.67 & 0.18 & 0.05 & 0.06 & nd & 0.05 & 0.07 \\
\hline C12:1n1 & nd & nd & nd & nd & nd & nd & nd & 0.03 & nd & nd & nd \\
\hline C13:0 & nd & nd & nd & nd & nd & 0.09 & nd & 0.21 & nd & nd & nd \\
\hline C14:0 & 1.89 & 3.27 & 2.50 & 1.64 & 3.07 & 3.46 & 1.46 & 3.96 & 4.13 & 2.19 & 2.28 \\
\hline C14:1n5 & nd & 3.35 & nd & nd & 2.04 & nd & nd & nd & 0.80 & nd & nd \\
\hline C15:0 & 1.51 & 2.63 & 1.25 & 1.21 & 1.70 & 11.78 & 1.24 & 4.75 & 4.10 & 1.48 & 2.17 \\
\hline C15:1n5 & nd & nd & 0.08 & 0.08 & nd & nd & 0.08 & 0.07 & nd & 0.15 & 0.08 \\
\hline C16:0 DMA & 0.67 & nd & 0.48 & 0.56 & 1.57 & 0.27 & 0.61 & 0.49 & 1.13 & 0.80 & 0.56 \\
\hline C16:0 & 36.53 & 41.52 & 36.58 & 35.80 & 30.61 & 33.65 & 34.32 & 32.09 & 29.48 & 36.06 & 34.34 \\
\hline C16:1n7 & 2.66 & 3.77 & 3.50 & 3.42 & 3.34 & 3.87 & 3.23 & 5.26 & 5.13 & 3.99 & 4.02 \\
\hline C17:0 & 1.20 & nd & 1.48 & 0.99 & 1.93 & 1.00 & 1.25 & 1.72 & 2.26 & 1.52 & 1.50 \\
\hline C17:1n7 & nd & nd & 0.47 & 0.44 & nd & nd & nd & nd & nd & nd & nd \\
\hline C18:0 & 10.27 & 16.34 & 9.99 & 8.75 & 12.97 & 9.37 & 9.46 & 7.40 & 12.66 & 9.75 & 9.50 \\
\hline C18:1n12t & nd & nd & nd & nd & nd & 0.29 & nd & nd & nd & nd & nd \\
\hline C18:1n9t & nd & nd & nd & nd & nd & 0.12 & nd & nd & nd & nd & nd \\
\hline C18:1n9 & 6.42 & 7.61 & 5.82 & 4.76 & 6.22 & 6.69 & 4.96 & 4.17 & 5.35 & 5.80 & 5.08 \\
\hline C18:1n7 & 2.48 & 1.95 & 2.73 & 2.33 & 2.91 & 1.93 & 2.55 & 2.46 & 2.26 & 2.53 & 2.44 \\
\hline C18:2n6 & 1.29 & nd & 1.74 & 1.21 & 1.47 & 1.16 & 1.28 & 1.42 & nd & 1.59 & 1.51 \\
\hline C19:0 + C18:3n6 & 0.31 & nd & 0.30 & 0.24 & 0.33 & 0.22 & 0.30 & 0.46 & nd & 0.37 & 0.37 \\
\hline C18:3n3 & 0.98 & nd & 1.72 & 0.93 & 1.01 & 1.07 & 1.08 & 1.14 & 0.72 & 0.97 & nd \\
\hline C18:4n3 & 0.63 & nd & 1.05 & 0.59 & 0.68 & 0.86 & 0.49 & 1.18 & 1.03 & 0.47 & 0.84 \\
\hline C20:0 & 0.21 & nd & 0.22 & 0.18 & 0.59 & 0.21 & 0.19 & 0.23 & nd & 0.24 & nd \\
\hline C20:1n12 & nd & nd & 0.37 & nd & nd & 0.24 & 0.07 & 0.16 & nd & nd & nd \\
\hline
\end{tabular}


Table A9 continued. Menhaden collected from the upper bay in spring.

\begin{tabular}{lccccccccccc}
\hline \multicolumn{10}{c}{ Sample number } \\
\hline \hline C20:1n9 & 1A & 1B & $2 A \& B$ & $3 A$ & $3 B$ & $4 A$ & $5 A \& B$ & $6 A$ & $7 A$ & $7 B$ & $8 A \& B$ \\
C20:1n7 & nd & nd & 0.39 & 0.11 & nd & 0.25 & nd & 0.18 & 1.40 & 0.15 & 0.15 \\
C20:2n6 & nd & nd & 0.18 & 0.13 & nd & 0.09 & 0.16 & 0.30 & nd & 0.15 & 0.12 \\
C20:3n6 + C21:0 & nd & nd & 0.11 & 0.14 & nd & 0.09 & 0.14 & 0.17 & nd & 0.19 & 0.23 \\
C20:4n6 & 1.68 & nd & 1.22 & 1.72 & 1.92 & 0.95 & 2.14 & 1.94 & 3.66 & 1.76 & 2.14 \\
C20:3n3 & 0.22 & nd & 0.18 & 0.27 & nd & 0.19 & 0.28 & 0.24 & nd & 0.24 & 0.30 \\
C20:5n3 & 4.68 & 3.94 & 4.85 & 4.45 & 3.45 & 3.28 & 5.29 & 6.17 & 5.47 & 5.09 & 5.17 \\
C22:0 & nd & nd & 0.44 & 0.42 & nd & 0.29 & 0.43 & 0.49 & nd & 0.40 & 0.49 \\
C22:1n11 & nd & nd & nd & nd & nd & 0.07 & nd & nd & nd & nd & 0.17 \\
C22:1n9 & nd & nd & nd & 0.04 & nd & 0.05 & nd & 0.08 & nd & nd & nd \\
C22:2n6 & nd & nd & nd & nd & nd & 0.01 & nd & nd & nd & nd & nd \\
C23:0 & 0.57 & nd & 0.17 & 0.16 & nd & 0.14 & 0.15 & 0.40 & nd & 0.13 & 0.18 \\
C22:4n6 & nd & nd & nd & nd & nd & 0.06 & 0.14 & 0.16 & nd & 0.12 & nd \\
C22:3n3 & nd & nd & nd & nd & nd & nd & nd & nd & nd & nd & nd \\
C22:5n6 & 0.69 & nd & 0.47 & 0.64 & 0.41 & 0.40 & 0.82 & 0.67 & nd & 0.56 & 0.57 \\
C22:5n3 & 0.61 & nd & 0.64 & 0.52 & 0.58 & 0.38 & 0.59 & 0.61 & nd & 0.55 & 0.63 \\
C24:0 & 1.28 & nd & 0.46 & 0.68 & 0.81 & 0.40 & 0.78 & 0.46 & 2.75 & 0.09 & 0.72 \\
C22:6n3 & 20.24 & 15.61 & 18.89 & 24.09 & 17.79 & 15.55 & 24.37 & 18.08 & 16.68 & 20.71 & 22.49 \\
C24:1n9 & 1.62 & nd & 1.39 & 1.72 & 1.17 & 1.12 & 1.66 & 1.24 & 0.97 & 1.65 & 1.37 \\
\hline
\end{tabular}


Table A10. Menhaden collected from the lower bay in spring.

\begin{tabular}{|c|c|c|c|c|c|c|c|c|c|c|}
\hline & \multicolumn{10}{|c|}{ Sample number } \\
\hline & 1 & 2 & 3 & 4 & 5 & 6 & 7 & 8 & 9 & 10 \\
\hline Average total length (mm) & 57.03 & 58.88 & 48.28 & 47.98 & 47.58 & 45.25 & 43.82 & 45.86 & 55.83 & 54.46 \\
\hline Weight (g) & 3.93 & 3.63 & 3.21 & 3.37 & 3.06 & 3.77 & 3.23 & 3.56 & 14.88 & 13.99 \\
\hline Lipid content (\%) & 9.28 & 9.70 & & 5.23 & 10.39 & & & & & \\
\hline C12:0 & 0.12 & 0.15 & 0.15 & 0.15 & 0.16 & 0.35 & 0.09 & nd & 0.30 & 0.20 \\
\hline C13:0 & nd & nd & nd & 0.17 & 0.26 & nd & 0.33 & nd & nd & nd \\
\hline C14:0 & 8.58 & 12.81 & 10.85 & 12.94 & 11.21 & 10.38 & 7.26 & 8.14 & 11.80 & 11.19 \\
\hline C14:1n5 & nd & nd & nd & 0.07 & nd & nd & nd & nd & nd & nd \\
\hline C15:0 & 0.97 & 1.06 & 0.85 & 0.97 & 0.95 & 1.54 & 0.80 & 1.16 & 1.07 & 0.97 \\
\hline C15:1n5 & nd & nd & nd & 0.04 & nd & nd & nd & nd & nd & nd \\
\hline C16:0 DMA & 0.44 & 0.28 & 0.35 & 0.30 & 0.32 & nd & 0.50 & 0.64 & 0.43 & 0.37 \\
\hline C16:0 & 38.95 & 38.27 & 37.29 & 38.11 & 34.29 & 37.00 & 34.34 & 35.32 & 36.26 & 35.00 \\
\hline C16:1n7 & 13.05 & 16.80 & 15.18 & 16.06 & 14.50 & 14.34 & 9.61 & 12.11 & 15.55 & 13.91 \\
\hline C17:0 & 1.27 & 0.85 & 0.69 & 0.62 & 0.65 & 1.64 & 0.84 & 0.49 & 0.40 & 0.41 \\
\hline C17:1n7 & nd & nd & nd & 0.23 & 0.27 & nd & nd & nd & nd & nd \\
\hline C18:0 & 6.42 & 4.36 & 4.94 & 4.03 & 4.24 & 6.76 & 6.82 & 6.76 & 4.57 & 4.88 \\
\hline C18:1n9 & 3.56 & 3.10 & 3.31 & 3.09 & 2.86 & 4.53 & 3.79 & 4.21 & 2.87 & 3.15 \\
\hline C18:1n7 & 3.58 & 2.96 & 3.29 & 3.14 & 3.37 & 4.26 & 3.49 & 3.53 & 2.87 & 3.15 \\
\hline C18:2n6 & 1.33 & 1.30 & 1.25 & 1.13 & 1.20 & 1.05 & 0.94 & 1.03 & 1.25 & 1.31 \\
\hline$C 19: 0+C 18: 3 n 6$ & 0.38 & 0.37 & 0.38 & 0.30 & 0.37 & nd & 0.41 & nd & 0.45 & 0.46 \\
\hline C18:3n3 & 0.90 & 1.67 & 1.15 & 1.60 & 1.34 & 0.79 & 0.61 & 1.03 & 1.51 & 1.22 \\
\hline C18:4n3 & 2.52 & 2.66 & 2.49 & 2.53 & 3.10 & 1.92 & 2.06 & 2.44 & 2.90 & 3.20 \\
\hline C20:0 & nd & 0.16 & 0.18 & 0.16 & 0.18 & nd & 0.24 & nd & 0.21 & nd \\
\hline C20:1n12 & nd & nd & nd & 0.13 & nd & nd & nd & nd & nd & nd \\
\hline C20:1n9 & nd & nd & nd & 0.10 & nd & nd & nd & nd & nd & nd \\
\hline C20:1n7 & nd & nd & 0.12 & 0.13 & 0.08 & nd & nd & nd & nd & nd \\
\hline
\end{tabular}


Table A10 continued. Menhaden collected from the lower bay in spring.

\begin{tabular}{lccccccccccc}
\hline & \multicolumn{10}{c}{ Sample number } \\
\hline \hline C20:2n6 & 1 & 2 & 3 & 4 & 5 & 6 & 7 & 8 & 9 & 10 \\
C20:3n6 + C21:0 & nd & nd & nd & 0.08 & nd & nd & nd & nd & nd & nd \\
C20:4n6 & 1.11 & 0.65 & 0.22 & 0.10 & 0.26 & nd & nd & nd & nd & nd \\
C20:5n3 & 6.61 & 5.90 & 6.80 & 6.02 & 0.86 & 0.93 & 1.70 & 1.67 & 0.81 & 1.08 \\
C22:0 & nd & nd & 0.24 & 0.23 & 0.31 & nd & 0.38 & nd & 0.33 & nd \\
C22:5n6 & nd & 0.17 & 0.18 & 0.14 & 0.30 & nd & 0.38 & nd & 0.23 & nd \\
C22:5n3 & 0.53 & 0.77 & 0.67 & 0.47 & 0.75 & 0.82 & 0.91 & 0.53 & 0.43 & 0.96 \\
C24:0 & 0.67 & 0.36 & 0.66 & 0.47 & 0.56 & 0.54 & 0.86 & 0.79 & 0.50 & 0.81 \\
C22:6n3 & 8.43 & 4.89 & 7.50 & 5.65 & 8.97 & 7.19 & 14.24 & 11.87 & 7.84 & 9.85 \\
C24:1n9 & 0.60 & 0.22 & 0.30 & 0.23 & 0.26 & nd & 0.70 & 0.15 & nd & nd \\
\hline
\end{tabular}


Table A11. Menhaden collected from the upper bay in summer (Choptank River).

\begin{tabular}{|c|c|c|c|c|c|c|c|c|}
\hline & \multicolumn{8}{|c|}{ Sample number } \\
\hline & 1 & 2 & 3 & 4 & 5 & 6 & 7 & 8 \\
\hline Total length (mm) & 79 & 95 & 81 & 93 & 85 & 101 & 85 & 75 \\
\hline Weight (g) & 5.00 & 8.44 & 4.87 & 7.66 & 5.89 & 9.83 & 7.42 & 5.42 \\
\hline Lipid content (\%) & 0.53 & 0.05 & 0.24 & 0.60 & 0.18 & 0.24 & 0.47 & 0.79 \\
\hline C12:0 & nd & 0.07 & nd & nd & 0.12 & nd & nd & nd \\
\hline C12:1n1 & nd & 0.03 & nd & nd & 0.07 & nd & nd & nd \\
\hline C13:0 & nd & nd & nd & nd & 0.55 & 0.57 & 1.23 & nd \\
\hline C14:0 & 2.54 & 1.85 & 3.54 & 2.78 & 3.21 & 4.42 & 3.31 & 1.63 \\
\hline C14:1n5 & nd & 0.02 & 0.06 & 0.14 & 0.09 & 0.19 & 0.14 & 0.07 \\
\hline C15:0 & 1.02 & 0.86 & 1.40 & 1.19 & 1.26 & 1.59 & 1.23 & 0.78 \\
\hline C15:1n5 & 0.18 & 0.58 & 0.59 & 0.47 & 0.48 & 0.33 & 0.37 & 0.37 \\
\hline C16:0 DMA & 0.27 & 0.31 & 0.25 & 0.23 & 0.22 & 0.32 & 0.25 & 0.44 \\
\hline C16:0 & 41.45 & 35.24 & 39.06 & 38.16 & 37.47 & 38.93 & 37.72 & 29.77 \\
\hline C16:1n7 & 2.41 & 3.18 & 4.51 & 3.33 & 3.88 & 5.39 & 3.51 & 3.51 \\
\hline C17:0 & 1.18 & 1.21 & 1.69 & 1.37 & 1.29 & 1.70 & 1.37 & 1.29 \\
\hline C18:0 & 10.17 & 10.40 & 9.99 & 10.32 & 9.52 & 9.12 & 9.67 & 9.01 \\
\hline C18:1n12t & nd & nd & 0.26 & nd & nd & nd & 0.20 & nd \\
\hline C18:1n9 & 9.26 & 8.22 & 7.60 & 8.67 & 7.00 & 7.97 & 8.18 & 7.01 \\
\hline C18:1n7 & 1.82 & 2.75 & 2.13 & 2.70 & 2.55 & 2.43 & 2.21 & 2.49 \\
\hline C18:2n6t & nd & nd & 0.08 & nd & nd & nd & nd & nd \\
\hline C18:1n9t & 0.49 & 0.41 & 0.27 & 0.60 & 0.46 & 0.61 & 0.31 & 0.81 \\
\hline C18:2n6 & nd & 1.83 & 1.74 & 1.88 & 1.81 & 1.77 & 2.10 & 1.60 \\
\hline C19:0 + C18:3n6 & 0.30 & 0.31 & 0.29 & 0.28 & 0.49 & 0.39 & 0.38 & 0.93 \\
\hline C18:3n3 & 0.91 & 0.71 & 1.43 & 0.81 & 1.04 & 1.14 & 1.22 & 1.32 \\
\hline C18:4n3 & 0.16 & 0.96 & 1.03 & 0.91 & 1.05 & 1.19 & 1.23 & 0.77 \\
\hline C19:2n6 & nd & nd & 0.14 & 0.10 & 0.21 & nd & nd & nd \\
\hline C20:0 & 0.35 & 0.31 & nd & 0.45 & 0.34 & 0.47 & 0.38 & 0.44 \\
\hline C20:1n15 & nd & 0.09 & 0.25 & nd & 0.11 & nd & 0.11 & 0.33 \\
\hline
\end{tabular}


Table A11 continued. Menhaden collected from the upper bay in summer (Choptank River).

\begin{tabular}{|c|c|c|c|c|c|c|c|c|}
\hline & \multicolumn{8}{|c|}{ Sample number } \\
\hline & 1 & 2 & 3 & 4 & 5 & 6 & 7 & 8 \\
\hline C20:1n12 & nd & 0.13 & 0.16 & nd & nd & 0.11 & 0.36 & 0.13 \\
\hline C20:1n9 & 0.11 & 0.22 & 0.23 & 0.40 & 0.28 & 0.26 & 0.35 & 0.28 \\
\hline C20:1n7 & nd & 0.22 & 0.14 & 0.16 & 0.12 & 0.23 & 0.28 & 0.33 \\
\hline$C 20: 2 n 6$ & 0.17 & 0.18 & 0.40 & 0.20 & 0.38 & nd & 0.20 & 0.21 \\
\hline$C 20: 3 n 6+C 21: 0$ & 0.10 & 0.13 & 0.05 & 0.04 & 0.25 & 0.36 & 0.23 & 0.27 \\
\hline C20:4n6 & 1.66 & 2.06 & 1.63 & 1.29 & 1.52 & 1.33 & 1.22 & 1.74 \\
\hline$C 20: 3 n 3$ & 0.29 & 0.18 & 0.15 & 0.11 & 0.26 & 0.15 & 0.19 & 0.27 \\
\hline$C 20: 5 n 3$ & 3.48 & 3.68 & 3.48 & 2.57 & 3.11 & 2.80 & 2.91 & 2.16 \\
\hline C22:0 & 0.72 & 0.74 & 0.75 & 0.56 & 0.58 & 0.87 & 1.12 & 0.67 \\
\hline C22:1n11 & nd & nd & 2.79 & 4.81 & 3.69 & 2.18 & 0.35 & nd \\
\hline C22:1n9 & 0.12 & 0.05 & 0.08 & 0.13 & 0.08 & 0.15 & 0.11 & 0.18 \\
\hline $\mathrm{C} 22: 2 \mathrm{n} 6$ & 0.08 & 0.01 & 0.06 & 0.03 & nd & 0.06 & 0.08 & nd \\
\hline$C 23: 0$ & 0.37 & 0.23 & 0.07 & 0.04 & 0.14 & 0.35 & 0.44 & 0.62 \\
\hline $\mathrm{C} 22: 4 \mathrm{n} 6$ & 0.28 & 0.29 & 0.74 & 0.17 & 0.58 & 0.22 & 0.23 & 1.03 \\
\hline$C 22: 3 n 3$ & 0.45 & 0.76 & 1.21 & 0.63 & 1.01 & 0.55 & 0.31 & 2.03 \\
\hline$C 22: 5 n 3$ & 0.47 & 0.39 & 0.26 & 0.25 & 0.34 & nd & nd & 1.78 \\
\hline C24:0 & 1.99 & 1.03 & 1.04 & 1.12 & 1.26 & 1.24 & 1.58 & 3.06 \\
\hline C22:6n3 & 16.08 & 18.61 & 9.84 & 12.08 & 12.26 & 10.23 & 12.85 & 19.31 \\
\hline C24:1n9 & 1.14 & 1.76 & 0.60 & 1.02 & 0.92 & 0.36 & 2.05 & 3.36 \\
\hline
\end{tabular}


Table A12. Menhaden collected from the upper bay in summer (Corsica River).

\begin{tabular}{|c|c|c|c|c|c|c|c|c|c|}
\hline & \multicolumn{9}{|c|}{ Sample number } \\
\hline & 1 & 2 & 3 & 4 & 5 & 6 & 7 & 8 & 9 \\
\hline Total length (mm) & 98 & 97 & 98 & 99 & 96 & 101 & 96 & 97 & 93 \\
\hline Weight (g) & 7.68 & 8.21 & 7.97 & 8.51 & 7.92 & 8.62 & 8.08 & 8.77 & 8.65 \\
\hline Lipid content (\%) & 11.20 & 10.69 & 7.41 & 3.37 & 20.69 & 16.93 & 7.75 & 10.40 & 19.08 \\
\hline C12:0 & 0.25 & 0.34 & 0.44 & 0.16 & 0.28 & 0.30 & 0.33 & 0.28 & nd \\
\hline C13:0 & 0.35 & 0.36 & 0.41 & 0.42 & 0.37 & 0.64 & 0.72 & 0.33 & nd \\
\hline C14:0 & 7.84 & 8.48 & 6.62 & 5.41 & 7.99 & 9.15 & 8.07 & 7.73 & 4.39 \\
\hline C14:1n5 & 0.04 & 0.05 & nd & 0.03 & 0.15 & nd & nd & 0.16 & nd \\
\hline C15:0 & 1.40 & 2.57 & 1.42 & 1.57 & 1.34 & 3.87 & 1.95 & 1.48 & 3.04 \\
\hline C16:0 DMA & 0.60 & 0.61 & 0.76 & 0.83 & 0.03 & 0.41 & 0.83 & 0.55 & nd \\
\hline C16:0 & 34.53 & 34.28 & 34.00 & 34.62 & 35.05 & 36.92 & 35.57 & 35.87 & 32.50 \\
\hline C16:1n7 & 4.44 & 6.62 & 3.45 & 4.54 & 8.07 & 9.24 & 3.04 & 5.05 & 5.11 \\
\hline C17:0 & 1.66 & 1.66 & 1.78 & 1.39 & 1.19 & 1.77 & 2.52 & 1.69 & 2.68 \\
\hline C17:1n7 & nd & nd & nd & nd & nd & 0.31 & nd & nd & nd \\
\hline C18:0 & 6.36 & 6.72 & 7.81 & 8.17 & 5.67 & 6.56 & 9.18 & 7.11 & 8.21 \\
\hline C18:1n12t & 0.18 & nd & 0.23 & 0.26 & nd & nd & 0.43 & 0.21 & nd \\
\hline C18:1n9t & nd & 0.23 & 0.23 & 0.23 & nd & 0.20 & 0.38 & nd & nd \\
\hline C18:1n9 & 7.32 & 6.81 & 8.31 & 7.55 & 6.41 & 4.96 & 7.34 & 7.35 & 6.73 \\
\hline C18:1n7 & 2.04 & 2.14 & 2.08 & 2.38 & 1.83 & 2.20 & 1.96 & 2.37 & 2.87 \\
\hline C18:2n6 & 1.91 & 2.26 & 2.32 & 2.12 & 2.68 & 1.78 & 1.79 & 2.72 & 4.16 \\
\hline C18:3n6 + C19:0 & 0.19 & 0.23 & 0.13 & 0.20 & 0.37 & 0.37 & nd & 0.27 & 2.00 \\
\hline C18:3n3 & 0.73 & 0.87 & 0.92 & 0.81 & 0.92 & 2.03 & 1.09 & 0.82 & 2.12 \\
\hline C18:4n3 & 3.51 & 2.97 & 2.90 & 1.74 & 3.59 & 2.89 & 2.24 & 2.91 & 2.56 \\
\hline C19:2n6 & 0.03 & nd & nd & nd & nd & nd & nd & 0.07 & 2.02 \\
\hline C20:0 & 0.79 & 0.88 & 0.85 & 0.87 & 0.94 & 0.97 & 1.19 & 1.18 & 2.58 \\
\hline C20:1n15 & 0.06 & nd & nd & nd & nd & nd & nd & 0.16 & nd \\
\hline
\end{tabular}


Table A12 continued. Menhaden collected from the lower bay in summer (Corsica River).

\begin{tabular}{|c|c|c|c|c|c|c|c|c|c|}
\hline & \multicolumn{9}{|c|}{ Sample number } \\
\hline & 1 & 2 & 3 & 4 & 5 & 6 & 7 & 8 & 9 \\
\hline C20:1n12 & 0.14 & 0.17 & 0.23 & 0.22 & nd & 0.31 & nd & 0.22 & nd \\
\hline C20:1n9 & 0.35 & 0.42 & 0.45 & 0.37 & 0.36 & 0.58 & 0.73 & 0.45 & 2.08 \\
\hline C20:1n7 & 0.14 & 0.15 & 0.22 & 0.18 & 0.17 & 0.36 & 0.35 & 0.26 & nd \\
\hline$C 20: 2 n 6$ & 0.17 & 0.21 & 0.27 & 0.17 & 0.29 & 0.34 & 0.35 & 0.27 & nd \\
\hline$C 20: 3 n 6+C 21: 0$ & 0.13 & 0.13 & 0.29 & 0.13 & 0.10 & 0.63 & 1.06 & 0.16 & nd \\
\hline$C 20: 4 n 6$ & 0.83 & 1.04 & 1.09 & 1.23 & 0.77 & 0.77 & 1.22 & 0.75 & 0.90 \\
\hline$c 20: 3 n 3$ & 0.10 & 0.12 & 0.33 & 0.10 & 0.10 & 0.39 & 0.45 & 0.11 & 1.58 \\
\hline C20:5n3 & 4.30 & 4.93 & 4.01 & 3.75 & 5.49 & 3.62 & 2.46 & 4.37 & 3.25 \\
\hline $\mathrm{C} 22: 0$ & 2.17 & 1.62 & 2.18 & 2.13 & 1.72 & 1.13 & 1.96 & 1.97 & 2.52 \\
\hline C22:1n9 & 0.32 & 0.10 & 0.25 & 0.26 & 0.08 & 0.15 & 0.51 & 0.11 & 1.68 \\
\hline$C 22: 2 n 6$ & 0.17 & 0.02 & 0.07 & 0.12 & nd & 0.26 & 0.47 & 0.07 & 0.83 \\
\hline $\mathrm{C} 23: 0$ & 0.28 & 0.05 & nd & 0.19 & nd & 0.64 & 0.46 & nd & 0.47 \\
\hline$C 22: 4 n 6$ & 0.47 & 0.14 & 0.32 & 0.47 & 0.32 & 0.06 & 0.19 & 0.17 & nd \\
\hline$C 22: 3 n 3+C 22: 5 n 6$ & 0.76 & 0.54 & 0.54 & 0.86 & 0.73 & nd & 0.80 & 0.44 & 1.31 \\
\hline$C 22: 5 n 3$ & 1.44 & 0.60 & 0.85 & 1.60 & 1.23 & 0.81 & 1.32 & 0.96 & 0.95 \\
\hline$C 24: 0+C 22: 6 n 3$ & 13.43 & 11.52 & 13.81 & 14.31 & 11.76 & 5.38 & 9.05 & 11.19 & 3.45 \\
\hline C24:1n9 & 0.55 & 0.14 & 0.41 & 0.65 & nd & nd & nd & 0.19 & nd \\
\hline
\end{tabular}


Table A13. Adult menhaden collected from the upper bay in summer.

\begin{tabular}{|c|c|c|c|c|c|c|c|c|c|}
\hline & \multicolumn{9}{|c|}{ Sample number } \\
\hline & 1 & 2 & 3 & 4 & 5 & 6 & 7 & 8 & 9 \\
\hline Total length (mm) & 222 & 190 & 238 & 315 & 208 & 244 & 219 & 221 & 228 \\
\hline Weight (g) & 110.2 & 68.2 & 140.2 & 292.3 & 85.0 & 144.7 & 105.1 & 103.9 & 222.1 \\
\hline Lipid content (\%) & 18.89 & 6.82 & 13.54 & 20.32 & 11.31 & 11.93 & & 11.40 & 7.97 \\
\hline C12:0 & 0.07 & 0.12 & 0.12 & 0.10 & 0.11 & 0.09 & 0.08 & 0.14 & 0.10 \\
\hline C12:1n1 & 0.34 & 0.34 & 0.22 & 0.50 & 0.58 & 0.24 & 0.40 & 0.33 & 0.18 \\
\hline C13:0 & 0.35 & 0.20 & 0.21 & 0.25 & 0.15 & 0.15 & nd & 0.19 & 0.31 \\
\hline C14:0 & 3.69 & 11.16 & 10.46 & 16.11 & 4.78 & 17.02 & 5.76 & 10.73 & 6.20 \\
\hline C14:1n5 & 0.02 & 0.07 & 0.04 & 0.07 & 0.04 & 0.07 & 0.02 & 0.06 & 0.04 \\
\hline C15:0 & 0.90 & 1.03 & 1.04 & 0.89 & 0.80 & 0.78 & 1.01 & 0.79 & 0.88 \\
\hline C15:1n5 & nd & nd & nd & nd & nd & nd & nd & 0.06 & 0.14 \\
\hline C16:0 DMA & nd & nd & nd & 0.02 & nd & nd & nd & 0.03 & 0.05 \\
\hline C16:0 & 32.89 & 23.52 & 30.37 & 23.42 & 31.28 & 24.92 & 31.17 & 29.74 & 31.65 \\
\hline C16:1n7 & 3.37 & 12.01 & 12.53 & 15.10 & 3.10 & 14.05 & 7.99 & 11.54 & 5.70 \\
\hline C17:0 & 1.53 & 1.08 & 1.25 & 1.03 & 1.45 & 1.03 & 1.59 & 0.89 & 1.44 \\
\hline C18:0 & 7.76 & 4.82 & 5.07 & 4.66 & 7.52 & 4.68 & 7.51 & 4.82 & 8.19 \\
\hline C18:1n12t & 0.37 & 0.46 & 0.26 & 0.28 & nd & 0.24 & 0.37 & 0.27 & nd \\
\hline C18:1n9t & nd & nd & nd & nd & 0.19 & nd & nd & nd & nd \\
\hline C18:1n9 & 4.12 & 3.07 & 2.68 & 2.63 & 6.19 & 2.66 & 3.13 & 5.29 & 4.92 \\
\hline C18:1n7 & 2.44 & 3.42 & 3.06 & 3.53 & 3.09 & 2.81 & 2.95 & 3.56 & 2.96 \\
\hline C18:2n6 & 1.45 & 1.39 & 1.17 & 1.25 & 1.84 & 1.27 & 1.42 & 2.27 & 1.73 \\
\hline C18:3n6 & 0.31 & 0.50 & 0.49 & 0.63 & 0.31 & 0.58 & 0.45 & 0.42 & 0.39 \\
\hline C18:3n3 & 1.53 & 1.17 & 1.23 & 1.22 & 3.30 & 1.27 & 0.97 & 1.15 & 1.81 \\
\hline C18:4n3 & 1.20 & 1.76 & 1.75 & 2.24 & 2.52 & 2.48 & 0.95 & 1.57 & 1.70 \\
\hline C20:0 & 0.23 & 0.27 & 0.20 & 0.23 & 0.37 & 0.22 & 0.21 & 0.20 & 0.28 \\
\hline C20:1n15 & 0.02 & 0.04 & nd & 0.04 & 0.03 & nd & nd & 0.01 & 0.01 \\
\hline
\end{tabular}


Table A13 continued. Adult menhaden collected from the upper bay in summer.

\begin{tabular}{lccccccccc}
\hline \multicolumn{10}{c}{ Sample number } \\
\hline \hline C20:1n12 & 1 & 2 & 3 & 4 & 5 & 6 & 7 & 8 & 9 \\
C20:1n9 & 0.12 & 0.23 & 0.13 & 0.12 & 0.16 & 0.08 & 0.14 & 0.08 & 0.10 \\
C20:1n7 & 0.30 & 0.42 & 0.21 & 0.21 & 0.95 & 0.18 & 0.24 & 0.52 & 0.35 \\
C20:2n6 & 0.23 & 0.48 & 0.21 & 0.24 & 0.37 & 0.19 & 0.27 & 0.22 & 0.26 \\
C20:3n6 & 0.29 & 0.33 & 0.14 & 0.20 & 0.40 & 0.17 & 0.22 & 0.21 & 0.25 \\
C20:4n6 & 0.17 & 0.44 & 0.24 & 0.31 & 0.18 & 0.26 & 0.34 & 0.25 & 0.18 \\
C20:3n3 & 1.43 & 1.30 & 2.03 & 1.35 & 0.60 & 1.16 & 2.78 & 1.02 & 1.41 \\
C20:5n3 & 0.26 & 0.55 & 0.21 & 0.25 & 0.50 & 0.25 & 0.15 & 0.23 & 0.26 \\
C22:0 & 5.58 & 7.73 & 9.15 & 8.78 & 7.34 & 8.66 & 7.43 & 7.32 & 5.96 \\
C22:1n11 & 0.64 & 0.66 & 0.40 & 0.39 & 1.30 & 0.43 & 0.43 & 0.34 & 0.30 \\
C22:1n9 & nd & nd & nd & nd & nd & nd & nd & 0.06 & nd \\
C22:2n6 & 0.10 & 0.63 & 0.08 & 0.08 & 0.63 & 0.08 & 0.06 & 0.13 & 0.09 \\
C22:4n6 & 0.02 & 0.24 & nd & 0.02 & 0.58 & 0.02 & 0.02 & nd & nd \\
C22:3n3 + C22:5n6 & 0.25 & 1.20 & 0.27 & 0.23 & 0.33 & 0.17 & 0.46 & nd & 0.24 \\
C22:5n3 & 0.86 & 2.72 & 1.05 & 1.36 & 0.91 & 1.15 & 1.71 & 1.00 & 1.18 \\
C24:0+C22:6n3 & 1.10 & 2.69 & 1.24 & 1.22 & 1.57 & 1.13 & 1.42 & 1.16 & 1.11 \\
C24:1n9 & 25.29 & 12.30 & 12.14 & 10.66 & 15.29 & 11.09 & 17.99 & 12.92 & 18.59 \\
\hline
\end{tabular}


Table A14. Menhaden collected from lower bay in summer.

\begin{tabular}{|c|c|c|c|c|c|c|c|c|c|c|}
\hline & \multicolumn{10}{|c|}{ Sample number } \\
\hline & 1 & 2 & 3 & 4 & 5 & 6 & 7 & 8 & 9 & 10 \\
\hline Total length (mm) & 139 & 147 & 150 & 161 & 128 & 151 & 139 & 137 & 142 & 146 \\
\hline Weight (g) & 36.11 & 39.95 & 44.04 & 51.83 & 25.59 & 44.56 & 33.33 & 37.28 & 42.20 & 40.79 \\
\hline Lipid content (\%) & 2.68 & - & 3.84 & 1.37 & - & - & 4.32 & 4.77 & 1.55 & 5.92 \\
\hline $\mathrm{C} 12: 0$ & nd & nd & 0.10 & 0.14 & 0.09 & 0.09 & 0.07 & 0.11 & nd & nd \\
\hline C12:1n1 & nd & 0.09 & 0.04 & nd & 0.03 & 0.05 & 0.05 & 0.02 & nd & nd \\
\hline C13:0 & 0.22 & 0.19 & 0.20 & 0.23 & 0.19 & 0.21 & 0.32 & 0.23 & 0.17 & 0.17 \\
\hline C14:0 & 10.44 & 10.51 & 12.41 & 12.01 & 16.81 & 13.37 & 12.69 & 10.69 & 12.69 & 11.01 \\
\hline $\mathrm{C} 14: 1 \mathrm{n} 5$ & 0.17 & 0.21 & 0.14 & 0.16 & 0.12 & 0.11 & 0.11 & 0.12 & 0.21 & 0.17 \\
\hline C15:0 & 1.19 & 1.36 & 1.17 & 1.35 & 0.91 & 1.35 & 1.28 & 1.14 & 1.15 & 1.39 \\
\hline C15:1n5 & 0.16 & 0.14 & 0.11 & 0.25 & 0.10 & 0.10 & 0.15 & nd & 0.21 & 0.23 \\
\hline C16:0 DMA & 0.28 & 0.28 & 0.22 & 0.28 & 0.14 & 0.18 & 0.20 & 0.23 & 0.22 & 0.38 \\
\hline C16:0 & 34.05 & 30.92 & 36.02 & 32.27 & 33.14 & 33.32 & 37.41 & 33.16 & 33.62 & 33.07 \\
\hline C16:1n7 & 16.20 & 15.67 & 12.89 & 14.31 & 12.52 & 13.61 & 12.44 & 13.60 & 15.38 & 17.70 \\
\hline C17:0 & 1.47 & 1.72 & 1.28 & 1.49 & 0.55 & 0.93 & 1.01 & 1.15 & 1.22 & 1.72 \\
\hline C17:1n7 & 0.45 & 0.50 & nd & 0.46 & nd & nd & nd & nd & nd & 0.40 \\
\hline C18:0 & 5.55 & 4.91 & 4.88 & 5.24 & 3.99 & 4.10 & 4.60 & 4.30 & 4.66 & 5.01 \\
\hline C18:1n12t & nd & nd & nd & nd & nd & nd & nd & nd & 0.14 & nd \\
\hline C18:1n9 & 4.52 & 4.48 & 3.43 & 4.75 & 2.95 & 3.22 & 2.83 & 3.09 & 3.52 & 5.06 \\
\hline C18:1n7 & 4.25 & 4.00 & 3.10 & 3.67 & 2.21 & 2.63 & 2.67 & 2.97 & 3.10 & 4.29 \\
\hline C18:1n9t & nd & 0.26 & nd & nd & nd & nd & nd & nd & nd & nd \\
\hline C18:2n6 & 1.91 & 1.91 & 1.45 & 1.88 & 1.18 & 1.31 & 1.57 & 1.59 & 1.52 & 2.01 \\
\hline $\mathrm{C} 19: 0+\mathrm{C} 18: 3 n 6$ & nd & 0.64 & 0.36 & 0.49 & 0.38 & 0.40 & 0.36 & 0.42 & 0.47 & 0.70 \\
\hline $\mathrm{C} 18: 3 \mathrm{n} 3$ & 2.36 & 2.86 & 0.94 & 1.84 & 0.52 & 0.77 & 0.76 & 1.24 & 0.96 & 3.25 \\
\hline $\mathrm{C} 18: 4 \mathrm{n} 3$ & 1.30 & 1.36 & 2.03 & 1.96 & 2.21 & 2.60 & 2.18 & 2.94 & 2.92 & 1.53 \\
\hline C19:2n6 & nd & 0.09 & nd & 0.09 & nd & 0.11 & nd & nd & 0.13 & 0.18 \\
\hline $\mathrm{C} 20: 0$ & 0.29 & 0.26 & 0.28 & 0.29 & 0.20 & 0.19 & 0.22 & 0.30 & 0.32 & 0.29 \\
\hline C20:1n15 & 0.05 & nd & 0.05 & 0.06 & 0.07 & 0.03 & 0.06 & 0.05 & 0.11 & 0.12 \\
\hline
\end{tabular}


Table A14 continued. Menhaden collected from lower bay in summer.

\begin{tabular}{|c|c|c|c|c|c|c|c|c|c|c|}
\hline & \multicolumn{10}{|c|}{ Sample number } \\
\hline & 1 & 2 & 3 & 4 & 5 & 6 & 7 & 8 & 9 & 10 \\
\hline C20:1n12 & 0.21 & nd & 0.14 & 0.25 & 0.12 & 0.19 & 0.13 & 0.16 & 0.14 & 0.25 \\
\hline C20:1n9 & 0.43 & 0.49 & 0.27 & 0.50 & 0.19 & 0.24 & 0.16 & 0.46 & 0.45 & 0.52 \\
\hline C20:1n7 & 0.31 & 0.30 & 0.19 & 0.21 & 0.16 & 0.23 & 0.14 & 0.16 & 0.38 & 0.28 \\
\hline$C 20: 2 n 6$ & 0.19 & 0.26 & 0.15 & 0.16 & 0.12 & 0.10 & 0.15 & 0.19 & 0.13 & 0.32 \\
\hline$C 20: 3 n 6+C 21: 0$ & 0.57 & 0.40 & 0.28 & 0.27 & 0.17 & 0.17 & 0.19 & 0.19 & 0.32 & 0.50 \\
\hline C20:4n6 & 1.33 & 1.09 & 0.09 & 0.91 & 1.08 & 0.82 & 0.83 & 0.90 & 0.76 & 0.99 \\
\hline$C 20: 3 n 3$ & 0.26 & 0.33 & 0.09 & 0.21 & 0.07 & 0.09 & 0.10 & 0.11 & 0.16 & 0.32 \\
\hline C20:5n3 & 5.07 & 4.84 & 7.97 & 6.40 & 8.98 & 7.65 & 6.94 & 7.84 & 7.19 & 4.94 \\
\hline $\mathrm{C} 22: 0$ & 0.54 & 0.31 & 0.51 & 0.46 & 0.56 & 0.48 & 0.41 & 0.47 & 0.37 & nd \\
\hline C22:1n11 & 0.03 & nd & nd & nd & nd & nd & nd & nd & 0.19 & nd \\
\hline C22:1n9 & 0.09 & 0.14 & nd & 0.14 & 0.06 & 0.07 & 0.04 & 0.11 & 0.07 & 0.21 \\
\hline $\mathrm{C} 22: 2 \mathrm{n} 6$ & nd & nd & 0.01 & 0.05 & nd & 0.10 & 0.03 & 0.10 & 0.10 & 0.23 \\
\hline C23:0 & 0.13 & nd & nd & 0.09 & nd & 0.14 & 0.11 & 0.17 & 0.13 & nd \\
\hline $\mathrm{C} 22: 4 \mathrm{n} 6$ & 0.28 & 1.61 & 0.19 & 0.12 & 0.29 & 0.42 & 0.19 & 0.44 & 0.12 & 0.16 \\
\hline$C 22: 3 n 3+C 22: 5 n 6$ & 0.64 & 0.84 & 0.41 & 0.37 & 0.55 & 0.57 & 0.23 & 1.11 & 0.21 & nd \\
\hline C22:5n3 & 1.71 & 1.81 & 0.84 & 1.30 & 1.75 & 1.23 & 0.78 & 1.26 & 0.71 & 0.42 \\
\hline C24:0 & nd & 1.11 & 0.48 & nd & nd & 1.07 & 0.50 & 0.50 & 0.32 & 0.36 \\
\hline C22:6n3 & 3.03 & 3.77 & 6.77 & 5.13 & 6.89 & 6.92 & 7.58 & 7.59 & 5.21 & 1.81 \\
\hline C24:1n9 & 0.29 & 0.35 & 0.53 & 0.24 & 0.69 & 0.83 & 0.52 & 0.91 & 0.32 & nd \\
\hline
\end{tabular}


Table A15. Menhaden collected from the upper bay in fall.

\begin{tabular}{|c|c|c|c|c|c|c|}
\hline & \multicolumn{6}{|c|}{ Sample number } \\
\hline & 1 & 2 & 3 & 4 & 5 & 6 \\
\hline Total length (mm) & 126 & 119 & 124 & 128 & 129 & 142 \\
\hline Weight (g) & 22.92 & 23.11 & 18.86 & 25.25 & 22.46 & 33.75 \\
\hline Lipid content (\%) & 8.66 & 12.93 & 14.92 & 10.55 & 8.93 & 16.67 \\
\hline C12:0 & nd & 0.17 & 0.32 & nd & 0.25 & 0.19 \\
\hline C12:1n1 & nd & 0.10 & nd & nd & nd & nd \\
\hline C13:0 & 1.30 & 0.49 & 0.73 & 4.44 & 0.30 & 0.17 \\
\hline C14:0 & 5.41 & 8.94 & 7.50 & 3.21 & 7.86 & 9.83 \\
\hline C14:1n5 & 1.18 & nd & 0.08 & 1.91 & 0.09 & 0.09 \\
\hline C15:0 & 1.88 & 1.29 & 1.23 & nd & 1.36 & 1.18 \\
\hline C15:1n5 & nd & nd & nd & nd & nd & 0.04 \\
\hline C16:0 DMA & nd & 0.45 & 0.74 & 1.63 & 0.56 & 0.35 \\
\hline C16:0 & 22.14 & 26.69 & 31.53 & 6.56 & 36.66 & 31.14 \\
\hline C16:1n7 & nd & 9.19 & 9.26 & 3.01 & 10.16 & 10.32 \\
\hline C17:0 & 1.26 & 0.99 & 0.98 & nd & 0.90 & 0.88 \\
\hline C17:1n7 & nd & 0.39 & 0.24 & 2.30 & nd & nd \\
\hline C18:0 & 7.60 & 5.67 & 5.84 & 3.10 & 6.48 & 5.66 \\
\hline C18:1n12t & nd & 0.29 & 0.25 & nd & 0.19 & 0.21 \\
\hline C18:1n9t & 0.93 & 0.12 & 0.26 & 2.64 & 0.22 & nd \\
\hline C18:1n9 & 4.09 & 3.70 & 5.07 & nd & 4.65 & 3.43 \\
\hline C18:1n7 & 3.10 & 2.65 & 2.68 & 1.75 & 3.26 & 2.83 \\
\hline C18:2n6t & nd & 0.11 & nd & 1.33 & nd & nd \\
\hline C18:2n6 & 1.00 & 1.57 & 1.92 & 2.85 & 1.81 & 1.94 \\
\hline C18:3n6 & 0.73 & 0.45 & 0.19 & 1.34 & 0.18 & 0.28 \\
\hline C19:0 & 0.50 & nd & nd & 2.09 & nd & nd \\
\hline C18:3n3 & 2.53 & 1.65 & 2.25 & 1.93 & 2.09 & 1.86 \\
\hline C18:4n3 & 1.80 & 2.03 & 2.05 & 0.56 & 2.36 & 3.91 \\
\hline C19:2n6 & 0.56 & 0.10 & nd & 1.59 & 0.04 & $\mathrm{Nd}$ \\
\hline
\end{tabular}


Table A15 continued. Menhaden collected from the upper bay in fall.

\begin{tabular}{lcccccc} 
& \multicolumn{6}{c}{ Sample number } \\
\hline \hline C20:0 & 1 & 2 & 3 & 4 & 5 & 6 \\
C20:1n15 & 3.59 & 0.88 & 0.81 & 1.15 & 0.85 & 1.03 \\
C20:1n12 & 0.79 & 0.37 & 0.16 & 1.63 & 0.06 & 0.12 \\
C20:1n9 & 1.43 & 0.48 & 0.28 & nd & 0.21 & 0.29 \\
C20:1n7 & nd & 0.34 & 0.58 & 0.64 & 0.35 & 0.39 \\
C20:2n6 & 1.95 & 0.34 & 0.49 & nd & 0.32 & 0.34 \\
C20:3n6 & nd & 0.52 & 0.36 & 3.08 & 0.15 & 0.39 \\
C21:0 & 1.18 & 0.27 & nd & 1.30 & 0.23 & 0.16 \\
C20:4n6 & 1.17 & nd & 0.14 & nd & 0.11 & 0.13 \\
C20:3n3 & 0.68 & 0.87 & 0.88 & 1.23 & 0.82 & 0.78 \\
C20:5n3 & 2.14 & 0.34 & 0.39 & 0.98 & 0.23 & 0.31 \\
C22:0 & 3.21 & 4.77 & 4.88 & 1.92 & 5.59 & 8.33 \\
C22:1n9 & 3.13 & 1.49 & 1.58 & 4.04 & 1.17 & 1.57 \\
C22:2n6 & 1.93 & 0.57 & 0.49 & nd & 0.11 & 0.27 \\
C22:4n6 & 1.72 & nd & 0.91 & 4.25 & 0.15 & 0.08 \\
C22:3n3+ C22:5n6 & 1.99 & nd & 0.85 & nd & 0.18 & 0.12 \\
C22:5n3 & 2.38 & 2.33 & 1.07 & 8.70 & 0.48 & 0.49 \\
C22:6n3 + C24:0 & nd & 1.64 & nd & nd & nd & nd \\
C24:1n9 & 10.02 & 9.66 & 11.38 & 20.29 & 9.20 & 10.44 \\
\hline
\end{tabular}


Table A16. Spot collected from the upper bay in summer.

\begin{tabular}{lcccccc} 
& \multicolumn{7}{c}{ Sample number } \\
\hline & 1 & 2 & 3 & 4 & 5 & 6 \\
\hline Total length (mm) & 90 & 71 & 86 & 90 & 93 & 72 \\
Weight (g) & 9.63 & 4.12 & 7.93 & 9.08 & 11.25 & 4.69 \\
Lipid content (\%) & 3.59 & 4.35 & 5.16 & 5.65 & 5.44 & 4.54 \\
C12:0 & 0.31 & 0.19 & nd & 0.53 & 0.44 & 4.46 \\
C12:1n1 & nd & nd & nd & 0.19 & nd & 0.88 \\
C13:0 & nd & 0.42 & 1.14 & 1.09 & 0.57 & nd \\
C14:0 & 3.26 & 2.55 & 2.59 & 3.55 & 3.94 & 3.20 \\
C14:1n5 & 0.15 & 0.08 & 0.35 & 0.25 & 0.45 & nd \\
C15:0 & 2.21 & 2.35 & 2.35 & 2.22 & 2.19 & 1.88 \\
C16:0 DMA & 1.49 & 1.10 & 1.18 & 1.35 & 1.10 & 1.36 \\
C16:0 & 27.33 & 25.62 & 21.60 & 25.47 & 26.22 & 28.00 \\
C16:1n7 & 1.99 & 2.65 & 1.88 & 2.14 & 2.48 & 1.60 \\
C17:0 & 2.55 & 2.78 & 2.77 & 2.15 & 2.48 & 2.78 \\
C17:1n7 & 0.20 & nd & nd & nd & 0.87 & 0.51 \\
C18:0 & 14.23 & 13.61 & 13.15 & 12.35 & 12.32 & 14.59 \\
C18:1n12t & 0.60 & 1.01 & nd & 0.47 & 0.37 & 0.57 \\
C18:1n9t & 0.35 & nd & 0.73 & 0.53 & nd & 0.26 \\
C18:1n7t & nd & nd & 0.40 & 0.38 & nd & 0.27 \\
C18:1n9 & 9.42 & 8.80 & 9.34 & 8.91 & 8.82 & 7.71 \\
C18:1n7 & 2.28 & 2.82 & 2.56 & 3.00 & 2.00 & 1.85 \\
C18:2n6 & 2.56 & 1.71 & 2.76 & 2.85 & 2.12 & 2.07 \\
C18:3n6 + C19:0 & 0.26 & 0.17 & 0.62 & 0.46 & 0.43 & nd \\
C18:3n3 & 0.92 & 0.86 & 1.71 & 1.12 & 1.01 & 0.81 \\
C18:4n3 & 0.66 & 0.58 & 0.60 & 0.85 & 0.93 & 0.70 \\
C19:2n6 & 0.48 & 0.13 & 0.39 & 0.27 & nd & nd \\
\hline & & & & & &
\end{tabular}


Table A16 continued. Spot collected from the upper bay in summer.

\begin{tabular}{lcccccc}
\hline & \multicolumn{7}{c}{ Sample number } \\
\hline \hline $\mathrm{C} 20: 0$ & 1 & 2 & 3 & 4 & 5 & 6 \\
$\mathrm{C} 20: 1 \mathrm{n} 15$ & 1.29 & 1.60 & 1.90 & 1.50 & 1.60 & 1.41 \\
$\mathrm{C} 20: 1 \mathrm{n} 12$ & 0.24 & nd & 0.51 & nd & nd & nd \\
$\mathrm{C} 20: 1 \mathrm{n} 9$ & 1.52 & 2.07 & 2.41 & 1.74 & 3.00 & 1.76 \\
$\mathrm{C} 20: 1 \mathrm{n} 7$ & 1.15 & 1.29 & 1.67 & 1.04 & 1.35 & 1.10 \\
$\mathrm{C} 20: 2 \mathrm{n} 6$ & 1.29 & 1.64 & 1.63 & 1.36 & 2.14 & 1.30 \\
$\mathrm{C} 20: 3 \mathrm{n} 6+\mathrm{C} 21: 0$ & 0.85 & 0.18 & 2.00 & nd & 0.53 & 0.32 \\
$\mathrm{C} 20: 4 \mathrm{n} 6$ & 2.54 & 3.03 & 3.57 & 3.07 & 2.06 & 1.22 \\
$\mathrm{C} 20: 3 \mathrm{n} 3$ & 0.81 & 0.33 & 1.38 & 1.02 & 0.48 & 0.36 \\
$\mathrm{C} 20: 5 \mathrm{n} 3$ & 3.32 & 5.02 & 3.33 & 4.38 & 4.35 & 1.25 \\
$\mathrm{C} 22: 0$ & 1.95 & 1.95 & 2.31 & 2.12 & 1.47 & 1.12 \\
$\mathrm{C} 22: 1 \mathrm{n} 9$ & 0.23 & 0.22 & 0.45 & 0.32 & $\mathrm{nd}$ & 0.92 \\
$\mathrm{C} 22: 2 \mathrm{n} 6$ & $\mathrm{nd}$ & 0.26 & nd & nd & nd & 1.01 \\
$\mathrm{C} 22: 4 \mathrm{n} 6$ & 0.37 & 0.79 & 0.88 & nd & 0.38 & $\mathrm{nd}$ \\
$\mathrm{C} 22: 3 \mathrm{n} 3+\mathrm{C} 22: 5 \mathrm{n} 6$ & 1.05 & 0.98 & 1.31 & 2.10 & 1.19 & $\mathrm{nd}$ \\
$\mathrm{C} 22: 5 \mathrm{n} 3$ & 1.19 & 1.49 & 0.92 & 1.46 & 1.04 & 2.24 \\
$\mathrm{C} 22: 6 \mathrm{n} 3+\mathrm{C} 24: 0$ & 8.77 & 11.14 & 8.68 & 7.82 & 9.30 & 7.46 \\
$\mathrm{C} 24: 1 \mathrm{n} 9$ & 0.87 & 0.31 & nd & 0.80 & 0.65 & 4.16 \\
\hline
\end{tabular}


Table A17. Spot collected from the upper bay in fall.

\begin{tabular}{lcccccccccccc}
\hline & \multicolumn{10}{c}{ Sample number } \\
\hline & 1 & 2 & 3 & 4 & 5 & 6 & 7 & 8 & 9 & 10 & 11 \\
\hline Total length (mm) & 81 & 103 & 75 & 71 & 87 & 76 & 86 & 74 & 75 & 76 & 71 \\
Weight (g) & 5.48 & 13.04 & 3.79 & 4.44 & 8.43 & 5.39 & 7.41 & 4.52 & 5.00 & 4.76 & 4.27 \\
Lipid content (\%) & 6.87 & 2.50 & 8.71 & 4.17 & 7.84 & 5.74 & 2.55 & 10.06 & 5.65 & 4.57 & 7.90 \\
C12:0 & 0.07 & 0.06 & 0.12 & nd & 0.03 & 0.04 & 0.02 & 0.08 & 0.06 & nd & 0.07 \\
C12:1n1 & 0.09 & nd & 0.02 & nd & nd & 0.02 & 0.01 & 0.02 & 0.01 & nd & 0.02 \\
C13:0 & 0.65 & 0.18 & 0.22 & nd & 0.24 & nd & nd & 0.39 & 0.74 & nd & 0.40 \\
C14:0 & 2.62 & 4.00 & 2.93 & 1.04 & 2.40 & 1.93 & 1.77 & 3.34 & 2.23 & 1.88 & 2.52 \\
C14:1n5 & 0.03 & 0.03 & 0.06 & nd & 0.04 & 0.03 & 0.02 & 0.04 & 0.02 & 0.02 & 0.03 \\
C15:0 & 1.20 & 1.37 & 1.34 & 0.96 & 1.38 & 1.09 & 1.30 & 1.37 & 1.35 & 1.39 & 1.58 \\
C16:0 & 23.94 & 27.47 & 25.82 & 22.23 & 23.14 & 24.60 & 23.58 & 26.64 & 24.26 & 22.23 & 23.98 \\
C16:1n7 & 4.15 & 4.63 & 4.22 & 2.39 & 4.70 & 3.80 & 4.13 & 5.77 & 4.06 & 4.00 & 4.48 \\
C17:0 & 2.22 & 2.16 & 2.62 & 1.99 & 2.28 & 2.30 & 2.51 & 2.86 & 2.55 & 2.26 & 3.52 \\
C18:0 & 9.24 & 10.99 & 9.97 & 11.15 & 10.33 & 11.70 & 12.06 & 9.97 & 11.55 & 9.95 & 12.25 \\
C18:1n12t & nd & nd & 0.39 & 0.29 & nd & nd & nd & nd & nd & nd & nd \\
C18:1n9t & nd & nd & 0.39 & 0.29 & nd & nd & nd & nd & nd & nd & nd \\
C18:1n9 & 9.75 & 8.67 & 10.58 & 8.88 & 8.55 & 10.15 & 8.69 & 10.56 & 8.84 & 8.95 & 8.65 \\
C18:1n7 & 3.56 & 3.39 & 4.01 & 3.13 & 3.95 & 3.79 & 3.87 & 4.08 & 3.94 & 3.74 & 5.20 \\
C18:2n6t & 0.14 & nd & nd & nd & nd & nd & nd & 0.15 & nd & nd & nd \\
C18:2n6 & 1.71 & 1.69 & 1.96 & 1.44 & 1.57 & 1.93 & 1.73 & 2.10 & 1.64 & 1.51 & 1.95 \\
C18:3n6 & 0.10 & 0.13 & 0.16 & 0.09 & 0.12 & 0.15 & 0.11 & 0.17 & 0.12 & 0.12 & 0.14 \\
C19:0 & 0.38 & 0.58 & 0.50 & 0.41 & 0.57 & 0.52 & 0.51 & 0.51 & 0.48 & 0.46 & 0.57 \\
C18:3n3 & 1.12 & 1.07 & 1.40 & 0.61 & 0.97 & 0.91 & 0.85 & 1.54 & 1.02 & 0.70 & 1.00 \\
C18:4n3 & 0.53 & 0.48 & 0.73 & 0.20 & 0.44 & 0.36 & 0.40 & 0.65 & 0.61 & 0.37 & 0.65 \\
C19:2n6 & 0.05 & 0.06 & 0.05 & 0.05 & 0.05 & 0.06 & 0.04 & 0.05 & 0.09 & 0.06 & 0.03 \\
\hline & & & & & & & & & & &
\end{tabular}


Table A17 continued. Spot collected from the upper bay in fall.

\begin{tabular}{|c|c|c|c|c|c|c|c|c|c|c|c|}
\hline & \multicolumn{11}{|c|}{ Sample number } \\
\hline & 1 & 2 & 3 & 4 & 5 & 6 & 7 & 8 & 9 & 10 & 11 \\
\hline C20:0 & 0.59 & 0.81 & 0.52 & 0.25 & 0.49 & 0.42 & 0.32 & 0.49 & 0.42 & 0.29 & 0.52 \\
\hline C20:1n15 & nd & nd & nd & nd & 0.07 & 0.06 & 0.06 & 0.05 & 0.06 & 0.06 & 0.04 \\
\hline C20:1n12 & 1.44 & 0.99 & 1.10 & 0.52 & 2.35 & 1.44 & 1.79 & 1.09 & 1.25 & 1.47 & 1.70 \\
\hline C20:1n9 & 1.43 & 0.95 & 0.90 & 0.44 & 1.10 & 0.90 & 0.79 & 0.87 & 0.79 & 0.81 & 0.89 \\
\hline $\mathrm{C} 20: 1 \mathrm{n} 7$ & 2.09 & 1.16 & 1.25 & 0.47 & 2.76 & 1.42 & 1.77 & 1.24 & 1.27 & 1.53 & 1.86 \\
\hline$C 20: 2 n 6$ & 1.82 & 0.79 & 0.88 & 0.58 & 1.12 & 0.86 & 1.03 & 0.82 & 0.95 & 0.87 & 1.14 \\
\hline$C 20: 3 n 6$ & 0.36 & 0.15 & 0.13 & 0.14 & 0.19 & 0.16 & 0.17 & 0.12 & 0.15 & 0.19 & 0.13 \\
\hline $\mathrm{C} 21: 0$ & 0.26 & nd & nd & nd & nd & nd & nd & nd & nd & nd & nd \\
\hline$C 20: 4 n 6$ & 4.36 & 4.12 & 3.81 & 5.40 & 3.82 & 4.93 & 4.93 & 3.33 & 4.60 & 5.84 & 4.97 \\
\hline$C 20: 3 n 3$ & 0.48 & 0.38 & 0.48 & 0.42 & 0.59 & 0.36 & 0.40 & 0.42 & 0.47 & 0.41 & 0.40 \\
\hline$C 20: 5 n 3$ & 5.57 & 5.95 & 5.91 & 6.99 & 6.51 & 6.83 & 7.38 & 6.63 & 7.04 & 7.22 & 5.64 \\
\hline $\mathrm{C} 22: 0$ & 0.53 & 0.46 & 0.48 & 0.40 & 0.42 & 0.32 & 0.27 & 0.38 & 0.35 & 0.31 & 0.28 \\
\hline C22:1n9 & 0.37 & 0.20 & 0.40 & 0.30 & 0.35 & 0.23 & 0.22 & 0.20 & 0.25 & 0.35 & 0.15 \\
\hline $\mathrm{C} 22: 2 \mathrm{n} 6$ & 0.19 & 0.06 & 0.24 & 0.21 & 0.36 & 0.12 & 0.07 & 0.11 & 0.09 & 0.09 & 0.10 \\
\hline$C 22: 4 n 6$ & 1.46 & 1.55 & 1.03 & 1.35 & 1.43 & 1.16 & 1.25 & 0.61 & 0.90 & 1.01 & 0.88 \\
\hline$C 22: 3 n 3+C 22: 5 n 6$ & 1.45 & 1.87 & 1.26 & 2.48 & 1.47 & 1.06 & 1.02 & 0.81 & 1.19 & 1.24 & 0.89 \\
\hline$C 22: 5 n 3$ & 2.59 & 2.01 & 2.15 & 2.60 & 2.50 & 2.20 & 2.27 & 1.55 & 1.72 & 1.81 & 1.68 \\
\hline$C 24: 0+C 22: 6 n 3$ & 12.68 & 11.28 & 11.45 & 21.41 & 12.57 & 13.67 & 14.21 & 10.69 & 14.39 & 18.35 & 11.44 \\
\hline C24:1n9 & 0.77 & 0.31 & 0.57 & 0.90 & 1.12 & 0.48 & 0.42 & 0.30 & 0.52 & 0.50 & 0.28 \\
\hline
\end{tabular}




\section{Chapter 3 Raw Data}

Values for length $(\mathrm{mm})$, weight $(\mathrm{g})$, lipid content (\% wet weight) and fatty acids routinely identified for striped bass liver and belly flap samples analyzed in Chapter 3 of this experiment.

Table B1. Striped bass liver samples from day 0.

\begin{tabular}{|c|c|c|c|c|c|c|c|c|c|}
\hline & \multicolumn{9}{|c|}{ Sample number } \\
\hline & 1 & 2 & 3 & 4 & 5 & 6 & 7 & 8 & 9 \\
\hline Total length (mm) & 344 & 344 & 314 & 303 & 373 & 313 & 322 & 303 & 300 \\
\hline Weight (g) & 491.4 & 493.4 & 357.6 & 326.2 & 594.0 & 353.1 & 382.4 & 325.6 & 358.8 \\
\hline Lipid content (\%) & 6.47 & 9.76 & 7.20 & 6.40 & 5.09 & 9.59 & 4.94 & 10.94 & 13.45 \\
\hline C12:0 & 0.09 & nd & 0.06 & 0.04 & 0.06 & nd & 0.05 & 0.06 & 0.04 \\
\hline C12:1n1 & 0.03 & 0.05 & 0.02 & 0.02 & 0.02 & 0.00 & 0.02 & 0.03 & 0.02 \\
\hline C13:0 & nd & nd & nd & 0.09 & 0.34 & nd & nd & nd & nd \\
\hline C14:0 & 3.70 & 4.50 & 3.34 & 2.86 & 2.05 & 2.22 & 3.28 & 4.75 & 3.30 \\
\hline C14:1n5 & 0.06 & 0.08 & 0.07 & 0.08 & 0.05 & 0.05 & 0.07 & 0.13 & 0.09 \\
\hline C15:0 & 0.62 & 0.71 & 0.62 & 0.47 & 0.30 & 0.40 & 0.54 & 0.61 & 0.43 \\
\hline C16:0 & 29.55 & 26.93 & 25.49 & 23.91 & 18.94 & 22.45 & 23.98 & 31.89 & 22.61 \\
\hline C16:1n7 & 5.05 & 5.77 & 4.57 & 4.69 & 3.34 & 3.89 & 4.92 & 6.45 & 5.79 \\
\hline C17:0 & 0.99 & 0.83 & 0.94 & 0.87 & 0.73 & 0.78 & 1.08 & 1.02 & 0.69 \\
\hline C18:0 & 8.62 & 6.36 & 7.40 & 6.68 & 5.49 & 7.04 & 6.84 & 7.84 & 5.71 \\
\hline C18:1n9t & 0.17 & 0.15 & 0.21 & 0.21 & 0.31 & 0.29 & 0.21 & 0.26 & 0.23 \\
\hline C18:1n9 & 13.66 & 13.63 & 13.02 & 18.96 & 15.99 & 14.23 & 13.97 & 21.57 & 23.80 \\
\hline C18:1n7 & 3.39 & 3.05 & 3.27 & 4.07 & 3.36 & 3.49 & 3.78 & 4.24 & 4.49 \\
\hline $\mathrm{C} 18: 2 \mathrm{n} 6$ & nd & 11.33 & 7.85 & 8.29 & 5.60 & 7.39 & 8.99 & 8.01 & 9.24 \\
\hline C18:3n6 & 0.18 & 0.21 & 0.16 & 0.19 & 0.32 & 0.25 & 0.20 & 0.12 & 0.28 \\
\hline C19:0 & 0.25 & 0.23 & 0.23 & 0.22 & 0.40 & 0.35 & 0.30 & 0.24 & 0.29 \\
\hline C18:3n3 & 1.28 & 1.31 & 1.08 & 1.15 & 1.30 & 1.17 & 1.27 & 1.27 & 1.48 \\
\hline C18:4n3 & 0.33 & 0.42 & 0.39 & 0.44 & 0.65 & 0.46 & 0.48 & 0.24 & 0.57 \\
\hline C19:2n6 & 0.07 & 0.05 & 0.07 & nd & 0.23 & 0.19 & 0.10 & nd & nd \\
\hline C20:0 & 0.19 & 0.15 & 0.15 & 0.14 & 0.56 & 0.32 & 0.20 & 0.23 & 0.17 \\
\hline
\end{tabular}


Table B1 continued. Striped bass liver samples from day 0 .

\begin{tabular}{lccccccccc}
\hline & \multicolumn{10}{c}{ Sample number } \\
\hline \hline $\mathrm{C} 20: 1 \mathrm{n} 15$ & 1 & 2 & 3 & 4 & 5 & 6 & 7 & 8 & 9 \\
$\mathrm{C} 20: 1 \mathrm{n} 12$ & nd & nd & 0.01 & 0.04 & 0.25 & 0.11 & 0.03 & 0.02 & 0.05 \\
$\mathrm{C} 20: 1 \mathrm{n} 9$ & 0.18 & 0.13 & 0.08 & 0.16 & 0.51 & 0.23 & 0.15 & 0.24 & 0.13 \\
$\mathrm{C} 20: 1 \mathrm{n} 7$ & 1.16 & 0.96 & 1.23 & 1.61 & 1.91 & 1.36 & 1.34 & 2.24 & 1.83 \\
$\mathrm{C} 20: 2 \mathrm{n} 6$ & 0.32 & 0.22 & 0.18 & 0.35 & 0.71 & 0.31 & 0.26 & 0.33 & 0.26 \\
$\mathrm{C} 20: 3 \mathrm{n} 6$ & 1.07 & 0.98 & 0.79 & 0.83 & 1.64 & 0.95 & 0.97 & 0.60 & 0.69 \\
$\mathrm{C} 21: 0$ & 0.12 & 0.14 & 0.13 & 0.14 & 0.48 & 0.33 & 0.20 & 0.08 & 0.14 \\
$\mathrm{C} 20: 4 \mathrm{n} 6$ & $\mathrm{nd}$ & $\mathrm{nd}$ & 0.01 & $\mathrm{nd}$ & $\mathrm{nd}$ & $\mathrm{nd}$ & $\mathrm{nd}$ & $\mathrm{nd}$ & 0.01 \\
$\mathrm{C} 20: 3 \mathrm{n} 3$ & 3.18 & 1.60 & 2.52 & 1.87 & 3.12 & 2.64 & 2.18 & 0.55 & 1.15 \\
$\mathrm{C} 20: 5 \mathrm{n} 3$ & 0.18 & 0.22 & 0.15 & 0.15 & 0.78 & 0.57 & 0.13 & 0.08 & 0.16 \\
$\mathrm{C} 22: 0$ & 5.45 & 5.53 & 5.45 & 6.55 & 5.91 & 5.80 & 5.18 & 2.45 & 3.91 \\
$\mathrm{C} 22: 1 \mathrm{n} 9$ & 0.08 & 0.82 & 0.09 & 0.44 & 0.80 & 0.52 & 0.15 & 0.45 & 0.16 \\
$\mathrm{C} 22: 2 \mathrm{n} 6$ & $\mathrm{nd}$ & $\mathrm{nd}$ & 0.16 & 0.22 & 0.85 & $\mathrm{nd}$ & 0.19 & $\mathrm{nd}$ & 0.18 \\
$\mathrm{C} 22: 4 \mathrm{n} 6$ & 0.04 & 0.22 & 0.05 & 0.04 & 1.06 & 0.53 & 0.09 & 0.05 & 0.05 \\
$\mathrm{C} 22: 3 \mathrm{n} 3+\mathrm{C} 22: 5 \mathrm{n} 6$ & 0.38 & 0.30 & 0.29 & 0.24 & 1.51 & 1.10 & 0.36 & 0.12 & 0.22 \\
$\mathrm{C} 22: 5 \mathrm{n} 3$ & 0.14 & $\mathrm{nd}$ & 0.13 & 0.13 & 0.61 & 0.37 & 0.17 & 0.08 & 0.11 \\
$\mathrm{C} 24: 0+\mathrm{C} 22: 6 \mathrm{n} 3$ & 18.32 & 11.98 & 18.67 & 12.88 & 15.08 & 17.48 & 17.03 & 3.18 & 10.63 \\
$\mathrm{C} 24: 1 \mathrm{n9}$ & 0.37 & 0.35 & 0.42 & 0.32 & 2.02 & 1.21 & 0.48 & 0.29 & 0.38 \\
\hline
\end{tabular}


Table B2. Striped bass belly flap samples from day 0 .

\begin{tabular}{|c|c|c|c|c|c|c|c|c|c|c|c|c|}
\hline & \multicolumn{12}{|c|}{ Sample number } \\
\hline & 1 & 2 & 3 & 4 & 5 & 6 & 7 & 8 & 9 & 10 & 11 & 12 \\
\hline Total length (mm) & 344 & 344 & 314 & 339 & 303 & 373 & 326 & 313 & 322 & 322 & 303 & 300 \\
\hline Weight (g) & 491.4 & 493.4 & 357.6 & 475.4 & 326.2 & 594.0 & 431.4 & 353.1 & 400.5 & 382.4 & 325.6 & 358.8 \\
\hline Lipid content (\%) & 5.63 & 12.02 & 15.48 & 10.84 & 20.10 & - & 10.41 & 9.68 & 14.10 & 10.07 & 10.94 & 12.57 \\
\hline C12:0 & 0.09 & 0.07 & 0.11 & 0.09 & 0.08 & 0.10 & 0.11 & 0.08 & nd & 0.08 & 0.06 & 0.15 \\
\hline C12:1n1 & 0.02 & 0.02 & 0.03 & 0.03 & 0.03 & 0.04 & 0.03 & 0.02 & 0.03 & 0.03 & 0.03 & 0.07 \\
\hline C13:0 & 0.29 & 0.18 & 0.23 & 0.13 & 0.11 & 0.12 & 0.24 & 0.37 & 0.18 & 0.17 & 0.13 & nd \\
\hline C14:0 & 5.97 & 4.81 & 5.77 & 5.65 & 5.14 & 5.72 & 6.21 & 5.26 & 6.15 & 5.83 & 5.54 & 5.33 \\
\hline C14:1n5 & 0.19 & 0.23 & 0.24 & 0.24 & 0.24 & 0.25 & 0.29 & 0.18 & 0.26 & 0.25 & 0.27 & 0.22 \\
\hline C15:0 & 0.64 & 0.46 & 0.63 & 0.55 & 0.57 & 0.66 & 0.62 & 0.56 & 0.68 & 0.69 & 0.58 & 0.62 \\
\hline C15:1n5 & nd & nd & nd & nd & nd & nd & nd & 0.01 & nd & nd & nd & nd \\
\hline C16:0 & 29.24 & 20.38 & 22.64 & 24.65 & 23.89 & 24.88 & 26.28 & 23.57 & 27.92 & 23.15 & 24.56 & 25.14 \\
\hline C16:1n7 & 7.70 & 7.05 & 7.91 & 7.99 & 7.76 & 7.99 & 8.72 & 7.81 & 8.63 & 8.28 & 8.08 & 8.18 \\
\hline C17:0 & 0.72 & 0.58 & 0.62 & 0.69 & 0.62 & 0.68 & 0.70 & 0.74 & 0.77 & 0.56 & 0.65 & 0.63 \\
\hline C18:0 & 4.25 & 3.03 & 3.58 & 3.68 & 3.72 & 3.44 & 3.49 & 4.05 & 3.77 & 3.27 & 3.78 & 4.30 \\
\hline C18:1n9t & 0.28 & 0.21 & 0.16 & 0.16 & 0.19 & 0.16 & 0.18 & 0.18 & 0.17 & 0.17 & 0.17 & 0.20 \\
\hline C18:1n9 & 23.64 & 21.31 & 22.21 & 22.92 & 24.58 & 22.50 & 24.72 & 24.58 & 25.60 & 22.59 & 24.59 & 24.16 \\
\hline C18:1n7 & 4.12 & 3.76 & 3.77 & 3.87 & 4.10 & 3.90 & 4.25 & 4.14 & 4.42 & 3.93 & 4.23 & 4.45 \\
\hline C18:2n6 & nd & 12.63 & 12.50 & 13.63 & 13.73 & 13.10 & 12.79 & 13.80 & 10.46 & 14.60 & 12.88 & 10.76 \\
\hline C18:3n6 & 0.32 & 0.38 & 0.28 & 0.32 & 0.33 & 0.32 & 0.28 & 0.27 & 0.23 & 0.32 & 0.32 & 0.30 \\
\hline C19:0 & 0.39 & 0.40 & 0.28 & 0.26 & 0.29 & 0.26 & 0.31 & 0.30 & 0.32 & 0.54 & 0.32 & 0.30 \\
\hline C18:3n3 & nd & 1.94 & 1.73 & 1.66 & 1.82 & 1.74 & 1.43 & 1.49 & 1.09 & 1.92 & 1.70 & 1.60 \\
\hline C18:4n3 & 0.78 & 0.82 & 0.85 & 0.70 & 0.73 & 0.79 & 0.51 & nd & 0.38 & 0.89 & 0.62 & 0.80 \\
\hline C19:2n6 & nd & nd & 0.11 & 0.11 & nd & nd & 0.05 & 0.02 & nd & 0.06 & nd & 0.19 \\
\hline$C 20: 0$ & 0.44 & 0.67 & 0.29 & 0.24 & 0.20 & 0.21 & 0.18 & 0.19 & 0.20 & 0.21 & 0.22 & 0.62 \\
\hline C20:1n15 & 0.14 & 0.13 & nd & 0.04 & 0.05 & nd & 0.03 & 0.04 & 0.01 & 0.06 & 0.02 & 0.19 \\
\hline C20:1n12 & 0.38 & 0.39 & 0.16 & 0.16 & 0.16 & 0.15 & 0.14 & 0.18 & 0.20 & 0.18 & 0.18 & 0.10 \\
\hline C20:1n9 & 1.75 & 1.70 & 1.31 & 1.33 & 1.29 & 1.18 & 1.38 & 1.46 & 1.66 & 1.23 & 1.52 & 1.47 \\
\hline
\end{tabular}


Table B2 continued. Striped bass belly flap samples day 0 .

Sample number

\begin{tabular}{lcccccccccccc}
\hline & 1 & 2 & 3 & 4 & 5 & 6 & 7 & 8 & 9 & 10 & 11 & 12 \\
\hline \hline $\mathrm{C} 20: 1 \mathrm{n} 7$ & 0.62 & 0.48 & 0.31 & 0.23 & 0.18 & 0.25 & 0.17 & 0.22 & 0.34 & 0.23 & 0.22 & 0.31 \\
$\mathrm{C} 20: 2 \mathrm{n} 6$ & 1.09 & 1.22 & 0.51 & 0.63 & nd & 0.60 & nd & 0.68 & 0.53 & 0.61 & 0.61 & 0.67 \\
$\mathrm{C} 20: 3 \mathrm{n} 6$ & 0.51 & 0.92 & 0.25 & 0.18 & 0.14 & 0.18 & 0.17 & 0.16 & 0.10 & 0.21 & 0.45 & 0.28 \\
$\mathrm{C} 21: 0$ & $\mathrm{nd}$ & $\mathrm{nd}$ & $\mathrm{nd}$ & $\mathrm{nd}$ & $\mathrm{nd}$ & 0.02 & $\mathrm{nd}$ & $\mathrm{nd}$ & $\mathrm{nd}$ & $\mathrm{nd}$ & 0.07 & $\mathrm{nd}$ \\
$\mathrm{C} 20: 4 \mathrm{n} 6$ & 0.97 & 0.94 & 0.80 & 0.61 & 0.58 & 0.61 & 0.38 & 0.60 & 0.27 & 0.61 & 0.92 & 0.69 \\
$\mathrm{C} 20: 3 \mathrm{n} 3$ & 0.35 & 0.67 & 0.27 & 0.10 & 0.12 & 0.13 & 0.11 & 0.13 & 0.08 & 0.13 & 0.36 & 0.12 \\
$\mathrm{C} 20: 5 \mathrm{n} 3$ & 3.35 & 3.51 & 5.28 & 2.98 & 3.28 & 3.27 & 2.09 & 2.82 & 1.93 & 3.26 & 2.36 & 2.77 \\
$\mathrm{C} 22: 0$ & 0.67 & 0.53 & 0.64 & 0.16 & 0.21 & 0.11 & 0.09 & 0.13 & 0.38 & 0.11 & 0.13 & 0.30 \\
$\mathrm{C} 22: 1 \mathrm{n} 9$ & 0.90 & 0.94 & 0.30 & 0.15 & 0.17 & 0.14 & 0.18 & 0.22 & 0.25 & 0.14 & 0.19 & 0.27 \\
$\mathrm{C} 22: 2 \mathrm{n} 6$ & 0.63 & 0.48 & 0.06 & 0.06 & 0.06 & 0.07 & 0.04 & 0.06 & 0.07 & 0.06 & 0.06 & 0.15 \\
$\mathrm{C} 23: 0$ & $\mathrm{nd}$ & $\mathrm{nd}$ & $\mathrm{nd}$ & 0.08 & $\mathrm{nd}$ & $\mathrm{nd}$ & $\mathrm{nd}$ & $\mathrm{nd}$ & $\mathrm{nd}$ & $\mathrm{nd}$ & $\mathrm{nd}$ & $\mathrm{nd}$ \\
$\mathrm{C} 22: 4 \mathrm{n} 6$ & 0.57 & 0.65 & 0.16 & 0.13 & 0.11 & 0.17 & 0.11 & 0.14 & 0.09 & 0.14 & 0.13 & 0.25 \\
$\mathrm{C} 22: 3 \mathrm{n} 3+\mathrm{C} 22: 5 \mathrm{n} 6$ & 0.97 & 1.03 & 0.28 & 0.25 & 0.27 & 0.30 & 0.22 & 0.24 & 0.12 & 0.23 & 0.15 & 0.28 \\
$\mathrm{C} 22: 5 \mathrm{n} 3$ & 1.49 & 2.00 & 0.76 & 0.71 & 0.70 & 0.77 & 0.59 & 0.73 & 0.43 & 0.78 & 0.58 & 0.50 \\
$\mathrm{C} 24: 0+\mathrm{C} 22: 6 \mathrm{n3}$ & 5.16 & 4.37 & 4.81 & 4.39 & 4.33 & 4.95 & 2.66 & 4.26 & 2.02 & 4.28 & 3.13 & 3.36 \\
$\mathrm{C} 24: 1 \mathrm{n} 9$ & 1.40 & 1.09 & 0.16 & 0.21 & 0.21 & 0.25 & 0.27 & 0.29 & 0.26 & 0.21 & 0.21 & 0.28 \\
\hline
\end{tabular}


Table B3. Striped bass liver samples from day 12 .

\begin{tabular}{|c|c|c|c|c|c|c|c|c|c|c|c|}
\hline & \multicolumn{11}{|c|}{ Sample number } \\
\hline & 1 & 2 & 3 & 4 & 5 & 6 & 7 & 8 & 9 & 10 & 11 \\
\hline Total length (mm) & 341 & 322 & 342 & 354 & 355 & 339 & 323 & 350 & 323 & 347 & 317 \\
\hline Weight (g) & 487.3 & 363.8 & 461.3 & 509.5 & 518.8 & 435.5 & 398.4 & 504.2 & 371.5 & 467.4 & 380.1 \\
\hline Lipid content (\%) & 6.81 & 4.26 & 9.81 & 7.59 & 2.14 & 9.32 & 5.77 & 6.34 & 6.03 & 7.82 & 5.72 \\
\hline C12:0 & 0.01 & 0.04 & 0.02 & 0.04 & 0.03 & 0.03 & 0.02 & 0.02 & 0.02 & 0.02 & 0.02 \\
\hline C12:1n1 & nd & 0.02 & nd & 0.01 & 0.02 & nd & 0.01 & 0.16 & 0.18 & 0.16 & 0.07 \\
\hline C14:0 & 1.71 & 2.76 & 2.59 & 2.06 & 2.37 & 2.76 & 2.61 & 2.37 & 2.27 & 3.23 & 1.60 \\
\hline C14:1n5 & 0.04 & 0.04 & 0.06 & 0.04 & 0.05 & 0.09 & 0.05 & 0.06 & 0.04 & 0.07 & 0.03 \\
\hline C15:0 & 0.45 & 0.75 & 0.58 & 0.43 & 0.67 & 0.53 & 0.64 & 0.51 & 0.57 & 0.57 & 0.41 \\
\hline C15:1n5 & nd & nd & nd & nd & nd & nd & nd & 0.02 & 0.01 & 0.01 & 0.04 \\
\hline C16:0 DMA & nd & nd & nd & nd & nd & nd & nd & 0.03 & 0.02 & 0.02 & 0.04 \\
\hline C16:0 & 20.15 & 23.58 & 24.73 & 18.79 & 23.92 & 22.35 & 22.75 & 24.54 & 27.46 & 24.98 & 17.06 \\
\hline C16:1n7 & 3.71 & 3.95 & 4.25 & 3.61 & 3.86 & 5.62 & 4.84 & 4.01 & 3.11 & 5.24 & 2.49 \\
\hline C17:0 & 1.13 & 1.39 & 1.35 & 1.04 & 1.47 & 0.96 & 1.28 & 0.96 & 1.04 & 0.84 & 0.85 \\
\hline C18:0 & 6.30 & 7.53 & 8.09 & 6.40 & 8.26 & 5.28 & 7.39 & 6.61 & 8.00 & 5.92 & 5.09 \\
\hline C18:1n12t & nd & nd & nd & nd & nd & nd & nd & 0.35 & 0.36 & 0.25 & 0.36 \\
\hline C18:1n9t & 0.47 & 0.19 & 0.30 & 0.40 & 0.23 & 0.29 & 0.29 & 0.24 & 0.23 & 0.20 & 0.25 \\
\hline C18:1n9 & 17.90 & 10.99 & 13.07 & 18.46 & 12.59 & 20.96 & 14.49 & 17.46 & 12.70 & 17.11 & 9.41 \\
\hline C18:1n7 & 4.31 & 3.43 & 3.54 & 4.23 & 3.57 & 4.65 & 4.11 & 3.95 & 3.23 & 3.82 & 2.66 \\
\hline C18:2n6 & 6.40 & 7.57 & 8.20 & 7.66 & 6.89 & 8.17 & 8.58 & 5.99 & 5.16 & 9.04 & 4.95 \\
\hline C18:3n6 & 0.24 & 0.18 & 0.20 & 0.30 & 0.19 & 0.24 & 0.22 & 0.37 & 0.36 & 0.37 & 0.74 \\
\hline C19:0 & 0.47 & 0.37 & 0.47 & 0.65 & 0.40 & 0.33 & 0.56 & nd & nd & nd & nd \\
\hline C18:3n3 & 1.09 & 1.03 & 1.18 & 1.64 & 0.92 & 1.25 & 1.33 & 0.83 & 0.72 & 1.11 & 1.21 \\
\hline C18:4n3 & 0.42 & 0.32 & 0.32 & 0.58 & 0.31 & 0.41 & 0.32 & 0.37 & 0.29 & 0.36 & 0.77 \\
\hline C19:2n6 & 0.13 & nd & 0.05 & nd & 0.09 & 0.05 & 0.04 & nd & nd & nd & nd \\
\hline C20:0 & 0.31 & 0.16 & 0.15 & 0.42 & 0.16 & 0.14 & 0.14 & 0.17 & 0.17 & 0.14 & 0.93 \\
\hline C20:1n15 & 0.15 & 0.01 & nd & 0.15 & nd & 0.03 & 0.04 & nd & nd & nd & nd \\
\hline
\end{tabular}


Table B3 continued. Striped bass liver samples from day 12.

\begin{tabular}{|c|c|c|c|c|c|c|c|c|c|c|c|}
\hline & \multicolumn{11}{|c|}{ Sample number } \\
\hline & 1 & 2 & 3 & 4 & 5 & 6 & 7 & 8 & 9 & 10 & 11 \\
\hline C20:1n12 & 0.44 & 0.25 & 0.20 & 0.51 & nd & 0.30 & 0.24 & 0.33 & 0.24 & 0.24 & 0.88 \\
\hline C20:1n9 & 1.94 & 1.02 & 1.25 & 2.21 & 0.99 & 2.12 & 1.27 & 1.62 & 1.54 & 1.65 & 1.71 \\
\hline C20:1n7 & 0.60 & 0.38 & 0.34 & 0.74 & 0.33 & 0.49 & 0.40 & 0.48 & 0.41 & 0.38 & 1.30 \\
\hline$C 20: 2 n 6$ & 1.12 & 0.92 & 0.92 & 1.36 & 0.89 & 0.86 & 0.90 & 0.74 & 0.81 & 0.93 & 1.73 \\
\hline C20:3n6 & 0.33 & 0.17 & 0.16 & 0.29 & 0.11 & 0.14 & 0.15 & 0.15 & 0.12 & 0.14 & 0.97 \\
\hline C21:0 & nd & nd & nd & nd & 0.01 & nd & nd & nd & nd & nd & nd \\
\hline C20:4n6 & 3.17 & 4.03 & 3.50 & 2.71 & 3.64 & 2.09 & 3.27 & 3.03 & 3.55 & 2.53 & 4.42 \\
\hline$C 20: 3 n 3$ & 0.45 & 0.25 & 0.19 & 0.57 & 0.23 & 0.27 & 0.23 & 0.20 & 0.18 & 0.18 & 1.26 \\
\hline$C 20: 5 n 3$ & 5.59 & 5.73 & 5.17 & 4.99 & 6.95 & 4.36 & 5.09 & 5.16 & 5.21 & 4.19 & 6.09 \\
\hline C22:0 & 0.34 & 0.10 & 0.14 & 0.40 & 0.52 & 0.21 & 0.12 & 0.28 & 0.28 & 0.23 & 1.37 \\
\hline C22:1n9 & nd & nd & nd & 0.64 & nd & 0.34 & nd & 0.13 & 0.18 & 0.14 & 1.34 \\
\hline $\mathrm{C} 22: 2 \mathrm{n} 6$ & 0.39 & 0.11 & 0.12 & 0.69 & 0.07 & 0.09 & 0.10 & 0.03 & 0.02 & 0.03 & 1.86 \\
\hline $\mathrm{C} 22: 4 \mathrm{n} 6$ & 0.52 & 0.29 & 0.22 & 0.59 & 0.26 & 0.21 & 0.23 & 0.46 & 0.41 & 0.26 & 2.31 \\
\hline$C 22: 3 n 3+C 22: 5 n 6$ & 1.33 & 0.68 & 0.43 & 1.21 & 0.47 & 0.41 & 0.44 & 0.53 & 0.50 & 0.39 & 3.71 \\
\hline$C 22: 5 n 3$ & 1.84 & 1.47 & 0.98 & 2.02 & 1.16 & 0.92 & 0.93 & 1.32 & 1.11 & 1.06 & 3.37 \\
\hline$C 24: 0+C 22: 6 n 3$ & 15.34 & 19.81 & 16.70 & 13.26 & 17.84 & 12.62 & 16.51 & 16.01 & 18.97 & 13.77 & 18.70 \\
\hline C24:1n9 & 1.22 & 0.47 & 0.53 & 0.87 & 0.50 & 0.43 & 0.40 & 0.50 & 0.53 & 0.40 & nd \\
\hline
\end{tabular}


Table B4. Striped bass belly flap samples from day 12 .

\begin{tabular}{|c|c|c|c|c|c|c|c|c|c|c|c|}
\hline & \multicolumn{11}{|c|}{ Sample number } \\
\hline & 1 & 2 & 3 & 4 & 5 & 6 & 7 & 8 & 9 & 10 & 11 \\
\hline Total length (mm) & 341 & 322 & 342 & 355 & 339 & 323 & 365 & 350 & 323 & 347 & 317 \\
\hline Weight (g) & 487.3 & 363.8 & 461.3 & 509.5 & 518.8 & 435.5 & 398.4 & 504.2 & 371.5 & 467.4 & 380.1 \\
\hline Lipid content (\%) & 13.92 & 9.81 & 16.16 & 14.03 & 11.42 & 11.45 & 8.92 & 13.12 & 11.91 & 8.62 & 10.97 \\
\hline $\mathrm{C} 12: 0$ & 0.05 & 0.10 & 0.03 & 0.08 & 0.08 & 0.02 & 0.05 & 0.07 & 0.10 & 0.08 & 0.08 \\
\hline $\mathrm{C} 12: 1 \mathrm{n} 1$ & nd & 0.05 & nd & 0.04 & nd & 0.16 & 0.49 & nd & 1.22 & 1.06 & 1.09 \\
\hline $\mathrm{C} 13: 0$ & 0.12 & 0.17 & nd & 0.06 & 0.22 & nd & nd & nd & nd & nd & nd \\
\hline C14:0 & 4.37 & 6.11 & 3.30 & 3.78 & 4.45 & 3.23 & 4.93 & 4.65 & 4.48 & 4.81 & 5.04 \\
\hline $\mathrm{C} 14: 1 \mathrm{n} 5$ & 0.32 & 0.25 & 0.21 & 0.17 & 0.23 & 0.07 & 0.22 & 0.25 & 0.25 & 0.26 & 0.23 \\
\hline C15:0 & 0.64 & 0.85 & 0.35 & 0.55 & 0.58 & 0.57 & 0.59 & 0.62 & 0.68 & 0.59 & 0.56 \\
\hline C15:1n5 & nd & nd & nd & nd & 0.01 & 0.01 & 0.05 & 0.06 & nd & 0.06 & nd \\
\hline C16:0 DMA & nd & nd & nd & nd & nd & 0.02 & 0.03 & 0.05 & 0.12 & nd & nd \\
\hline C16:0 & 21.42 & 22.86 & 14.94 & 16.38 & 23.11 & 24.98 & 22.89 & 22.86 & 23.24 & 22.19 & 21.90 \\
\hline $\mathrm{C} 16: 1 \mathrm{n}$ & 7.57 & 7.88 & 5.40 & 5.70 & 8.14 & 5.24 & 7.57 & 7.59 & 7.17 & 7.89 & 7.84 \\
\hline C17:0 & 0.75 & 0.73 & 0.49 & 0.59 & 0.71 & 0.84 & 0.59 & 0.58 & 0.63 & 0.52 & 0.54 \\
\hline C18:0 & 4.39 & 3.95 & 3.16 & 3.07 & 4.01 & 5.92 & 4.00 & 4.20 & 4.67 & 3.81 & 3.92 \\
\hline $\mathrm{C} 18: 1 \mathrm{n} 12 \mathrm{t}$ & nd & nd & nd & nd & nd & 0.25 & 0.15 & 0.20 & 0.15 & 0.15 & 0.12 \\
\hline C18:1n9t & 0.37 & 0.16 & 0.28 & 0.22 & 0.24 & 0.20 & 0.17 & 0.15 & 0.20 & 0.19 & 0.20 \\
\hline C18:1n9 & 22.18 & 20.50 & 17.19 & 18.38 & 22.27 & 17.11 & 23.02 & 21.17 & 21.66 & 23.83 & 23.07 \\
\hline C18:1n7 & 4.14 & 3.80 & 3.28 & 3.52 & 4.22 & 3.82 & 3.95 & 3.77 & 3.87 & 3.98 & 3.89 \\
\hline $\mathrm{C} 18 \mathrm{~s} 2 \mathrm{n} 6 \mathrm{t}$ & 0.20 & nd & nd & nd & nd & nd & nd & nd & nd & nd & nd \\
\hline C18:2n6 & 12.50 & 12.99 & 10.05 & 10.33 & 12.15 & 9.04 & 12.81 & 11.11 & 11.65 & 12.36 & 13.19 \\
\hline C18:3n6 & 0.36 & 0.30 & 0.42 & 0.43 & 0.31 & 0.37 & 0.38 & 0.41 & 0.38 & 0.34 & 0.39 \\
\hline C19:0 & 0.45 & 0.43 & 0.42 & 0.46 & 0.28 & nd & nd & nd & nd & nd & nd \\
\hline $\mathrm{C} 18: 3 \mathrm{n} 3$ & 1.43 & 1.68 & 1.91 & 1.90 & 1.67 & 1.11 & 1.54 & 1.57 & 1.48 & 1.55 & 1.68 \\
\hline $\mathrm{C} 18: 4 \mathrm{n} 3$ & 0.61 & 0.83 & 0.98 & 0.97 & 0.69 & 0.36 & 0.71 & 0.86 & 0.73 & 0.71 & 0.74 \\
\hline C19:2n6 & nd & nd & 0.63 & nd & nd & nd & nd & nd & 0.03 & nd & nd \\
\hline
\end{tabular}


Table B4 continued. Striped bass belly flap samples from day 12 .

\begin{tabular}{|c|c|c|c|c|c|c|c|c|c|c|c|}
\hline & \multicolumn{11}{|c|}{ Sample number } \\
\hline & 1 & 2 & 3 & 4 & 5 & 6 & 7 & 8 & 9 & 10 & 11 \\
\hline C20:0 & 0.41 & 0.19 & 0.81 & 0.79 & 0.19 & 0.14 & 0.22 & 0.21 & 0.23 & 0.22 & 0.23 \\
\hline C20:1n15 & 0.21 & nd & 0.42 & 0.26 & 0.03 & nd & 0.02 & nd & nd & nd & nd \\
\hline C20:1n12 & 0.12 & 0.21 & 0.57 & 0.66 & 0.25 & 0.24 & 0.25 & 0.31 & nd & 0.22 & 0.22 \\
\hline C20:1n9 & 1.43 & 1.12 & 1.72 & 1.67 & 1.37 & 1.65 & 1.42 & 1.14 & 1.00 & 1.65 & 1.29 \\
\hline C20:1n7 & 0.46 & 0.25 & 0.88 & 0.75 & 0.27 & 0.38 & 0.31 & 0.32 & 0.27 & 0.28 & 0.27 \\
\hline$C 20: 2 n 6$ & 0.80 & 0.60 & 1.09 & 1.26 & 0.66 & 0.93 & 0.70 & 0.58 & 0.66 & 0.78 & 0.72 \\
\hline C20:3n6 & 0.32 & 0.23 & 1.50 & 0.77 & 0.21 & 0.14 & 0.25 & 0.25 & 0.33 & 0.25 & 0.29 \\
\hline C21:0 & nd & 0.07 & nd & 0.42 & 0.02 & nd & nd & nd & nd & 0.07 & nd \\
\hline C20:4n6 & 1.15 & 0.99 & 2.16 & 1.52 & 1.01 & 2.53 & 0.89 & 1.35 & 1.14 & 1.04 & 0.98 \\
\hline$C 20: 3 n 3$ & 0.29 & 0.18 & 1.25 & 1.00 & 0.23 & 0.18 & 0.21 & 0.23 & 0.29 & 0.24 & 0.20 \\
\hline$C 20: 5 n 3$ & 4.06 & 3.76 & 3.87 & 4.04 & 3.82 & 4.19 & 3.64 & 4.89 & 3.91 & 3.60 & 3.81 \\
\hline $\mathrm{C} 22: 0$ & 0.38 & 0.14 & 1.72 & 1.21 & 0.13 & 0.23 & 0.22 & 0.21 & nd & 0.18 & 0.24 \\
\hline C22:1n9 & 0.27 & 0.16 & 1.15 & 1.15 & 0.14 & 0.14 & 0.16 & 0.13 & 0.16 & 0.23 & 0.16 \\
\hline $\mathrm{C} 22: 2 \mathrm{n} 6$ & nd & 0.10 & 0.99 & 0.80 & 0.04 & 0.03 & 0.09 & 0.08 & nd & nd & nd \\
\hline $\mathrm{C} 22: 4 \mathrm{n} 6$ & 0.32 & 0.24 & 1.82 & 1.38 & 0.17 & 0.26 & 0.35 & 0.52 & 0.25 & 0.45 & 0.19 \\
\hline$C 22: 3 n 3+C 22: 5 n 6$ & 0.45 & 0.30 & 2.54 & 1.90 & 0.42 & 0.39 & 0.47 & 0.58 & 0.51 & 0.28 & 0.53 \\
\hline$C 22: 5 n 3$ & 1.32 & 1.19 & 3.61 & 3.04 & 0.87 & 1.06 & 1.00 & 1.16 & 1.00 & 0.89 & 0.86 \\
\hline$C 24: 0+C 22: 6 n 3$ & 5.75 & 6.31 & 7.85 & 8.72 & 6.38 & 13.77 & 5.34 & 7.57 & 7.26 & 4.96 & 5.10 \\
\hline C24:1n9 & 0.43 & 0.31 & 2.98 & 2.01 & 0.40 & 0.40 & 0.34 & 0.31 & 0.26 & 0.30 & 0.44 \\
\hline
\end{tabular}


Table B5. Striped bass liver samples from day 28.

\begin{tabular}{|c|c|c|c|c|c|c|c|c|c|c|c|c|}
\hline & 1 & 2 & 3 & 4 & 5 & 6 & 7 & 8 & 9 & 10 & 11 & 12 \\
\hline Total length (mm) & 315 & 362 & 331 & 339 & 319 & 348 & 332 & 309 & 317 & 368 & 291 & 352 \\
\hline Weight (g) & 423.3 & 612.7 & 464.1 & 519.1 & 413.4 & 530.8 & 444.2 & 367.7 & 362.8 & 656.2 & 334.9 & 595.5 \\
\hline Lipid content (\%) & 4.70 & 6.58 & 6.30 & 5.51 & 10.63 & 4.75 & 9.41 & 10.91 & 5.19 & 7.35 & 4.45 & 6.52 \\
\hline $\mathrm{C} 12: 0$ & 0.01 & 0.02 & 0.02 & 0.03 & 0.01 & 0.01 & 0.03 & 0.03 & nd & nd & nd & 0.01 \\
\hline C12:1n1 & nd & 0.01 & nd & 0.02 & nd & nd & nd & nd & nd & 0.02 & nd & nd \\
\hline C13:0 & nd & 0.32 & 0.11 & 0.20 & nd & nd & 0.10 & 0.13 & nd & 0.07 & nd & 0.12 \\
\hline C14:0 & 1.77 & 2.47 & 2.38 & 2.31 & 1.68 & 1.85 & 3.44 & 2.14 & 1.62 & 2.42 & 1.80 & 2.25 \\
\hline C14:1n5 & 0.07 & 0.08 & 0.10 & 0.09 & 0.09 & 0.05 & 0.15 & 0.09 & 0.03 & 0.08 & 0.04 & 0.09 \\
\hline C15:0 & 0.48 & 0.60 & 0.77 & 0.62 & 0.29 & 0.65 & 0.67 & 0.40 & 0.65 & 0.61 & 0.82 & 0.55 \\
\hline C15:1n5 & nd & nd & nd & nd & 0.01 & nd & nd & nd & nd & nd & nd & nd \\
\hline C16:0 & 22.39 & 19.20 & 20.38 & 23.39 & 25.18 & 21.28 & 21.11 & 27.45 & 20.16 & 17.43 & 22.80 & 19.24 \\
\hline C16:1n7 & 3.66 & 5.34 & 4.35 & 3.94 & 4.31 & 3.17 & 5.75 & 4.42 & 2.70 & 4.95 & 3.07 & 5.33 \\
\hline C17:0 & 1.34 & 1.10 & 1.46 & 1.58 & 0.81 & 1.69 & 1.20 & 1.03 & 1.65 & 1.31 & 1.93 & 1.19 \\
\hline C18:0 & 6.31 & 5.01 & 7.42 & 7.45 & 5.55 & 8.09 & 6.05 & 6.23 & 7.87 & 6.27 & 9.62 & 5.36 \\
\hline C18:1n9t & 0.42 & 0.24 & 0.25 & 0.25 & 0.44 & 0.30 & 0.23 & 0.39 & 0.30 & 0.27 & 0.25 & 0.28 \\
\hline C18:1n9 & 21.69 & 19.84 & 14.13 & 15.93 & 28.64 & 10.95 & 20.67 & 27.39 & 9.34 & 18.20 & 11.16 & 24.02 \\
\hline C18:1n7 & 4.79 & 4.44 & 4.08 & 3.96 & 4.58 & 3.53 & 4.27 & 4.75 & 3.09 & 4.73 & 3.76 & 5.22 \\
\hline $\mathrm{C} 18: 2 \mathrm{n} 6$ & 3.25 & 9.63 & 7.93 & 5.12 & 1.34 & 5.49 & 9.42 & 3.07 & 4.38 & 9.03 & 3.56 & 7.71 \\
\hline C18:3n6 & 0.17 & 0.25 & 0.25 & 0.21 & 0.19 & 0.20 & 0.26 & 0.22 & 0.17 & 0.29 & 0.13 & 0.29 \\
\hline C19:0 & 0.37 & 0.39 & 0.42 & 0.43 & 0.34 & 0.52 & 0.42 & 0.41 & 0.54 & 0.47 & 0.47 & 0.47 \\
\hline C18:3n3 & 0.62 & 1.49 & 1.05 & 0.77 & 0.41 & 0.99 & 1.31 & 0.75 & 0.80 & 1.74 & 0.79 & 1.49 \\
\hline C18:4n3 & 0.32 & 0.48 & 0.47 & 0.35 & 0.24 & 0.29 & 0.52 & 0.35 & 0.37 & 0.58 & 0.26 & 0.59 \\
\hline C19:2n6 & 0.07 & 0.09 & nd & 0.07 & 0.11 & 0.06 & 0.09 & 0.08 & 0.11 & 0.15 & 0.07 & 0.08 \\
\hline C20:0 & 0.20 & 0.17 & 0.17 & 0.22 & 0.20 & 0.20 & 0.18 & 0.23 & 0.34 & 0.20 & 0.19 & 0.25 \\
\hline C20:1n15 & 0.05 & 0.07 & 0.03 & 0.05 & 0.07 & 0.05 & 0.03 & 0.08 & 0.13 & 0.09 & 0.03 & 0.07 \\
\hline C20:1n12 & 0.57 & 0.43 & 0.34 & 0.46 & 0.42 & 0.31 & 0.39 & 0.51 & 0.41 & 0.55 & 0.40 & 0.66 \\
\hline
\end{tabular}


Table B5 continued. Striped bass liver samples from day 28.

\begin{tabular}{|c|c|c|c|c|c|c|c|c|c|c|c|c|}
\hline & \multicolumn{12}{|c|}{ Sample number } \\
\hline & 1 & 2 & 3 & 4 & 5 & 6 & 7 & 8 & 9 & 10 & 11 & 12 \\
\hline C20:1n9 & 2.36 & 2.24 & 1.55 & 1.86 & 2.88 & 1.32 & 1.54 & 2.47 & 1.12 & 1.79 & 1.24 & 2.22 \\
\hline C20:1n7 & 0.84 & 0.63 & 0.48 & 0.63 & 0.50 & 0.44 & 0.49 & 0.61 & 0.56 & 0.72 & 0.56 & 0.88 \\
\hline$C 20: 2 n 6$ & 0.72 & 1.15 & 1.05 & 0.85 & 0.41 & 0.90 & 0.79 & 0.67 & 1.03 & 1.09 & 0.83 & 0.98 \\
\hline C20:3n6 & 0.09 & 0.22 & 0.19 & 0.17 & 0.09 & 0.11 & 0.14 & 0.09 & 0.39 & 0.25 & 0.11 & 0.23 \\
\hline C21:0 & 0.01 & nd & nd & nd & nd & nd & nd & nd & nd & nd & 0.01 & nd \\
\hline$C 20: 4 n 6$ & 3.30 & 2.82 & 3.94 & 4.25 & 2.33 & 5.05 & 2.62 & 2.02 & 5.27 & 2.55 & 4.97 & 2.21 \\
\hline$C 20: 3 n 3$ & 0.27 & 0.24 & 0.24 & 0.23 & 0.21 & 0.24 & 0.20 & 0.16 & 0.62 & 0.39 & 0.27 & 0.23 \\
\hline C20:5n3 & 5.25 & 5.02 & 5.66 & 5.93 & 3.98 & 7.06 & 4.68 & 3.20 & 7.09 & 4.98 & 6.33 & 4.28 \\
\hline $\mathrm{C} 22: 0$ & 0.19 & 0.19 & 0.18 & 0.19 & 0.20 & 0.31 & 0.11 & 0.07 & 0.44 & 0.27 & 0.12 & 0.08 \\
\hline C22:1n9 & 0.51 & 0.40 & 0.21 & 0.23 & 0.57 & nd & 0.20 & 0.25 & nd & 0.33 & 0.14 & 0.30 \\
\hline $\mathrm{C} 22: 2 \mathrm{n} 6$ & 0.08 & 0.23 & 0.06 & 0.05 & 0.16 & 0.11 & 0.07 & 0.03 & 0.32 & 0.40 & 0.05 & 0.06 \\
\hline $\mathrm{C} 22: 4 \mathrm{n} 6$ & 0.39 & 0.44 & 0.35 & 0.35 & 0.35 & 0.41 & 0.26 & 0.27 & 0.61 & 0.46 & 0.42 & 0.36 \\
\hline$C 22: 3 n 3+C 22: 5 n 6$ & 0.63 & 0.86 & 0.66 & 0.67 & 0.83 & 0.68 & 0.46 & 0.43 & 1.77 & 0.80 & 0.73 & 0.56 \\
\hline$C 22: 5 n 3$ & 1.36 & 1.74 & 1.48 & 1.41 & 1.16 & 1.35 & 1.12 & 0.79 & 2.21 & 1.96 & 1.49 & 1.39 \\
\hline$C 24: 0+C 22: 6 n 3$ & 15.18 & 11.81 & 17.35 & 15.39 & 10.64 & 21.81 & 10.66 & 8.56 & 21.75 & 14.07 & 21.29 & 10.64 \\
\hline C24:1n9 & 0.30 & 0.34 & 0.48 & 0.31 & 0.77 & 0.53 & 0.36 & 0.23 & 2.16 & 0.48 & 0.29 & 0.33 \\
\hline
\end{tabular}


Table B6. Striped bass belly flap samples from day 28.

\begin{tabular}{|c|c|c|c|c|c|c|c|c|c|c|c|c|}
\hline & \multicolumn{12}{|c|}{ Sample number } \\
\hline & 1 & 2 & 3 & 4 & 5 & 6 & 7 & 8 & 9 & 10 & 11 & 12 \\
\hline Total length (mm) & 315 & 362 & 331 & 339 & 319 & 348 & 332 & 309 & 317 & 368 & 291 & 352 \\
\hline Weight (g) & 423.3 & 612.7 & 464.1 & 519.1 & 413.4 & 530.8 & 444.2 & 367.7 & 362.8 & 656.2 & 334.9 & 595.5 \\
\hline Lipid content (\%) & 15.50 & 10.48 & 12.47 & 12.60 & 9.26 & 8.65 & 22.09 & 12.22 & - & 11.92 & 9.89 & 17.13 \\
\hline C12:0 & 0.03 & 0.08 & 0.07 & 0.08 & 0.08 & 0.05 & 0.06 & 0.06 & 0.06 & 0.06 & 0.03 & nd \\
\hline C12:1n1 & nd & nd & nd & 0.03 & nd & nd & nd & nd & 0.02 & 0.08 & nd & nd \\
\hline C13:0 & 0.43 & 0.41 & 0.13 & 0.43 & 0.41 & 0.26 & 0.45 & 0.23 & 0.22 & 0.68 & 0.57 & nd \\
\hline C14:0 & 3.60 & 3.95 & 4.80 & 4.52 & 3.93 & 5.04 & 4.94 & 3.87 & 4.41 & 4.18 & 4.33 & 4.57 \\
\hline C14:1n5 & 0.23 & 0.32 & 0.22 & 0.20 & 0.16 & 0.23 & 0.28 & 0.20 & 0.23 & 0.28 & 0.18 & 0.29 \\
\hline C15:0 & 0.74 & 0.49 & 0.58 & 0.85 & 0.86 & 0.68 & 0.70 & 0.84 & 0.72 & 0.58 & 0.91 & 0.84 \\
\hline C15:1n5 & 0.03 & nd & nd & nd & nd & nd & 0.02 & nd & nd & nd & nd & nd \\
\hline C16:0 & 19.42 & 19.78 & 21.94 & 22.27 & 24.89 & 21.62 & 20.91 & 23.22 & 23.52 & 20.75 & 23.83 & 21.79 \\
\hline C16:1n7 & 6.24 & 7.30 & 7.65 & 6.90 & 6.17 & 7.31 & 7.65 & 6.54 & 7.26 & 7.52 & 6.50 & 7.76 \\
\hline C17:0 & 0.95 & 0.67 & 0.90 & 1.11 & 1.48 & 0.88 & 0.72 & 1.25 & 0.82 & 0.85 & 1.20 & 1.03 \\
\hline $\mathrm{C} 17: 1 \mathrm{n} 7$ & nd & 0.16 & nd & nd & nd & 0.04 & nd & nd & nd & nd & nd & nd \\
\hline C18:0 & 4.34 & 4.03 & 4.29 & 4.91 & 5.96 & 4.45 & 4.25 & 4.90 & 4.81 & 3.93 & 5.93 & 4.12 \\
\hline C18:1n9t & 0.21 & 0.21 & 0.23 & 0.24 & 0.26 & 0.22 & 0.27 & 0.23 & 0.21 & 0.21 & 0.21 & 0.14 \\
\hline C18:1n9 & 17.80 & 21.61 & 23.71 & 19.96 & 20.60 & 20.83 & 24.63 & 18.77 & 22.48 & 22.55 & 18.99 & 22.40 \\
\hline C18:1n7 & 3.71 & 3.59 & 3.95 & 4.03 & 4.28 & 3.76 & 4.36 & 3.77 & 3.90 & 3.95 & 3.99 & 3.80 \\
\hline $\mathrm{C} 18: 2 \mathrm{n} 6 \mathrm{t}$ & 0.37 & nd & nd & nd & nd & 0.20 & nd & nd & nd & 0.16 & nd & nd \\
\hline C18:2n6 & 8.37 & 12.29 & 13.78 & 10.75 & 4.70 & 11.38 & 12.98 & 7.17 & 12.36 & 11.65 & 8.79 & 11.40 \\
\hline C18:3n6 & 0.17 & 0.33 & 0.45 & 0.31 & 0.19 & 0.23 & 0.34 & 0.17 & 0.27 & 0.49 & 0.22 & 0.43 \\
\hline C19:0 & 0.38 & 0.23 & 0.48 & 0.31 & 0.41 & 0.36 & 0.33 & 0.35 & 0.34 & 0.42 & 0.34 & 0.46 \\
\hline C18:3n3 & 1.28 & 1.46 & 2.26 & 1.63 & 1.30 & 1.53 & 1.72 & 1.12 & 1.41 & 1.92 & 1.33 & 1.69 \\
\hline C18:4n3 & 0.65 & 0.60 & 1.10 & 0.75 & 0.49 & 0.74 & 0.75 & 0.62 & 0.54 & 0.92 & 0.64 & 0.95 \\
\hline C19:2n6 & 0.09 & 0.09 & nd & 0.14 & 0.07 & 0.21 & nd & 0.12 & nd & 0.11 & 0.14 & 0.17 \\
\hline C20:0 & 0.21 & 0.18 & 0.18 & 0.25 & 0.32 & 0.22 & 0.22 & 0.24 & 0.23 & 0.46 & 0.29 & 0.42 \\
\hline
\end{tabular}


Table B6 continued. Striped bass belly flap samples from day 28 .

\begin{tabular}{|c|c|c|c|c|c|c|c|c|c|c|c|c|}
\hline & \multicolumn{12}{|c|}{ Sample number } \\
\hline & 1 & 2 & 3 & 4 & 5 & 6 & 7 & 8 & 9 & 10 & 11 & 12 \\
\hline C20:1n15 & 0.05 & nd & 0.06 & 0.09 & 0.02 & 0.03 & 0.06 & 0.03 & nd & 0.08 & 0.06 & 0.22 \\
\hline C20:1n12 & 0.63 & 0.22 & nd & 0.68 & 0.80 & 0.43 & nd & 0.59 & 0.46 & 0.23 & 0.71 & 0.58 \\
\hline C20:1n9 & 1.17 & 1.31 & 1.34 & 1.37 & 1.64 & 1.17 & 1.30 & 1.20 & 1.37 & 1.32 & 1.21 & 1.46 \\
\hline C20:1n7 & 0.69 & 0.07 & 0.16 & 0.60 & 1.01 & 0.42 & 0.31 & 0.62 & 0.55 & 0.23 & 0.73 & 0.69 \\
\hline$C 20: 2 n 6$ & 0.59 & 0.75 & 0.68 & 0.82 & 0.70 & 0.77 & 0.58 & 0.67 & 0.61 & 0.67 & 0.78 & 0.85 \\
\hline$C 20: 3 n 6$ & 0.25 & 0.38 & 0.30 & 0.21 & 0.31 & 0.32 & 0.29 & 0.31 & 0.17 & 0.24 & 0.20 & 0.28 \\
\hline C21:0 & nd & nd & nd & nd & nd & nd & 0.02 & nd & nd & 0.11 & nd & nd \\
\hline$C 20: 4 n 6$ & 1.34 & 1.18 & 1.13 & 1.35 & 1.58 & 1.26 & 0.79 & 1.54 & 1.03 & 1.26 & 1.65 & 1.20 \\
\hline$C 20: 3 n 3$ & 0.82 & 0.20 & 0.21 & 0.40 & 0.30 & 0.21 & nd & 0.45 & 0.25 & 0.31 & 0.32 & 0.35 \\
\hline$C 20: 5 n 3$ & 7.37 & 4.15 & 3.66 & 5.32 & 4.52 & 3.94 & 5.25 & 4.57 & 3.43 & 4.97 & 4.38 & 4.06 \\
\hline $\mathrm{C} 22: 0$ & 1.09 & 0.57 & 0.21 & 0.29 & 0.27 & 0.30 & 0.21 & 0.39 & 0.24 & 0.27 & 0.17 & 0.18 \\
\hline C22:1n9 & 0.70 & 0.68 & nd & 0.33 & 0.20 & 0.11 & 0.22 & 0.35 & 0.23 & nd & 0.14 & 0.19 \\
\hline $\mathrm{C} 22: 2 \mathrm{n} 6$ & 0.45 & nd & nd & 0.14 & 0.09 & 0.03 & 0.06 & 0.32 & 0.04 & 0.12 & 0.07 & 0.11 \\
\hline $\mathrm{C} 22: 4 \mathrm{n} 6$ & 1.03 & 0.69 & 0.19 & 0.33 & 0.49 & 0.31 & 0.25 & 1.04 & 0.28 & nd & 0.34 & 0.25 \\
\hline$C 22: 3 n 3+C 22: 5 n 6$ & 1.10 & 0.71 & 0.30 & 0.66 & 0.72 & 0.51 & 0.34 & 1.03 & 0.49 & 0.56 & 0.54 & 0.49 \\
\hline$C 22: 5 n 3$ & 2.77 & 2.48 & 0.88 & 1.39 & 1.78 & 1.73 & 0.81 & 2.96 & 1.04 & 1.19 & 1.38 & 1.00 \\
\hline$C 24: 0+C 22: 6 n 3$ & 8.85 & 7.87 & 4.08 & 5.95 & 8.63 & 7.69 & 3.63 & 8.87 & 5.63 & 6.21 & 8.49 & 5.68 \\
\hline C24:1n9 & 1.87 & 0.94 & 0.08 & 0.42 & 0.41 & 0.52 & 0.30 & 1.39 & 0.39 & 0.44 & 0.42 & 0.15 \\
\hline
\end{tabular}


Table B7. Striped bass liver samples from day 40.

\begin{tabular}{|c|c|c|c|c|c|c|c|c|c|c|c|c|}
\hline & \multicolumn{12}{|c|}{ Sample number } \\
\hline & 1 & 2 & 3 & 4 & 5 & 6 & 7 & 8 & 9 & 10 & 11 & 12 \\
\hline Total length (mm) & 360 & 330 & 344 & 366 & 371 & 350 & 382 & 356 & 379 & 355 & 299 & 342 \\
\hline Weight (g) & 698.8 & 526.4 & 644.2 & 707.2 & 704.3 & 581.6 & 705.3 & 612.9 & 689.1 & 604.8 & 319.9 & 495.2 \\
\hline Lipid content (\%) & 5.67 & 6.16 & 5.48 & 4.70 & 5.44 & 6.78 & 3.82 & 5.36 & 4.50 & 8.29 & 5.56 & 4.68 \\
\hline C12:0 & 0.02 & 0.02 & 0.03 & 0.00 & 0.01 & 0.02 & 0.03 & 0.02 & 0.02 & 0.01 & 0.01 & 0.01 \\
\hline C12:1n1 & nd & nd & nd & nd & nd & nd & 0.12 & 0.10 & nd & 0.01 & nd & 0.04 \\
\hline C13:0 & nd & 0.07 & 0.09 & nd & nd & 0.16 & 0.07 & 0.08 & 0.27 & 0.06 & nd & 0.30 \\
\hline C14:0 & 1.98 & 1.63 & 1.97 & 1.99 & 1.94 & 2.11 & 2.63 & 2.59 & 1.83 & 1.94 & 1.50 & 2.07 \\
\hline C14:1n5 & 0.11 & 0.05 & 0.06 & 0.06 & 0.05 & 0.07 & 0.09 & 0.09 & 0.06 & 0.07 & 0.04 & 0.08 \\
\hline C15:0 & 0.33 & 0.29 & 0.54 & 0.48 & 0.54 & 0.50 & 0.64 & 0.61 & 0.60 & 0.42 & 0.56 & 0.56 \\
\hline C15:1n5 & nd & nd & nd & 0.01 & nd & nd & 0.03 & 0.03 & nd & nd & nd & 0.00 \\
\hline C16:0 DMA & nd & nd & nd & nd & nd & nd & 0.04 & 0.04 & nd & nd & nd & nd \\
\hline C16:0 & 25.22 & 23.85 & 24.02 & 25.46 & 22.82 & 21.75 & 28.61 & 25.52 & 21.27 & 23.95 & 26.26 & 21.59 \\
\hline C16:1n7 & 5.37 & 3.47 & 4.15 & 3.71 & 4.24 & 4.83 & 4.65 & 4.18 & 3.65 & 4.52 & 3.40 & 3.86 \\
\hline C17:0 & 0.88 & 1.16 & 1.57 & 1.11 & 1.45 & 1.26 & 1.20 & 1.19 & 1.25 & 1.11 & 1.60 & 1.56 \\
\hline C18:0 & 6.46 & 7.05 & 7.47 & 7.65 & 7.54 & 6.47 & nd & 7.66 & 7.19 & 7.06 & 8.02 & 7.84 \\
\hline C18:1n9t & 0.43 & 0.42 & 0.41 & 0.39 & 0.45 & 0.27 & 0.29 & nd & 0.33 & 0.40 & 0.31 & 0.25 \\
\hline C18:1n9 & 30.50 & 22.41 & 21.88 & 21.47 & 20.88 & 21.06 & 20.06 & 17.85 & 14.15 & 26.02 & 18.53 & 16.24 \\
\hline C18:1n7 & 5.01 & 4.14 & 5.01 & 4.38 & 5.09 & 4.86 & 4.58 & 4.10 & 4.04 & 5.05 & 4.38 & 4.25 \\
\hline $\mathrm{C} 18: 2 \mathrm{n} 6 \mathrm{t}$ & 0.15 & nd & nd & nd & nd & nd & nd & nd & nd & nd & nd & nd \\
\hline $\mathrm{C} 18: 2 \mathrm{n} 6$ & 3.30 & 2.14 & 3.57 & 3.06 & 4.58 & 5.45 & 5.82 & 4.99 & 6.40 & 3.78 & 1.83 & 4.80 \\
\hline C18:3n6 & 0.21 & 0.23 & 0.20 & 0.16 & 0.22 & 0.22 & 0.43 & 0.42 & 0.19 & 0.22 & 0.14 & 0.20 \\
\hline C19:0 & 0.54 & 0.48 & 0.52 & 0.34 & 0.46 & 0.38 & nd & nd & 0.39 & 0.40 & 0.43 & 0.44 \\
\hline C18:3n3 & 0.72 & 0.81 & 0.86 & 0.70 & 1.02 & 1.21 & 0.88 & 0.75 & 0.91 & 0.90 & 0.54 & 0.89 \\
\hline C18:4n3 & 0.35 & 0.42 & 0.36 & 0.29 & 0.43 & 0.39 & 0.39 & 0.40 & 0.36 & 0.42 & 0.31 & 0.41 \\
\hline C19:2n6 & 0.10 & nd & 0.07 & 0.07 & 0.11 & nd & 0.03 & nd & 0.10 & 0.08 & 0.05 & 0.04 \\
\hline C20:0 & 0.19 & 0.55 & 0.24 & 0.18 & 0.31 & 0.16 & 0.20 & 0.20 & 0.18 & 0.26 & 0.21 & 0.19 \\
\hline
\end{tabular}


Table B7 continued. Striped bass liver samples from day 40.

\begin{tabular}{|c|c|c|c|c|c|c|c|c|c|c|c|c|}
\hline & \multicolumn{12}{|c|}{ Sample number } \\
\hline & 1 & 2 & 3 & 4 & 5 & 6 & 7 & 8 & 9 & 10 & 11 & 12 \\
\hline C20:1n15 & 0.04 & 0.12 & 0.04 & 0.04 & 0.07 & 0.03 & nd & nd & 0.04 & 0.06 & 0.03 & 0.03 \\
\hline C20:1n12 & 0.49 & 0.62 & 0.58 & 0.42 & 0.73 & 0.50 & 0.44 & 0.44 & 0.40 & 0.61 & 0.61 & 0.46 \\
\hline C20:1n9 & 2.81 & 2.30 & 3.00 & 2.25 & 3.25 & 2.97 & 2.55 & 1.84 & 1.76 & 2.72 & 2.25 & 2.03 \\
\hline C20:1n7 & 0.55 & 0.76 & 0.83 & 0.64 & 0.87 & 0.68 & 0.65 & 0.59 & 0.52 & 0.72 & 0.72 & 0.63 \\
\hline $\mathrm{C} 20: 2 \mathrm{n} 6$ & 0.49 & 0.94 & 0.78 & 0.61 & 0.87 & 0.93 & nd & 0.80 & 1.01 & 0.78 & 0.65 & 0.85 \\
\hline$C 20: 3 n 6$ & 0.09 & 0.28 & 0.09 & 0.13 & 0.15 & 0.14 & 0.16 & 0.18 & 0.14 & 0.09 & 0.10 & 0.15 \\
\hline$C 20: 4 n 6$ & 1.86 & 3.17 & 2.93 & 3.44 & 2.78 & 2.52 & 3.48 & 3.59 & 5.05 & 2.18 & 3.89 & 3.70 \\
\hline$C 20: 3 n 3$ & 0.13 & 0.44 & 0.21 & 0.20 & 0.26 & 0.25 & 0.22 & 0.23 & 0.37 & 0.21 & 0.22 & 0.24 \\
\hline C20:5n3 & 2.99 & 4.28 & 3.96 & 4.61 & 4.07 & 3.94 & 4.67 & 4.40 & 6.55 & 3.68 & 4.64 & 5.23 \\
\hline $\mathrm{C} 22: 0$ & 0.08 & 0.36 & 0.12 & 0.09 & 0.09 & 0.12 & 0.16 & 0.16 & 0.21 & 0.10 & 0.14 & 0.17 \\
\hline C22:1n9 & 0.30 & 0.87 & 0.27 & 0.33 & 0.32 & 0.53 & 0.25 & 0.18 & nd & 0.34 & 0.24 & 0.34 \\
\hline$C 22: 2 n 6$ & 0.03 & 0.85 & 0.07 & 0.11 & 0.09 & 0.19 & 0.05 & 0.05 & 0.07 & 0.04 & nd & 0.25 \\
\hline $\mathrm{C} 22: 4 \mathrm{n} 6$ & 0.26 & 0.62 & 0.37 & 0.40 & 0.39 & 0.48 & 0.76 & 0.75 & 0.38 & 0.31 & 0.51 & 0.50 \\
\hline$C 22: 3 n 3+C 22: 5 n 6$ & 0.38 & 1.14 & 0.52 & 0.57 & 0.50 & 0.86 & 0.62 & 0.63 & 0.65 & 0.40 & 0.88 & 0.80 \\
\hline$C 22: 5 n 3$ & 0.70 & 1.98 & 1.16 & 1.16 & 1.18 & 1.73 & 1.49 & 1.52 & 1.59 & 1.08 & 1.64 & 1.95 \\
\hline$C 24: 0+C 22: 6 n 3$ & 6.78 & 11.43 & 11.65 & 13.12 & 12.02 & 12.30 & 13.22 & 13.31 & 17.63 & 9.75 & 14.11 & 16.52 \\
\hline C24:1n9 & 0.15 & 0.64 & 0.40 & 0.36 & 0.21 & 0.65 & 0.51 & 0.51 & 0.44 & 0.23 & 1.27 & 0.51 \\
\hline
\end{tabular}


Table B8. Striped bass belly flap samples from day 40 .

\begin{tabular}{|c|c|c|c|c|c|c|c|c|c|c|c|c|}
\hline & \multicolumn{12}{|c|}{ Sample number } \\
\hline & 1 & 2 & 3 & 4 & 5 & 6 & 7 & 8 & 9 & 10 & 11 & 12 \\
\hline Total length (mm) & 360 & 330 & 344 & 366 & 371 & 350 & 382 & 356 & 379 & 355 & 299 & 342 \\
\hline Weight (g) & 698.8 & 526.4 & 644.2 & 707.2 & 704.3 & 581.6 & 705.3 & 612.9 & 689.1 & 604.8 & 319.9 & 495.2 \\
\hline Lipid content (\%) & 20.50 & 14.84 & 16.47 & 17.95 & 7.95 & 10.98 & 16.72 & 10.73 & 8.84 & 10.15 & 7.27 & 8.99 \\
\hline C12:0 & 0.04 & 0.02 & 0.06 & 0.07 & nd & nd & 0.14 & 0.08 & 0.06 & 0.02 & 0.06 & 0.15 \\
\hline C12:1n1 & nd & nd & nd & nd & nd & 0.93 & nd & nd & nd & nd & nd & nd \\
\hline C13:0 & 0.10 & 0.14 & 0.13 & 0.16 & 0.09 & nd & 0.23 & 0.16 & 0.25 & 0.32 & nd & nd \\
\hline C14:0 & 2.81 & 3.04 & 4.54 & 4.83 & 4.72 & 4.35 & 4.41 & 4.21 & 3.85 & 3.93 & 3.68 & 5.24 \\
\hline C14:1n5 & 0.16 & 0.15 & 0.21 & 0.25 & 0.24 & 0.50 & 0.22 & 0.21 & 0.18 & 0.18 & 0.15 & 0.37 \\
\hline C15:0 & 0.50 & 0.59 & 0.79 & 0.86 & 0.69 & 0.88 & 0.71 & 0.81 & 0.58 & 0.76 & 1.11 & 0.83 \\
\hline C15:1n5 & nd & nd & nd & nd & 0.07 & 0.15 & 0.11 & 0.09 & nd & na & nd & 0.15 \\
\hline C16:0 DMA & nd & nd & nd & nd & nd & 0.23 & 0.05 & 0.06 & nd & nd & nd & 0.06 \\
\hline C16:0 & 15.07 & 15.48 & 22.89 & 22.31 & 21.11 & 21.11 & 22.33 & 23.62 & 20.41 & 23.80 & 25.88 & 21.96 \\
\hline $\mathrm{C} 16: 1 \mathrm{n}$ & 4.72 & 4.87 & 7.24 & 7.23 & 6.67 & 7.57 & 7.13 & 7.23 & 6.73 & 6.84 & 5.86 & 7.59 \\
\hline C17:0 & 0.69 & 0.95 & 1.09 & 0.96 & 1.01 & 0.85 & 0.81 & 1.06 & 0.91 & 1.24 & 1.43 & 0.74 \\
\hline C18:0 & 3.41 & 3.68 & 5.03 & 4.99 & 4.95 & 4.17 & 4.44 & 4.99 & 4.41 & 5.38 & 6.90 & 4.28 \\
\hline C18:1n12t & nd & nd & nd & nd & 0.31 & nd & 0.23 & nd & nd & nd & 0.27 & 0.18 \\
\hline C18:1n9t & 0.25 & 0.29 & 0.28 & 0.21 & nd & 0.30 & 0.19 & 0.24 & 0.19 & 0.24 & nd & 0.23 \\
\hline C18:1n12 & nd & nd & nd & nd & nd & 0.14 & nd & nd & nd & nd & nd & nd \\
\hline C18:1n9 & 14.26 & 13.51 & 20.89 & 20.29 & 19.49 & 19.49 & 20.37 & 19.80 & 20.89 & 21.12 & 16.23 & 21.35 \\
\hline C18:1n7 & 3.00 & 3.16 & 4.35 & 3.85 & 4.07 & 3.69 & 3.79 & 4.01 & 3.81 & 4.24 & 3.87 & 3.87 \\
\hline $\mathrm{C} 18: 2 \mathrm{n} 6 \mathrm{t}$ & nd & nd & nd & nd & nd & nd & nd & nd & nd & nd & 0.09 & nd \\
\hline $\mathrm{C} 18: 2 \mathrm{n} 6$ & 7.54 & 6.44 & 10.37 & 9.21 & 9.53 & 9.24 & 9.63 & 9.02 & 11.57 & 9.26 & 4.27 & 10.90 \\
\hline C18:3n6 & 0.54 & 0.35 & 0.36 & 0.30 & 0.56 & nd & 0.39 & 0.45 & 0.30 & 0.28 & 0.27 & 0.41 \\
\hline C19:0 & 0.62 & 0.67 & 0.50 & 0.25 & 0.58 & 0.86 & nd & nd & 0.37 & 0.40 & 0.45 & 0.06 \\
\hline C18:3n3 & 2.07 & 1.60 & 1.91 & 1.49 & 1.68 & 1.53 & 1.52 & 1.33 & 1.70 & 1.72 & 1.11 & 1.31 \\
\hline $\mathrm{C} 18: 4 \mathrm{n} 3$ & 1.32 & 1.08 & 0.98 & 0.69 & 0.92 & 0.83 & 0.79 & 0.63 & 0.73 & 0.77 & 0.80 & 0.54 \\
\hline
\end{tabular}


Table B8 continued. Striped bass belly flap samples from day 40 .

\begin{tabular}{lcccccccccccc}
\hline \multicolumn{10}{c}{} & \multicolumn{10}{c}{ Sample number } \\
\hline \hline C19:2n6 & 1 & 2 & 3 & 4 & 5 & 6 & 7 & 8 & 9 & 10 & 11 & 12 \\
C20:0 & nd & nd & 0.21 & 0.10 & nd & nd & 0.08 & nd & nd & 0.15 & 0.24 & nd \\
C20:1n15 & 0.74 & 0.76 & 0.28 & 0.28 & 0.30 & 0.67 & 0.29 & 0.23 & 0.36 & 0.42 & 0.44 & 0.30 \\
C20:1n12 & 0.51 & nd & nd & 0.18 & nd & 0.45 & nd & 0.03 & 0.07 & 0.21 & nd & 0.10 \\
C20:1n9 & 1.15 & 1.52 & 0.66 & 0.68 & 0.85 & 0.90 & 0.69 & 0.60 & 0.53 & 0.95 & 1.14 & 0.45 \\
C20:1n7 & 1.96 & 1.64 & 1.35 & 1.29 & 1.97 & 1.55 & 1.89 & 1.28 & 1.57 & 1.42 & 1.49 & 1.34 \\
C20:2n6 & 1.67 & 1.24 & 0.71 & 0.65 & 1.00 & 0.94 & 0.63 & 0.67 & 0.57 & 0.61 & 1.24 & 0.61 \\
C20:3n6 & 2.11 & 1.70 & 0.81 & 0.70 & 1.06 & 1.52 & 0.92 & 0.70 & 0.80 & 0.70 & 0.67 & 0.71 \\
C21:0 & 1.26 & 0.71 & 0.24 & 0.38 & 0.43 & 0.49 & 0.30 & 0.23 & 0.24 & 0.17 & 0.16 & 0.30 \\
C20:4n6 & 0.43 & nd & 0.06 & 0.11 & nd & 0.16 & nd & 0.02 & 0.01 & 0.02 & nd & 0.10 \\
C20:3n3 & 2.08 & 2.20 & 1.24 & 1.50 & 1.87 & 1.97 & 1.64 & 1.84 & 1.23 & 1.31 & 2.17 & 1.47 \\
C20:5n3 & 1.84 & 1.12 & 0.45 & 0.28 & 0.31 & 0.81 & 0.21 & 0.28 & 0.30 & 0.42 & 0.26 & 0.17 \\
C22:0 & 5.85 & 5.41 & 4.01 & 4.51 & 4.27 & 4.44 & 4.22 & 4.58 & 3.37 & 4.28 & 4.90 & 3.45 \\
C22:1n9 & 0.85 & 1.35 & 0.28 & 0.37 & 0.38 & 0.30 & 0.21 & 0.26 & 0.28 & 0.16 & 0.16 & 0.25 \\
C22:2n6 & 1.57 & 1.15 & 0.22 & 0.28 & 0.43 & 0.44 & 0.12 & 0.16 & 0.28 & 0.19 & 0.11 & 0.27 \\
C23:0 & 1.05 & 1.83 & 0.06 & nd & 0.19 & 0.22 & 0.08 & 0.16 & 0.51 & 0.02 & 0.20 & 0.09 \\
C22:4n6 & nd & nd & nd & nd & nd & nd & nd & nd & nd & nd & nd & 0.11 \\
C22:3n3 + C22:5n6 & 1.61 & 2.15 & 0.41 & 0.71 & 0.26 & nd & 0.54 & 0.45 & 0.86 & 0.35 & 0.80 & 0.70 \\
C22:5n3 & 2.51 & 2.82 & 0.42 & 0.56 & 0.70 & 0.62 & 0.54 & 0.33 & 1.22 & 0.47 & 0.64 & 0.49 \\
C24:0+ C22:6n3 & 4.85 & 4.48 & 1.32 & 1.60 & 1.38 & 1.34 & 1.81 & 1.48 & 2.37 & 1.18 & 1.89 & 1.39 \\
C24:1n9 & 9.34 & 10.47 & 5.31 & 7.13 & 7.58 & 6.16 & 7.79 & 8.35 & 7.30 & 6.23 & 10.65 & 6.41 \\
& 1.55 & 3.42 & 0.34 & 0.73 & 0.32 & 0.24 & 0.54 & 0.35 & 1.20 & 0.25 & 0.42 & 1.06 \\
\hline
\end{tabular}


Table B9. Striped bass liver samples from day 71.

\begin{tabular}{|c|c|c|c|c|}
\hline & \multicolumn{4}{|c|}{ Sample number } \\
\hline & 1 & 2 & 3 & 4 \\
\hline Total length (mm) & 371 & 360 & 340 & 372 \\
\hline Weight (g) & 827.1 & 778.4 & 581.3 & 795.5 \\
\hline Lipid content (\%) & 12.54 & 7.30 & 8.08 & 11.81 \\
\hline C12:0 & 0.03 & 0.02 & 0.03 & 0.02 \\
\hline C12:1n1 & nd & nd & 0.26 & nd \\
\hline $\mathrm{C} 14: 0$ & 1.83 & 1.37 & 2.69 & 1.93 \\
\hline C14:1n5 & 0.08 & 0.06 & 0.09 & 0.08 \\
\hline C15:0 & 0.17 & 0.12 & 0.28 & 0.16 \\
\hline C15:1n5 & 0.01 & 0.05 & nd & 0.01 \\
\hline C16:0 DMA & 0.01 & 0.05 & 0.02 & 0.02 \\
\hline C16:0 & 23.34 & 18.24 & 28.06 & 25.11 \\
\hline C16:1n7 & 4.38 & 2.96 & 4.58 & 4.28 \\
\hline C17:0 & 0.42 & 0.50 & 0.63 & 0.39 \\
\hline C18:0 & 6.31 & 6.04 & 6.14 & 7.05 \\
\hline $\mathrm{C} 18: 1 \mathrm{n} 12 \mathrm{t}$ & 0.13 & nd & 0.14 & nd \\
\hline C18:1n9t & 0.33 & 0.41 & 0.27 & 0.31 \\
\hline C18:1n9 & 35.43 & 26.65 & 23.77 & 33.97 \\
\hline C18:1n7 & 4.78 & 3.40 & 4.47 & 4.40 \\
\hline $\mathrm{C} 18: 2 \mathrm{n} 6$ & 0.85 & 1.27 & 1.31 & 0.81 \\
\hline C18:3n6 & 0.20 & 0.62 & 0.23 & 0.20 \\
\hline C18:3n3 & 0.57 & 1.01 & 0.60 & 0.60 \\
\hline C18:4n3 & 0.74 & 1.69 & 0.74 & 0.84 \\
\hline C20:0 & 0.12 & 0.84 & 0.14 & 0.13 \\
\hline C20:1n15 & nd & 0.16 & nd & nd \\
\hline C20:1n12 & 0.08 & nd & 0.09 & 0.09 \\
\hline
\end{tabular}


Table B9 continued. Striped bass liver samples from day 71.

\begin{tabular}{lcccc} 
& \multicolumn{4}{c}{ Sample number } \\
\hline \hline $\mathrm{C} 20: 1 \mathrm{n} 9$ & 1 & 2 & 3 & 4 \\
$\mathrm{C} 20: 1 \mathrm{n} 7$ & 2.39 & 2.43 & 2.34 & 2.62 \\
$\mathrm{C} 20: 2 \mathrm{n} 6$ & 0.20 & 1.07 & 0.22 & 0.21 \\
$\mathrm{C} 20: 3 \mathrm{n} 6$ & 0.19 & 1.16 & 0.32 & 0.20 \\
$\mathrm{C} 20: 4 \mathrm{n} 6$ & 0.09 & 1.05 & 0.12 & 0.09 \\
$\mathrm{C} 20: 3 \mathrm{n} 3$ & 1.17 & 2.66 & 1.71 & 1.15 \\
$\mathrm{C} 20: 5 \mathrm{n} 3$ & 0.13 & 0.74 & 0.14 & 0.12 \\
$\mathrm{C} 22: 0$ & 4.65 & 4.58 & 4.96 & 4.18 \\
$\mathrm{C} 22: 1 \mathrm{n} 9$ & 0.21 & 1.20 & 0.25 & 0.18 \\
$\mathrm{C} 22: 2 \mathrm{n} 6$ & 0.16 & 1.34 & 0.16 & 0.16 \\
$\mathrm{C} 22: 4 \mathrm{n} 6$ & 0.02 & 0.59 & 0.03 & 0.01 \\
$\mathrm{C} 22: 3 \mathrm{n} 3+\mathrm{C} 22: 5 \mathrm{n} 6$ & 0.51 & 2.89 & 0.51 & 0.57 \\
$\mathrm{C} 22: 5 \mathrm{n} 3$ & 0.74 & 3.17 & 0.93 & 0.76 \\
$\mathrm{C} 24: 0+\mathrm{C} 22: 6 \mathrm{n} 3$ & 9.40 & 8.31 & 13.16 & 9.00 \\
$\mathrm{C} 24: 1 \mathrm{n} 9$ & 0.33 & 2.51 & 0.45 & 0.32 \\
\hline
\end{tabular}


Table B10. Striped bass belly flap samples from day 71 .

\begin{tabular}{lcccc} 
& \multicolumn{4}{c}{ Sample number } \\
\hline \hline Total length (mm) & 1 & 2 & 3 & 4 \\
Weight (g) & 827.1 & 360 & 340 & 372 \\
Lipid content (\%) & 23.32 & 34.14 & 13.67 & 17.62 \\
C12:0 & 0.13 & 0.14 & 0.09 & 0.11 \\
C12:1n1 & nd & nd & 0.87 & nd \\
C14:0 & 5.86 & 5.86 & 6.91 & 6.02 \\
C14:1n5 & 0.24 & 0.17 & 0.21 & 0.19 \\
C15:0 & 0.76 & 0.89 & 0.85 & 0.79 \\
C15:1n5 & 0.17 & 0.20 & 0.06 & nd \\
C16:0 DMA & 0.09 & nd & nd & nd \\
C16:0 & 23.35 & 22.74 & 24.10 & 23.33 \\
C16:1n7 & 8.04 & 7.82 & 8.15 & 7.74 \\
C17:0 & 0.88 & 0.98 & 0.90 & 0.99 \\
C18:0 & 4.66 & 4.72 & 4.45 & 4.83 \\
C18:1n12t & 0.30 & 0.25 & 0.16 & 0.21 \\
C18:1n9t & 0.11 & 0.26 & 0.19 & 0.24 \\
C18:1n9 & 15.06 & 15.59 & 14.77 & 14.89 \\
C18:1n7 & 3.79 & 4.18 & 3.91 & 4.03 \\
C18:2n6 & 5.01 & 4.21 & 5.98 & 4.27 \\
C18:3n6 & 0.50 & 0.58 & 0.43 & 0.33 \\
C18:3n3 & 2.07 & 2.21 & 1.80 & 1.93 \\
C18:4n3 & 1.92 & 1.94 & 1.60 & 1.94 \\
C19:2n6 & nd & 0.14 & nd & nd \\
C20:0 & 0.39 & 0.35 & 0.22 & 0.36 \\
C20:1n15 & nd & 0.05 & 0.02 & nd \\
C20:1n12 & nd & 0.40 & 0.24 & 0.49 \\
C20:1n9 & 1.29 & 1.28 & 1.24 & 1.35 \\
\hline & & & & \\
& & & & \\
& & & &
\end{tabular}


Table B10 continued. Striped bass belly flap samples from day 71 .

Sample number

\begin{tabular}{lcccc}
\hline & 1 & 2 & 3 & 4 \\
\hline \hline $\mathrm{C} 20: 1 \mathrm{n} 7$ & 0.50 & 0.72 & 0.41 & 0.76 \\
$\mathrm{C} 20: 2 \mathrm{n} 6$ & 0.46 & 0.55 & 0.52 & 0.51 \\
$\mathrm{C} 20: 3 \mathrm{n} 6$ & 0.28 & 0.50 & 0.29 & 0.35 \\
$\mathrm{C} 21: 0$ & 0.13 & nd & nd & nd \\
$\mathrm{C} 20: 4 \mathrm{n} 6$ & 1.45 & 1.59 & 1.10 & 1.33 \\
$\mathrm{C} 20: 3 \mathrm{n} 3$ & 0.42 & 0.25 & 0.36 & 0.51 \\
$\mathrm{C} 20: 5 \mathrm{n} 3$ & 6.69 & 6.43 & 5.63 & 6.41 \\
$\mathrm{C} 22: 0$ & 0.23 & 0.39 & 0.35 & 0.43 \\
$\mathrm{C} 22: 1 \mathrm{n} 9$ & $\mathrm{nd}$ & 0.17 & 0.16 & 0.19 \\
$\mathrm{C} 22: 2 \mathrm{n} 6$ & 0.07 & 0.10 & 0.08 & $\mathrm{nd}$ \\
$\mathrm{C} 22: 4 \mathrm{n} 6$ & $\mathrm{nd}$ & $\mathrm{nd}$ & 0.32 & 0.55 \\
$\mathrm{C} 22: 3 \mathrm{n} 3+\mathrm{C} 22: 5 \mathrm{n} 6$ & 0.90 & 0.89 & 0.82 & 1.04 \\
$\mathrm{C} 22: 5 \mathrm{n} 3$ & 1.73 & 1.94 & 1.68 & 1.82 \\
$\mathrm{C} 24: 0+\mathrm{C} 22: 6 \mathrm{n} 3$ & 12.01 & 11.04 & 10.57 & 11.44 \\
$\mathrm{C} 24: 1 \mathrm{n} 9$ & 0.46 & 0.47 & 0.57 & 0.61 \\
\hline
\end{tabular}


Table B11. Striped bass liver samples from day 88.

\begin{tabular}{lcccc}
\hline & \multicolumn{4}{c}{ Sample number } \\
\hline & 1 & 2 & 3 & 4 \\
\hline Total length (mm) & 407 & 394 & 374 & 387 \\
Weight (g) & 1006.3 & 1010.8 & 696.1 & 942.6 \\
Lipid content (\%) & 9.90 & 11.72 & 8.72 & 11.14 \\
C12:0 & 0.03 & 0.03 & nd & 0.03 \\
C12:1n1 & nd & nd & 0.04 & nd \\
C13:0 & nd & nd & 0.06 & nd \\
C14:0 & 2.22 & 1.96 & 2.94 & 1.86 \\
C14:1n5 & 0.10 & 0.11 & 0.13 & 0.08 \\
C15:0 & 0.26 & 0.22 & 0.38 & 0.17 \\
C15:1n5 & nd & nd & nd & 0.01 \\
C16:0 DMA & 0.02 & 0.02 & nd & 0.01 \\
C16:0 & 26.09 & 23.97 & 18.88 & 21.36 \\
C16:1n7 & 5.14 & 5.34 & 7.13 & 4.97 \\
C17:0 & 0.55 & 0.44 & 0.54 & 0.37 \\
C18:0 & 5.73 & 5.61 & 3.58 & 4.90 \\
C18:1n12t & 0.15 & 0.13 & nd & 0.15 \\
C18:1n9t & 0.33 & 0.44 & 0.27 & 0.28 \\
C18:1n9 & 24.87 & 30.45 & 24.60 & 35.60 \\
C18:1n7 & 4.90 & 4.83 & 5.58 & 4.99 \\
C18:2n6 & 1.06 & 0.96 & 1.73 & 0.74 \\
C18:3n6 & 0.25 & 0.22 & 0.31 & 0.18 \\
C18:3n3 & 0.93 & 0.89 & 1.29 & 0.64 \\
C18:4n3 & 0.93 & 1.01 & 1.29 & 0.86 \\
C20:0 & 0.18 & 0.19 & 0.16 & 0.16 \\
C20:1n12 & 0.10 & 0.12 & 0.17 & 0.10 \\
C20:1n9 & 3.52 & 3.91 & 3.43 & 3.12 \\
C20:1n7 & 0.29 & 0.28 & 0.41 & 0.25 \\
\hline & & & & \\
& & & & \\
& & & &
\end{tabular}


Table B11 continued. Striped bass liver samples from day 88 .

\begin{tabular}{lcccc} 
& \multicolumn{4}{c}{ Sample number } \\
\hline \hline C20:2n6 & 1 & 2 & 3 & 4 \\
C20:3n6 & 0.30 & 0.28 & 0.46 & 0.23 \\
C21:0 & 0.09 & 0.09 & 0.13 & 0.10 \\
C20:4n6 & nd & nd & 0.01 & nd \\
C20:3n3 & 1.23 & 1.12 & 1.55 & 1.14 \\
C20:5n3 & 0.20 & 0.18 & 0.31 & 0.14 \\
C22:0 & 5.30 & 4.94 & 6.58 & 4.50 \\
C22:1n9 & 0.32 & 0.32 & 0.30 & 0.17 \\
C22:2n6 & 0.25 & 0.26 & 0.23 & 0.16 \\
C22:3n3 + C22:5n6 & 0.02 & 0.03 & 0.02 & 0.03 \\
C22:5n3 & 0.69 & 0.54 & 0.77 & 0.58 \\
C24:0+C22:6n3 & 1.11 & 0.84 & 1.38 & 1.05 \\
C24:1n9 & 12.36 & 9.84 & 14.76 & 10.29 \\
& 0.48 & 0.44 & 0.58 & 0.76 \\
\hline
\end{tabular}


Table B12. Striped bass belly flap samples from day 88 .

\begin{tabular}{|c|c|c|c|c|}
\hline & \multicolumn{4}{|c|}{ Sample number } \\
\hline & 1 & 2 & 3 & 4 \\
\hline Total length (mm) & 407 & 394 & 374 & 387 \\
\hline Weight (g) & 1006.3 & 1010.8 & 696.1 & 942.6 \\
\hline Lipid content (\%) & 18.62 & 25.67 & 14.40 & 16.88 \\
\hline C12:0 & 0.09 & 0.16 & 0.10 & 0.11 \\
\hline C12:1n1 & 0.62 & nd & nd & nd \\
\hline C13:0 & 0.09 & 0.11 & nd & 0.13 \\
\hline C14:0 & 6.71 & 6.13 & 5.65 & 6.59 \\
\hline C14:1n5 & 0.22 & 0.25 & 0.20 & 0.19 \\
\hline C15:0 & 0.83 & 0.86 & 0.80 & 0.90 \\
\hline C15:1n5 & nd & 0.06 & nd & 0.01 \\
\hline C16:0 DMA & 0.03 & 0.08 & nd & nd \\
\hline C16:0 & 24.48 & 23.93 & 23.64 & 24.66 \\
\hline C16:1n7 & 7.77 & 7.98 & 7.79 & 8.15 \\
\hline C17:0 & 0.85 & 0.87 & 0.89 & 1.03 \\
\hline C18:0 & 4.34 & 4.24 & 4.78 & 4.58 \\
\hline C18:1n12t & 0.14 & 0.20 & 0.19 & 0.20 \\
\hline C18:1n9t & 0.19 & 0.20 & 0.23 & nd \\
\hline C18:1n7t & 0.08 & nd & 0.08 & nd \\
\hline C18:1n9 & 13.48 & 15.36 & 15.08 & 14.24 \\
\hline C18:1n7 & 3.86 & 3.89 & 3.98 & 4.15 \\
\hline C18:2n6 & 3.88 & 4.23 & 4.49 & 4.19 \\
\hline C18:3n6 & 0.56 & 0.35 & 0.37 & 0.43 \\
\hline C18:3n3 & 2.31 & 2.30 & 1.91 & 2.17 \\
\hline C18:4n3 & 2.11 & 2.22 & 1.59 & 2.00 \\
\hline C20:0 & 0.31 & 0.27 & 0.27 & 0.28 \\
\hline C20:1n15 & nd & 0.06 & 0.06 & 0.06 \\
\hline C20:1n12 & 0.32 & 0.31 & 0.40 & 0.36 \\
\hline
\end{tabular}


Table B12 continued. Striped bass belly flap samples from day 88 .

Sample number

\begin{tabular}{lcccc}
\hline & 1 & 2 & 3 & 4 \\
\hline \hline $\mathrm{C} 20: 1 \mathrm{n} 9$ & 1.37 & 1.41 & 1.37 & 1.30 \\
$\mathrm{C} 20: 1 \mathrm{n} 7$ & 0.36 & 0.45 & 0.50 & 0.55 \\
$\mathrm{C} 20: 2 \mathrm{n} 6$ & 0.54 & 0.53 & 0.61 & 0.50 \\
$\mathrm{C} 20: 3 \mathrm{n} 6$ & 0.20 & 0.25 & 0.29 & 0.30 \\
$\mathrm{C} 21: 0$ & 0.07 & $\mathrm{nd}$ & $\mathrm{nd}$ & $\mathrm{nd}$ \\
$\mathrm{C} 20: 4 \mathrm{n} 6$ & 1.06 & 1.07 & 1.32 & 1.01 \\
$\mathrm{C} 20: 3 \mathrm{n} 3$ & 0.50 & 0.46 & 0.37 & 0.39 \\
$\mathrm{C} 20: 5 \mathrm{n} 3$ & 6.31 & 6.09 & 6.31 & 6.27 \\
$\mathrm{C} 22: 0$ & 0.37 & 0.47 & 0.36 & 0.19 \\
$\mathrm{C} 22: 1 \mathrm{n} 9$ & 0.17 & 0.18 & 0.16 & $\mathrm{nd}$ \\
$\mathrm{C} 22: 2 \mathrm{n} 6$ & 0.07 & $\mathrm{nd}$ & 0.05 & 0.14 \\
$\mathrm{C} 22: 4 \mathrm{n} 6$ & 0.42 & 0.38 & 0.59 & 0.47 \\
$\mathrm{C} 22: 3 \mathrm{n} 3+\mathrm{C} 22: 5 \mathrm{n} 6$ & 0.98 & 1.07 & 0.99 & 0.83 \\
$\mathrm{C} 22: 5 \mathrm{n} 3$ & 1.80 & 1.84 & 1.86 & 1.81 \\
$\mathrm{C} 24: 0+\mathrm{C} 22: 6 \mathrm{n} 3$ & 11.97 & 11.08 & 12.16 & 11.24 \\
$\mathrm{C} 24: 1 \mathrm{n} 9$ & 0.56 & 0.67 & 0.57 & 0.57 \\
\hline
\end{tabular}




\section{Chapter 4 Raw Data}

Values for length $(\mathrm{mm})$, weight $(\mathrm{g})$, lipid content (\% wet weight) and fatty acids routinely identified for striped bass belly flap samples analyzed in Chapter 4 of this experiment. Small, medium and large refers to the size class of striped bass.

Table C1. Striped bass belly flap samples from day 0.

\begin{tabular}{|c|c|c|c|c|c|c|c|c|c|c|c|c|}
\hline & \multicolumn{12}{|c|}{ Sample number } \\
\hline & \multicolumn{4}{|c|}{ Small } & \multicolumn{4}{|c|}{ Medium } & \multicolumn{4}{|c|}{ Large } \\
\hline & 1 & 2 & 3 & 4 & 1 & 2 & 3 & 4 & 1 & 2 & 3 & 4 \\
\hline Total length (mm) & 163 & 176 & 167 & 164 & 312 & 302 & 282 & 318 & 379 & 388 & 368 & 420 \\
\hline Weight (g) & 74 & 92 & 82 & 78 & 528 & 560 & 508 & 750 & 996 & 1108 & 870 & 1538 \\
\hline Lipid content (\%) & 4.75 & 6.10 & 5.83 & 6.31 & 1.98 & 8.16 & 15.93 & 15.68 & 13.49 & 2.43 & 5.58 & 12.58 \\
\hline C12:0 & 0.06 & 0.24 & 0.13 & 0.15 & 0.10 & 0.10 & 0.02 & 0.01 & 0.15 & nd & 0.11 & nd \\
\hline C13:0 & 0.39 & 0.41 & 0.48 & 0.34 & 0.49 & 0.22 & 0.14 & 0.19 & 0.35 & 1.49 & 0.27 & nd \\
\hline C14:0 & 3.90 & 5.15 & 4.35 & 4.04 & 3.52 & 3.58 & 3.89 & 3.75 & 4.54 & 4.59 & 3.43 & 3.94 \\
\hline C14:1n5 & 0.15 & 0.10 & 0.17 & 0.12 & 0.07 & 0.12 & 0.18 & 0.18 & 0.20 & nd & 0.15 & nd \\
\hline C15:0 & 1.19 & 1.55 & 1.56 & 1.19 & 1.04 & 1.20 & 1.27 & 1.24 & 1.39 & 1.49 & 1.13 & 1.19 \\
\hline C16:0 DMA & 0.44 & 0.31 & 0.37 & 0.44 & 0.64 & 0.25 & 0.28 & 0.26 & 0.24 & 0.56 & 0.37 & 0.49 \\
\hline C16:0 & 26.62 & 26.37 & 27.08 & 26.00 & 27.05 & 27.91 & 25.85 & 27.63 & 25.70 & 30.21 & 26.81 & 25.05 \\
\hline C16:1n7 & 6.54 & 7.90 & 7.29 & 6.28 & 6.12 & 6.30 & 7.04 & 6.91 & 8.07 & 6.91 & 7.10 & 8.13 \\
\hline C17:0 & 1.41 & 1.31 & 1.27 & 1.11 & 1.10 & 1.18 & 1.06 & 1.19 & 1.20 & 1.37 & 1.04 & 1.08 \\
\hline C18:0 & 7.04 & 5.84 & 6.13 & 6.61 & 7.02 & 5.67 & 5.57 & 6.10 & 6.07 & 7.86 & 5.93 & 6.51 \\
\hline C18:1n12t & 1.03 & 0.96 & 0.99 & 0.56 & 0.96 & 0.51 & 0.48 & 0.54 & 0.60 & 0.77 & 0.60 & 0.69 \\
\hline C18:1n9t & nd & nd & nd & nd & nd & 0.40 & nd & 0.38 & nd & nd & 0.41 & nd \\
\hline C18:1n7t & 0.16 & nd & nd & nd & nd & nd & nd & nd & nd & nd & nd & nd \\
\hline C18:1n9 & 14.81 & 13.94 & 14.27 & 14.32 & 12.25 & 16.28 & 17.30 & 17.30 & 17.44 & 15.13 & 17.86 & 18.84 \\
\hline C18:1n7 & 4.68 & 4.29 & 3.99 & 3.94 & 3.58 & 3.80 & 4.03 & 4.11 & 4.08 & 3.63 & 4.19 & 4.37 \\
\hline C18:2n6 & 2.72 & 2.23 & 1.87 & 3.27 & 1.34 & 1.43 & 1.81 & 1.69 & 1.55 & 1.12 & 1.32 & 3.01 \\
\hline C18:3n6 & nd & nd & nd & nd & nd & 0.11 & nd & nd & nd & nd & 0.11 & nd \\
\hline C18:3n3 & 0.89 & 1.11 & 0.91 & 0.76 & 0.77 & 0.87 & 0.97 & 0.93 & 0.93 & 0.77 & 0.90 & 1.42 \\
\hline $\mathrm{C} 18: 4 \mathrm{n} 3$ & 0.50 & 0.80 & 0.63 & 0.81 & 0.47 & 0.59 & 0.52 & 0.54 & 0.60 & 0.47 & 0.47 & 0.68 \\
\hline
\end{tabular}


Table C1 continued. Striped bass belly flap samples from day 0 .

\begin{tabular}{|c|c|c|c|c|c|c|c|c|c|c|c|c|}
\hline & \multicolumn{12}{|c|}{ Sample number } \\
\hline & \multicolumn{4}{|c|}{ Small } & \multicolumn{4}{|c|}{ Medium } & \multicolumn{4}{|c|}{ Large } \\
\hline & 1 & 2 & 3 & 4 & 1 & 2 & 3 & 4 & 1 & 2 & 3 & 4 \\
\hline C20:0 & 1.18 & 1.12 & 1.14 & 1.13 & 1.17 & 1.09 & 1.23 & 1.20 & 1.32 & 1.36 & 1.34 & 1.24 \\
\hline C20:1n15 & nd & nd & 0.08 & nd & nd & nd & nd & nd & nd & nd & nd & nd \\
\hline $\mathrm{C} 20: 2 \mathrm{n} 6$ & 0.75 & 0.71 & 0.53 & 0.65 & 0.60 & 0.59 & 0.58 & 0.59 & 0.75 & 0.68 & 0.55 & 0.57 \\
\hline C20:3n6 & 0.13 & 0.12 & 0.10 & nd & 0.10 & 0.10 & 0.16 & 0.13 & 0.13 & nd & 0.12 & nd \\
\hline$C 20: 4 n 6$ & 2.36 & 2.28 & 2.60 & 2.21 & 2.66 & 1.84 & 2.01 & 1.94 & 2.40 & 2.22 & 2.45 & 2.13 \\
\hline$C 20: 3 n 3$ & 0.45 & 0.31 & 0.45 & 0.35 & 0.33 & 0.35 & 0.47 & 0.36 & 0.38 & 0.27 & 0.20 & 0.32 \\
\hline$C 20: 5 n 3$ & 4.61 & 5.58 & 5.41 & 5.49 & 5.29 & 4.44 & 4.99 & 4.90 & 4.85 & 3.80 & 4.42 & 3.62 \\
\hline C22:0 & 1.43 & 1.81 & 1.77 & 2.07 & 2.25 & 1.99 & 1.84 & 1.90 & 1.78 & 1.60 & 1.87 & 1.63 \\
\hline C22:1n9 & 0.22 & 0.19 & 0.18 & 0.07 & 0.24 & 0.26 & 0.23 & 0.22 & nd & nd & nd & nd \\
\hline $\mathrm{C} 22: 2 \mathrm{n} 6$ & nd & nd & nd & nd & nd & 0.06 & nd & nd & nd & nd & nd & nd \\
\hline C22:4n6 & 0.59 & 0.69 & 0.61 & 0.60 & 0.06 & 0.55 & 0.57 & 0.63 & 0.87 & 0.51 & 0.72 & 1.04 \\
\hline$C 22: 3 n 3+C 22: 5 n 6$ & 0.62 & 0.87 & 0.68 & 0.76 & 0.08 & 0.71 & 0.62 & 0.71 & 0.62 & 0.58 & 0.82 & 0.62 \\
\hline$C 22: 5 n 3$ & 1.95 & 2.02 & 2.00 & 1.88 & 2.44 & 2.55 & 2.47 & 2.29 & 0.07 & 2.11 & 2.22 & 2.67 \\
\hline$C 22: 6 n 3+C 24: 0$ & 10.59 & 10.13 & 10.85 & 12.78 & 15.96 & 12.14 & 11.30 & 9.59 & 9.86 & 7.56 & 9.74 & 7.94 \\
\hline C24:1n9 & 0.35 & 0.30 & 0.32 & 0.28 & 0.60 & 0.44 & 0.45 & 0.23 & 0.26 & 0.22 & 0.18 & nd \\
\hline
\end{tabular}


Table C2. Striped bass belly flap samples from day 13.

\begin{tabular}{|c|c|c|c|c|c|c|c|c|c|c|c|c|}
\hline & \multicolumn{12}{|c|}{ Sample number } \\
\hline & \multicolumn{4}{|c|}{ Small } & \multicolumn{4}{|c|}{ Medium } & \multicolumn{4}{|c|}{ Large } \\
\hline & 1 & 2 & 3 & 4 & 1 & 2 & 3 & 4 & 1 & 2 & 3 & 4 \\
\hline Total length (mm) & 170 & 168 & 166 & 216 & 299 & 312 & 331 & 304 & 455 & 413 & 365 & 407 \\
\hline Weight (g) & 92.1 & 100.6 & 96.4 & 246.4 & 504.5 & 664.7 & 722.6 & 590.9 & 1814.2 & 1344.0 & 994.2 & 1154.1 \\
\hline Lipid content (\%) & 5.92 & 2.74 & 3.47 & 11.88 & 11.08 & 7.44 & 4.98 & 5.07 & 7.55 & 2.49 & 3.98 & 1.64 \\
\hline $\mathrm{C} 12: 0$ & 0.12 & 0.12 & nd & nd & nd & 0.11 & nd & 0.12 & 0.17 & nd & 0.54 & nd \\
\hline C13:0 & 0.21 & 0.24 & nd & nd & nd & 0.19 & 0.44 & nd & 0.34 & nd & nd & nd \\
\hline C14:0 & 4.13 & 4.31 & 4.51 & 4.77 & 4.23 & 3.72 & 4.18 & 3.85 & 5.27 & 4.01 & 3.14 & 3.46 \\
\hline C14:1n5 & 0.15 & 0.11 & nd & nd & 0.26 & 0.15 & 0.20 & 0.16 & 0.49 & 1.15 & nd & 0.21 \\
\hline C15:0 & 1.40 & 1.26 & 1.19 & 1.72 & 1.46 & 1.23 & 1.28 & 1.32 & 1.66 & 1.78 & 1.30 & 1.01 \\
\hline C16:0 DMA & 0.33 & 0.32 & 0.50 & 1.62 & 0.49 & 0.47 & 0.25 & 0.44 & 0.66 & nd & 0.99 & 0.90 \\
\hline C16:0 & 27.63 & 30.01 & 28.18 & 22.75 & 26.62 & 27.90 & 26.95 & 29.61 & 23.95 & 21.26 & 26.44 & 30.10 \\
\hline C16:1n7 & 7.06 & 6.88 & 6.83 & 6.41 & 7.14 & 6.84 & 6.39 & 6.11 & 8.01 & 4.24 & 4.32 & 5.18 \\
\hline C17:0 & 1.40 & 1.25 & 1.30 & 1.96 & 1.30 & 1.17 & 1.40 & 1.35 & 1.39 & 3.77 & 1.67 & 1.17 \\
\hline C18:0 & 7.12 & 7.46 & 8.00 & 6.39 & 6.26 & 6.17 & 6.69 & 7.10 & 6.41 & 11.86 & 7.87 & 10.26 \\
\hline C18:1n12t & 0.49 & 0.49 & 0.83 & 1.46 & 0.55 & 0.45 & 0.54 & 0.55 & 0.51 & nd & 0.60 & 0.77 \\
\hline C18:1n9t & nd & nd & nd & nd & 0.37 & nd & nd & nd & nd & nd & nd & nd \\
\hline C18:1n7t & nd & nd & nd & 0.56 & nd & 0.13 & nd & nd & nd & nd & nd & nd \\
\hline C18:1n9 & 15.85 & 14.89 & 17.16 & 14.89 & 16.67 & 16.76 & 15.04 & 16.51 & 15.14 & 9.25 & 13.07 & 14.12 \\
\hline C18:1n7 & 3.62 & 3.44 & 3.64 & 3.41 & 3.56 & 3.49 & 3.51 & 3.66 & 3.69 & 4.65 & 2.52 & 4.77 \\
\hline $\mathrm{C} 18 \mathrm{2n} 6 \mathrm{t}$ & nd & nd & nd & 1.54 & nd & nd & nd & nd & nd & nd & nd & nd \\
\hline C18:2n6 & 1.95 & 1.80 & 3.37 & 2.37 & 1.96 & 1.89 & 1.54 & 2.34 & 1.64 & 6.37 & 0.96 & 0.87 \\
\hline C18:3n6 & 0.11 & 0.14 & nd & nd & 0.11 & 0.16 & 0.20 & nd & 0.18 & nd & nd & nd \\
\hline C18:3n3 & 1.07 & 0.93 & 0.99 & 0.90 & 0.88 & 1.01 & 0.77 & 1.18 & 1.21 & nd & 1.58 & 0.43 \\
\hline C18:4n3 & 0.60 & 0.62 & 0.38 & 1.66 & 0.91 & 0.68 & 0.55 & 0.74 & 1.18 & nd & 1.22 & 0.51 \\
\hline C19:2n6 & 0.06 & nd & nd & nd & nd & 0.06 & nd & nd & 0.24 & 1.87 & nd & 0.20 \\
\hline$C 20: 0$ & 1.38 & 1.23 & 1.71 & 1.40 & 1.40 & 1.26 & 1.10 & 1.40 & 1.85 & 3.26 & 1.41 & 1.29 \\
\hline C20:1n15 & nd & 0.09 & nd & 0.81 & nd & 0.09 & 0.09 & nd & nd & nd & nd & nd \\
\hline
\end{tabular}


Table C2 continued. Striped bass belly flap samples from day 13.

\begin{tabular}{|c|c|c|c|c|c|c|c|c|c|c|c|c|}
\hline & \multicolumn{12}{|c|}{ Sample number } \\
\hline & \multicolumn{4}{|c|}{ Small } & \multicolumn{4}{|c|}{ Medium } & \multicolumn{4}{|c|}{ Large } \\
\hline & 1 & 2 & 3 & 4 & 1 & 2 & 3 & 4 & 1 & 2 & 3 & 4 \\
\hline C20:1n9 & 1.82 & 1.64 & 1.98 & 1.95 & 1.76 & 1.64 & 1.65 & 1.74 & 2.28 & nd & 1.92 & 2.40 \\
\hline C20:1n7 & 2.07 & 1.43 & 1.67 & 1.75 & 1.39 & 1.29 & 1.58 & 1.25 & 2.17 & nd & 1.76 & 1.23 \\
\hline$C 20: 2 n 6$ & 0.75 & 0.59 & 0.96 & 2.11 & 0.87 & 0.67 & 0.76 & 0.75 & 0.91 & nd & 0.88 & 0.68 \\
\hline C20:3n6 & 0.16 & 0.14 & nd & nd & 0.22 & 0.30 & 0.20 & 0.42 & 0.17 & 3.44 & 0.42 & nd \\
\hline C21:0 & nd & nd & nd & nd & nd & nd & nd & 0.27 & nd & 4.05 & nd & nd \\
\hline C20:4n6 & 2.42 & 2.20 & 2.29 & 2.14 & 2.34 & 2.16 & 1.83 & 1.87 & 2.20 & nd & 2.48 & 2.43 \\
\hline$C 20: 3 n 3$ & 0.47 & 0.31 & nd & 0.58 & 0.38 & 0.37 & 0.38 & 0.40 & 0.70 & nd & 0.80 & 0.37 \\
\hline C20:5n3 & 4.09 & 3.80 & 3.16 & 4.13 & 4.59 & 4.31 & 2.82 & 3.42 & 3.91 & nd & 2.67 & 2.58 \\
\hline $\mathrm{C} 22: 0$ & 1.70 & 1.67 & 1.48 & 1.87 & 1.84 & 1.85 & 1.62 & 1.65 & 1.93 & nd & 1.85 & 1.82 \\
\hline C22:1n9 & 0.27 & 0.19 & nd & 0.67 & 0.21 & 0.12 & 0.43 & 0.40 & 0.42 & 1.58 & 0.37 & 0.41 \\
\hline $\mathrm{C} 22: 2 \mathrm{n} 6$ & nd & nd & nd & 0.46 & 0.10 & 0.05 & 0.45 & 0.09 & 0.11 & 2.88 & nd & 0.09 \\
\hline C23:0 & 0.02 & nd & nd & 0.47 & 0.16 & 0.03 & 0.32 & 0.23 & nd & nd & nd & nd \\
\hline C22:4n6 & 0.66 & 0.53 & 0.67 & nd & 0.62 & 0.55 & 1.29 & 0.58 & nd & 7.84 & 1.62 & 0.76 \\
\hline$C 22: 3 n 3+C 22: 5 n 6$ & nd & nd & 0.51 & nd & 0.68 & 0.69 & 2.12 & 0.89 & 0.66 & 1.75 & nd & 0.92 \\
\hline$C 22: 5 n 3$ & 1.99 & 2.11 & 1.58 & 2.39 & 1.87 & 1.83 & 2.41 & 1.35 & 2.96 & nd & 9.13 & 1.35 \\
\hline$C 24: 0+C 22: 6 n 3$ & 8.51 & 9.44 & 7.11 & 6.43 & 8.29 & 9.93 & 9.43 & 7.81 & 6.71 & 2.04 & 8.46 & 9.25 \\
\hline C24:1n9 & 0.38 & 0.38 & nd & 0.45 & 0.50 & 0.29 & 1.58 & 0.44 & 0.87 & 2.94 & nd & 0.45 \\
\hline
\end{tabular}


Table C3.Small and medium striped bass belly flap samples from day 28 .

Sample number

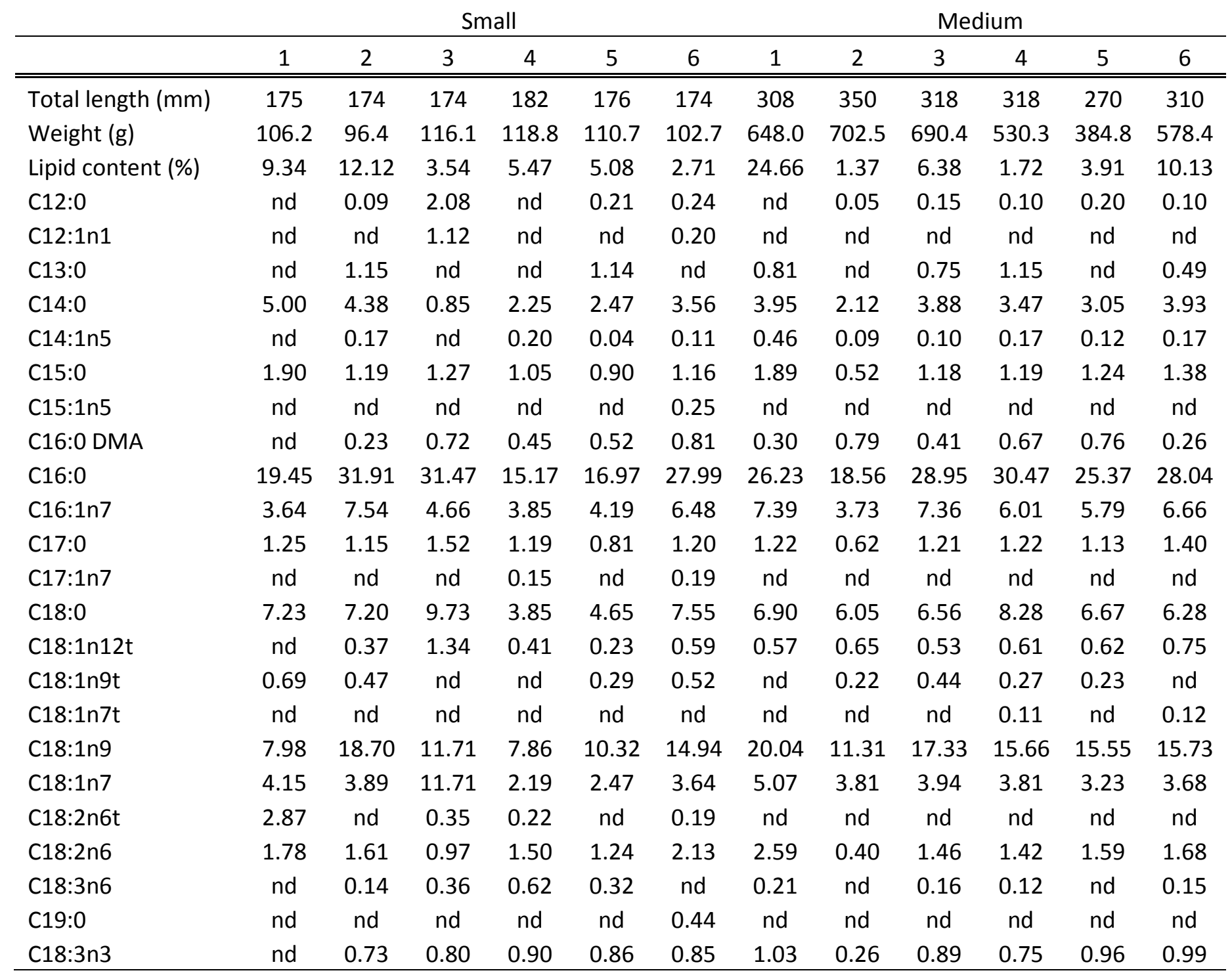


Table C3 continued. Small and medium striped bass belly flap samples from day 28.

\begin{tabular}{|c|c|c|c|c|c|c|c|c|c|c|c|c|}
\hline & \multicolumn{12}{|c|}{$\underline{\text { Sample number }}$} \\
\hline & \multicolumn{6}{|c|}{ Small } & \multicolumn{6}{|c|}{ Medium } \\
\hline & 1 & 2 & 3 & 4 & 5 & 6 & 1 & 2 & 3 & 4 & 5 & 6 \\
\hline C18:4n3 & 3.77 & 0.61 & 0.95 & 0.68 & 0.82 & 1.00 & 1.10 & 0.16 & 0.62 & 0.35 & 0.72 & 0.75 \\
\hline C19:2n6 & 1.84 & 0.06 & nd & 0.50 & nd & nd & nd & 0.07 & 0.07 & 0.09 & 0.11 & 0.04 \\
\hline C20:0 & 5.41 & 1.03 & 1.81 & 1.64 & 0.77 & 1.64 & 1.55 & 1.04 & 1.21 & 1.39 & 1.26 & 1.26 \\
\hline C20:1n15 & 1.45 & 0.07 & nd & 0.38 & 0.26 & nd & 0.39 & 0.15 & 0.09 & nd & nd & 0.10 \\
\hline C20:1n12 & 4.88 & nd & nd & 1.55 & nd & nd & nd & nd & nd & nd & nd & nd \\
\hline C20:1n9 & 2.14 & 2.17 & 2.08 & 1.90 & 1.97 & 2.09 & 2.15 & 2.34 & 1.87 & 1.67 & 1.46 & 1.87 \\
\hline C20:1n7 & 0.58 & 1.00 & 1.47 & 1.38 & 1.32 & 1.62 & 1.84 & 0.98 & 1.37 & 1.31 & 1.30 & 1.35 \\
\hline C20:2n6 & 0.61 & 0.04 & nd & 1.47 & 1.19 & 0.65 & 1.08 & 0.63 & 0.69 & 0.59 & 0.86 & 0.76 \\
\hline C20:3n6 & 2.64 & 0.11 & nd & 1.41 & 0.86 & 0.46 & nd & 0.37 & 0.12 & 0.19 & 0.21 & 0.15 \\
\hline C21:0 & 1.03 & 0.05 & 0.26 & 0.87 & 0.26 & nd & nd & nd & nd & nd & 0.30 & nd \\
\hline C20:4n6 & nd & 1.32 & 1.28 & 1.97 & 2.25 & 2.09 & 2.29 & 2.13 & 2.08 & 2.50 & 3.16 & 1.84 \\
\hline$C 20: 3 n 3$ & nd & 0.25 & nd & 1.13 & 0.89 & 0.31 & 0.36 & 0.49 & 0.28 & 0.39 & 0.45 & 0.35 \\
\hline$C 20: 5 n 3$ & nd & 2.56 & 1.57 & 4.18 & 4.73 & 2.89 & 3.49 & 3.74 & 3.50 & 2.71 & 4.13 & 4.03 \\
\hline$C 22: 0$ & 8.67 & 1.06 & 1.82 & 3.45 & 2.48 & 1.62 & 1.48 & 3.12 & 1.49 & 1.57 & 2.17 & 1.81 \\
\hline C22:1n9 & 2.97 & 0.27 & 0.40 & 1.96 & 2.19 & 0.37 & 0.40 & 1.32 & 0.23 & 0.24 & 0.44 & 0.25 \\
\hline $\mathrm{C} 22: 2 \mathrm{n} 6$ & 0.91 & 0.06 & 0.86 & nd & 1.74 & 0.26 & 0.64 & nd & 0.20 & 0.07 & 0.12 & nd \\
\hline C23:0 & nd & 0.06 & nd & 3.24 & nd & nd & nd & nd & nd & nd & 0.28 & nd \\
\hline $\mathrm{C} 22: 4 \mathrm{n} 6$ & 1.56 & 0.39 & 0.85 & 3.83 & 2.91 & 0.61 & 0.74 & 2.22 & 0.56 & 0.48 & 0.90 & 0.51 \\
\hline$C 22: 3 n 3+C 22: 5 n 6$ & nd & 0.40 & 0.65 & 3.42 & 3.94 & 0.74 & 1.24 & 4.46 & 0.55 & 0.76 & 1.07 & 0.67 \\
\hline$C 22: 5 n 3$ & 2.37 & 1.10 & 1.04 & 7.27 & 7.27 & 1.28 & 2.06 & 5.34 & 1.64 & 1.23 & 2.04 & 2.16 \\
\hline$C 24: 0+C 22: 6 n 3$ & 2.33 & 6.17 & 4.32 & 15.93 & 13.78 & 8.71 & 0.54 & 16.99 & 7.92 & 8.99 & 12.50 & 9.93 \\
\hline C24:1n9 & 0.92 & 0.31 & nd & nd & 2.74 & 0.61 & nd & 5.26 & 0.22 & 0.30 & nd & 0.37 \\
\hline
\end{tabular}


Table C4. Large striped bass belly flap samples from day 28 .

Sample number

\begin{tabular}{|c|c|c|c|c|c|c|}
\hline & \multicolumn{6}{|c|}{ Large } \\
\hline & 1 & 2 & 3 & 4 & 5 & 6 \\
\hline Total length (mm) & 409 & 382 & 407 & 391 & 430 & 410 \\
\hline Weight (g) & 1340.1 & 1230.3 & 1192.9 & 1168.6 & 1310.8 & 1296.0 \\
\hline Lipid content (\%) & 11.44 & 8.20 & 2.10 & 19.95 & 0.72 & 3.07 \\
\hline C12:0 & 0.15 & 0.12 & nd & 0.16 & 0.07 & 0.08 \\
\hline $\mathrm{C} 12: 1 \mathrm{n} 1$ & nd & nd & nd & nd & nd & nd \\
\hline C13:0 & 0.52 & 0.41 & 32.71 & 0.34 & 0.34 & 0.13 \\
\hline $\mathrm{C} 14: 0$ & 3.75 & 5.93 & nd & 4.41 & 3.20 & 2.55 \\
\hline C14:1n5 & 0.15 & 0.22 & nd & 0.15 & 0.20 & 0.10 \\
\hline $\mathrm{C} 15: 0$ & 1.12 & 1.27 & nd & 1.27 & 0.73 & 0.81 \\
\hline C15:1n5 & nd & nd & nd & 0.07 & nd & nd \\
\hline C16:0 DMA & 0.30 & 0.33 & 1.56 & 0.33 & 0.48 & 0.60 \\
\hline C16:0 & 27.20 & 26.69 & 8.49 & 25.45 & 26.30 & 27.13 \\
\hline $\mathrm{C} 16: 1 \mathrm{n} 7$ & 7.72 & 8.70 & nd & 7.63 & 8.44 & 5.78 \\
\hline C17:0 & 1.07 & 1.13 & 1.69 & 1.20 & 0.69 & 0.87 \\
\hline $\mathrm{C} 17: 1 \mathrm{n} 7$ & 0.09 & nd & nd & nd & nd & nd \\
\hline C18:0 & 6.87 & 5.94 & 4.99 & 6.34 & 6.38 & 6.69 \\
\hline $\mathrm{C} 18: 1 \mathrm{n} 12 \mathrm{t}$ & 0.58 & 0.46 & nd & 0.59 & 0.58 & 0.57 \\
\hline C18:1n9t & 0.39 & 0.26 & 6.62 & 0.33 & 0.35 & 0.33 \\
\hline $\mathrm{C} 18: 1 \mathrm{n} 7 \mathrm{t}$ & nd & nd & 1.15 & nd & nd & nd \\
\hline C18:1n9 & 22.26 & 14.06 & 5.23 & 17.10 & 20.23 & 14.80 \\
\hline C18:1n7 & 4.61 & 3.97 & nd & 4.28 & 4.43 & 3.64 \\
\hline $\mathrm{C} 18: 2 \mathrm{n} 6 \mathrm{t}$ & nd & nd & nd & nd & nd & nd \\
\hline C18:2n6 & 1.92 & 1.85 & 3.53 & 1.71 & 0.98 & 1.20 \\
\hline C18:3n6 & 0.12 & 0.17 & 1.06 & 0.20 & 0.08 & 0.11 \\
\hline C19:0 & nd & nd & 2.47 & 0.07 & nd & nd \\
\hline C18:3n3 & 0.82 & 1.20 & nd & 1.13 & 0.46 & 0.67 \\
\hline
\end{tabular}


Table C4 continued. Large striped bass belly flap samples from day 28.

\section{Sample number}

\begin{tabular}{|c|c|c|c|c|c|c|}
\hline & \multicolumn{6}{|c|}{ Large } \\
\hline & 1 & 2 & 3 & 4 & 5 & 6 \\
\hline C18:4n3 & 0.36 & 1.23 & 2.33 & 1.14 & 0.23 & 0.60 \\
\hline C19:2n6 & 0.02 & nd & 3.86 & 0.10 & 0.07 & 0.09 \\
\hline C20:0 & 1.20 & 1.15 & 2.83 & 1.35 & 1.07 & 1.12 \\
\hline C20:1n15 & 0.08 & 0.10 & 2.42 & nd & 0.10 & nd \\
\hline $\mathrm{C} 20: 1 \mathrm{n} 12$ & nd & nd & nd & nd & nd & nd \\
\hline C20:1n9 & 2.47 & 1.64 & nd & 2.28 & 2.50 & 1.78 \\
\hline C20:1n7 & 1.94 & 1.08 & 1.62 & 1.44 & 1.64 & 0.81 \\
\hline $\mathrm{C} 20: 2 \mathrm{n} 6$ & 0.75 & 0.59 & 1.13 & 0.74 & 0.61 & 0.54 \\
\hline C20:3n6 & 0.17 & 0.17 & nd & 0.46 & 0.12 & 0.11 \\
\hline C21:0 & nd & nd & nd & nd & nd & nd \\
\hline C20:4n6 & 1.51 & 1.75 & nd & 1.78 & 2.34 & 2.50 \\
\hline$C 20: 3 n 3$ & 0.27 & 0.29 & 3.14 & 0.39 & 0.15 & 0.24 \\
\hline$C 20: 5 n 3$ & 2.19 & 4.91 & 2.33 & 3.85 & 2.66 & 4.90 \\
\hline C22:0 & 1.18 & 1.98 & 3.31 & 1.84 & 1.70 & 2.22 \\
\hline C22:1n9 & 0.29 & 0.26 & 0.58 & 0.31 & 0.29 & 0.21 \\
\hline $\mathrm{C} 22: 2 \mathrm{n} 6$ & 0.07 & 0.08 & 1.52 & 0.24 & 0.10 & 0.08 \\
\hline$C 23: 0$ & nd & nd & nd & nd & nd & 0.01 \\
\hline C22:4n6 & 0.61 & 0.50 & 1.74 & 0.73 & 0.75 & 0.47 \\
\hline$C 22: 3 n 3+C 22: 5 n 6$ & 0.59 & 0.58 & nd & 0.66 & 0.65 & 0.77 \\
\hline$C 22: 5 n 3$ & 1.56 & 0.05 & nd & 1.98 & 2.51 & 2.33 \\
\hline$C 24: 0+C 22: 6 n 3$ & 4.90 & 10.45 & 3.68 & 7.95 & 8.17 & 14.70 \\
\hline C24:1n9 & 0.35 & 0.50 & nd & 0.56 & 0.40 & 0.44 \\
\hline
\end{tabular}




\section{Chapter 5 Raw Data}

Values for length $(\mathrm{mm})$, weight $(\mathrm{g})$, lipid content (\% wet weight) and fatty acids routinely identified for striped bass liver and belly flap samples analyzed in Chapter 5 of this experiment. Mixed diets shown are a homogenous mixture of spot and menhaden samples and do not have a length measurement.

Table D1. Menhaden and spot (70:30 by weight) diet mixture.

\begin{tabular}{lrrrrrrrr}
\hline & \multicolumn{7}{c}{ Sample number } \\
\hline & \multicolumn{1}{c}{1} & \multicolumn{1}{c}{2} & \multicolumn{1}{c}{3} & \multicolumn{1}{c}{4} & \multicolumn{1}{c}{6} & \multicolumn{1}{c}{7} & \multicolumn{1}{c}{8} & \multicolumn{1}{c}{9} \\
\hline Weight (g) & 6.34 & 4.80 & 5.76 & 5.44 & 5.72 & 5.38 & 4.55 & 4.37 \\
Lipid content (\%) & 6.58 & 6.29 & 9.76 & 6.18 & 6.48 & 6.14 & 5.67 & 5.41 \\
C12:0 & 0.24 & 0.11 & 0.10 & 0.13 & 0.12 & 0.12 & 0.10 & 0.10 \\
C12:1n1 & 0.04 & 0.02 & 0.02 & 0.03 & 0.00 & 0.03 & 0.02 & 0.02 \\
C13:0 & 0.44 & 0.30 & 0.22 & 0.24 & 0.29 & 0.22 & 0.24 & 0.20 \\
C14:0 & 10.12 & 5.62 & 5.47 & 5.41 & 5.56 & 6.02 & 6.89 & 5.81 \\
C14:1n5 & 0.21 & 0.06 & 0.12 & 0.08 & 0.08 & 0.07 & 0.11 & 0.08 \\
C15:0 & 3.32 & 1.44 & 1.62 & 1.77 & 1.84 & 1.57 & 1.82 & 1.64 \\
C16:0 & 40.14 & 31.52 & 30.30 & 30.53 & 29.25 & 22.75 & 22.23 & 22.05 \\
C16:1n7 & 12.57 & 6.30 & 7.23 & 6.74 & 7.01 & 6.97 & 7.61 & 6.82 \\
C17:0 & 4.97 & 2.23 & 2.42 & 2.52 & 2.82 & 2.24 & 2.70 & 2.79 \\
C18:0 & 17.61 & 8.83 & 8.24 & 9.12 & 9.31 & 7.41 & 9.86 & 9.58 \\
C18:1n9 & 20.44 & 10.10 & 11.37 & 10.18 & 10.70 & 8.03 & 10.04 & 11.76 \\
C18:1n7 & 7.38 & 3.75 & 3.61 & 3.77 & 3.67 & 3.33 & 4.30 & 3.96 \\
C18:2n6 & 3.35 & 1.71 & 1.65 & 1.77 & 1.64 & 1.66 & 1.66 & 2.04 \\
C18:3n6 & 0.31 & 0.12 & 0.15 & 0.16 & 0.14 & 0.27 & 0.21 & 0.18 \\
C19:0 & 0.96 & 0.39 & 0.47 & 0.50 & 0.53 & 0.60 & 0.55 & 0.56 \\
C18:3n3 & 3.30 & 2.12 & 1.35 & 1.85 & 1.28 & 1.66 & 1.35 & 2.20 \\
C18:4n3 & 2.60 & 1.64 & 1.09 & 1.25 & 0.88 & 1.35 & 0.98 & 1.47 \\
C19:2n6 & 0.00 & 0.04 & 0.06 & 0.00 & 0.00 & 0.00 & 0.00 & 0.10 \\
C20:0 & 0.82 & 0.43 & 0.39 & 0.43 & 0.47 & 0.65 & 0.47 & 0.49 \\
C20:1n15 & 0.12 & 0.00 & 0.06 & 0.03 & 0.05 & 0.07 & 0.00 & 0.04 \\
\hline
\end{tabular}


Table D1 continued. Menhaden and spot (70:30 by weight) diet mixture.

\begin{tabular}{lrrrrrrrr}
\hline & \multicolumn{8}{c}{ Sample number } \\
\hline \hline $\mathrm{C} 20: 1 \mathrm{n} 12$ & 1 & 2 & 3 & 4 & 6 & 7 & 8 & 9 \\
$\mathrm{C} 20: 1 \mathrm{n} 9$ & 3.99 & 1.44 & 2.32 & 2.03 & 2.43 & 1.98 & 2.08 & 2.14 \\
$\mathrm{C} 20: 1 \mathrm{n} 7$ & 2.06 & 0.92 & 0.98 & 1.04 & 0.95 & 1.11 & 1.22 & 1.18 \\
$\mathrm{C} 20: 2 \mathrm{n} 6$ & 3.69 & 1.26 & 2.10 & 1.93 & 2.16 & 2.19 & 1.92 & 2.07 \\
$\mathrm{C} 20: 3 \mathrm{n} 6$ & 1.42 & 0.61 & 0.69 & 0.75 & 0.00 & 1.10 & 0.75 & 0.71 \\
$\mathrm{C} 20: 4 \mathrm{n} 6$ & 0.25 & 0.13 & 0.14 & 0.13 & 0.13 & 0.37 & 0.17 & 0.14 \\
$\mathrm{C} 20: 3 \mathrm{n} 3$ & 2.96 & 1.46 & 1.48 & 1.53 & 1.86 & 2.02 & 1.69 & 1.72 \\
$\mathrm{C} 20: 5 \mathrm{n} 3$ & 0.90 & 0.46 & 0.38 & 0.40 & 0.41 & 1.04 & 0.39 & 0.45 \\
$\mathrm{C} 22: 0$ & 9.77 & 4.77 & 4.57 & 4.57 & 5.09 & 6.11 & 5.79 & 5.45 \\
$\mathrm{C} 22: 1 \mathrm{n} 9$ & 0.59 & 0.23 & 0.26 & 0.29 & 0.34 & 0.84 & 0.37 & 0.43 \\
$\mathrm{C} 22: 2 \mathrm{n} 6$ & 0.32 & 0.13 & 0.19 & 0.14 & 0.15 & 0.71 & 0.21 & 0.29 \\
$\mathrm{C} 22: 4 \mathrm{n} 6$ & 0.11 & 0.04 & 0.00 & 0.03 & 0.05 & 0.60 & 0.06 & 0.09 \\
$\mathrm{C} 22: 3 \mathrm{n} 3+\mathrm{C} 22: 5 \mathrm{n} 6$ & 1.00 & 0.35 & 0.47 & 0.49 & 0.66 & 1.43 & 0.55 & 0.51 \\
$\mathrm{C} 22: 5 \mathrm{n} 3$ & 1.46 & 0.66 & 0.66 & 0.71 & 1.13 & 1.87 & 0.94 & 0.77 \\
$\mathrm{C} 24: 0+\mathrm{C} 22: 6 \mathrm{n} 3$ & 16.89 & 8.99 & 8.05 & 7.78 & 7.13 & 9.33 & 10.24 & 10.08 \\
$\mathrm{C} 24: 1 \mathrm{n} 9$ & 0.88 & 0.56 & 0.44 & 0.42 & 0.41 & 1.56 & 0.56 & 0.48 \\
\hline
\end{tabular}


Table D2. Menhaden and spot (30:70 by weight) diet mixture.

\begin{tabular}{|c|c|c|c|c|c|c|c|}
\hline & \multicolumn{7}{|c|}{ Sample number } \\
\hline & 1 & 2 & 3 & 4 & 5 & 6 & 7 \\
\hline Weight (g) & 4.39 & 3.62 & 4.44 & 4.27 & 3.96 & 4.31 & 4.49 \\
\hline Lipid content (\%) & 10.67 & 10.09 & 4.81 & 4.74 & 8.57 & 8.19 & 5.94 \\
\hline C12:0 & 0.10 & 0.11 & 0.16 & 0.10 & 0.14 & 0.12 & 0.10 \\
\hline C12:1n1 & 0.03 & 0.07 & 0.05 & 0.02 & 0.04 & 0.04 & 0.03 \\
\hline C13:0 & 0.13 & 0.40 & 0.27 & 0.13 & 0.22 & 0.18 & 0.12 \\
\hline $\mathrm{C} 14: 0$ & 8.63 & 3.12 & 10.62 & 8.73 & 10.38 & 7.07 & 9.79 \\
\hline C14:1n5 & 0.10 & 0.08 & 0.14 & 0.13 & 0.11 & 0.08 & 0.11 \\
\hline $\mathrm{C} 15: 0$ & 1.09 & 0.57 & 1.44 & 1.11 & 1.71 & 1.14 & 1.19 \\
\hline C15:1n5 & 0.00 & 0.00 & 0.00 & 0.00 & 0.02 & 0.00 & 0.00 \\
\hline C16:0 & 26.08 & 18.44 & 32.97 & 32.30 & 23.69 & 32.98 & 28.60 \\
\hline C16:1n7 & 7.18 & 3.76 & 8.08 & 7.62 & 10.66 & 6.50 & 8.89 \\
\hline C17:0 & 1.58 & 1.32 & 1.93 & 1.67 & 2.16 & 2.01 & 1.52 \\
\hline C18:0 & 6.19 & 5.23 & 8.14 & 6.80 & 8.06 & 7.92 & 6.55 \\
\hline $\mathrm{C} 18: 1 \mathrm{n} 12 \mathrm{t}$ & 0.00 & 0.17 & 0.27 & 0.24 & 0.00 & 0.25 & 0.00 \\
\hline C18:1n9t & 0.00 & 0.29 & 0.00 & 0.00 & 0.00 & 0.00 & 0.00 \\
\hline C18:1n9 & 6.40 & 7.16 & 7.95 & 8.40 & 7.69 & 8.23 & 6.80 \\
\hline C18:1n7 & 3.51 & 2.69 & 3.38 & 3.84 & 4.03 & 3.26 & 3.62 \\
\hline $\mathrm{C} 18: 2 \mathrm{n} 6 \mathrm{t}$ & 0.00 & 0.00 & 0.00 & 0.00 & 0.00 & 0.08 & 0.00 \\
\hline C18:2n6 & 1.72 & 1.47 & 1.60 & 1.52 & 1.71 & 1.88 & 1.48 \\
\hline C18:3n6 & 0.29 & 0.53 & 0.20 & 0.21 & 0.24 & 0.18 & 0.25 \\
\hline C19:0 & 0.44 & 0.92 & 0.35 & 0.33 & 0.40 & 0.37 & 0.30 \\
\hline C18:3n3 & 2.33 & 3.25 & 1.64 & 1.76 & 1.67 & 2.98 & 1.67 \\
\hline C18:4n3 & 2.18 & 1.60 & 1.49 & 1.40 & 1.47 & 2.26 & 1.73 \\
\hline C19:2n6 & 0.00 & 0.73 & 0.13 & 0.00 & 0.00 & 0.00 & 0.00 \\
\hline C20:0 & 0.58 & 0.79 & 0.54 & 0.30 & 0.37 & 0.36 & 0.30 \\
\hline C20:1n15 & 0.00 & 0.00 & 0.05 & 0.02 & 0.03 & 0.03 & 0.04 \\
\hline C20:1n12 & 1.05 & 1.06 & 0.68 & 0.48 & 1.10 & 0.57 & 0.67 \\
\hline
\end{tabular}


Table D2 continued. Menhaden and spot (30:70 by weight) diet mixture.

\begin{tabular}{|c|c|c|c|c|c|c|c|}
\hline & \multicolumn{7}{|c|}{ Sample number } \\
\hline & 1 & 2 & 3 & 4 & 5 & 6 & 7 \\
\hline C20:1n9 & 1.13 & 2.31 & 1.03 & 1.18 & 0.86 & 1.10 & 0.94 \\
\hline C20:1n7 & 1.07 & 1.43 & 0.93 & 0.66 & 1.21 & 0.69 & 0.84 \\
\hline$C 20: 2 n 6$ & 0.90 & 1.34 & 0.44 & 0.33 & 0.44 & 0.40 & 0.35 \\
\hline C20:3n6 & 0.30 & 0.94 & 0.11 & 0.12 & 0.14 & 0.10 & 0.18 \\
\hline C21:0 & 0.00 & 0.00 & 0.01 & 0.00 & 0.00 & 0.00 & 0.00 \\
\hline C20:4n6 & 1.05 & 1.62 & 0.74 & 0.69 & 1.35 & 0.75 & 1.06 \\
\hline C20:3n3 & 0.63 & 1.34 & 0.32 & 0.27 & 0.32 & 0.43 & 0.36 \\
\hline$C 20: 5 n 3$ & 6.55 & 6.46 & 5.08 & 6.62 & 6.49 & 4.64 & 7.09 \\
\hline $\mathrm{C} 22: 0$ & 0.80 & 2.38 & 0.52 & 0.27 & 0.33 & 0.29 & 0.35 \\
\hline C22:1n9 & 0.70 & 2.86 & 0.37 & 0.21 & 0.23 & 0.16 & 0.31 \\
\hline $\mathrm{C} 22: 2 \mathrm{n} 6$ & 0.46 & 0.00 & 0.00 & 0.04 & 0.03 & 0.04 & 0.08 \\
\hline$C 22: 4 n 6$ & 1.19 & 2.46 & 0.16 & 0.15 & 0.29 & 0.17 & 0.32 \\
\hline$C 22: 3 n 3+C 22: 5 n 6$ & 1.78 & 3.30 & 0.41 & 0.48 & 0.73 & 0.63 & 0.75 \\
\hline$C 22: 5 n 3$ & 2.23 & 3.61 & 0.78 & 1.49 & 1.23 & 1.16 & 1.53 \\
\hline$C 24: 0+C 22: 6 n 3$ & 9.46 & 13.61 & 6.39 & 9.70 & 9.93 & 10.12 & 11.45 \\
\hline C24:1n9 & 2.14 & 2.53 & 0.64 & 0.64 & 0.51 & 0.81 & 0.63 \\
\hline
\end{tabular}


Table D3. Liver and belly flap samples from striped bass fed the $70 \%$ menhaden $30 \%$ spot mixture from day 71 .

\begin{tabular}{lcccccccc} 
& \multicolumn{9}{c}{ Liver } & \multicolumn{5}{c}{ Belly flap } \\
\hline \hline Length (mm) & 1 & 2 & 3 & 4 & 1 & 2 & 3 & 4 \\
Weight (g) & 329 & 360 & 371 & 362 & - & - & - & - \\
Lipid content (\%) & 478.2 & 626.7 & 714.0 & 554.9 & - & - & - & - \\
C12:0 & 5.14 & 8.63 & 9.30 & 7.93 & 8.63 & 9.30 & 6.55 \\
C12:1n1 & 0.02 & 0.01 & 0.02 & 0.01 & 0.07 & 0.08 & 0.08 & 0.06 \\
C13:0 & 0.00 & 0.00 & 0.00 & 0.13 & 0.21 & 0.34 & 0.76 & 0.21 \\
C14:0 & 0.08 & 0.00 & 0.07 & 0.07 & 0.16 & 0.11 & 0.00 & 0.00 \\
C14:1n5 & 3.07 & 2.79 & 3.28 & 3.47 & 5.40 & 5.26 & 5.15 & 5.64 \\
C15:0 & 0.05 & 0.04 & 0.06 & 0.03 & 0.20 & 0.18 & 0.19 & 0.21 \\
C15:1n5 & 0.66 & 0.69 & 0.70 & 0.75 & 0.86 & 0.88 & 0.79 & 0.77 \\
C16:0 DMA & 0.02 & 0.03 & 0.03 & 0.02 & 0.09 & 0.00 & 0.07 & 0.04 \\
C16:0 & 0.04 & 0.04 & 0.05 & 0.04 & 0.06 & 0.03 & 0.05 & 0.03 \\
C16:1n7 & 26.43 & 29.14 & 27.06 & 29.25 & 25.33 & 24.08 & 24.31 & 24.60 \\
C17:0 & 4.54 & 3.32 & 4.36 & 4.00 & 7.24 & 7.13 & 7.37 & 7.66 \\
C18:0 & 1.19 & 1.22 & 1.14 & 1.19 & 1.07 & 1.12 & 0.90 & 0.78 \\
C18:1n12t & 7.52 & 9.12 & 7.63 & 8.94 & 5.46 & 5.69 & 4.98 & 4.75 \\
C18:1n9t & 0.25 & 0.00 & 0.26 & 0.00 & 0.00 & 0.00 & 0.24 & 0.19 \\
C18:1n9 & 0.24 & 0.21 & 0.18 & 0.00 & 0.21 & 0.00 & 0.18 & 0.18 \\
C18:1n7 & 11.59 & 8.11 & 10.07 & 6.44 & 16.92 & 16.37 & 18.87 & 22.03 \\
C18:2n6 & 4.14 & 3.18 & 3.30 & 2.94 & 4.15 & 4.14 & 3.97 & 4.02 \\
C18:3n6 & 2.52 & 2.07 & 3.35 & 2.63 & 6.55 & 5.98 & 8.15 & 9.84 \\
C18:3n3 & 0.40 & 0.38 & 0.36 & 0.37 & 0.41 & 0.43 & 0.44 & 0.39 \\
C18:4n3 & 0.84 & 0.65 & 0.80 & 0.77 & 1.36 & 1.32 & 1.45 & 1.28 \\
C20:0 & 0.49 & 0.37 & 0.46 & 0.39 & 0.84 & 0.89 & 0.85 & 0.64 \\
C20:1n15 & 0.17 & 0.16 & 0.14 & 0.13 & 0.27 & 0.29 & 0.24 & 0.23 \\
C20:1n12 & 0.00 & 0.00 & 0.00 & 0.00 & 0.01 & 0.00 & 0.02 & 0.01 \\
C20:1n9 & 0.17 & 0.14 & 0.18 & 0.12 & 0.47 & 0.69 & 0.00 & 0.00 \\
& 1.61 & 1.20 & 1.41 & 0.71 & 1.37 & 1.40 & 1.45 & 1.46 \\
\hline & & & & & & & & \\
& & & & & & & \\
& & & & & &
\end{tabular}


Table D3 continued. Liver and belly flap samples from striped bass fed the $70 \%$ menhaden $30 \%$ spot mixture from day 71 .

\begin{tabular}{|c|c|c|c|c|c|c|c|c|}
\hline & \multicolumn{4}{|c|}{ Liver } & \multicolumn{4}{|c|}{ Belly flap } \\
\hline & 1 & 2 & 3 & 4 & 1 & 2 & 3 & 4 \\
\hline C20:1n7 & 0.34 & 0.30 & 0.35 & 0.28 & 0.60 & 0.00 & 0.57 & 0.52 \\
\hline C20:2n6 & 0.53 & 0.50 & 0.62 & 0.54 & 0.59 & 0.67 & 0.66 & 0.66 \\
\hline$C 20: 3 n 6$ & 0.14 & 0.13 & 0.17 & 0.13 & 0.22 & 0.28 & 0.23 & 0.23 \\
\hline C20:4n6 & 3.20 & 4.06 & 3.85 & 3.66 & 1.63 & 1.83 & 1.39 & 1.21 \\
\hline$C 20: 3 n 3$ & 0.23 & 0.22 & 0.23 & 0.23 & 0.25 & 0.38 & 0.23 & 0.16 \\
\hline C20:5n3 & 6.14 & 6.85 & 6.89 & 5.27 & 4.78 & 5.50 & 4.77 & 3.26 \\
\hline$C 22: 0$ & 0.18 & 0.22 & 0.21 & 0.18 & 0.15 & 0.20 & 0.16 & 0.13 \\
\hline C22:1n9 & 0.18 & 0.15 & 0.15 & 0.10 & 0.19 & 0.13 & 0.09 & 0.12 \\
\hline$C 22: 2 n 6$ & 0.03 & 0.02 & 0.03 & 0.02 & 0.17 & 0.98 & 0.10 & 0.02 \\
\hline $\mathrm{C} 22: 4 \mathrm{n} 6$ & 0.51 & 0.49 & 0.54 & 0.31 & 0.49 & 0.75 & 0.59 & 0.44 \\
\hline$C 22: 3 n 3+C 22: 5 n 6$ & 0.67 & 0.66 & 0.63 & 0.69 & 0.69 & 0.00 & 0.66 & 0.47 \\
\hline$C 22: 5 n 3$ & 1.44 & 1.23 & 1.40 & 1.32 & 1.60 & 1.98 & 1.43 & 1.23 \\
\hline$C 24: 0+C 22: 6 n 3$ & 19.58 & 21.61 & 19.34 & 24.11 & 9.50 & 10.30 & 8.15 & 6.14 \\
\hline C24:1n9 & 0.78 & 0.69 & 0.69 & 0.76 & 0.45 & 0.59 & 0.42 & 0.39 \\
\hline
\end{tabular}


Table D4. Liver and belly flap samples from striped bass fed the $30 \%$ menhaden $70 \%$ spot mixture from day 71 .

\begin{tabular}{lrrrrr}
\hline & \multicolumn{3}{c}{ Liver } & \multicolumn{3}{c}{ Belly flap } \\
\hline \hline Length (mm) & \multicolumn{1}{c}{1} & \multicolumn{1}{c}{2} & \multicolumn{1}{c}{1} & \multicolumn{1}{c}{2} & \multicolumn{1}{c}{3} \\
Weight (g) & 496.2 & \multicolumn{1}{c}{763.3} & \multicolumn{1}{c}{-} & \multicolumn{1}{c}{-} & \multicolumn{1}{c}{-} \\
Lipid content (\%) & 6.25 & 6.73 & \multicolumn{1}{c}{9.70} & 10.51 & \multicolumn{1}{c}{-} \\
C12:0 & 0.02 & 0.01 & 0.05 & 0.05 & 0.06 \\
C12:1n1 & 0.01 & 0.00 & 0.00 & 0.03 & 0.00 \\
C13:0 & 0.14 & 0.07 & 0.14 & 0.21 & 0.00 \\
C14:0 & 3.02 & 2.68 & 4.89 & 5.02 & 5.16 \\
C14:1n5 & 0.10 & 0.05 & 0.13 & 0.24 & 0.22 \\
C15:0 & 0.75 & 0.57 & 1.08 & 0.80 & 0.88 \\
C15:1n5 & 0.00 & 0.00 & 0.06 & 0.00 & 0.00 \\
C16:0 DMA & 0.00 & 0.00 & 0.03 & 0.00 & 0.05 \\
C16:0 & 21.86 & 19.37 & 24.08 & 24.60 & 24.00 \\
C16:1n7 & 4.76 & 4.42 & 6.81 & 7.82 & 7.30 \\
C17:0 & 1.64 & 1.32 & 1.49 & 1.01 & 0.98 \\
C18:0 & 6.82 & 6.20 & 6.39 & 4.88 & 5.29 \\
C18:1n12t & 0.00 & 0.00 & 0.00 & 0.00 & 0.29 \\
C18:1n9t & 0.33 & 0.32 & 0.12 & 0.20 & 0.22 \\
C18:1n9 & 13.34 & 13.87 & 16.24 & 19.66 & 17.82 \\
C18:1n7 & 4.43 & 4.40 & 4.40 & 4.18 & 4.07 \\
C18:2n6 & 2.98 & 3.45 & 5.65 & 9.01 & 6.88 \\
C18:3n6 & 0.23 & 0.30 & 0.19 & 0.24 & 0.42 \\
C19:0 & 0.48 & 0.58 & 0.47 & 0.35 & 0.00 \\
C18:3n3 & 1.09 & 1.52 & 1.42 & 1.61 & 1.55 \\
C18:4n3 & 0.78 & 0.97 & 1.03 & 0.84 & 1.12 \\
C19:2n6 & 0.11 & 0.20 & 0.11 & 0.00 & 0.00 \\
C20:0 & 0.31 & 0.44 & 0.41 & 0.23 & 0.25 \\
C20:1n15 & 0.09 & 0.00 & 0.08 & 0.02 & 0.00 \\
\hline & & & & &
\end{tabular}


Table D4 continued. Liver and belly flap samples from striped bass fed the $30 \%$ menhaden $70 \%$ spot mixture from day 71 .

\begin{tabular}{lrrrcc} 
& \multicolumn{3}{c}{ Liver } & \multicolumn{3}{c}{ Belly flap } \\
\hline \hline C20:1n12 & \multicolumn{1}{c}{1} & \multicolumn{1}{c}{2} & 1 & 2 & 3 \\
$\mathrm{C} 20: 1 \mathrm{n} 9$ & 0.52 & 0.58 & 0.99 & 0.51 & 0.59 \\
$\mathrm{C} 20: 1 \mathrm{n} 7$ & 2.08 & 2.04 & 1.68 & 1.26 & 1.35 \\
$\mathrm{C} 20: 2 \mathrm{n} 6$ & 0.69 & 0.81 & 1.08 & 0.57 & 0.00 \\
$\mathrm{C} 20: 3 \mathrm{n} 6$ & 0.91 & 1.31 & 0.99 & 0.68 & 0.77 \\
$\mathrm{C} 20: 4 \mathrm{n} 6$ & 0.21 & 0.29 & 0.32 & 0.23 & 0.24 \\
$\mathrm{C} 20: 3 \mathrm{n} 3$ & 3.46 & 2.96 & 1.87 & 1.23 & 1.82 \\
$\mathrm{C} 20: 5 \mathrm{n} 3$ & 0.57 & 0.86 & 0.41 & 0.24 & 0.30 \\
$\mathrm{C} 22: 0$ & 6.26 & 5.75 & 4.82 & 4.31 & 5.63 \\
$\mathrm{C} 22: 1 \mathrm{n} 9$ & 0.33 & 0.35 & 0.34 & 0.13 & 0.17 \\
$\mathrm{C} 22: 2 \mathrm{n} 6$ & 0.70 & 0.68 & 0.36 & 0.15 & 0.13 \\
$\mathrm{C} 22: 4 \mathrm{n} 6$ & 0.52 & 0.81 & 0.13 & 0.06 & 0.08 \\
$\mathrm{C} 22: 3 n 3+\mathrm{C} 22: 5 \mathrm{n} 6$ & 1.41 & 2.29 & 0.60 & 0.46 & 0.76 \\
$\mathrm{C} 22: 5 \mathrm{n} 3$ & 1.93 & 2.64 & 1.73 & 1.30 & 1.67 \\
$\mathrm{C} 24: 0+\mathrm{C} 22: 6 \mathrm{n3}$ & 15.53 & 15.66 & 8.20 & 7.23 & 8.61 \\
$\mathrm{C} 24: 1 \mathrm{n} 9$ & 1.04 & 1.54 & 0.50 & 0.33 & 0.43 \\
\hline
\end{tabular}


Table D5. Liver and belly flap samples from striped bass fed the $70 \%$ menhaden $30 \%$ spot mixture from day 88 .

\begin{tabular}{|c|c|c|c|c|c|c|c|c|}
\hline & \multicolumn{4}{|c|}{ Liver } & \multicolumn{4}{|c|}{ Belly flap } \\
\hline & 1 & 2 & 3 & 4 & 1 & 2 & 3 & 4 \\
\hline Length (mm) & 312 & 399 & 406 & 360 & - & - & - & - \\
\hline Weight (g) & 670.2 & 851.9 & 943.7 & 741.4 & - & - & - & - \\
\hline Lipid content (\%) & 5.02 & 5.48 & 4.90 & 5.15 & 10.98 & 6.21 & 12.31 & 15.93 \\
\hline C12:0 & 0.02 & 0.03 & 0.03 & 0.02 & 0.09 & & 0.08 & \\
\hline C12:1n1 & 0.00 & 0.00 & 0.22 & 0.00 & 0.46 & & 0.36 & \\
\hline C13:0 & 0.04 & 0.03 & 0.00 & 0.07 & 0.08 & & 0.14 & \\
\hline C14:0 & 2.31 & 3.33 & 3.42 & 2.27 & 5.77 & & 5.28 & \\
\hline C14:1n5 & 0.04 & 0.04 & 0.08 & 0.05 & 0.23 & & 0.25 & \\
\hline C15:0 & 0.46 & 0.67 & 0.61 & 0.47 & 0.89 & & 0.76 & \\
\hline C16:0 DMA & 0.01 & 0.03 & 0.03 & 0.03 & 0.04 & & 0.04 & \\
\hline C16:0 & 26.37 & 22.79 & 22.21 & 21.56 & 23.56 & & 22.25 & \\
\hline C16:1n7 & 3.81 & 4.25 & 4.98 & 4.53 & 7.90 & & 7.74 & \\
\hline C17:0 & 1.03 & 1.24 & 1.08 & 0.93 & 0.95 & & 0.72 & \\
\hline C18:0 & 8.52 & 8.04 & 6.94 & 5.95 & 4.75 & & 4.43 & \\
\hline C18:1n12t & 0.00 & 0.28 & 0.29 & 0.00 & 0.24 & & 0.24 & \\
\hline C18:1n9t & 0.58 & 0.41 & 0.19 & 0.23 & 0.19 & & 0.16 & \\
\hline C18:1n9 & 14.61 & 9.65 & 13.56 & 15.17 & 16.27 & & 20.58 & \\
\hline C18:1n7 & 4.02 & 4.05 & 4.55 & 4.43 & 3.89 & & 3.98 & \\
\hline C18:2n6 & 1.30 & 2.65 & 3.57 & 1.69 & 6.06 & & 9.06 & \\
\hline C18:3n6 & 0.33 & 0.43 & 0.39 & 0.34 & 0.40 & & 0.41 & \\
\hline C18:3n3 & 0.71 & 1.05 & 1.06 & 0.86 & 1.57 & & 1.61 & \\
\hline $\mathrm{C} 18: 4 \mathrm{n} 3$ & 0.62 & 0.79 & 0.85 & 0.73 & 1.13 & & 0.90 & \\
\hline C19:2n6 & 0.00 & 0.00 & 0.00 & 0.00 & 0.00 & & 0.02 & \\
\hline C2O:0 & 0.25 & 0.23 & 0.24 & 0.22 & 0.65 & & 0.26 & \\
\hline C20:1n15 & 0.00 & 0.00 & 0.02 & 0.00 & 0.09 & & 0.03 & \\
\hline C20:1n12 & 0.30 & 0.31 & 0.29 & 0.33 & 0.82 & & 0.40 & \\
\hline C20:1n9 & 2.58 & 1.64 & 2.41 & 3.04 & 1.56 & & 1.36 & \\
\hline
\end{tabular}


Table D5 continued. Liver and belly flap samples from striped bass fed the $70 \%$ menhaden $30 \%$ spot mixture from day 88 .

\begin{tabular}{|c|c|c|c|c|c|c|c|c|}
\hline & \multicolumn{4}{|c|}{ Liver } & \multicolumn{4}{|c|}{ Belly flap } \\
\hline & 1 & 2 & 3 & 4 & 1 & 2 & 3 & 4 \\
\hline C20:1n7 & 0.45 & 0.47 & 0.54 & 0.59 & 0.86 & & 0.56 & \\
\hline$C 20: 2 n 6$ & 0.44 & 0.63 & 0.67 & 0.57 & 0.70 & & 0.66 & \\
\hline C20:3n6 & 0.13 & 0.16 & 0.17 & 0.16 & 0.32 & & 0.25 & \\
\hline C21:0 & 0.00 & 0.00 & 0.00 & 0.00 & 0.12 & & 0.03 & \\
\hline C20:4n6 & 2.61 & 3.16 & 2.78 & 2.90 & 1.56 & & 1.35 & \\
\hline C20:3n3 & 0.24 & 0.32 & 0.25 & 0.28 & 0.34 & & 0.31 & \\
\hline C20:5n3 & 6.11 & 6.62 & 6.30 & 6.61 & 5.31 & & 4.64 & \\
\hline C22:0 & 0.58 & 0.66 & 0.43 & 0.44 & 0.30 & & 0.28 & \\
\hline C22:1n9 & 0.22 & 0.21 & 0.27 & 0.35 & 0.14 & & 0.12 & \\
\hline C22:2n6 & 0.04 & 0.06 & 0.05 & 0.17 & 0.03 & & 0.06 & \\
\hline$C 22: 4 n 6$ & 0.41 & 0.56 & 0.48 & 0.80 & 0.55 & & 0.54 & \\
\hline$C 22: 3 n 3+C 22: 5 n 6$ & 0.62 & 0.92 & 0.71 & 1.33 & 0.81 & & 0.57 & \\
\hline$C 22: 5 n 3$ & 1.18 & 1.86 & 1.54 & 2.01 & 1.56 & & 1.43 & \\
\hline$C 24: 0+C 22: 6 n 3$ & 18.33 & 21.36 & 18.17 & 19.67 & 9.32 & & 7.79 & \\
\hline C24:1n9 & 0.74 & 1.06 & 0.61 & 1.19 & 0.46 & & 0.35 & \\
\hline
\end{tabular}


Table D6. Liver and belly flap samples from striped bass fed the $30 \%$ menhaden $70 \%$ spot mixture from day 88 .

\begin{tabular}{|c|c|c|c|c|c|c|c|}
\hline & \multicolumn{4}{|c|}{ Liver } & \multicolumn{3}{|c|}{ Belly flap } \\
\hline & 1 & 2 & 3 & 4 & 1 & 2 & 3 \\
\hline Length (mm) & 373 & 341 & 365 & 366 & - & - & - \\
\hline Weight (g) & 790 & 592.6 & 893.7 & 702.1 & - & - & - \\
\hline Lipid content (\%) & 6.71 & 5.15 & 8.16 & 5.69 & 7.64 & 14.22 & 6.54 \\
\hline $\mathrm{C} 12: 0$ & 0.02 & 0.03 & 0.02 & 0.03 & 0.11 & 0.07 & 0.10 \\
\hline C12:1n1 & 0.13 & 0.00 & 0.00 & 0.00 & 0.72 & 0.00 & 0.92 \\
\hline C13:0 & 0.00 & 0.06 & 0.05 & 0.07 & 0.40 & 0.06 & 0.30 \\
\hline C14:0 & 1.90 & 2.54 & 2.21 & 2.44 & 5.65 & 4.65 & 5.78 \\
\hline C14:1n5 & 0.06 & 0.07 & 0.07 & 0.06 & 0.17 & 0.19 & 0.20 \\
\hline C15:0 & 0.52 & 0.71 & 0.58 & 0.73 & 1.09 & 0.88 & 1.02 \\
\hline C15:1n5 & 0.02 & 0.02 & 0.00 & 0.00 & 0.00 & 0.00 & 0.00 \\
\hline C16:0 DMA & 0.02 & 0.02 & 0.02 & 0.03 & 0.05 & 0.00 & 0.04 \\
\hline C16:0 & 25.87 & 23.04 & 20.29 & 22.12 & 25.28 & 21.84 & 23.70 \\
\hline C16:1n7 & 4.29 & 4.95 & 5.26 & 4.03 & 7.25 & 6.93 & 7.29 \\
\hline C17:0 & 1.02 & 1.22 & 0.94 & 1.37 & 1.09 & 1.04 & 1.06 \\
\hline $\mathrm{C} 17: 1 \mathrm{n} 7$ & 0.00 & 0.00 & 0.00 & 0.00 & 0.00 & 0.00 & 0.00 \\
\hline C18:0 & 7.23 & 6.83 & 5.13 & 7.33 & 5.49 & 4.89 & 5.47 \\
\hline C18:1n12t & 0.48 & 0.00 & 0.00 & 0.00 & 0.48 & 0.45 & 0.48 \\
\hline C18:1n9t & 0.25 & 0.36 & 0.00 & 0.26 & 0.00 & 0.00 & 0.00 \\
\hline C18:1n9 & 17.84 & 15.27 & 18.93 & 13.55 & 14.90 & 18.56 & 14.64 \\
\hline C18:1n7 & 4.31 & 4.33 & 4.86 & 4.26 & 3.54 & 3.75 & 3.64 \\
\hline C18:2n6 & 1.32 & 1.88 & 1.96 & 1.86 & 6.11 & 6.91 & 6.03 \\
\hline C18:3n6 & 0.35 & 0.41 & 0.34 & 0.42 & 0.43 & 0.42 & 0.43 \\
\hline C18:3n3 & 0.66 & 0.86 & 0.87 & 0.84 & 1.29 & 1.46 & 1.50 \\
\hline C18:4n3 & 0.49 & 0.63 & 0.64 & 0.57 & 0.94 & 1.00 & 1.15 \\
\hline C19:2n6 & 0.00 & 0.00 & 0.00 & 0.00 & 0.04 & 0.00 & 0.00 \\
\hline C20:0 & 0.21 & 0.25 & 0.25 & 0.31 & 0.22 & 0.26 & 0.27 \\
\hline C20:1n15 & 0.00 & 0.00 & 0.00 & 0.00 & 0.02 & 0.00 & 0.03 \\
\hline
\end{tabular}


Table D6 continued. Liver and belly flap samples from striped bass fed the $30 \%$ menhaden $70 \%$ spot mixture from day 88 .

\begin{tabular}{lccccccc} 
Day 88 Tank 3 & \multicolumn{4}{c}{ Liver } & \multicolumn{4}{c}{ Belly flap } \\
\hline \hline C20:1n12 & 1 & 2 & 3 & 4 & 1 & 2 & 3 \\
C20:1n9 & 0.49 & 0.70 & 0.66 & 0.69 & 0.67 & 0.79 & 0.69 \\
C20:1n7 & 2.89 & 2.37 & 3.69 & 2.31 & 1.07 & 1.49 & 1.14 \\
C20:2n6 & 0.67 & 0.84 & 0.91 & 0.87 & 0.72 & 0.86 & 0.82 \\
C20:3n6 & 0.53 & 0.64 & 0.69 & 0.66 & 0.63 & 0.78 & 0.65 \\
C20:4n6 & 0.14 & 0.18 & 0.18 & 0.19 & 0.30 & 0.26 & 0.26 \\
C20:3n3 & 2.63 & 2.93 & 2.53 & 3.95 & 1.97 & 1.37 & 1.96 \\
C20:5n3 & 0.24 & 0.35 & 0.33 & 0.37 & 0.27 & 0.34 & 0.30 \\
C22:0 & 5.53 & 5.90 & 5.69 & 6.80 & 5.11 & 4.12 & 5.43 \\
C22:1n9 & 0.29 & 0.54 & 0.41 & 0.41 & 0.24 & 0.43 & 0.30 \\
C22:2n6 & 0.17 & 0.28 & 0.28 & 0.17 & 0.08 & 0.14 & 0.16 \\
C22:4n6 & 0.03 & 0.18 & 0.07 & 0.02 & 0.00 & 0.15 & 0.10 \\
C22:3n3 + C22:5n6 & 0.61 & 0.94 & 0.71 & 0.64 & 0.50 & 1.09 & 0.62 \\
C22:5n3 & 0.78 & 1.41 & 1.22 & 0.93 & 0.76 & 1.60 & 0.98 \\
C24:0 + C22:6n3 & 1.47 & 2.45 & 2.05 & 1.87 & 1.69 & 2.84 & 1.81 \\
C24:1n9 & 16.05 & 15.80 & 17.18 & 19.22 & 10.29 & 8.81 & 10.34 \\
\hline & 0.50 & 0.99 & 0.96 & 0.60 & 0.43 & 1.56 & 0.42 \\
\hline
\end{tabular}




\section{Chapter 6 Raw Data}

Values for length $(\mathrm{mm})$, weight $(\mathrm{g})$, lipid content (\% wet weight) and fatty acids routinely identified for striped bass belly flap samples analyzed in Chapter 6 of this experiment.

Table E1. Striped bass collected from the Choptank River for field validation of the QFASA model.

\begin{tabular}{|c|c|c|c|c|c|c|c|c|c|c|c|c|}
\hline & \multicolumn{12}{|c|}{ Sample number } \\
\hline & 1 & 2 & 3 & 4 & 5 & 6 & 7 & 8 & 9 & 10 & 11 & 12 \\
\hline Total length (mm) & 496 & 426 & 580 & 504 & 554 & 515 & 490 & 504 & 456 & 539 & 542 & 545 \\
\hline Weight (g) & 1088.2 & 762.4 & 1880.3 & 1098.0 & 1408.2 & 1256.6 & 1200.8 & 1054.7 & 772.2 & 1422.2 & 1482.9 & 1586.0 \\
\hline Lipid content (\%) & 4.29 & 2.05 & 8.87 & 2.37 & - & 3.09 & 9.45 & 3.15 & 2.35 & 22.05 & 2.21 & 3.27 \\
\hline $\mathrm{C} 12: 0$ & 0.13 & 0.06 & 0.13 & 0.12 & 3.06 & 0.03 & 0.11 & 0.14 & 0.30 & 0.05 & 0.06 & 0.03 \\
\hline C12:1n1 & nd & 0.04 & 0.05 & 0.22 & 0.84 & nd & nd & nd & nd & 0.03 & 0.08 & 0.02 \\
\hline C13:0 & nd & nd & 0.37 & nd & 1.34 & nd & nd & nd & 0.17 & nd & nd & nd \\
\hline C14:0 & 5.67 & 3.53 & 9.20 & 4.85 & 2.82 & 2.04 & 2.51 & 6.28 & 4.08 & 2.40 & 2.29 & 1.55 \\
\hline C14:1n5 & 0.04 & 0.09 & 0.27 & nd & 1.84 & 0.02 & 0.04 & 0.14 & 0.25 & 0.01 & 0.08 & 0.01 \\
\hline C15:0 & 1.06 & 0.70 & 1.22 & 1.13 & 1.33 & 0.54 & 0.76 & 1.05 & 1.06 & 0.60 & 0.76 & 0.88 \\
\hline C15:1n5 & nd & nd & nd & nd & 0.89 & nd & 0.01 & nd & 0.00 & nd & nd & nd \\
\hline C16:0 & 27.10 & 30.12 & 27.01 & 36.35 & 3.81 & 32.88 & 31.37 & 30.12 & 27.08 & 34.16 & 32.23 & 30.41 \\
\hline C16:1n7 & 7.37 & 5.27 & 9.70 & 5.42 & 1.90 & 3.03 & 4.10 & 6.17 & 10.40 & 3.26 & 5.52 & 3.06 \\
\hline C17:0 & 1.05 & 1.24 & 1.36 & 1.04 & 2.13 & 0.54 & 1.29 & 1.12 & 1.03 & 1.11 & 1.21 & 1.36 \\
\hline C17:1n7 & nd & nd & nd & nd & 1.21 & nd & nd & nd & nd & nd & nd & nd \\
\hline C18:0 & 6.38 & 6.35 & 4.07 & 8.47 & 2.73 & 8.18 & 8.57 & 7.82 & 4.61 & 9.27 & 7.28 & 9.94 \\
\hline $\mathrm{C} 18: 1 \mathrm{n} 9 \mathrm{t}$ & 0.38 & 0.35 & 0.22 & 0.23 & 0.99 & 0.22 & 0.32 & nd & 0.41 & 0.19 & 0.31 & 0.22 \\
\hline $\mathrm{C} 18: 1 \mathrm{n} 7 \mathrm{t}$ & nd & nd & nd & nd & 0.69 & nd & nd & nd & nd & nd & nd & nd \\
\hline C18:1n9 & 6.52 & 12.43 & 11.13 & 8.01 & 1.97 & 6.24 & 9.34 & 13.61 & 21.21 & 5.72 & 14.45 & 5.63 \\
\hline C18:1n7 & 3.88 & 4.52 & 4.62 & 3.35 & 1.17 & 3.14 & 3.78 & 4.69 & 5.46 & 2.73 & 4.25 & 2.91 \\
\hline $\mathrm{C} 18: 2 \mathrm{n} 6$ & 1.99 & 1.30 & 1.49 & 0.89 & 4.46 & 0.97 & 0.87 & 1.12 & 1.18 & 1.08 & 0.78 & 1.59 \\
\hline C18:3n6 & 0.21 & 0.13 & 0.18 & 0.06 & 4.07 & 0.06 & 0.07 & 0.09 & 0.11 & 0.07 & 0.04 & 0.09 \\
\hline C19:0 & 0.28 & 0.22 & 0.21 & 0.29 & nd & 0.18 & 0.20 & 0.26 & 0.24 & 0.16 & 0.19 & 0.22 \\
\hline C18:3n3 & 1.58 & 0.69 & 1.65 & 0.38 & 5.88 & 0.43 & 0.37 & 0.50 & 0.59 & 0.70 & 0.27 & 1.22 \\
\hline
\end{tabular}


Table E1 continued. Striped bass collected from the Choptank River for field validation of the QFASA model.

\begin{tabular}{|c|c|c|c|c|c|c|c|c|c|c|c|c|}
\hline & \multicolumn{12}{|c|}{ Sample number } \\
\hline & 1 & 2 & 3 & 4 & 5 & 6 & 7 & 8 & 9 & 10 & 11 & 12 \\
\hline C18:4n3 & 2.48 & 0.84 & 1.57 & 0.39 & 1.10 & 0.62 & 0.33 & 0.70 & 0.44 & 1.01 & 0.14 & 0.24 \\
\hline C19:2n6 & 0.32 & 0.12 & nd & 0.16 & 2.63 & 0.13 & 0.13 & 0.04 & 0.03 & 0.18 & 0.13 & 0.18 \\
\hline C20:0 & 0.22 & 0.11 & 0.17 & 0.25 & 1.67 & 0.09 & 0.22 & 0.33 & 0.30 & 0.12 & 0.17 & 0.13 \\
\hline C20:1n15 & 0.02 & 0.01 & 0.01 & 0.05 & 0.77 & 0.02 & 0.05 & nd & nd & 0.01 & 0.02 & 0.08 \\
\hline $\mathrm{C} 20: 1 \mathrm{n} 12$ & 0.49 & 0.46 & 0.47 & 1.14 & 0.83 & 0.36 & 1.04 & 2.20 & 1.54 & 0.17 & 1.27 & 0.21 \\
\hline C20:1n9 & 1.00 & 1.33 & 0.99 & 1.48 & 1.74 & 1.04 & 1.88 & 2.98 & 2.52 & 0.70 & 1.94 & 0.81 \\
\hline C20:1n7 & 0.43 & 0.53 & 0.57 & 0.72 & nd & 0.32 & 1.12 & 1.96 & 2.50 & 0.19 & 1.08 & 0.23 \\
\hline C20:2n6 & 0.41 & 0.34 & 0.40 & 0.48 & 4.13 & 0.32 & 0.46 & 0.63 & 0.74 & 0.31 & 0.48 & 0.44 \\
\hline C20:3n6 & 0.10 & 0.09 & 0.24 & 0.14 & 3.98 & 0.09 & 0.09 & 0.11 & 0.13 & 0.10 & 0.10 & 0.31 \\
\hline C21:0 & 0.01 & 0.01 & nd & 0.04 & nd & 0.02 & 0.01 & 0.01 & nd & 0.01 & nd & 0.00 \\
\hline C20:4n6 & 1.64 & 1.61 & 1.16 & 2.72 & 3.59 & 2.73 & 3.02 & 1.73 & 1.45 & 3.31 & 3.04 & 6.07 \\
\hline$C 20: 3 n 3$ & 0.25 & 0.18 & 0.41 & 0.24 & 5.61 & 0.16 & 0.14 & 0.16 & 0.19 & 0.19 & 0.18 & 0.27 \\
\hline C20:5n3 & 5.51 & 5.41 & 5.68 & 4.31 & 3.05 & 5.14 & 5.23 & 2.99 & 3.25 & 6.87 & 3.93 & 7.28 \\
\hline C22:0 & 0.27 & 0.13 & 0.46 & 0.15 & 1.69 & 0.07 & 0.11 & 0.08 & 0.11 & 0.05 & 0.09 & 0.08 \\
\hline C22:1n9 & 0.18 & 0.10 & 0.93 & 0.19 & 1.96 & 0.14 & 0.13 & 0.14 & 0.32 & nd & 0.18 & 0.09 \\
\hline $\mathrm{C} 22: 2 \mathrm{n} 6$ & 0.04 & 0.02 & 0.03 & nd & 4.15 & 0.04 & nd & nd & 0.05 & 0.01 & nd & 0.02 \\
\hline $\mathrm{C} 22: 4 \mathrm{n} 6$ & 0.30 & 0.26 & 0.32 & 0.49 & 2.98 & 0.43 & 0.45 & 0.61 & 0.40 & 0.29 & 0.83 & 0.39 \\
\hline$C 22: 3 n 3+C 22: 5 n 6$ & 0.68 & 0.63 & 0.47 & 0.59 & 7.01 & 1.06 & 0.92 & 0.52 & 0.46 & 0.83 & 0.80 & 2.24 \\
\hline$C 22: 5 n 3$ & 1.65 & 1.56 & 2.02 & 1.40 & 3.10 & 1.39 & 1.38 & 1.49 & 1.41 & 1.21 & 2.05 & 1.73 \\
\hline$C 22: 6 n 3+C 24: 0$ & 19.58 & 18.18 & 10.63 & 13.66 & 5.24 & 26.35 & 18.98 & 9.62 & 5.78 & 22.21 & 13.24 & 19.33 \\
\hline C24:1n9 & 0.80 & 1.04 & 0.60 & 0.57 & 1.65 & 0.98 & 0.59 & 0.57 & 0.19 & 0.71 & 0.56 & 0.73 \\
\hline
\end{tabular}


Table E2. Striped bass collected from the Choptank River for field validation of the QFASA model.

\begin{tabular}{|c|c|c|c|c|c|c|c|c|c|c|c|c|}
\hline & \multicolumn{12}{|c|}{ Sample number } \\
\hline & 13 & 14 & 15 & 16 & 17 & 18 & 19 & 20 & 21 & 22 & 23 & 24 \\
\hline Total length (mm) & 521 & 419 & 557 & 440 & 576 & 457 & 587 & 545 & 439 & 607 & 482 & 521 \\
\hline Weight (g) & 1136.7 & 608.4 & 1702.3 & 736.3 & 1688.8 & 816.1 & 1868.2 & 1572.4 & 904.2 & 1940.6 & 1102.9 & 1238.0 \\
\hline Lipid content (\%) & 2.39 & 2.17 & 8.65 & 1.90 & - & 3.06 & 4.96 & 7.34 & 18.75 & 5.23 & 4.32 & 1.12 \\
\hline C12:0 & nd & 0.12 & 0.07 & 0.87 & 0.06 & 0.12 & 0.09 & 0.43 & 0.14 & 0.08 & 0.04 & 0.04 \\
\hline $\mathrm{C} 12: 1 \mathrm{n} 1$ & 0.03 & nd & 0.03 & 0.51 & 0.03 & nd & nd & nd & 0.12 & nd & nd & nd \\
\hline $\mathrm{C} 13: 0$ & nd & 0.38 & nd & nd & nd & nd & nd & 0.33 & 0.40 & 0.29 & nd & nd \\
\hline $\mathrm{C} 14: 0$ & 1.20 & 6.63 & 2.60 & 2.99 & 3.14 & 4.43 & 3.72 & 2.61 & 5.58 & 4.13 & 1.24 & 1.58 \\
\hline C14:1n5 & 0.02 & 0.15 & 0.02 & 0.16 & 0.04 & 0.16 & 0.18 & 0.14 & 0.18 & 0.12 & 0.01 & 0.03 \\
\hline C15:0 & 0.48 & 0.89 & 0.87 & 0.51 & 0.75 & 0.89 & 0.86 & 1.21 & 0.87 & 0.66 & 0.45 & 0.51 \\
\hline C15:1n5 & nd & 0.01 & nd & nd & nd & nd & nd & nd & nd & nd & nd & nd \\
\hline C16:0 & 31.74 & 25.49 & 32.52 & 22.22 & 34.21 & 29.44 & 31.01 & 24.28 & 26.68 & 31.32 & 26.26 & 29.43 \\
\hline C16:1n7 & 2.47 & 8.36 & 3.86 & 2.67 & 3.56 & 7.18 & 8.86 & 8.06 & 8.12 & 6.43 & 2.15 & 2.97 \\
\hline C17:0 & 0.97 & 0.77 & 1.26 & 0.64 & 0.89 & 0.91 & 1.35 & 1.29 & 1.06 & 1.17 & 0.92 & 0.71 \\
\hline $\mathrm{C} 17: 1 \mathrm{n} 7$ & nd & nd & nd & nd & nd & nd & nd & nd & nd & nd & nd & nd \\
\hline C18:0 & 9.44 & 5.18 & 8.36 & 10.47 & 9.09 & 6.54 & 5.85 & 5.22 & 5.36 & 6.11 & 8.02 & 9.57 \\
\hline C18:1n9t & 0.20 & 0.26 & 0.23 & 0.73 & 0.27 & 0.28 & 0.83 & 0.37 & 0.31 & 0.35 & 0.23 & 0.40 \\
\hline $\mathrm{C} 18 \mathrm{~s} 1 \mathrm{n} 7 \mathrm{t}$ & nd & nd & nd & nd & nd & nd & nd & nd & nd & nd & nd & nd \\
\hline C18:1n9 & 6.19 & 12.15 & 9.04 & 8.40 & 8.73 & 16.00 & 18.19 & 20.15 & 15.41 & 14.56 & 5.40 & 9.94 \\
\hline C18:1n7 & 2.30 & 4.39 & 3.22 & 2.26 & 2.90 & 4.33 & 5.33 & 5.18 & 4.84 & 3.53 & 1.92 & 3.50 \\
\hline $\mathrm{C} 18: 2 \mathrm{n} 6$ & 0.81 & 1.31 & 0.94 & 6.74 & 0.82 & 0.93 & 2.28 & 1.60 & 1.40 & 1.31 & 0.93 & 1.01 \\
\hline C18:3n6 & 0.03 & 0.14 & 0.05 & 1.08 & 0.06 & 0.07 & 0.26 & 0.16 & 0.17 & 0.14 & 0.06 & 0.11 \\
\hline C19:0 & 0.19 & 0.17 & 0.24 & 0.99 & 0.23 & 0.25 & 0.34 & 0.33 & 0.26 & 0.18 & 0.19 & 0.33 \\
\hline C18:3n3 & 0.36 & 1.11 & 0.44 & 2.77 & 0.42 & 0.51 & 0.60 & 0.82 & 0.92 & 1.03 & 0.45 & 0.40 \\
\hline C18:4n3 & 0.32 & 1.21 & 0.28 & 3.54 & 0.42 & 0.44 & 0.54 & 0.34 & 1.28 & 1.44 & 0.42 & 0.39 \\
\hline C19:2n6 & 0.17 & 0.10 & 0.13 & 1.41 & 0.11 & 0.12 & 0.09 & 0.07 & 0.07 & 0.11 & 0.18 & 0.23 \\
\hline$C 20: 0$ & 0.10 & 0.17 & 0.21 & 3.12 & 0.26 & 0.29 & 0.10 & 0.27 & 0.28 & 0.17 & 0.16 & 0.20 \\
\hline C20:1n15 & 0.00 & 0.02 & 0.04 & 0.79 & 0.02 & 0.06 & nd & 0.05 & 0.05 & 0.02 & 0.06 & 0.03 \\
\hline
\end{tabular}


Table E2 continued. Striped bass collected from the Choptank River for field validation of the QFASA model.

\begin{tabular}{|c|c|c|c|c|c|c|c|c|c|c|c|c|}
\hline & \multicolumn{12}{|c|}{ Sample number } \\
\hline & 13 & 14 & 15 & 16 & 17 & 18 & 19 & 20 & 21 & 22 & 23 & 24 \\
\hline C20:1n12 & 0.09 & 0.59 & 0.93 & nd & 0.93 & 1.36 & nd & 1.02 & 1.17 & 0.18 & 0.22 & 0.74 \\
\hline C20:1n9 & 0.61 & 1.56 & 1.34 & 3.82 & 1.65 & 2.39 & 1.24 & 1.92 & 2.66 & 1.11 & 0.61 & 1.47 \\
\hline C20:1n7 & 0.13 & 0.85 & 0.73 & 3.41 & 0.63 & 1.42 & 0.72 & 1.46 & 1.06 & 0.22 & 0.26 & 0.50 \\
\hline C20:2n6 & 0.32 & 0.46 & 0.33 & 5.75 & 0.35 & 0.49 & 0.46 & 0.73 & 0.55 & 0.28 & 0.48 & 0.34 \\
\hline C20:3n6 & 0.07 & 0.12 & 0.09 & nd & 0.09 & 0.10 & 0.11 & 0.16 & 0.16 & 0.10 & 0.38 & 0.10 \\
\hline$C 21: 0$ & 0.01 & nd & nd & nd & nd & 0.01 & 0.01 & 0.14 & 0.05 & 0.03 & 0.16 & 0.02 \\
\hline$C 20: 4 n 6$ & 4.42 & 0.65 & 4.19 & 5.48 & 4.12 & 2.72 & 1.84 & 2.52 & 1.30 & 1.84 & 4.42 & 3.84 \\
\hline C20:3n3 & 0.13 & 0.16 & 0.13 & 0.20 & 0.15 & 0.14 & 0.22 & 0.18 & 0.16 & 0.15 & 0.36 & 0.11 \\
\hline C20:5n3 & 6.38 & 4.83 & 4.16 & 1.62 & 4.32 & 2.75 & 3.25 & 4.62 & 3.54 & 5.05 & 5.65 & 6.03 \\
\hline$C 22: 0$ & 0.04 & 0.19 & 0.11 & nd & 0.12 & 0.15 & 0.05 & 0.19 & 0.14 & 0.17 & 0.58 & 0.13 \\
\hline C22:1n9 & nd & 0.59 & 0.10 & nd & 0.32 & 0.87 & 0.12 & 0.43 & 0.37 & 0.22 & 0.53 & 0.21 \\
\hline $\mathrm{C} 22: 2 \mathrm{n} 6$ & 0.03 & 0.35 & 0.03 & nd & nd & 0.32 & 0.02 & 0.11 & nd & 0.07 & 1.23 & nd \\
\hline C22:4n6 & 0.36 & 0.59 & 0.73 & nd & 0.94 & 0.70 & 0.26 & 0.56 & 0.50 & 0.30 & 1.86 & 0.52 \\
\hline$C 22: 3 n 3+C 22: 5 n 6$ & 1.05 & 1.35 & 1.08 & 0.13 & 1.17 & 0.84 & 0.50 & 0.55 & 0.67 & 0.65 & 2.97 & 0.99 \\
\hline$C 22: 5 n 3$ & 0.99 & 3.10 & 1.43 & 0.47 & 1.40 & 1.65 & 1.57 & 2.39 & 2.48 & 1.13 & 2.98 & 1.61 \\
\hline$C 24: 0+C 22: 6 n 3$ & 27.58 & 13.92 & 19.73 & 6.00 & 17.10 & 10.63 & 9.00 & 9.88 & 11.09 & 14.80 & 25.57 & 21.32 \\
\hline C24:1n9 & 0.76 & 1.70 & 0.49 & 0.24 & 0.71 & 0.50 & 0.19 & 0.24 & 0.62 & 0.54 & 2.64 & 0.67 \\
\hline
\end{tabular}


Table E3. Striped bass collected from the Choptank River for field validation of the QFASA model.

\begin{tabular}{|c|c|c|c|c|c|c|c|c|c|c|c|c|}
\hline & \multicolumn{12}{|c|}{ Sample number } \\
\hline & 25 & 26 & 27 & 28 & 29 & 30 & 31 & 32 & 33 & 34 & 35 & 36 \\
\hline Total length (mm) & 490 & 565 & 486 & 468 & 537 & 510 & 540 & 530 & 524 & 539 & 570 & 606 \\
\hline Weight (g) & 914.4 & 1876.7 & 1132.2 & 1054.1 & 1620.0 & 1372.9 & 1512 & 1340 & 1474 & 1710 & 1986 & 2032 \\
\hline Lipid content (\%) & 2.50 & 14.39 & 7.81 & 2.82 & 7.81 & 32.51 & 4.16 & 0.56 & 2.01 & 1.45 & 1.12 & 2.25 \\
\hline C12:0 & 0.11 & 0.07 & 0.01 & 0.09 & 0.39 & 0.07 & 0.10 & 0.06 & 0.04 & 0.04 & 0.05 & 0.05 \\
\hline $\mathrm{C} 12: 1 \mathrm{n} 1$ & 0.05 & nd & nd & nd & nd & 0.02 & 0.01 & nd & 0.01 & nd & nd & 0.01 \\
\hline $\mathrm{C} 13: 0$ & nd & nd & nd & nd & 0.24 & nd & nd & nd & nd & nd & nd & nd \\
\hline $\mathrm{C} 14: 0$ & 4.07 & 5.13 & 1.16 & 3.40 & 4.76 & 2.23 & 5.29 & 3.24 & 2.73 & 1.66 & 2.91 & 2.87 \\
\hline C14:1n5 & 0.10 & 0.05 & 0.01 & 0.06 & 0.27 & 0.02 & 0.07 & 0.03 & 0.03 & 0.03 & 0.16 & 0.02 \\
\hline C15:0 & 0.83 & 0.80 & 0.60 & 0.78 & 1.41 & 0.68 & 0.84 & 0.93 & 0.59 & 0.89 & 0.55 & 0.65 \\
\hline C15:1n5 & nd & 0.03 & nd & 0.00 & 0.12 & nd & nd & nd & nd & nd & nd & nd \\
\hline C16:0 & 25.75 & 28.39 & 31.47 & 22.49 & 23.14 & 32.69 & 28.91 & 32.75 & 28.15 & 26.39 & 30.44 & 29.74 \\
\hline C16:1n7 & 8.62 & 8.06 & 2.56 & 6.02 & 8.99 & 3.95 & 7.08 & 5.05 & 4.38 & 3.58 & 7.49 & 4.08 \\
\hline C17:0 & 0.99 & 1.28 & 0.94 & 0.88 & 1.01 & 1.01 & 1.14 & 1.14 & 0.66 & 1.08 & 0.68 & 0.75 \\
\hline $\mathrm{C} 17: 1 \mathrm{n} 7$ & nd & nd & nd & nd & 0.15 & nd & nd & nd & nd & nd & nd & nd \\
\hline C18:0 & 5.13 & 7.69 & 8.59 & 5.00 & 5.02 & 8.60 & 6.57 & 7.49 & 8.06 & 5.42 & 5.73 & 8.83 \\
\hline C18:1n9t & 0.38 & nd & 0.24 & 0.26 & 0.50 & 0.27 & 0.29 & 0.26 & 0.27 & 0.27 & 0.44 & 0.21 \\
\hline $\mathrm{C} 18 \mathrm{~s} 1 \mathrm{n} 7 \mathrm{t}$ & nd & nd & nd & nd & nd & nd & nd & nd & nd & nd & nd & nd \\
\hline C18:1n9 & 14.89 & 7.21 & 8.15 & 7.77 & 20.91 & 7.02 & 9.72 & 7.70 & 7.26 & 6.41 & 20.41 & 6.21 \\
\hline C18:1n7 & 4.14 & 3.70 & 2.90 & 3.18 & 4.68 & 3.33 & 3.74 & 3.42 & 3.15 & 2.52 & 4.65 & 2.73 \\
\hline $\mathrm{C} 18: 2 \mathrm{n} 6$ & 1.66 & 1.09 & 0.95 & 1.17 & 1.89 & 0.85 & 1.30 & 1.03 & 0.93 & nd & 0.84 & 1.10 \\
\hline C18:3n6 & 0.17 & 0.18 & 0.06 & 0.16 & 0.24 & 0.06 & 0.14 & 0.10 & 0.12 & 0.12 & 0.07 & 0.07 \\
\hline C19:0 & 0.19 & 0.23 & 0.32 & 0.32 & 0.34 & 0.23 & 0.20 & 0.25 & 0.27 & 0.36 & 0.21 & 0.23 \\
\hline C18:3n3 & 2.09 & 1.01 & 0.50 & 1.29 & 1.29 & 0.74 & 1.28 & 0.76 & 0.86 & 0.62 & 0.35 & 0.96 \\
\hline C18:4n3 & 2.18 & 1.26 & 0.50 & 1.38 & 1.60 & 0.65 & 2.49 & 1.21 & 1.08 & 0.54 & 0.35 & 1.81 \\
\hline C19:2n6 & nd & 0.15 & 0.16 & 0.33 & 0.06 & 0.18 & 0.14 & 0.11 & 0.25 & 0.22 & 0.08 & 0.13 \\
\hline$C 20: 0$ & 0.21 & 0.20 & 0.13 & 0.49 & 0.59 & 0.18 & 0.20 & 0.18 & 0.26 & 0.34 & 0.19 & 0.18 \\
\hline C20:1n15 & 0.05 & 0.04 & 0.04 & 0.34 & nd & 0.05 & 0.04 & 0.05 & 0.10 & 0.13 & 0.05 & 0.03 \\
\hline
\end{tabular}


Table E3 continued. Striped bass collected from the Choptank River for field validation of the QFASA model.

\begin{tabular}{|c|c|c|c|c|c|c|c|c|c|c|c|c|}
\hline & \multicolumn{12}{|c|}{ Sample number } \\
\hline & 25 & 26 & 27 & 28 & 29 & 30 & 31 & 32 & 33 & 34 & 35 & 36 \\
\hline C20:1n12 & 0.28 & 0.20 & 0.26 & 0.78 & 1.84 & 0.47 & 0.67 & 0.58 & 0.33 & 0.85 & 1.34 & 0.25 \\
\hline C20:1n9 & 1.29 & 1.14 & 0.86 & 1.44 & 2.28 & 1.29 & 1.58 & 1.17 & 1.08 & 1.56 & 2.13 & 0.81 \\
\hline C20:1n7 & 0.53 & 0.36 & 0.27 & 1.08 & 2.48 & 0.44 & 0.57 & 0.57 & 0.42 & 0.94 & 1.24 & 0.30 \\
\hline$C 20: 2 n 6$ & 0.47 & 0.37 & 0.19 & 1.02 & 0.79 & 0.39 & 0.42 & 0.38 & 0.52 & 1.03 & 0.42 & 0.39 \\
\hline$C 20: 3 n 6$ & 0.15 & 0.18 & 0.14 & 0.46 & 0.24 & 0.09 & 0.09 & 0.18 & 0.32 & 0.61 & 0.13 & 0.12 \\
\hline C21:0 & 0.03 & nd & nd & nd & nd & 0.02 & nd & nd & nd & nd & nd & nd \\
\hline C20:4n6 & 1.82 & 2.26 & 4.11 & 2.25 & 1.40 & 2.62 & 1.81 & 2.57 & 2.79 & 4.45 & 2.30 & 2.56 \\
\hline$C 20: 3 n 3$ & 0.34 & 0.20 & 0.18 & 0.70 & 0.24 & 0.15 & 0.17 & 0.13 & 0.46 & 0.69 & 0.13 & 0.16 \\
\hline C20:5n3 & 6.97 & 7.62 & 6.70 & 6.78 & 3.38 & 5.72 & 6.87 & 6.34 & 6.05 & 5.82 & 3.44 & 7.15 \\
\hline $\mathrm{C} 22: 0$ & 0.15 & 0.22 & 0.09 & 0.87 & 0.17 & 0.05 & 0.14 & 0.13 & 0.35 & 0.92 & 0.07 & 0.07 \\
\hline C22:1n9 & nd & 0.57 & 0.09 & 0.80 & 0.62 & 0.30 & 0.23 & 0.15 & 1.01 & 2.22 & 0.19 & 0.28 \\
\hline$C 22: 2 n 6$ & 0.10 & 0.20 & 0.11 & 0.82 & nd & 0.03 & nd & 0.03 & nd & 0.43 & nd & 0.01 \\
\hline $\mathrm{C} 22: 4 \mathrm{n} 6$ & 0.26 & 0.39 & 1.05 & 1.69 & 0.27 & 0.44 & 0.39 & 0.48 & 0.94 & 2.64 & 0.66 & 0.27 \\
\hline$C 22: 3 n 3+C 22: 5 n 6$ & 0.56 & 0.80 & 1.41 & 2.15 & 0.75 & 0.90 & 0.64 & 0.80 & 2.06 & 2.67 & 0.63 & 0.87 \\
\hline C22:5n3 & 1.26 & 1.37 & 2.80 & 5.83 & 1.40 & 1.33 & 1.42 & 1.78 & 2.00 & 4.51 & 2.35 & 1.11 \\
\hline$C 24: 0+C 22: 6 n 3$ & 13.84 & 16.73 & 21.96 & 15.56 & 6.14 & 22.26 & 14.88 & 18.29 & 20.81 & 17.35 & 8.89 & 24.38 \\
\hline C24:1n9 & 0.36 & 0.45 & 0.50 & 2.26 & 0.42 & 0.69 & 0.56 & 0.67 & 1.63 & 2.67 & 0.46 & 0.62 \\
\hline
\end{tabular}


Table E4. Striped bass collected from the Choptank River for field validation of the QFASA model.

\begin{tabular}{|c|c|c|c|c|c|c|c|c|c|c|c|c|}
\hline & \multicolumn{12}{|c|}{ Sample number } \\
\hline & 37 & 38 & 39 & 40 & 41 & 42 & 43 & 44 & 45 & 46 & 47 & 48 \\
\hline Total length (mm) & 440 & 457 & 514 & 544 & 557 & 554 & 540 & 513 & 473 & 519 & 497 & 522 \\
\hline Weight (g) & 822 & 956 & 1260 & 1742 & 1770 & 1670 & 1534 & 1558 & 1106 & 1374 & 1192 & 1448 \\
\hline Lipid content (\%) & 1.88 & 6.38 & 4.68 & 5.55 & 2.45 & 2.02 & 3.51 & 7.55 & 3.48 & 3.31 & 3.52 & 1.10 \\
\hline C12:0 & 0.07 & 0.06 & 0.12 & 0.11 & 0.04 & 0.07 & 0.18 & 0.05 & 0.09 & 0.12 & 0.10 & 0.06 \\
\hline C12:1n1 & nd & 0.04 & nd & 0.01 & 0.06 & 0.04 & 0.06 & 0.03 & 0.02 & 0.02 & 0.03 & 0.04 \\
\hline $\mathrm{C} 13: 0$ & nd & nd & nd & nd & nd & nd & 0.54 & nd & 0.37 & nd & nd & nd \\
\hline C14:0 & 4.24 & 3.21 & 5.57 & 2.32 & 1.74 & 3.40 & 4.40 & 2.03 & 3.40 & 2.27 & 1.66 & 1.83 \\
\hline C14:1n5 & 0.10 & 0.08 & 0.08 & 0.03 & 0.03 & 0.05 & 0.18 & 0.02 & 0.06 & 0.02 & 0.02 & 0.03 \\
\hline C15:0 & 0.77 & 0.66 & 0.98 & 0.66 & 0.63 & 0.88 & 1.13 & 0.61 & 0.78 & 0.78 & 0.84 & 0.61 \\
\hline C15:1n5 & 0.01 & nd & nd & nd & nd & nd & nd & nd & nd & nd & nd & nd \\
\hline C16:0 & 28.62 & 28.27 & 29.01 & 29.76 & 20.56 & 27.47 & 25.73 & 18.69 & 26.88 & 30.52 & 29.80 & 29.80 \\
\hline C16:1n7 & 5.76 & 4.66 & 6.87 & 4.37 & 4.93 & 5.76 & 7.09 & 3.11 & 5.91 & 3.37 & 3.77 & 3.12 \\
\hline C17:0 & 0.83 & 1.13 & 0.94 & 1.01 & 6.20 & 0.96 & 1.78 & 0.45 & 0.84 & 0.79 & 1.40 & 1.70 \\
\hline C17:1n7 & nd & nd & nd & nd & nd & nd & nd & nd & nd & nd & nd & nd \\
\hline C18:0 & 6.92 & 7.84 & 6.58 & 7.59 & 5.84 & 7.40 & 4.45 & 5.31 & 6.85 & 9.67 & 8.53 & 8.76 \\
\hline C18:1n9t & 0.32 & 0.36 & 0.26 & 0.18 & nd & 0.30 & 0.17 & nd & 0.19 & nd & 0.21 & 0.19 \\
\hline C18:1n7t & nd & nd & nd & nd & nd & nd & nd & nd & nd & nd & nd & nd \\
\hline C18:1n9 & 12.06 & 12.76 & 11.26 & 6.36 & 5.57 & 6.87 & 13.27 & 4.79 & 8.29 & 7.26 & 8.72 & 9.64 \\
\hline C18:1n7 & 3.67 & 4.19 & 3.94 & 2.78 & 3.33 & 3.41 & 3.84 & 2.39 & 3.30 & 3.44 & 2.75 & 3.07 \\
\hline C18:2n6 & 1.11 & 0.89 & 1.25 & 0.95 & 0.77 & 0.93 & 1.30 & 0.87 & 1.26 & 0.90 & 1.06 & 0.99 \\
\hline C18:3n6 & 0.12 & 0.10 & 0.14 & 0.09 & 0.04 & 0.16 & 0.25 & 0.28 & 0.09 & 0.17 & 0.05 & 0.06 \\
\hline C19:0 & 0.19 & 0.23 & 0.24 & 0.18 & 0.14 & 0.28 & 0.26 & 0.28 & 0.23 & 0.25 & 0.25 & 0.24 \\
\hline C18:3n3 & 1.15 & 0.69 & 1.21 & 0.77 & 1.08 & 1.31 & 1.73 & 0.95 & 1.16 & 0.86 & 0.49 & 0.50 \\
\hline C18:4n3 & 2.06 & 0.66 & 2.05 & 1.13 & 0.65 & 1.11 & 1.85 & 1.24 & 1.93 & 0.84 & 0.45 & 0.74 \\
\hline C19:2n6 & 0.13 & 0.11 & 0.12 & 0.17 & 0.19 & 0.20 & 0.14 & 0.54 & 0.17 & 0.21 & 0.14 & 0.36 \\
\hline C20:0 & 0.25 & 0.27 & 0.32 & 0.12 & 0.10 & 0.22 & 0.34 & 0.81 & nd & 0.28 & 0.16 & 0.38 \\
\hline C20:1n15 & nd & 0.07 & 0.04 & 0.02 & 0.18 & 0.04 & 0.04 & nd & nd & 0.03 & 0.00 & 0.02 \\
\hline
\end{tabular}


Table E4 continued. Striped bass collected from the Choptank River for field validation of the QFASA model.

\begin{tabular}{|c|c|c|c|c|c|c|c|c|c|c|c|c|}
\hline & \multicolumn{12}{|c|}{ Sample number } \\
\hline & 37 & 38 & 39 & 40 & 41 & 42 & 43 & 44 & 45 & 46 & 47 & 48 \\
\hline C20:1n12 & 0.76 & 1.27 & 0.92 & 0.25 & 0.34 & 0.37 & 0.57 & 1.15 & 0.46 & 0.33 & 0.33 & 0.66 \\
\hline C20:1n9 & 1.91 & 2.90 & 2.22 & 0.82 & 0.91 & 1.13 & 1.58 & 1.41 & 1.00 & 1.16 & 1.04 & 1.44 \\
\hline C20:1n7 & 0.55 & 1.19 & 0.63 & 0.31 & 0.51 & 0.35 & 0.66 & 0.88 & 0.54 & 0.36 & 0.67 & 0.68 \\
\hline$C 20: 2 n 6$ & 0.39 & 0.61 & 0.51 & 0.39 & 0.54 & 0.26 & 0.49 & 0.97 & 0.45 & 0.59 & 0.57 & 0.58 \\
\hline$C 20: 3 n 6$ & 0.13 & 0.14 & 0.23 & 0.15 & 0.22 & 0.14 & 0.17 & 0.66 & 0.18 & 0.14 & 0.21 & 0.10 \\
\hline $\mathrm{C} 21: 0$ & nd & nd & nd & nd & nd & 0.10 & nd & nd & nd & 0.10 & nd & 0.16 \\
\hline$C 20: 4 n 6$ & 1.46 & 1.75 & 1.83 & 3.58 & 3.72 & 2.82 & 2.02 & 3.19 & 2.42 & 2.56 & 4.57 & 3.17 \\
\hline$C 20: 3 n 3$ & 0.18 & 0.21 & 0.29 & 0.17 & 0.35 & 1.20 & 0.30 & 0.85 & 0.29 & 0.23 & 0.23 & 0.24 \\
\hline$C 20: 5 n 3$ & 5.40 & 4.14 & 5.18 & 7.48 & 6.25 & 6.88 & 6.27 & 8.42 & 7.78 & 5.64 & 6.69 & 4.86 \\
\hline$C 22: 0$ & 0.22 & 0.35 & 0.15 & 0.22 & 0.25 & 0.17 & 0.31 & 1.63 & 0.40 & 0.41 & 0.14 & 2.36 \\
\hline C22:1n9 & 0.67 & 0.97 & 0.28 & 0.14 & 0.31 & 0.20 & 0.49 & 2.03 & 0.49 & 0.37 & 0.15 & 0.71 \\
\hline $\mathrm{C} 22: 2 \mathrm{n} 6$ & 0.10 & 0.17 & nd & 0.02 & 0.11 & nd & 0.11 & 0.79 & 0.05 & nd & 0.02 & 0.18 \\
\hline$C 22: 4 n 6$ & 0.37 & 0.50 & 0.61 & 0.46 & 1.00 & 0.55 & 0.38 & 2.17 & 0.36 & 0.24 & 0.81 & 0.41 \\
\hline$C 22: 3 n 3+C 22: 5 n 6$ & 0.59 & 0.69 & 0.72 & 1.39 & 1.52 & 0.87 & 0.76 & 3.00 & 0.84 & 0.85 & 1.08 & 1.04 \\
\hline$C 22: 5 n 3$ & 1.51 & 1.45 & 1.71 & 1.64 & 2.69 & 1.56 & 2.05 & 4.65 & 1.76 & 1.30 & 2.00 & 1.39 \\
\hline$C 24: 0+C 22: 6 n 3$ & 16.77 & 16.88 & 13.33 & 23.83 & 25.72 & 21.28 & 14.60 & 23.60 & 20.68 & 23.15 & 20.38 & 19.27 \\
\hline C24:1n9 & 0.64 & 0.52 & 0.40 & 0.50 & 3.49 & 1.26 & 0.51 & 2.08 & 0.48 & 0.74 & 0.69 & 0.63 \\
\hline
\end{tabular}


Table E5. Striped bass collected from the Choptank River for field validation of the QFASA model.

\begin{tabular}{|c|c|c|c|c|c|c|c|c|c|c|c|c|}
\hline & \multicolumn{12}{|c|}{ Sample number } \\
\hline & 49 & 50 & 51 & 52 & 53 & 54 & 55 & 56 & 57 & 58 & 59 & 60 \\
\hline Total length (mm) & 532 & 560 & 481 & 465 & 550 & 568 & 519 & 476 & 460 & 542 & 525 & 552 \\
\hline Weight (g) & 1328 & 1822 & 1200 & 854 & 1460 & 1794 & 1256 & 1026 & 996 & 1482 & 1446 & 1818 \\
\hline Lipid content (\%) & 3.49 & 4.58 & 9.92 & 2.24 & 2.46 & 6.46 & 2.96 & 3.22 & 3.74 & 2.70 & 7.95 & 3.19 \\
\hline C12:0 & 0.12 & 0.12 & 0.13 & 0.09 & 0.08 & 0.03 & 0.10 & 0.06 & 0.11 & 0.10 & 0.10 & 0.13 \\
\hline C12:1n1 & 0.02 & nd & nd & 0.04 & nd & nd & 0.04 & 0.02 & 0.04 & 0.03 & nd & 0.03 \\
\hline $\mathrm{C} 13: 0$ & 0.43 & 0.29 & nd & nd & 0.34 & nd & nd & nd & nd & 0.24 & 0.33 & 0.55 \\
\hline C14:0 & 3.80 & 8.75 & 3.06 & 2.47 & 4.37 & 1.87 & 2.64 & 2.43 & 2.67 & 6.17 & 5.42 & 4.46 \\
\hline C14:1n5 & 0.08 & 0.28 & 0.03 & 0.03 & 0.09 & 0.02 & 0.03 & 0.04 & 0.05 & 0.08 & 0.08 & 0.04 \\
\hline C15:0 & 1.06 & 1.20 & 0.82 & 0.68 & 0.86 & 0.72 & 0.84 & 0.85 & 0.86 & 0.96 & 0.98 & 0.74 \\
\hline C15:1n5 & nd & nd & nd & nd & nd & nd & nd & nd & nd & nd & nd & nd \\
\hline C16:0 & 29.31 & 26.13 & 29.13 & 21.60 & 22.08 & 20.45 & 35.02 & 29.11 & 27.46 & 27.92 & 30.59 & 27.86 \\
\hline C16:1n7 & 5.91 & 9.23 & 4.66 & 3.52 & 6.12 & 3.30 & 3.67 & 3.59 & 4.48 & 7.77 & 7.16 & 5.91 \\
\hline C17:0 & 0.96 & 1.47 & 0.74 & 1.41 & 1.31 & 1.37 & 1.40 & 1.41 & 1.29 & 1.31 & 1.36 & 1.40 \\
\hline $\mathrm{C} 17: 1 \mathrm{n} 7$ & nd & nd & nd & nd & nd & nd & nd & nd & nd & nd & nd & nd \\
\hline C18:0 & 7.54 & 4.65 & 8.36 & 5.92 & 5.13 & 6.55 & 8.53 & 7.79 & 7.34 & 6.25 & 6.47 & 7.39 \\
\hline C18:1n9t & 0.22 & nd & 0.17 & 0.18 & 0.27 & 0.26 & 0.25 & nd & 0.19 & 0.12 & nd & 0.14 \\
\hline $\mathrm{C} 18 \mathrm{~s} 1 \mathrm{n} 7 \mathrm{t}$ & nd & nd & nd & nd & nd & nd & nd & nd & nd & nd & nd & nd \\
\hline C18:1n9 & 11.17 & 9.43 & 5.82 & 5.78 & 10.36 & 5.26 & 7.02 & 8.80 & 10.13 & 8.76 & 9.62 & 6.46 \\
\hline C18:1n7 & 3.39 & 4.15 & 2.67 & 2.70 & 3.32 & 2.57 & 2.58 & 2.83 & 3.34 & 3.64 & 3.57 & 3.29 \\
\hline $\mathrm{C} 18: 2 \mathrm{n} 6$ & 1.24 & 1.69 & 1.09 & 1.11 & 1.42 & 0.97 & 1.19 & 0.84 & 0.86 & 1.30 & 1.43 & 1.27 \\
\hline C18:3n6 & 0.10 & 0.21 & 0.11 & 0.19 & 0.26 & 0.18 & 0.09 & 0.07 & 0.09 & 0.16 & 0.14 & 0.14 \\
\hline C19:0 & 0.27 & 0.21 & 0.22 & 0.33 & 0.29 & 0.39 & 0.23 & 0.25 & 0.21 & 0.22 & 0.22 & 0.19 \\
\hline C18:3n3 & 0.99 & 2.07 & 0.86 & 0.99 & 1.51 & 1.34 & 1.11 & 0.63 & 0.73 & 1.44 & 1.45 & 1.33 \\
\hline C18:4n3 & 1.29 & 1.95 & 1.27 & 1.49 & 1.94 & 0.94 & 1.21 & 0.66 & 1.06 & 2.53 & 2.14 & 2.85 \\
\hline C19:2n6 & 0.15 & nd & 0.22 & 0.60 & 0.30 & 0.39 & 0.15 & 0.12 & 0.18 & 0.15 & 0.14 & 0.23 \\
\hline$C 20: 0$ & 0.34 & 0.27 & 0.38 & 0.47 & 0.48 & 0.62 & 0.22 & 0.24 & 0.18 & 0.28 & 0.25 & 0.20 \\
\hline C20:1n15 & 0.03 & nd & nd & 0.43 & 0.30 & 0.24 & 0.04 & 0.02 & 0.03 & 0.05 & 0.04 & 0.03 \\
\hline
\end{tabular}


Table E5 continued. Striped bass collected from the Choptank River for field validation of the QFASA model.

\begin{tabular}{|c|c|c|c|c|c|c|c|c|c|c|c|c|}
\hline & \multicolumn{12}{|c|}{ Sample number } \\
\hline & 49 & 50 & 51 & 52 & 53 & 54 & 55 & 56 & 57 & 58 & 59 & 60 \\
\hline C20:1n12 & 1.12 & 0.34 & 0.29 & 0.79 & 0.85 & 0.71 & 0.18 & 0.55 & 0.76 & 0.73 & 0.64 & 0.39 \\
\hline C20:1n9 & 1.69 & 1.17 & 0.94 & 1.60 & 1.83 & 1.24 & 0.88 & 1.49 & 1.73 & 1.47 & 1.41 & 0.95 \\
\hline C20:1n7 & 1.24 & 0.53 & 0.31 & 0.96 & 0.83 & 0.76 & 0.19 & 0.48 & 0.62 & 0.65 & 0.48 & 0.31 \\
\hline$C 20: 2 n 6$ & 0.58 & 0.44 & 0.37 & 0.71 & 0.90 & 0.96 & 0.31 & 0.60 & 0.40 & 0.39 & 0.43 & 0.44 \\
\hline$C 20: 3 n 6$ & 0.12 & 0.19 & 0.16 & 0.72 & 0.39 & 0.73 & 0.13 & 0.25 & 0.18 & 0.10 & 0.10 & 0.91 \\
\hline C21:0 & 0.06 & nd & nd & 0.40 & 0.19 & nd & nd & nd & nd & 0.04 & 0.04 & nd \\
\hline$C 20: 4 n 6$ & 2.58 & 1.04 & 4.55 & 3.41 & 2.05 & 4.04 & 2.80 & 3.56 & 2.84 & 1.46 & 1.81 & 3.78 \\
\hline$C 20: 3 n 3$ & 0.23 & 0.33 & 0.18 & 0.58 & 0.91 & 0.83 & 0.18 & 0.33 & 0.23 & 0.23 & 0.26 & 0.81 \\
\hline$C 20: 5 n 3$ & 5.66 & 6.29 & 7.92 & 6.28 & 5.60 & 7.80 & 5.31 & 6.78 & 6.78 & 7.15 & 5.85 & 7.18 \\
\hline $\mathrm{C} 22: 0$ & 0.49 & nd & 0.25 & 1.44 & 1.02 & 1.34 & 0.15 & 0.47 & 0.80 & 0.52 & 0.13 & 0.14 \\
\hline C22:1n9 & 0.44 & 0.12 & 0.21 & 1.01 & 1.18 & 1.21 & 0.12 & 0.40 & 0.54 & 0.48 & 0.21 & 0.19 \\
\hline $\mathrm{C} 22: 2 \mathrm{n} 6$ & 0.03 & 0.04 & 0.06 & 0.58 & 0.92 & 0.36 & 0.03 & 0.10 & 0.06 & 0.05 & nd & nd \\
\hline$C 22: 4 n 6$ & 0.33 & 0.20 & 0.27 & 1.54 & 0.91 & 1.33 & 0.30 & 0.66 & 0.65 & 0.34 & 0.38 & 0.43 \\
\hline$C 22: 3 n 3+C 22: 5 n 6$ & 0.72 & 0.63 & 1.26 & 3.19 & 2.18 & 3.51 & 0.87 & 1.07 & 0.91 & 0.64 & 0.66 & 0.71 \\
\hline$C 22: 5 n 3$ & 1.42 & 2.19 & 1.92 & 4.20 & 3.40 & 4.32 & 0.92 & 1.81 & 2.16 & 1.64 & 1.54 & 1.36 \\
\hline$C 24: 0+C 22: 6 n 3$ & 14.40 & 13.86 & 20.81 & 19.19 & 13.64 & 20.35 & 20.86 & 21.12 & 19.61 & 14.00 & 14.06 & 17.16 \\
\hline C24:1n9 & 0.48 & 0.52 & 0.74 & 3.36 & 2.39 & 3.03 & 0.43 & 0.56 & 0.44 & 0.60 & 0.51 & 0.59 \\
\hline
\end{tabular}


Table E6. Striped bass collected from the Choptank River for field validation of the QFASA model.

\begin{tabular}{|c|c|c|c|c|c|c|c|c|c|c|c|c|}
\hline & \multicolumn{12}{|c|}{ Sample number } \\
\hline & 61 & 62 & 63 & 64 & 65 & 66 & 67 & 68 & 69 & 70 & 71 & 72 \\
\hline Total length (mm) & 511 & 488 & 515 & 557 & 406 & 432 & 434 & 491 & 536 & 449 & 527 & 511 \\
\hline Weight (g) & 1170 & 1266 & 1392 & 1440 & 594 & 864 & 820 & 1250 & 1524 & 1232 & 1526 & 1194 \\
\hline Lipid content (\%) & 4.40 & 2.87 & 2.22 & 2.92 & 3.54 & 6.11 & 9.19 & 11.13 & 10.07 & 5.33 & 3.49 & 2.94 \\
\hline C12:0 & 0.09 & 0.07 & 0.04 & 0.07 & 0.23 & 0.19 & 0.07 & 0.09 & 0.10 & 0.07 & 0.07 & 0.06 \\
\hline C12:1n1 & 0.03 & 0.02 & 0.01 & 0.04 & 0.03 & 0.02 & 0.03 & 0.02 & 0.03 & 0.03 & 0.04 & 0.03 \\
\hline C13:0 & 0.43 & 0.33 & nd & nd & 0.30 & 0.21 & 0.24 & 0.13 & 0.26 & nd & 0.42 & nd \\
\hline C14:0 & 4.95 & 4.36 & 1.91 & 2.34 & 2.34 & 2.86 & 3.32 & 3.04 & 5.05 & 2.84 & 4.06 & 2.44 \\
\hline C14:1n5 & 0.08 & 0.12 & 0.04 & 0.04 & 0.15 & 0.18 & 0.16 & 0.16 & 0.12 & 0.08 & 0.04 & 0.08 \\
\hline C15:0 & 0.95 & 0.72 & 0.58 & 0.57 & 0.86 & 0.80 & 1.02 & 0.64 & 0.81 & 0.59 & 0.71 & 0.86 \\
\hline C15:1n5 & nd & nd & nd & nd & nd & nd & nd & nd & nd & nd & nd & nd \\
\hline C16:0 & 27.81 & 30.14 & 29.21 & 29.09 & 25.30 & 26.99 & 30.17 & 21.18 & 26.17 & 22.15 & 28.00 & 29.21 \\
\hline C16:1n7 & 7.01 & 6.78 & 3.18 & 3.96 & 6.21 & 7.66 & 5.51 & 7.11 & 6.88 & 4.81 & 6.25 & 5.47 \\
\hline C17:0 & 0.97 & 1.34 & 0.78 & 0.76 & 1.14 & 1.04 & 1.22 & 0.97 & 0.77 & 1.05 & 1.24 & 1.19 \\
\hline C17:1n7 & nd & nd & nd & nd & nd & nd & nd & nd & nd & nd & nd & nd \\
\hline C18:0 & 7.48 & 6.99 & 9.14 & 8.67 & 4.64 & 5.40 & 4.95 & 4.55 & 5.94 & 5.19 & 7.47 & 7.31 \\
\hline C18:1n9t & nd & 0.39 & 0.23 & 0.20 & 0.26 & 0.25 & 0.24 & 0.30 & 0.14 & 0.25 & 0.22 & 0.26 \\
\hline $\mathrm{C} 18 \mathrm{~s} 1 \mathrm{n} 7 \mathrm{t}$ & nd & nd & nd & nd & nd & nd & nd & nd & nd & nd & nd & nd \\
\hline C18:1n9 & 9.12 & 14.84 & 8.69 & 8.71 & 20.15 & 24.03 & 21.81 & 18.03 & 11.17 & 9.16 & 7.20 & 16.60 \\
\hline C18:1n7 & 4.28 & 4.32 & 3.43 & 2.74 & 4.36 & 4.53 & 4.24 & 5.51 & 3.85 & 3.53 & 3.52 & 3.95 \\
\hline C18:2n6 & 1.33 & 1.17 & 0.82 & 0.89 & 1.44 & 1.20 & 2.01 & 1.10 & 1.49 & 1.18 & 1.66 & 0.86 \\
\hline C18:3n6 & 0.17 & 0.15 & 0.06 & 0.08 & 0.13 & 0.09 & 0.15 & 0.21 & 0.15 & 0.18 & 0.19 & 0.07 \\
\hline C19:0 & 0.25 & 0.24 & 0.27 & 0.23 & 0.37 & 0.22 & 0.26 & 0.35 & 0.20 & 0.25 & 0.23 & 0.21 \\
\hline C18:3n3 & 1.14 & 0.97 & 0.45 & 0.60 & 0.86 & 0.48 & 1.37 & 0.73 & 1.41 & 0.94 & 1.35 & 0.60 \\
\hline C18:4n3 & 2.00 & 1.39 & 0.36 & 0.55 & 0.50 & 0.17 & 1.03 & 0.65 & 2.36 & 1.01 & 2.08 & 0.61 \\
\hline C19:2n6 & 0.14 & 0.14 & 0.19 & 0.12 & 0.03 & 0.04 & 0.06 & 0.30 & 0.12 & 0.30 & 0.19 & 0.07 \\
\hline$C 20: 0$ & 0.26 & 0.21 & 0.15 & 0.18 & 0.35 & 0.29 & 0.26 & 0.40 & 0.23 & 0.38 & 0.25 & 0.21 \\
\hline C20:1n15 & 0.05 & 0.04 & 0.02 & 0.03 & nd & 0.02 & nd & 0.23 & 0.03 & 0.11 & 0.07 & 0.06 \\
\hline
\end{tabular}


Table E6 continued. Striped bass collected from the Choptank River for field validation of the QFASA model.

\begin{tabular}{|c|c|c|c|c|c|c|c|c|c|c|c|c|}
\hline & \multicolumn{12}{|c|}{ Sample number } \\
\hline & 61 & 62 & 63 & 64 & 65 & 66 & 67 & 68 & 69 & 70 & 71 & 72 \\
\hline C20:1n12 & 1.01 & 0.88 & 0.84 & 0.56 & 0.93 & 1.15 & 0.33 & 1.59 & 0.87 & 0.82 & 0.31 & 0.83 \\
\hline C20:1n9 & 1.63 & 2.83 & 1.80 & 0.93 & 2.04 & 1.99 & 1.62 & 2.98 & 2.02 & 2.03 & 1.09 & 2.36 \\
\hline C20:1n7 & 0.76 & 0.78 & 0.55 & 0.49 & 1.25 & 1.75 & 0.41 & 1.74 & 0.60 & 0.89 & 0.33 & 0.82 \\
\hline$C 20: 2 n 6$ & 0.46 & 0.34 & 0.37 & 0.32 & 0.72 & 0.55 & 0.46 & 1.56 & 0.51 & 0.97 & 0.41 & 0.46 \\
\hline$C 20: 3 n 6$ & 0.12 & 0.09 & 0.09 & 0.11 & 0.13 & 0.12 & 0.13 & 0.36 & 0.13 & 0.71 & 0.12 & 0.10 \\
\hline C21:0 & nd & nd & nd & nd & nd & nd & nd & nd & nd & nd & nd & nd \\
\hline$C 20: 4 n 6$ & 1.54 & 1.26 & 3.85 & 3.23 & 2.07 & 1.72 & 1.56 & 1.88 & 2.23 & 3.23 & 2.19 & 2.00 \\
\hline C20:3n3 & 0.23 & 0.18 & 0.15 & 0.12 & 0.24 & 0.17 & 0.28 & 0.80 & 0.26 & 0.60 & 0.20 & 0.06 \\
\hline C20:5n3 & 6.22 & 4.11 & 5.32 & 7.72 & 8.17 & 5.80 & 2.35 & 5.32 & 6.29 & 7.81 & 7.07 & 5.20 \\
\hline$C 22: 0$ & 0.14 & 0.11 & 0.10 & 1.41 & 1.47 & 1.31 & 0.10 & 0.58 & 0.26 & 0.77 & 0.13 & 0.35 \\
\hline C22:1n9 & 0.23 & 0.24 & 0.19 & 0.55 & 0.61 & 0.59 & 0.25 & 0.87 & 0.31 & 1.09 & 0.18 & 0.37 \\
\hline $\mathrm{C} 22: 2 \mathrm{n} 6$ & nd & nd & nd & nd & 0.10 & 0.05 & 0.04 & 0.34 & nd & nd & 0.04 & 0.03 \\
\hline$C 22: 4 n 6$ & 0.45 & 0.42 & 0.63 & 0.51 & 0.47 & 0.38 & 0.42 & 1.66 & 0.53 & 1.69 & 0.32 & 0.50 \\
\hline$C 22: 3 n 3+C 22: 5 n 6$ & 0.71 & 0.53 & 1.19 & 0.99 & 0.57 & 0.37 & 0.70 & 1.81 & 0.80 & 1.95 & 0.91 & 0.58 \\
\hline$C 22: 5 n 3$ & 1.67 & 1.38 & 1.52 & 1.65 & 1.90 & 1.53 & 1.65 & 3.31 & 1.94 & 3.30 & 1.37 & 1.80 \\
\hline$C 24: 0+C 22: 6 n 3$ & 15.67 & 11.76 & 23.06 & 21.03 & 9.48 & 5.71 & 11.20 & 8.35 & 15.45 & 18.38 & 19.49 & 13.94 \\
\hline C24:1n9 & 0.63 & 0.33 & 0.79 & 0.49 & 0.20 & 0.11 & 0.36 & 1.13 & 0.53 & 1.64 & 0.58 & 0.46 \\
\hline
\end{tabular}


Table E7. Striped bass collected from the Choptank River for field validation of the QFASA model.

\begin{tabular}{lccccc} 
& \multicolumn{5}{c}{ Sample number } \\
\hline & 73 & 74 & 75 & 76 & 77 \\
\hline Total length (mm) & 470 & 503 & 545 & 454 & 573 \\
Weight (g) & 1036 & 1020 & 1560 & 958 & 1100 \\
Lipid content (\%) & 6.20 & 1.68 & 3.09 & 6.36 & 8.87 \\
C12:0 & 0.06 & 0.05 & 0.10 & 0.20 & 0.15 \\
C12:1n1 & nd & 0.03 & 0.04 & 0.11 & 0.04 \\
C13:0 & nd & 0.26 & nd & 0.45 & 0.30 \\
C14:0 & 2.33 & 2.28 & 3.88 & 2.65 & 6.17 \\
C14:1n5 & 0.04 & 0.08 & 0.11 & 0.11 & 0.15 \\
C15:0 & 0.60 & 0.69 & 0.85 & 0.66 & 0.91 \\
C15:1n5 & nd & nd & nd & nd & nd \\
C16:0 & 28.22 & 22.14 & 32.27 & 21.57 & 25.51 \\
C16:1n7 & 3.87 & 5.85 & 6.58 & 3.91 & 7.86 \\
C17:0 & 1.18 & 1.10 & 1.28 & 0.94 & 1.11 \\
C17:1n7 & nd & nd & nd & nd & nd \\
C18:0 & 8.02 & 4.60 & 7.06 & 5.08 & 6.20 \\
C18:1n9t & 0.21 & 0.33 & 0.25 & 0.33 & 0.15 \\
C18:1n7t & nd & nd & nd & nd & nd \\
C18:1n9 & 9.75 & 12.53 & 15.61 & 11.33 & 12.04 \\
C18:1n7 & 3.95 & 3.61 & 3.66 & 2.31 & 4.31 \\
C18:2n6 & 0.92 & 1.08 & 1.22 & 0.77 & 1.47 \\
C18:3n6 & 0.07 & 0.21 & 0.11 & 0.22 & 0.18 \\
C19:0 & 0.22 & 0.40 & 0.25 & 0.30 & 0.26 \\
C18:3n3 & 0.72 & 0.64 & 1.06 & 0.99 & 1.46 \\
C18:4n3 & 0.52 & 0.82 & 1.00 & 0.81 & 2.38 \\
C19:2n6 & 0.13 & 0.25 & 0.12 & 0.14 & 0.11 \\
C20:0 & 0.18 & 0.79 & 0.32 & 0.31 & 0.28 \\
C20:1n15 & 0.03 & 0.33 & nd & nd & 0.04 \\
\hline & & & & & \\
& & & & \\
& & & & &
\end{tabular}


Table E7 continued. Striped bass collected from the Choptank River for field validation of the QFASA model.

\begin{tabular}{lccccc} 
& \multicolumn{5}{c}{ Sample number } \\
\hline \hline C20:1n12 & 73 & 74 & 75 & 76 & 77 \\
C20:1n9 & 0.77 & 1.30 & 0.58 & 0.38 & 1.48 \\
C20:1n7 & 2.00 & 1.96 & 1.40 & 1.20 & 2.32 \\
C20:2n6 & 0.55 & 1.53 & 0.73 & 0.75 & 1.12 \\
C20:3n6 & 0.40 & 1.47 & 0.47 & 0.35 & 0.55 \\
C21:0 & 0.15 & 0.36 & 0.15 & nd & 0.12 \\
C20:4n6 & 0.03 & nd & nd & nd & nd \\
C20:3n3 & 3.09 & 2.86 & 1.89 & 2.45 & 1.28 \\
C20:5n3 & 0.29 & 0.99 & 0.19 & 0.24 & 0.19 \\
C22:0 & 6.18 & 5.83 & 4.40 & 15.32 & 6.21 \\
C22:1n9 & 0.34 & 1.04 & 0.21 & 11.51 & 0.45 \\
C22:2n6 & 0.39 & 1.40 & 0.17 & 3.01 & 0.35 \\
C22:4n6 & nd & 0.47 & 0.07 & nd & 0.08 \\
C22:3n3 + C22:5n6 & 0.59 & 2.05 & 0.30 & 0.96 & 0.74 \\
C22:5n3 & 0.96 & 2.35 & 0.61 & 0.70 & 0.59 \\
C24:0+C22:6n3 & 1.56 & 3.98 & 1.20 & 1.07 & 2.22 \\
C24:1n9 & 20.97 & 12.32 & 11.40 & 8.60 & 10.82 \\
\hline
\end{tabular}




\section{Methods Appendix}

The following information represents the methods used at the NOAA Fisheries James J. Howard Marine Sciences Laboratory in Sandy Hook, New Jersey. Some methods described were attempted but were not used in the final preparation of samples due to an inability to obtain proper results or to save time and money. All glassware and metal tools, e.g. spatulas, were cleaned three times with acetone and three times with methylene chloride dispensed from PTFE spray bottles prior to any sample addition. Air in test tubes containing fatty acids in methylene chloride or hexane was flushed under a gentle stream of nitrogen prior to storage in the freezer to prevent oxidation. All liquid and solid hazardous waste was disposed of in accordance with safety protocols of the laboratory.

\section{Grinding the samples}

Samples were removed from the freezer at the time of analysis and weighed to the nearest $0.1 \mathrm{~g}$. Accelerated solvent extractor (ASE) stainless steel cells $(34 \mathrm{ml})$ were prepped and filled with diatomaceous earth. A sample consisted of three to five grams of the sample. The diatomaceous earth was added to the mortar along with the sample. The sample was ground using a pestle until the sample was thoroughly mixed with the diatomaceous earth. The entire contents of the mortar were then added to the ASE cell. A known amount of C23:0 triacylglycerol standard (typically 60 to $100 \mu \mathrm{g}$ ) was added to each cell and to a cell that only contained diatomaceous earth. Samples that exceeded three to five grams in weight were homogenized in a blender first, and then three to five grams of sample was removed, and the above procedure was followed. 


\section{Running samples on the Accelerated Solvent Extractor (ASE)}

Cells were placed onto the ASE along with glass collecting bottles. A solution of 3:1 by volume of methylene chloride and methanol was prepared and $0.01 \%$ of butylated hydroxytoluene (BHT) was added as an antioxidant. The ASE and the nitrogen supply were turned on, and the line was rinsed with the methylene chloride:methanol solution four times. Once this process was complete, the program was initiated. This program heated each cell to $100^{\circ} \mathrm{C}$ and applied a pressure of 1500 psi to each cell along with adding the organic solution. The first extraction provided $90.8 \%$ of the lipids that were sufficient to perform the quantitative FAME analysis. The second extraction provided $9.2 \%$ of the lipids extracted in the first extraction step. All subsequent extractions involved only one ASE extraction. The total lipid data was corrected for the amount of lipid still remaining in the sample after the first extraction.

\section{Backwashing samples}

Once the extraction process was complete, the collection bottles were transferred to a prepped $125 \mathrm{ml}$ separatory funnel. The following backwash procedure was used assuming the volume of the extract was approximately $80 \mathrm{ml}$. The extract was combined with $20 \mathrm{ml}$ of a $0.88 \%$ saline solution (potassium chloride and deionized water) and the solution was swirled, frequently venting the stopcock on the funnel to release the built up gas. The two layers were allowed to completely separate. Two distinct layers formed in the funnel, with the lower layer consisting primarily of a mixture of methylene chloride and the fatty acids and their derivatives. The upper layer is primarily a mixture of water and methanol. The lower layer was drained and collected in a prepped collection bottle. The upper layer that remained in the funnel was drained off as waste. The methylene chloride layer was poured into the separatory funnel and $10 \mathrm{ml}$ of 
the potassium chloride solution and $10 \mathrm{ml}$ of methanol added to the separatory funnel. The funnel was swirled again and the stopper was removed periodically to release any built up gas. The lower layer was collected in a prepped collection bottle and the upper was discarded as waste. The lower layer was combined with anhydrous sodium sulfate and stored in the freezer overnight.

\section{Sample evaporation and lipid determination}

The sample that was backwashed was removed from the freezer the following day and transferred to a Turbovap tube to concentrate the sample to about $10 \mathrm{ml}$. The sample was transferred to a $10 \mathrm{ml}$ volumetric flask, and the volume was adjusted to $10 \mathrm{ml}$ with methylene chloride. As necessary the sample was run under nitrogen until the proper volume was obtained.

To determine the total organics extracted, aluminum pans were prepped, labeled, and weighed. An aliquot of one to two $\mathrm{ml}$ was then placed into each pan. The sample was allowed to evaporate for a period of several hours, at which time, the pan was weighed again. The final weight was subtracted from the original to calculate the total organics extracted, which was a surrogate for the lipid concentration for our samples.

\section{Thin layer chromatography}

Thin layer chromatography (TLC) was used in an attempt to separate the various fatty acid precursor species from the fatty acids and from each other. TLC plates were placed in the muffle furnace for one hour at $110^{\circ} \mathrm{C}$. After the plates were cooled, they were placed in the developing chamber that contained toluene, and remained in the chamber until the toluene rose 
drawn to the top of the plate by capillary action. Toluene from the plates was first allowed to air out in the hood and then the plates were allowed to dry in a dessicator overnight.

Approximately $200 \mu \mathrm{l}$, which equates to 20 to $30 \mu \mathrm{g}$ of sample, was applied to the bottom of the plate. The plate was then placed in a beaker and the toluene was drawn to the top of the band and then evaporated. The process of drawing toluene to the top of the band was repeated two more times to focus the band to a narrow band.

The plate was then placed in the developing chamber and toluene was allowed to be drawn to within one inch of the top of the plate. Plates were then removed from the chamber and allowed to dry in the hood. Plates were sprayed with a fluorescent dye (2-7-dichloroflourescin). Plates were illuminated with ultraviolet (UV) light and bands were marked with a razor. Bands were then scraped with the razor blade onto aluminum foil sheets prepared with acetone and methylene chloride. Scrapings were gathered from each band separately and placed into a test tube with methylene chloride. Test tubes were placed on the inverter for an hour. Solvent was removed and placed into a prepared test tube with the solid material being discarded as hazardous waste.

Despite several attempts using TLC to separate the fatty acid precursors for oxidation using Jones reagent, no fatty acid precursors were present in the bands. Therefore, this method was discontinued and not used for any of the samples. Instead, fatty acid precursor standards were obtained, e.g. C16:0 dimethyl acetal (DMA), C17:0 DMA, C18:0 DMA, and compared to the output from the mass spectrometer to determine if fatty acid precursors were present in the samples. 


\section{Oxidation of fatty acid precursors}

The oxidation step will reduce the proportion of polyunsaturated fatty acids (PUFAs) in the mixture if FAMEs are not separated from fatty alcohols prior to the oxidation step. Thin layer chromatography (TLC) normally separates these compounds; however, we did not achieve separation of the bands when TLC was attempted. Instead, an aliquot of sample was analyzed on the GC/MS, and an aliquot was oxidized. Because PUFAs are rarely present in wax esters, the resulting chromatograms could be compared to determine the contribution of fatty alcohols to the overall signature.

Approximately one to two $\mathrm{ml}$, which equates to 40 to $60 \mu \mathrm{g}$ of sample, was placed into a test tube. The sample was evaporated with nitrogen and had $250 \mu$ of Jones reagent $\left(13.5 \mathrm{~g} \mathrm{CrO}_{3}\right.$ $+6.4 \mathrm{ml} \mathrm{H}_{2} \mathrm{SO}_{4}$ with enough distilled water to prepare 50-ml of Jones reagent) and two $\mathrm{ml}$ of acetone added. The test tube was vortexed for one minute and allowed to stand for 10 minutes. After 10 minutes, one $\mathrm{ml}$ of deionized water and $2 \mathrm{ml}$ of hexane were added and the test tube was vortexed for one minute. The contents of the test tube were added to a separatory funnel, and the test tube was washed with hexane two more times to obtain as much of the sample in the test tube as possible. Once the sample separated into two distinct layers in the separatory funnel, the lower layer was drained into the original test tube and the top layer was drained into a new test tube. Hexane was added to the original test tube, and the process of draining the layers was repeated as above two more times. Anhydrous sodium sulfate was added to the new test tube containing the hexane and sample and allowed to sit in the freezer overnight. The following day, samples were removed from the anhydrous sodium sulfate and were derivatized. 


\section{Derivatization with boron triflouride $\left(\mathrm{BF}_{3}\right)$}

Approximately two millimeters of a 20 to $30 \mu \mathrm{g} / \mathrm{ml}$ solution was used for the Derivatization process and evaporated to dryness. A 0.5 molar solution of sodium hydroxide $(\mathrm{NaOH})$ and methanol was prepared. The sample was combined with $1.5 \mathrm{ml}$ of the methanolic $\mathrm{NaOH}$ solution in a test tube and placed on the heater at $100^{\circ} \mathrm{C}$ for five minutes. The test tube was removed from heat and allowed to cool in a beaker of water. The prepared aliquot of boron triflouride and methanol $\left(\mathrm{BF}_{3}\right)$ along with 250 - $\mu 1$ 2,2-dimethoxypropane was added to each test tube and vortex for 1 minute. Three millimeters of saturated sodium chloride solution was added to the sample and was placed on the inverter for one minute. Samples were removed from the inverter and placed onto a centrifuge for two minutes at $1300 \mathrm{rpm}$. The liquid portion of the sample was removed from the solid collected at the bottom and place into a new test tube with anhydrous sodium sulfate for 20 minutes. The liquid portion was removed from the anhydrous sodium sulfate and placed into a new test tube. This method was also conducted using $\mathrm{BF}_{3}$ without $\mathrm{NaOH}$ at $60^{\circ} \mathrm{C}$ and $100^{\circ} \mathrm{C}$.

\section{Derivatization with Hilditch reagent}

Hilditch reagent was used to derivatize most of the samples in this study. This method uses sulfuric acid $\left(\mathrm{H}_{2} \mathrm{SO}_{4}\right)$ and methanol to perform the transesterification step. Due to the simplicity, effectiveness, and lower costs associated with this method, it was deemed to be a more favorable technique.

Methanol was placed in a $100 \mathrm{ml}$ volumetric flask and had two to three grams of sodium sulfate added to the flask. Methanol was allowed to dry overnight at room temperature. On the day of the experiment, methanol was placed into a clean Erlenmeyer flask along with $1.5 \mathrm{ml}$ 
concentrated $\mathrm{H}_{2} \mathrm{SO}_{4}$. The flask was swirled to evenly distribute the acid. This solution remained viable for one week and excess solution was stored in a stoppered flask at room temperature.

Two $\mathrm{ml}$ of sample was evaporated to dryness under a steady stream of nitrogen in a clean $10 \mathrm{ml} \mathrm{screw}$ top test tube. Thee $\mathrm{ml}$ of Hilditch reagent was added and the test tube was vortexed for 10 seconds. Test tubes were placed on the heat block at $62 \mathrm{C}$ for $1 \mathrm{hr}$. Samples were cooled to room temperature (time: approximately $30 \mathrm{~min}$; alternatively run cool tap water over the tubes for $1 \mathrm{~min})$. Three $\mathrm{ml}$ of hexane was added and the sample was vortexed. Three $\mathrm{ml}$ saturated $\mathrm{NaCl}$ was added and the test tube was gently swirled. Lastly, the test tube was centrifuged at $1300 \mathrm{rpm}$ for two min. The top layer was removed and placed in a second tube that contained approximately $0.5 \mathrm{~g}$ anhydrous sodium sulfate. The aqueous bottom layer was washed two more times with one $\mathrm{ml}$ hexane, each time removing the top layer and adding it to the new test tube. The pooled FAME mixture was allowed to sit at room temperature for 20 min on anhydrous sodium sulfate. The maximum amount of Hexane solution of fatty acid methyl esters was carefully decanted from anhydrous sodium sulfate, and it was placed into a clean test tube.

\section{Silver ion chromatography}

Silver ion chromatography was performed in order to verify the elution order of cis and trans fatty acids on the gas chromatograph - mass spectrometer. The only difference between some monounsaturated fatty acids is the orientation of the double bond, e.g. oleic acid (C18:1n9c) and elaidic acid (C18:1n9t). Several solutions need to be prepared prior to the initiation of silver ion chromatography (these solutions are prepared by volume and the volume in parentheses is the elution volume needed for each sample): 1) 96:4 hexane:acetone (six ml), 2) 75:25 hexane:acetone (4 ml), 3) 25:75 hexane:acetone $(5 \mathrm{ml}), 4)$ 95:5 acetone:acetonitrile (5 $\mathrm{ml})$, 
5) $93: 7$ acetone:acetonitrile (5 ml), 6) $88: 12$ acteone:acetonitrile (5 ml), and 7) $85: 15$ 85:15 acteone:acetonitrile $(5 \mathrm{ml})$.

A Supelco vacuum manifold for SPE cartridges is needed for this process. The flow rate using the vacuum should be about $5 \mathrm{ml} /$ minute. The silver ion cartridge is attached to the top port of the manifold. A test tube was attached to the manifold and five $\mathrm{ml}$ of acetone was drawn through the manifold. This process was repeated with five $\mathrm{ml}$ of hexane drawn through the cartridge. A prepped test tube was attached to the bottom of the manifold to collect the sample as it is drawn through the manifold. The sample was added, and the first mixture was drawn through the cartridge after the sample was added. When the sample was done eluting, the vacuum was turned off and two $\mathrm{ml}$ of the solvent mixture was added and the vacuum was turned back on. The test tube was removed and labeled with which fraction with which it was combined. This was repeated for each solution added to the cartridge so that the sample had seven different mixtures added to the cartridge and collected in seven different test tubes. These samples were run on the gas chromatograph - mass spectrometer to determine which fatty acids were present and to verify their elution times and order.

\section{Column cleanup}

Each sample will require $20 \mathrm{ml}$ of solvent mixture containing 95 hexane: 5 diethyl ether (v:v). Exeter glass chromatography/drying columns $(22 \mathrm{~mm}$ x $275 \mathrm{~mm})$ were prepped for each sample prior to the column cleanup. Silica gel was the adsorbent required for the cleanup process, and it was activated at $700^{\circ} \mathrm{C}$ in a muffle furnace for 24 hours. Once all materials were prepared, a glass wool plug was inserted into the column, followed by a two cm layer of silica gel, and lastly a one cm layer of anhydrous sodium sulfate was added. The column was 
conditioned with $20 \mathrm{ml}$ of hexane prior to sample addition. A Turbovap tube was then placed under the glass column to collect the cleaned sample. The sample was then added, and eluted with $20 \mathrm{ml}$ of the hexane:diethyl ether solution. The sample was then concentrated to a smaller known volume using the same procedure as the backwashing step.

\section{GLC standard mixture}

In this experiment, a group of standards were combined to create a GLC standard mixture of target fatty acid methyl esters. Known standards from Nu-Chek Prep (GLC MIX 85, 411, 642, 632, Elysian, MN) were combined along with stearidonic acid (C18:4n3, Cayman Chemical, Ann Arbor, MI) to make a total FAME standard solution of $12.25 \mu \mathrm{g} / \mathrm{ml}$. Matreya $25 \mathrm{FAME}$ mixture (Pleasant Gap, PA) was used to obtain the retention time for C20:1n7. Restek cis/trans FAME mixture (Bellefonte, PA) was used to obtain retention times for C18:1n9 trans and C18:2n6 trans.

\section{Running samples on the gas chromatograph/mass spectrometer (GC/MS)}

The GC/MS was used to identify and quantify fatty acid methyl esters in each sample. FAMEs were injected into a fused capillary column, DB-23 60m length X $0.250 \mathrm{~mm}$ OD X $0.25 \mu \mathrm{m}$ film thickness (Agilent, Santa Clara, CA) using an autosampler (Agilent 7683 Series Auto Sampler). Hydrogen was used as a carrier gas. The temperature program was as follows: hold at an initial temp of $50^{\circ} \mathrm{C}$ for $2 \mathrm{~min}$, hold at $150^{\circ} \mathrm{C}$ after ramping at $20^{\circ} \mathrm{C} \cdot \mathrm{min}^{-1}$, hold at $215^{\circ} \mathrm{C}$ after ramping at $1.25^{\circ} \mathrm{C} \cdot \mathrm{min}^{-1}$.

The GC/MS tracks the select ion signature of each compound and was used to verify the identity of each peak. There were peaks which consisted of more than one fatty acid and it was 
impossible to determine which fatty acid(s) constituted the peaks. Therefore, a term fatty acid "complex" was assigned to this peak. The complex refers to which fatty acids could be responsible for the peak, e.g. C22:3n3 and C22:5n6.

The goal for the sample concentration to be run on the GC/MS was approximately 100 $\mu \mathrm{g} / \mathrm{ml}$. After the sample was concentrated after column cleanup, it was diluted as needed to reach this concentration and added to a prepped GC vial. Prior to the analyses of the samples, calibration standards were run to verify the elution order on the column. A group of samples was run in batches of approximately 15 to 20 . After four samples were run, a GLC standard mix was run to verify that elution times were not shifting during the course of this batch run. The chromatograms were obtained from the MS using the Agilent ChemStation software, and the peaks present were compared to the known standards for identification. The area under the peaks was quantified by this program allowing proportions of each fatty present to be calculated, which became the fatty acid signature of each sample.

The Autotune function was performed on the GC/MS prior to every batch run (20-26 samples). This function measures the relative abundance of three mass ions, 69.00, 219.00, and 502.00. Once the relative abundance of mass ion 219.00 dropped below 90.00 , the mass spectrometer source was cleaned. Also prior to each batch run, the injector septum was changed. The column, injector inlet, and seal were changed as needed during the course of this experiment. After each column change, the column was allowed to condition before any samples were run. Standards were run through the instrument several times to ensure the correct retention times were being recorded. 


\title{
Curriculum vitae
}

\section{Edward McGinley}

\author{
236 S. High St. Apt. 2, Morgantown, WV 26501 \\ PHONE: 484-358-5389•EMAIL: ED MCGINLEY11@,YAHOO.COM
}

\section{Education}

Ph.D. Candidate, (ABD) Wildlife and Fisheries

Started May 2008

Division of Forestry and Natural Resources

West Virginia University, Morgantown, WV

Dissertation: Estimation of striped bass diets using fatty acid analysis

GPA: 3.88

M.S. Wildlife and Fisheries

Graduated: May 2008

Department of Biology

Frostburg State University, Frostburg, MD

Thesis: The effects of sedimentation on the seasonal feeding of mottled sculpin GPA: 3.88

B.S. Biology

Graduated: May 2004

Department of Biology

Saint Francis University, Loretto, PA

GPA: 3.26

\section{Research Experience}

\section{West Virginia University}

Graduate student, Department of Wildlife and Fisheries

May 2008 - present

- Dr. Kyle Hartman, 310A Percival Hall, PO Box 6125, Morgantown, WV 26506, 304 293-4797

Use fatty acid signature analysis to determine striped bass diets. Run tank experiments to establish the effects of size and mixed diets upon the fatty acid signature. Evaluate the timeline for striped bass incorporation of a new fatty acid signature.

Research Assistant

July 2012

- Dr. Kyle Hartman

In July 2012, I will be joining Dr. Hartman for a research expedition to Mongolia. The goal of our trip is to measure bioenergetics parameters for several fish species in Lake Hovsgol. This area is under extreme thermal stress from climate change and offers an undisturbed system to measure how increases in air temperature affects fish metabolism. 
- Drs. Richard Raesly and William Seddon, 201 Compton Science Center, 101 Braddock

Road Frostburg, MD 21532, 301-687-4166

Studied diets of mottled sculpin in western Maryland headwater streams. Quantified the effects of sediment loading on diets throughout the year.

Field Technician:

May 2006-August 2006

- Gabriel Strain, 322 Percival Hall, Morgantown, WV 26506

Assisted in comparing methods for sampling salamanders in southern Maryland watersheds. Duties included electrofishing, trap assemblage, and identification of salamanders.

Rutgers University

Field Technician: Haskins Shellfish Research Laboratory

May 2006 - August 2006

- Greg DeBrosse, Haskin Shellfish Research Laboratory, 6959 Miller Avenue, Port Norris, NJ 08349, 609-463-0633

Rearing of adult Asiatic oyster species, and maintenance of system housing them.

Maintenance and care for adult Atlantic oyster raised on tidal flats of the Delaware Bay, NJ.

\section{Professional Experience}

\section{Maryland Sea Grant Ecosystem based fisheries management: Food Web Team}

Quantitative support staff

March 2009 - present

- Maryland Sea Grant assembled this group in order to modify current fisheries management plans by implementing a multispecies approach. The specific goal of the food web team is to establish benchmarks to assess the health of striped bass in the Chesapeake Bay. These benchmarks are based upon data relating to striped bass, and also to their prey items including Atlantic menhaden and plankton.

\section{Teaching Experience}

\section{West Virginia University}

Morgantown, WV: Department of Wildlife and Fisheries

Lecturer -Responsible for developing and teaching the class

- Wildlife Management 493N - Environmental Physiology

Graduate student instructor -Assisted in grading and teaching the class

- Wildlife Management 314 - Marine Ecology, Dr. Kyle Hartman

May 2011

- University 194X - Finned Friends in Society, Dr. Kyle Hartman

Fall 2009 


\section{Frostburg State University}

Frostburg, MD: Department of Biology

Graduate student instructor - Responsible for teaching the lab and assisted in teaching the lecture

- Biology 201 - Anatomy and Physiology I, Dr. David Morton

Fall 2005-2007

- Biology 202 - Anatomy and Physiology II, Dr. David Morton

Spring 2006-2008

\section{Presentations}

Invited seminars

- McGinley, E.J. November 2010. Organized chaos: my life as a grad student. Frostburg State University Career Day, Frostburg, MD.

- McGinley, E.J., R. Raesly, and W. Seddon. October 2008. The effects of sedimentation on the seasonal feeding of mottled sculpin. James J. Howard Marine Science Lab, Sandy Hook, NJ.

Submitted professional presentations

- McGinley, E.J. and K.J. Hartman, January 2012. A comparison of striped bass liver and belly flap fatty acid signatures. American Fisheries Society Southern Division Meeting: Biloxi, MI

- McGinley, E.J. and K.J. Hartman., September 2011. Which Tissues Provide the Best Results In Evaluating Striped Bass Diet Using Fatty Acid Signatures? American Fisheries Society national meeting: Seattle, WA.

- McGinley, E.J., K.J. Hartman, and J. Jacobs. November 2010. Spatial and temporal patterns in select striped bass prey items. American Fisheries Society student colloquium: Virginia Tech University, Blacksburg, VA

- McGinley, E.J., K.J. Hartman, and J. Jacobs. September 2010. The effect of size on striped bass fatty acid signature incorporation. American Fisheries Society national meeting: Pittsburgh, PA

- McGinley, E.J., K.J. Hartman, J. Jacobs, and J. Councilman. March 2010. Spatial and temporal patterns in select striped bass prey items. American Fisheries Society Tidewater Chapter meeting: Annapolis, MD.

- McGinley, E.J., K.J. Hartman, and J. Jacobs. March 2010. Spatial and temporal patterns in select striped bass prey items. West Virginia University Davis College of Agriculture, Natural Resources and Design and West Virginia Agriculture \& Forestry Experiment Station Graduate Research Day: Morgantown, WV.

- McGinley, E.J., K.J. Hartman, and J. Jacobs. August 2009. Spatial and temporal patterns in select striped bass prey items. American Fisheries Society national meeting: Nashville, TN.

- McGinley, E.J, R. Raesly, and W. Seddon. February 2008. The effects of sedimentation on the seasonal feeding of mottled sculpin. American Fisheries Society Southern Division meeting: Wheeling, WV. 
Submitted posters

- Porto, M., A. Anderson, E.J. McGinley, K.J. Hartman, and E. Merriam. September 2011. The development of a brown bullhead bioenergetics model. Seattle, WA.

- McGinley, E.J. April 2011. Spatial and temporal patterns in select striped bass prey items. West Virginia University Davis College of Agriculture, Natural Resources and Design and West Virginia Agriculture \& Forestry Experiment Station Graduate Research Day: Morgantown, WV.

- McGinley, E.J., R. Raesly, and W. Seddon. July 2007. The effects of sedimentation on the seasonal feeding of mottled sculpin. American Society of Ichthyologists and Herpetologists: St. Louis, MO

\section{Publications}

Articles

- McGinley, E.J., R. Raesly, and W. Seddon. In revision. The effects of sedimentation on the seasonal feeding of mottled sculpin. American Midland Naturalist

- McGinley, E.J., K.J. Hartman, A. Deshpande, and J. Jacobs. In review. Spatial and temporal patterns in select striped bass prey items. Northeast Fisheries Science Center

- McGinley, E.J., K.J. Hartman, A. Deshpande, and J. Jacobs. In review. A comparison between liver and adipose tissue fatty acid incorporation in striped bass. Northeast Fisheries Science Center

Master's thesis

- McGinley, E.J., R. Raesly, and W. Seddon. 2008. The effects of sedimentation on the seasonal feeding of mottled sculpin. Thesis, Frostburg State University

\section{Professional memberships and Leadership}

American Fisheries Society

- Parent society 2007 - present, Southern Division representative for the Student Subsection on Education (2008)

- West Virginia State Chapter 2008 - present

- West Virginia University student chapter 2008 - present, President (2009)

- Estuaries Section 2009 - present

- Tidewater Chapter 2010 - present

Awards

- 2009 American Fisheries Society Estuaries Section Travel Award (\$500)

\section{Laboratory techniques}

- Accelerated solvent extractor (ASE)

- Gas chromatograph and mass spectrometer (GC/MS) 


\section{Certifications}

- PADI Open water SCUBA

- CPR/First AID

\section{Computer skills}

- Proficient in Microsoft Word, Excel, and PowerPoint

- Statistical package R

- Working knowledge of Arc-GIS

- Proficient in GC/MS software package ChemStation 


\section{References}

- Dr. Kyle Hartman, West Virginia University, 310A Percival Hall, PO Box 6125, Morgantown, WV 26506, 304-293-4797, Hartman@wvu.edu

- Dr. Patricia Mazik, USGS Coop Office, West Virginia University, 333 Percival Hall, PO Box 6108, Morgantown, WV, 26506, 304-293-4943, pmazik@wvu.edu

- Dr. John Jacobs, NOAA/NOS/Cooperative Oxford Laboratory, Oxford, MD 21654 410-226-5193, John.Jacobs@,noaa.gov 